ADRIANO DOBRANSZKI

ANÁLISE DE ELEMENTOS FINITOS DA DISTALIZAÇÃO DO PRIMEIRO MOLAR SUPERIOR COM BARRA TRANSPALATINA ANCORADA EM MICROPARAFUSOS ORTODÔNTICOS

BRASÍLIA, 2014 


\author{
UNIVERSIDADE DE BRASÍLIA \\ FACULDADE DE CIÊNCIAS DA SAÚDE \\ PROGRAMA DE PÓS-GRADUAÇÃO EM CIÊNCIAS DA SAÚDE
}

ADRIANO DOBRANSZKI

\begin{abstract}
ANÁLISE DE ELEMENTOS FINITOS DA DISTALIZAÇÃO DO PRIMEIRO MOLAR SUPERIOR COM BARRA TRANSPALATINA ANCORADA EM MICROPARAFUSOS ORTODÔNTICOS
\end{abstract}

Tese apresentada como requisito parcial para a obtenção do Título de Doutor em Ciências da Saúde pelo Programa de Pós-Graduação em Ciências da Saúde da Universidade de Brasília.

Orientador: Prof. Dr. Orlando Ayrton de Toledo Co-Orientador: Prof. Dr. Jorge do Nascimento Faber

Brasília 
ADRIANO DOBRANSZKI

\section{ANÁLISE DE ELEMENTOS FINITOS DA DISTALIZAÇÃO DO PRIMEIRO MOLAR SUPERIOR COM BARRA TRANSPALATINA ANCORADA EM MICROPARAFUSOS ORTODÔNTICOS}

Tese apresentada como requisito parcial para a obtenção do Título de Doutor em Ciências da Saúde pelo Programa de Pós-Graduação em Ciências da Saúde da Universidade de Brasília.

Aprovado em

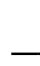

BANCA EXAMINADORA

Orlando Ayrton de Toledo (Presidente)

Universidade de Brasília - UnB

Jorge do Nascimento Faber

Universidade de Brasília - UnB

An Tien Li

Universidade de Brasília - UnB

Adriano Gonçalves Barbosa de Castro

Universidade Católica de Brasília - UCB e Faculdades Integradas do Planalto Central - FACIPLAC

Pedro Yoshito Noritomi

Centro de Tecnologia da Informação Renato Archer - Campinas - SP

Maurício Barriviera (suplente)

Universidade Católica de Brasília - UCB 
Dedico este trabalho às minhas filhas, Caroline e Fernanda. 


\section{AGRADECIMENTOS}

Ao professor Maurício Barriviera, que generosamente cedeu seu precioso tempo e permissão para a utilização das imagens tomográficas do banco de dados de sua clínica radiológica, imprescindíveis para a realização deste trabalho.

À Dra. Sandra Suzuki, que pacientemente converteu os formatos dos arquivos digitais e me ensinou como usar os programas para mensuração em tomografias.

Aos estudantes de graduação em engenharia Eduardo Moraes, Afonso, Paulo, Tiago e Daniel Takanori, que dispenderam muitas horas de trabalho para criação dos modelos virtuais; ao chefe de setor, Pedro "Wikipedro" Yoshito Noritomi, que direcionou os esforços desta dedicada equipe com grande simpatia, bom senso e conhecimento admiráveis; ao Chefe da Divisão de Tecnologias Tridimensionais do Centro de Tecnologia da Informação Renato Archer, Jorge Vicente Lopes da Silva, que colocou à disposição esta formidável equipe e permitiu o uso das instalações, equipamentos e programas desta magnífica instituição; e em especial, ao seu Diretor, Victor Pellegrini Mammana, um dos mais brilhantes pesquisadores do país, por me incentivar a trilhar este caminho.

Ao professor Jorge Faber que, com sua grande experiência e sagacidade, contribuiu para a criação do corpo deste trabalho e para as publicações.

Ao professor Orlando Ayrton de Toledo, que confiou na minha capacidade de conduzir este projeto e foi fundamental para sua realização. Líder nato pelo exemplo, destaca-se por seu amor ao que faz, profissionalismo, experiência, amabilidade, humildade e perspicácia.

À minha esposa Nara, que me incentiva, ajuda, tolera e ama. 
"We are just an advanced breed of monkeys on a minor planet of a very average star. But we can understand the Universe. That makes us something very special." Stephen Hawking

A pénz beszél, a kutya ugat. (O dinheiro fala, o cachorro late) Ditado húngaro 


\section{RESUMO}

O objetivo deste estudo foi avaliar, por meio de análise de elementos finitos, a distribuição de tensões em um primeiro molar superior, após aplicação de força de distalização em uma barra transpalatina (BTP) presa ao molar e ancorada em microparafusos ortodônticos (MPO) instalados em diferentes locais do palato e sugerir a indicação clínica para cada tipo de ativação. Tendo como fonte um banco de dados de tomografias volumétricas, medidas foram feitas e submetidas a análise estatística para criação de um modelo virtual válido de uma maxila humana de um indivíduo portador de relação maxilomandibular de Classe II esquelética típico. Este modelo foi utilizado como base para uma análise combinatória de 3 locais de instalação do MPO (2, 5 e $8 \mathrm{~mm}$ ) e 3 pontos de ativação na BTP: próximo ao tubo lingual, na metade do comprimento do braço da barra e próximo ao ômega central, resultando em 9 modelos analisados com o programa ANSYS, cada um com aproximadamente 500.000 elementos tetraédricos. Imediatamente após aplicação de carga de 1,5 N na BTP, os valores do deslocamento inicial da trifurcação do molar e da rotação da coroa foram tabulados. Os resultados sugeriram que mudanças na posição de instalação do MPO e do ponto de ativação na BTP produziram diferentes efeitos na movimentação do primeiro molar superior, no sentido A-P, vertical e na rotação (angulação). Com os dados do modelo preliminar, concluiu-se que a maior concentração de tensões na BTP foi localizada na dobra próxima à entrada do tubo lingual, indicando o ponto de maior propensão à falha; no MPO, foi localizada na região do pescoço próximo à transição do perfil transmucoso para as espiras, região em contato com a borda externa do osso cortical palatino, indicando o ponto de maior propensão à falha; no osso cortical palatino, foi localizada na borda externa, mesial ao microparafuso, indicando o ponto em que provavelmente ocorreria maior demanda biológica inflamatória. No modelo definitivo, a ativação "2 mm apical", próxima ao ômega central da BTP, foi a única que resultou em efeito extrusivo, com deslocamento mesial da coroa e distal das raízes e furca, ativação sugerida para distalização com aumento da dimensão vertical, por extrusão do molar. A ativação "2 mm cervical", próxima ao tubo lingual do molar, resultou em um efeito leve de intrusão, distalização e acentuado giro distal da coroa, ativação sugerida para distalização quando o molar encontra-se mésioangulado. A ativação 
"5 mm média", na metade do comprimento do braço da BTP, resultou em giro distal da coroa e leve movimento intrusivo, ativação sugerida quando o molar encontra-se com leve mesioangulação e ligeiramente extruído, ou quando se deseja distalizar fechando levemente a mordida anterior. A ativação "8 mm médio" produziu pouco efeito de distalização e pouco giro distal da coroa, sugerida quando se deseja pouca distalização com intrusão quase pura do molar, com angulação distal da coroa. A ativação "8 mm apical" produziu muito pouca distalização e acentuada intrusão e angulação distal da coroa, sugerida quando se deseja intruir o molar.

Palavras-chave: Análise do Estresse Dentário; Análise de Elementos Finitos; Procedimentos de Ancoragem Ortodôntica; Desenho do Aparelho Ortodôntico, Movimentação Dentária. 


\section{ABSTRACT}

The aim of this study was to evaluate by finite element analysis the stress distribution in a maxillary first molar after application of a distalization force on a transpalatal arch (TPA) attached to the molar and anchored on orthodontic microscrews (OMS) in different locations of the palate and suggest the clinical indication for each type of activation. Having as source a database of volumetric scans, measurements were made and subjected to statistical analysis to create a valid virtual model of a typical skeletal Class II maxillo-mandibular relationship individual. This virtual maxillary model was used as the basis for a combinatorial analysis of 3 OMS installation positions (2, 5 and $8 \mathrm{~mm}$ ) and 3 TPA activation positions (near the lingual tube, in the half length of the bar arm and near the central omega, resulting in 9 models analyzed using ANSYS program, each with approximately 500.000 tetrahedral elements. Immediately after application of load of $1.5 \mathrm{~N}$ in the BTP, the values of the initial displacement of the trifurcation and of the rotation of the molar crown were tabulated. The results suggested that changes in the position of installation and OMS activation point of the TPA produced different effects on the movement of the upper first molar in the A-P and vertical directions and rotation (angle). With the data of the preliminary study it was concluded that the highest stress concentration on the TPA was located at the bend next to the entrance of the lingual tube, indicating the point of higher propensity to failure; on the OMS, it was located at the neck, near to the transition from the transmucosal profile for the thread, site in contact with the external edge of the palatal cortical bone, indicating the point of higher propensity to failure; on the palatal cortical bone, it was located at the external edge, mesial to the OMS, indicating the point where most likely would occur a higher inflammatory biological demand. In the definitive model, the "2 $\mathrm{mm}$ apical" activation, next to the central omega of the TPA, was the only activation that resulted in extrusive effect, with mesial displacement of the crown and distal displacement of the roots and of the furcation, suggested activation for distalization with increase of the vertical dimension, by molar extrusion. The "2 $\mathrm{mm}$ cervical" activation, next to the molar lingual tube, resulted in a light intrusive effect, distalization and marked crown distal rotation, activation suggested for distalization when the molar is angle to the mesial. The " $5 \mathrm{~mm}$ activation", at the half of the TPA 
arm's lenght, resulted in distal rotation of the crown and light intrusive movement, activation suggested when the molar is slightly angled to the mesial and slightly extruded, or when it is desired to distalize and close the anterior bite slightly. The "8 mm medium" activation produced little effect to the distalization and a slightly distal rotation of the crown, suggested when a slight distalization it is desirable, with almost pure intrusion of the molar with distal angulation of the crown. The "8 mm apical" activation produced very little effect on the distalization and a marked intrusion with distal angulation of the crown, suggested when it is desired to intrude the molar.

Key-words: Dental stress analysis; Finite element analysis; Orthodontic anchorage procedures; Orthodontic appliance design; Tooth movement. 


\section{LISTA DE FIGURAS}

Figura 1 - Mensuração da distância entre o forame palatino maior e a sutura interpalatina. .27

Figura 2 - Vetor de força e relação com Cres. ....................................... 32

Figura 3 - Média de graus de angulação por nível de linha de tração. .33

Figura 4 - Diagrama demonstrando pontos de fixação A, B e C do gancho na BTP.

Figura 5 - (a) Forças de tração aplicada ao molar direito. .49

Figura 6 - Representação alternativa do ponto do centro de resistência projetado em 2D, compatível com a teoria dos eixos de resistência em 3D. .51

Figura 7 - Tela capturada após mensurações lineares axiais e coronais com software Invesalius 3.0. .57

Figura 8 - Saída do SPSS - gráfico de Número de clusters X Caso. 63

Figura 9 - Saída do SPSS - Dendrograma usando conexão entre o centróide e a distância entre a combinação dos clusters. 63

Figura 10 - Arquivo digital importado do MESHLAB para o RHINOCEROS...65

Figura 11 - Visão em perspectiva do modelo da hemimaxila e seus elementos anatômicos constituintes, além do primeiro molar com ligamento periodontal, banda, tubo lingual, BTP, MPO e elástico - Rhinoceros®.

Figura 12 - Visão oclusal do modelo texturizado da hemimaxila e seus elementos anatômicos constituintes, além do primeiro molar com ligamento periodontal, banda, tubo lingual, BTP, MPO e elástico - Rhinoceros®.

Figura 13 - Visão lingual do modelo texturizado da hemimaxila e seus elementos anatômicos constituintes, além do primeiro molar com ligamento periodontal, banda, tubo lingual, BTP, MPO e elástico - Rhinoceros®. 68

Figura 14 - Visão lingual do modelo texturizado e com transparência da hemimaxila e seus elementos anatômicos constituintes, além do primeiro molar com ligamento periodontal, banda, tubo lingual, BTP, MPO e elástico - Rhinoceros®....68

Figura 15 - Visão em perspectiva do modelo texturizado da hemimaxila e seus elementos anatômicos constituintes, além do primeiro molar com ligamento periodontal, banda, tubo lingual, BTP, MPO e elástico - Rhinoceros®.

Figura 16 - Visão oclusal do modelo com a malha em tetraedros - ANSYS® 70 
Figura 17 - Visão lingual do modelo com a malha em tetraedros - ANSYS® 70

Figura 18 - Visão lingual do modelo com a malha em tetraedros - ANSYS®.71

Figura 19 - Diagrama com as distâncias de instalação dos MPOs em relação à cervical do primeiro molar, no plano axial.

Figura 20 - Imagem do modelo com o MPO instalado a $2 \mathrm{~mm}$ e dos três pontos de ativação na BTP. .76

Figura 21 - Imagem do modelo com transparência e MPO instalado a $2 \mathrm{~mm}$ e dos três pontos de ativação na BTP. .76

Figura 22 - Imagem do modelo com o MPO instalado a $5 \mathrm{~mm}$ e dos três pontos de ativação na BTP. .77

Figura 23 - Imagem do modelo com transparência e MPO instalado a $5 \mathrm{~mm}$ e dos três pontos de ativação na BTP. .77

Figura 24 - Imagem do modelo com o MPO instalado a $8 \mathrm{~mm}$ e dos três pontos de ativação na BTP.

Figura 25 - Imagem do modelo com transparência e MPO instalado a $8 \mathrm{~mm}$ e dos três pontos de ativação na BTP. .78

Figura 26 - Tensão Máxima Principal no MPO, indicando o ponto de maior tração.

Figura 27 - Tensão Mínima Principal no MPO, indicando o ponto de maior compressão.

Figura 28 - Tensão Máxima e Mínima Principais no osso adjacente ao MPO 83

Figura 29 - Tensão Máxima e Mínima Principais no ligamento periodontal ....84

Figura 30 - Tensão Máxima e Mínima Principais no ligamento periodontal ....84

Figura 31 - Tensões de von Mises na BTP. .85

Figura 32 - Tensões de von Mises no osso adjacente ao MPO. 85

Figura 33 - Deslocamento máximo e mínimo, no eixo $X$ (horizontal transversal). .86

Figura 34 - Deslocamento máximo e mínimo, no eixo Y (horizontal A-P) ......86

Figura 35 - Deslocamento máximo e mínimo, no eixo Z (vertical)

Figura 36 - Posição do elástico (1) cervical, (2) médio, (3) apical. Distâncias do parafuso ao rebordo $(2,5$ e $8 \mathrm{~mm})$ 90

Figura 37 - Posição do elástico (1) cervical, (2) médio, (3) apical. Distâncias do parafuso ao rebordo (2, 5 e $8 \mathrm{~mm}$ ) 90

Figura 38 - Configuração do elástico em função dos efeitos de rotação e 
translação na fossa

Figura 39 - Diagrama da decomposição dos vetores dos deslocamentos verticais (intrusão e extrusão) e horizontais (distalização), seguido pelo sentido e intensidade da rotação

Figura 40 - Intensidade do deslocamento da furca no sentido horizontal (azul) e vertical (vermelho) de acordo com o tipo de ativação, em milímetros..... .95

Figura 41 - Deslocamento direcional (eixo Y) com ativação $2 \mathrm{~mm}$ apical, 2 cores - vista lingual..... 96

Figura 42 - Deslocamento direcional (eixo Y) com ativação $2 \mathrm{~mm}$ apical - vista lingual

Figura 43 - Deslocamento direcional (eixo Z) com ativação $2 \mathrm{~mm}$ apical, 2 cores - perspectiva

Figura 44 - Deslocamento direcional (eixo Z) com ativação $2 \mathrm{~mm}$ apical perspectiva 98

Figura 45 - Tensão Máxima Principal no ligamento periodontal com ativação 2 $\mathrm{mm}$ apical, vista oclusal

Figura 46 - Tensão Mínima Principal no ligamento periodontal com ativação 2 $\mathrm{mm}$ apical, vista oclusal. 99

Figura 47 - Deslocamento Total com ativação 2 mm apical - Isosurface .......99

Figura 48 - Deslocamento direcional (eixo Y) com ativação $2 \mathrm{~mm}$ cervical, 2 cores - vista lingual..... 101

Figura 49 - Deslocamento direcional (eixo Y) com ativação $2 \mathrm{~mm}$ "cervical vista lingual.

Figura 50 - Deslocamento direcional (eixo Z) com ativação $2 \mathrm{~mm}$ cervical, 2 cores - perspectiva 102

Figura 51 - Deslocamento direcional (eixo Z) com ativação 2 mm cervical perspectiva 102

Figura 52 - Tensão Máxima Principal no ligamento periodontal com ativação 2 $\mathrm{mm}$ cervical, vista oclusal 103

Figura 53 - Tensão Mínima Principal no ligamento periodontal com ativação 2 $\mathrm{mm}$ cervical, vista oclusal.

Figura 54 - Deslocamento Total com ativação $2 \mathrm{~mm}$ cervical - Isosurface. . 104

Figura 55 - Deslocamento direcional (eixo Y) com ativação $5 \mathrm{~mm}$ médio, 2 cores - vista lingual 
Figura 56 - Deslocamento direcional (eixo Y) com ativação $5 \mathrm{~mm}$ médio vista lingual.

Figura 57 - Deslocamento direcional (eixo Z) com ativação 5 mm médio, 2 cores - perspectiva 106

Figura 58 - Deslocamento direcional (eixo Z) com ativação 5 mm médio perspectiva

Figura 59 - Tensão Máxima Principal no ligamento periodontal com ativação 5 mm médio, vista oclusal

Figura 60 - Tensão Mínima Principal no ligamento periodontal com ativação 5 mm médio, vista oclusal

Figura 61 - Deslocamento Total com ativação 5 mm médio - Isosurface.....108

Figura 62 - Deslocamento direcional (eixo Y) com ativação 8 mm médio, 2 cores - vista lingual

Figura 63 - Deslocamento direcional (eixo Y) com ativação 8 mm médio vista lingual.

Figura 64 - Deslocamento direcional (eixo Z) com ativação 8 mm médio, 2 cores - perspectiva

Figura 65 - Deslocamento direcional (eixo Z) com ativação 8 mm médio perspectiva

Figura 66 - Tensão Máxima Principal no ligamento periodontal com ativação 8 $\mathrm{mm}$ médio, vista oclusal

Figura 67 - Tensão Mínima Principal no ligamento periodontal com ativação 8 mm médio, vista oclusal

Figura 68 - Deslocamento Total com ativação 8 mm médio - Isosurface.....113

Figura 69 - Deslocamento direcional (eixo Y) com ativação $8 \mathrm{~mm}$ apical, 2 cores - vista lingual

Figura 70 - Deslocamento direcional (eixo Y) com ativação 8 mm apical - vista lingual.....

Figura 71 - Deslocamento direcional (eixo Z) com ativação $8 \mathrm{~mm}$ apical, 2 cores - perspectiva

Figura 72 - Deslocamento direcional (eixo Z) com ativação 8 mm apical perspectiva.

Figura 73 - Tensão Máxima Principal no ligamento periodontal com ativação 8 $\mathrm{mm}$ apical, vista oclusal. 
Figura 74 - Tensão Mínima Principal no ligamento periodontal com ativação 8

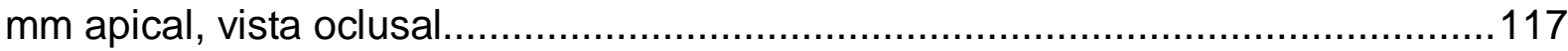

Figura 75 - Deslocamento Total com ativação 8 mm apical - Isosurface .....117

Figura 76 - Vetor de Tensão Principal no alvéolo com ativação 8 mm apical,

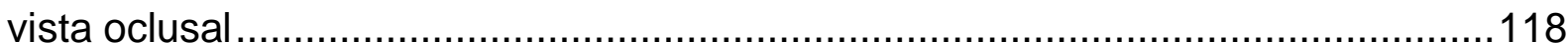

Figura 77 - Desenho esquemático da diferença entre Deslocamento Direcional e Deslocamento Total............................................................ 127 


\section{LISTA DE TABELAS}

Tabela 1 - Espessuras médias em milímetros da mucosa mastigatória palatina de acordo com a distância da cervical do molar em direção à sutura palatina mediana. 26

Tabela 2 - Número da tomografia e descrição e tabulação das medidas. ......58

Tabela 3 - Número da tomografia e diferenças entre as duas medições........59

Tabela 4 - Média das variações das duas medições em relação ao desvio padrão.

Tabela 5 - Saída do SPSS - Análise de agrupamento hierarquizada utilizando o centróide das médias como referência para a formação dos grupos.

Tabela 6 - Descrição das dimensões das estruturas anatômicas e referências: 66

Tabela 7 - Propriedades mecânicas das estruturas dentais, estruturas de suporte e biomateriais. .73

Tabela 8 - Medidas do deslocamento direcional do ponto na trifurcação do molar, nos eixos $X$ (transversal), $Y(A-P)$ e $Z$ (vertical). 88

Tabela 9 - Listagem dos arranjos em que a combinação indica distalização e extrusão. .88

Tabela 10 - Medidas do deslocamento direcional do centro da fossa principal do molar, nos eixos $X$ (transversal), $Y(A-P)$ e $Z$ (vertical).

Tabela 11 - Resultantes dos movimentos de Distalização..............................92

Tabela 12 - Combinações de distalização e intrusão .......................................93

Tabela 13 - Combinações de distalização e extrusão....................................93 


\section{LISTA DE ABREVIATURAS E SIGLAS}

$A=$ Ponto cefalométrico localizado na maior concavidade da porção anterior da maxila

A-P = Sentido Antero-Posterior

$\mathrm{AEB}=$ Arco Extrabucal

$\mathrm{AEF}=$ Análise de Elementos Finitos

ANB = Ângulo formado entre as linhas A-N e N-B

$\mathrm{B}=$ Ponto cefalométrico localizado na maior concavidade da porção anterior da mandíbula

Cl. II, 1 = Má oclusão de Classe II, divisão 1 de Angle, caracterizada por por relação molar de Classe II associada a um posicionamento vestibularizado ou proclinado dos incisivos superiores e, geralmente, a uma sobressaliência aumentada

Cl. II, 2 = Má oclusão de Classe II, divisão 2 de Angle, caracterizada por relação molar de Classe II associada a um posicionamento verticalizado ou retroinclinado dos incisivos superiores e, geralmente, a uma sobremordida aumentada

Cres $=$ Centro de Resistência

Crot $=$ Centro de Rotação

DP = Desvio Padrão

$\mathrm{N}=$ Ponto cefalométrico localizado no ponto mais anterior da sutura frontonasal

$S=$ Ponto cefalométrico localizado no centro geométrico da sela túrcica

SNA = Ângulo formado entre as linhas S-N e N-A

SNB = Ângulo formado entre as linhas S-N e N-B

MPO = Microparafuso Ortodôntico*

*Não há consenso na literatura, na qual foram encontrados os sinônimos: miniimplantes, microimplantes, miniparafusos, parafusos e dispositivos de ancoragem temporária (TAD). Estes termos foram mantidos de acordo com denominação dos autores na revisão da literatura, mas nas outras partes deste trabalho, foram unificados como microparafuso ortodôntico - MPO - ou seu plural, MPOs. 


\section{SUMÁRIO}

AGRADECIMENTOS

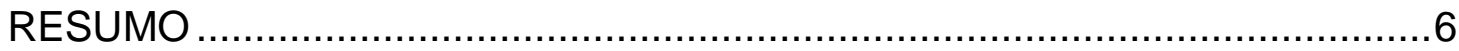

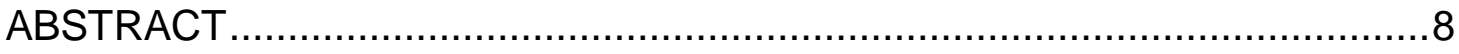

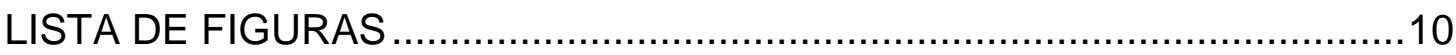

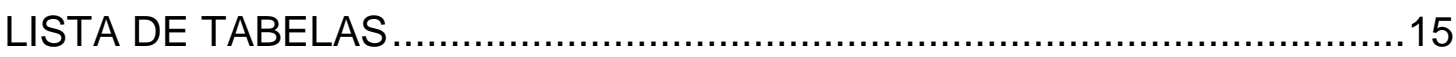

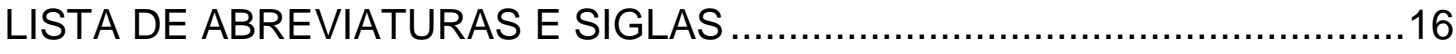

1 INTRODUÇÃO

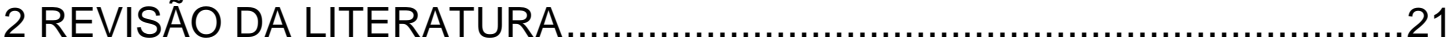

2.1 Prevalência das más oclusões..........................................................21

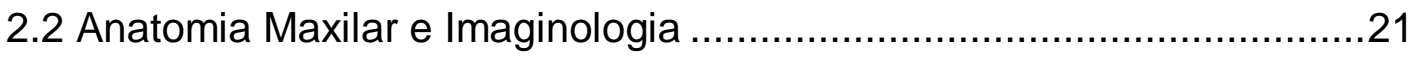

2.2.1 Importância para condutas seguras na instalação de

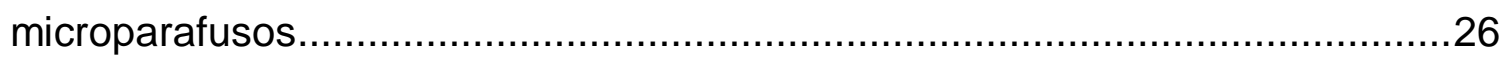

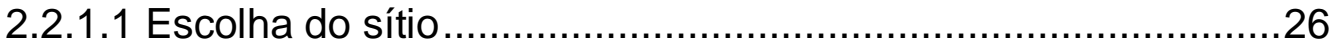

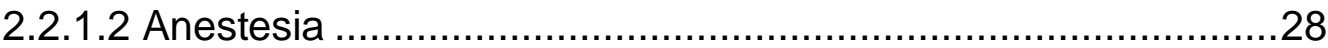

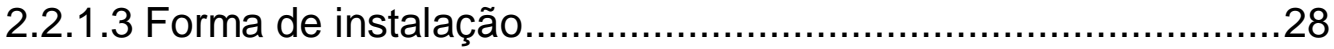

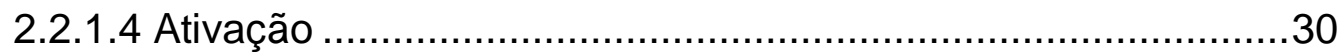

2.3 Movimentos A-P e Ancoragem Esquelética ………............................30

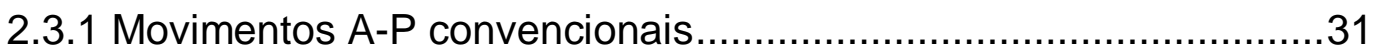

2.3.2 Tipos de ancoragem esquelética e outras informações relevantes 34

2.3.3 Aplicações para movimentos A-P e verticais na maxila...................36

2.4 Análise de Elementos Finitos .............................................................4

2.4.1 Entendimento da elaboração do modelo de Elementos Finitos ......41

2.4.2 Limitações do estudo da mecânica ortodôntica in vivo e a evolução da tecnologia, geração e trabalho das imagens in silico ..................................43

2.4.3 Elementos Finitos em Ortodontia................................................... 46

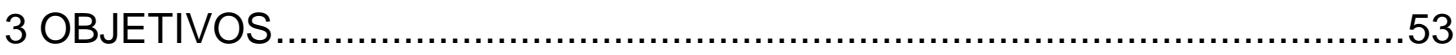

4 MÉTODOS

4.1 Critérios para inclusão das imagens tomográficas na amostra ..............54

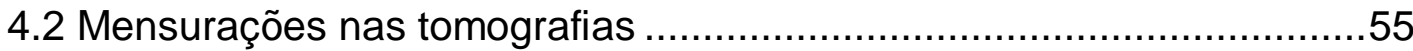

4.3 Método estatístico para avaliação de erro de mensuração intra-operador 
4.4 Escolha da tomografia do indivíduo médio 60

4.5 Tratamento da imagem tomográfica (segmentação PARA reconstrução tridimensional) 64

4.6 Adaptação e compatibilização das medidas 64

4.7 Alimentação de dados dos elementos anatômicos e ortodônticos constituintes - teste preliminar .66

4.8 Avaliação de parâmetros de comparação clínica com pilotos .74

4.9 Definição dos parâmetros primários de otimização (distalização bilateral simétrica) .75

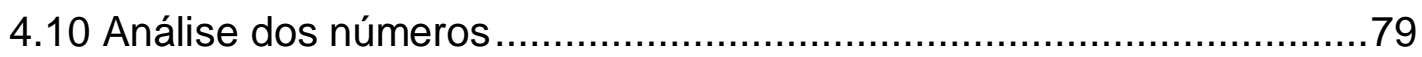

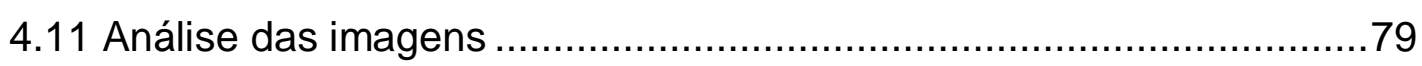

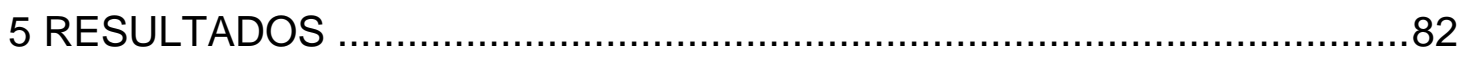

5.1 Resultados no Modelo de Teste Preliminar......................................82

5.2 Resultados no Modelo Definitivo ................................................. 87

5.2.1 Análise quantitativa da distribuição das tensões (números) ..........87

5.2.2 Análise qualitativa da distribuição das tensões (imagens)..............95

5.2.2.1 Ativação $2 \mathrm{~mm}$ apical .................................................... 95

5.2.2.2 Ativação $2 \mathrm{~mm}$ cervical ...............................................100

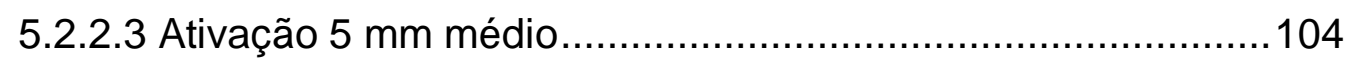

5.2.2.4 Ativação $8 \mathrm{~mm}$ médio...............................................109

5.2.2.5 Ativação $8 \mathrm{~mm}$ apical ...............................................113

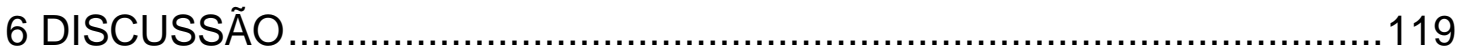

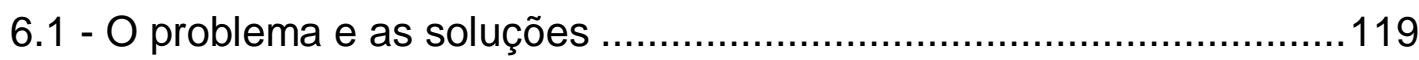

6.2 - Análise de elementos finitos e discussão sobre a elaboração do modelo ........................................................................... 121

6.3 DISCUSSÃO DOS RESULTADOS ....................................... 126

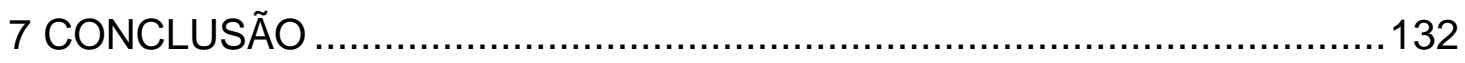

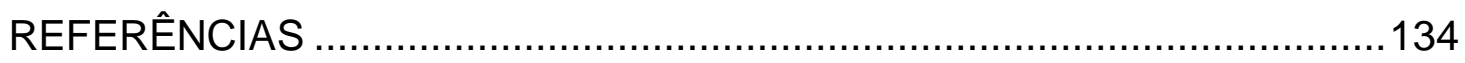

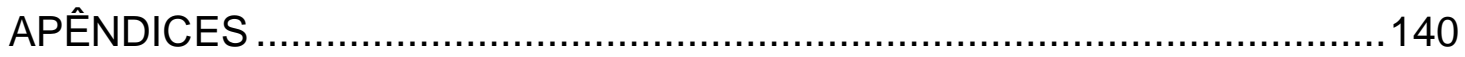

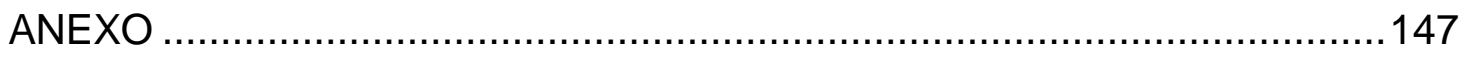




\section{INTRODUÇÃO}

Ao estudar a frequência das más oclusões em pacientes brasileiros que buscam tratamento ortodôntico, Freitas et al. (1) encontraram uma alta prevalência de má oclusão de Classe II divisão 1 (50\%), seguida por Classe I (40 a 44\%) e Classe II divisão 2 (2,4 a 8\%), o que torna a Classe II o tipo de má oclusão mais comum (52 a 58\%) entre os pacientes que buscam tratamento ortodôntico no Brasil. A maioria das relações de Classe II molar tende a ser acompanhada por uma, relação canina de Classe II, sobremordida aumentada (2) e discrepância esquelética anteroposterior, por protrusão da maxila, retrusão da mandíbula ou uma combinação de ambos (3).

A má oclusão de Classe II maxilar ou com leve protrusão dentária pode ser tratada de várias formas, que incluem extrações (4), cirurgia ortognática e a forma mais comum, em pacientes com pouco ou nenhum crescimento, com aparelhos que provoquem distalização dos molares (5). A distalização também pode ser indicada para tratamentos sem extração, como casos de Classe I com biprotrusão (distalização superior e inferior), correção de apinhamento e nos preparos ortocirúrgicos em pacientes Classe III (distalização superior) $(4,6)$.

Vários aparelhos e técnicas de distalização do molar superior, que diminuem ou eliminam a necessidade de colaboração do paciente para a movimentação do molar, já foram propostos $(2,5,6,7,8)$. Apesar de demonstrarem eficácia na distalização do molar superior, todos apresentam efeitos colaterais ou características inerentes a cada técnica que podem ser vistas como desvantajosas, quando comparadas aos outros métodos $(2,4,5,6,7,8,9,10,11,12,13,14,15,16,17,18$, $19,20)$. Por este motivo, quando o clínico escolhe um método de distalização, sua decisão parece ser em parte baseada em informações técnicas e em parte por preferência pessoal e esta escolha pode ser fortemente influenciada por sua análise de viabilidade clínica, ou seja, se em sua opinião este dispositivo é o que melhor se adequa à sua prática diária.

A técnica de distalização estudada neste trabalho, com microparafusos ortodônticos (MPOs) instalados no palato, apresenta como principais vantagens (1) não serem necessários trabalhos laboratoriais, (2) tampouco materiais ou instrumentais diferentes dos utilizados pelo ortodontista em sua prática diária; (3) a forma de ativação é simples e pode ser feita de forma uni ou bilateral; (4) não é 
necessária sobrecorreção; (5) os dentes anteriores podem ser retraídos em massa, sem necessidade de alteração na mecânica, de aparelhos adicionais ou de reposicionamento dos MPOs; (6) a distalização pode ser feita simultaneamente com a mecânica por vestibular; (7) após a distalização, o MPO pode servir como ancoragem indireta para imobilização; e (8) possibilita controle A-P, vertical, transversal e de angulação do molar, (9) tem baixo custo e todas as etapas podem ser executadas pelo ortodontista (21). Nesta técnica, a variação dos locais de instalação do MPO e da ativação na BTP podem produzir diferentes resultados no movimento do molar, o que ainda não foi estudado. A análise de elementos finitos é uma ferramenta indicada para este tipo de estudo biomecânico, por ser confiável e não invasiva $(19,22,23,24)$.

Este estudo teve como objetivo (1) encontrar e descrever, por meio de mensurações tomográficas e análise estatística, medidas da maxila de um indivíduo médio dentro do universo dos pacientes com características de uma má oclusão de Classe II esquelética não cirúrgica; (2) criar um modelo virtual da maxila deste paciente, a partir das medidas obtidas; (3) avaliar neste modelo a distribuição de tensões, após aplicação de 9 carregamentos com diferentes vetores de força, nos primeiros molares superiores, nos elementos constituintes ortodônticos (barra transpalatina e microparafuso ortodôntico) e nas estruturas biológicas adjacentes, nos três planos do espaço, pelo método de elementos finitos (MEF); e (4) sugerir a indicação clínica para cada tipo de ativação. 


\section{REVISÃO DA LITERATURA}

\subsection{PREVALÊNCIA DAS MÁS OCLUSÕES}

O conhecimento da prevalência das más oclusões da população tem importância epidemiológica, pois serve como modelo para planejamento e estruturação de pesquisas, serviços particulares e governamentais de saúde bucal prestados à população. Há especial interesse na população que busca tratamento ortodôntico, pois o aumento ou diminuição da incidência dos transtornos oclusais servem como indicador de eficiência das técnicas preventivas e corretivas instituídas, assim como para traçar novas diretrizes de pesquisa e tratamento. Neste âmbito, Freitas et al. (1) analisaram, de forma descritiva, modelos de estudo de 520 pacientes no final da dentadura mista e início da dentadura permanente que procuraram tratamento na Faculdade de Odontologia de Bauru - USP. Encontraram apinhamento primário em mais de $2 / 3$ da amostra (67\% nos arcos superiores e $71 \%$ nos arcos inferiores), Classe II divisão 1 em metade da amostra (50\%), Classe I em $44 \%$ dos indivíduos do sexo masculino e $40 \%$ do sexo feminino, Classe II divisão 2 em $2,4 \%$ dos indivíduos do sexo masculino e $8 \%$ do sexo feminino, mordida cruzada anterior em $18 \%$, posterior em $27 \%$ e mordida aberta anterior em $9 \%$ dos indivíduos.

\subsection{ANATOMIA MAXILAR E IMAGINOLOGIA}

McNamara (25) fez uma extensa revisão da literatura, além de avaliar cefalometrias de 277 crianças entre 8 e 10 anos de uma escola primária e secundária em Michigan. O objetivo do estudo foi o de avaliar a posição A-P da maxila, mandíbula, dentes superiores e inferiores (retruído, neutro ou protruído) e o componente vertical (longo, neutro ou curto). Concluiu que a má oclusão de Classe II não é uma entidade única, assim como não existe consenso na literatura sobre a importância nem a ocorrência dos seus cinco principais componentes. Das 243 combinações possíveis entre os 5 elementos, encontrou 77 e listou os 10 mais comuns, representando 105 crianças. Entre os 10 mais comuns, o fator recorrente mais comum relacionado à Classe II foi a retrusão mandibular, presente em 7 dos 10 mais comuns, seguido pelo aumento na dimensão vertical (em 5 dos 10), retrusão dos dentes mandibulares (4 dos 10), retrusão maxilar (3 dos 10), retrusão dos dentes maxilares (1 dos 10) e protrusão dos dentes mandibulares (1 dos 10). A 
única combinação que representou mais que 10\% da amostra (28 em 277 = 10,1\%) foi a de retrusão mandibular com excesso vertical, seguida por retrusão bimaxilar com excesso vertical (12 em $277=4,3 \%$ ) e por somente retrusão mandibular (11 em 277 = 3,9\%). Quando a maxila não foi encontrada na posição neutra, que representou a maioria dos casos, estava mais frequentemente retruída do que protruída, sendo que as retruídas geralmente estavam associadas à excesso de desenvolvimento vertical.

Hubar (26) usou radiografias digitalizadas para quantificar a espessura da lâmina dura em diferentes regiões da cavidade bucal de adultos saudáveis. Os resultados mostraram diferenças na espessura da lâmina dura na região anterior e posterior, com médias entre 0,22 a 0,54. mm. Os ápices apresentaram as menores espessuras de lâmina dura, que aumentavam progressivamente nas regiões do terço médio e crista alveolar.

Rosenblum (27) também estudou a relação A-P e vertical maxilomandibular em pacientes portadores de má oclusão de Classe II, com maiores detalhes e análise estatística. Citou algumas limitações dos estudos anteriores que apontam mandíbulas retruídas, incluindo o de McNamara (25) e 12 estudos listados em seu artigo, ressaltando que ou usaram indicadores baseados em Sela-Násion, ou tiveram uma amostra pequena, ou baseada em idade cronológica ou sem seleção de idade ou somente com medidas lineares, mais passíveis de distorções radiográficas, em vez de proporções. Neste estudo, a amostra de 103 pacientes entre 11 e 16 anos de idade foi classificada de acordo com o indicador de maturação esquelética de Fishman e as medidas cefalométricas foram baseadas em NA-FH (Frankfurt), Ba-A, SNA e A-NaPerp, sobre as quais foi feita análise estatística. Concluiu que o padrão dominante foi de protrusão maxilar com mandíbula normal. A incidência média de protrusão maxilar nestes três grupos foi de 56,3\%, retrusão mandibular de $27 \%$ e tendência de crescimento vertical $13,5 \%$.

Björk (3) estudou o prognatismo facial em uma amostra de 603 suecos do gênero masculino (322 crianças com 12 anos de idade e 281 soldados alistados) e 400 indivíduos da Rodésia (África), em telerradiografias laterais. Concluiu que nos casos de distoclusão com trespasse horizontal aumentado (classe II, 1), havia diferença no prognatismo dos ossos basais, processos alveolares ou inclinação dos incisivos, e que esta diferença das bases ósseas foi causada por alterações no tamanho e posição da maxila e mandíbula, por protrusão da maxila, retrusão da 
mandíbula ou uma combinação de ambos, e que estariam relacionadas a aumento do comprimento maxilar, diminuição do comprimento mandibular ou ambos.

Riedel (28) estudou a maxila e sua relação com o crânio e mandíbula em telerradiografias laterais de 52 adultos e 24 crianças com oclusão excelente e 38 indivíduos com má oclusão de classe II,1, 10 com classe II,2 e 9 com Classe III. O autor notou uma tendência da maxila a se tornar mais prognata com o crescimento, pela medida SNA, sem diferenças significantes entre o grupo normal e o grupo com má oclusão. Também percebeu, pela medida SNB, que a mandíbula também tende a se tornar mais prognata com o crescimento, mas que existem diferenças significantes entre o grupo normal e o com má oclusão, em especial o portador de classe II,1, com menor prognatismo mandibular. Para avaliar a relação anteroposterior entre maxila e mandíbula, ressaltou o ângulo ANB como o achado mais significante deste estudo, com valor médio de $2^{\circ}$.

Tukasan (29) definiu valores cefalométricos da Análise de Tweed em 212 radiografias cefalométricas de brasileiros, do sexo masculino e feminino, entre 12 e 15 anos, sendo 169 portadores de má oclusão de classe II,1 e 43 de um grupo controle. Os resultados demonstraram não existir dimorfismo sexual dentro de cada grupo, comprovado pelo Teste "t" de Student e que a maxila apresentou-se bem posicionada em relação à base do crânio, sem diferença estatisticamente significativa na posição da maxila entre os grupos. Por outro lado, a mandíbula apresentou-se retruída em relação à base do crânio nos casos de classe II. A relação entre maxila e mandíbula foi determinada pelo ângulo ANB, que apresentou

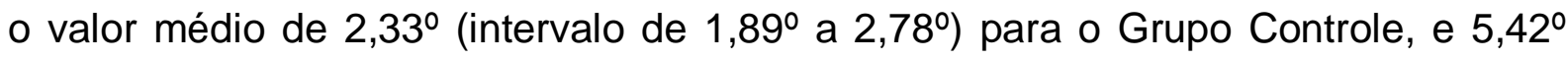
(intervalo de $4,23^{\circ}$ a $6,61^{\circ}$ ) para o Grupo Classe II.

Deguchi et al. (30) usaram tomografias tridimensionais de 10 pacientes para avaliar quantitativamente a espessura do osso cortical em vários locais da maxila e mandíbula, as distâncias da superfície do osso intercortical até as superfícies radiculares e as distâncias entre as raízes de segundos pré-molares (dente 5) e molares (dentes 6 e 7), com propósito de determinar comprimento e largura aceitáveis de mini-implantes ortodônticos. Na maxila, a menor espessura cortical foi encontrada na região disto-vestibular dos segundos molares $(1,3 \pm 0,5 \mathrm{~mm})$. A espessura da cortical entre os dentes 5-6 foi de 1,8 $\pm 0,6 \mathrm{~mm}$ na vestibular e 1,7 \pm 0,9 mm na lingual a nível oclusal. Entre 6-7 a espessura cortical teve média de 1,5 \pm $0,5 \mathrm{~mm}$ para vestibular e 1,7 $\pm 0,7 \mathrm{~mm}$ para lingual a nível oclusal. Observaram que 
quanto menor o ângulo de inserção do mini-implante, maior o contato com osso cortical, sendo que a espessura cortical foi 1,5 vezes maior com $30^{\circ}$ quando comparado a $90^{\circ}$ de inclinação (no palato, respectivamente 2,0 \pm 0,8 mm e 1,2 \pm 0,5 $\mathrm{mm})$. Encontraram maior distância entre a superfície do osso intercortical e a superfície radicular entre 5-6 (4 \pm 1,5 mm) do que entre 6-7 (2,1 \pm 1,0 mm). Próximo à oclusal, a distância entre as raízes 5-6 foi de 2,1 \pm 0,7 mm e entre as raízes 6-7 foi de 1,5 \pm 0,5 mm; próximo à apical, a distância entre as raízes 5-6 foi de 6,1 \pm 1,1 $\mathrm{mm}$ e entre as raízes 6-7 foi de 3,8 $\pm 1,6 \mathrm{~mm}$. Os autores recomendam o uso de mini-implantes com angulação de $30^{\circ}$ e mais longos (8 a $10 \mathrm{~mm}$ ) no palato, pela mucosa ser mais espessa do que em outras áreas. No palato, afirmam que os miniimplantes devem ser instalados nas regiões mesiais ou distais ao primeiro molar porque existe quantidade adequada de osso cortical, o que não ocorre na região posterior ao segundo molar.

Esteves \& Bommarito (31) mediram modelos de estudo de gesso de 135 pacientes entre 12 e 21 anos do sexo masculino e feminino, com diferentes padrões faciais e más oclusões. O objetivo foi estudar a correlação destas características com a profundidade do palato e com as dimensões do arco dentário superior. Não encontraram diferenças significantes nas distâncias intercaninos e intermolares, entre pacientes dolicofaciais, mesofaciais e braquifaciais, mas houve quando comparadas as medidas de profundidade palatina entre braquifaciais e dolicofaciais (médias respectivas de 18,18 $\mathrm{mm}$ e 19,52 mm). Quanto ao dimorfismo sexual, indivíduos do gênero masculino apresentaram médias da distância intermolares superiores $(51,36 \mathrm{~mm})$ e da profundidade do palato $(19,61 \mathrm{~mm})$ aumentadas, de forma significante, em relação às médias obtidas para o gênero feminino $(50,15 \mathrm{~mm}$ e 18,37mm para as medidas da distância intermolares e da profundidade do palato, respectivamente). Avaliando o tipo de má oclusão, constataram que houve diferença estatisticamente significante apenas para a medida do comprimento do arco, sendo que indivíduos com má oclusão de Classe II apresentaram arcos dentários superiores com maior comprimento ântero-posterior (média $=31,23 \mathrm{~mm}$ ) que indivíduos com má oclusão de Classe III (média $=29,64 \mathrm{~mm}$ ), diferença não significante na comparação entre as médias obtidas no grupo Classe I (30,52mm) em relação aos grupos Classe II e Classe III.

Shelly et al. (32) investigaram o impacto da cirurgia de avanço mandibular na estética do perfil em 34 pacientes classe II divisão1 mandibular, na tentativa de 
definir parâmetros de predição de mudança. As imagens, produzidas a partir de silhuetas de telerradiografias iniciais e pós-tratamento, foram mostradas aleatoriamente a leigos e residentes em ortodontia, aos quais foi solicitada uma nota para cada perfil. $O$ ponto $B$ foi movido em média $5 \mathrm{~mm}(\mathrm{DP}=2,6 \mathrm{~mm}$ ) para frente e 4,7 mm (DP = $3.1 \mathrm{~mm}$ ) para baixo, com o ângulo ANB diminuindo $3^{\circ}\left(\mathrm{DP}=1,6^{\circ}\right)$. $\mathrm{A}$ análise estatística com testes "t" pareados revelou que para pacientes com ANB inicial $\geq 6^{\circ}$, a mudança na estética do perfil foi significativa após a cirurgia $(p<.001)$, representando uma melhora de $45 \%$ na estética. Em pacientes com ANB inicial $<6^{\circ}$, o resultado estético foi pobre. Estes resultados enfatizam o uso do ângulo ANB como parâmetro na decisão de quando tratar um paciente com avanço mandibular cirúrgico, indicado para melhorar a estética do perfil nos casos de ângulo ANB inicial de pelo menos $6^{\circ}$.

Baumgaertel (33) avaliou a espessura das corticais ósseas palatinas em 30 crânios secos com tomografia computadorizada. Em fatias coronais, mediu a profundidade óssea e a espessura cortical em 4 níveis e 34 sítios de instalação no palato. Encontraram profundidade óssea média de 2,71 $\pm 1,40 \mathrm{~mm}$ a $2 \mathrm{~mm}$ do plano sagital mediano, 1,99 $\pm 1,46 \mathrm{~mm}$ a $4 \mathrm{~mm}, 1,59 \pm 1,14 \mathrm{~mm}$ a $6 \mathrm{~mm}, 1,62 \pm 1,07 \mathrm{~mm}$ a $8 \mathrm{~mm}$ e $2,40 \pm 1,41 \mathrm{~mm}$ a $10 \mathrm{~mm}$. A espessura cortical palatina média variou de 1,49 $\pm 1,16 \mathrm{~mm}$ na região do ponto de contato do canino com o primeiro pré-molar a 1,00 $\pm 0,40 \mathrm{~mm}$ na região ponto de contato do primeiro e segundo molares. Afirma que, para instalação de um mini-implante, é importante se conhecer a anatomia local e que atualmente a tomografia tridimensional é a única forma de se obter estas informações em três dimensões. Sem as imagens da tomografia, uma opção válida é usar médias de estudos de imagem para identificar sítios adequados para instalação de mini-implantes. Considerando a espessura óssea, recomenda que a instalação seja feita na região entre caninos, primeiros pré-molares e segundos prémolares. Concluiu que a profundidade óssea diminui de anterior para posterior e com o aumento da distância do plano palatino mediano, e que a profundidade óssea e a espessura cortical são mais favoráveis para a instalação de mini-implantes no palato entre os primeiros e segundos pré-molares.

Barriviera et al. (34) desenvolveram um método inovador para medir a mucosa mastigatória palatina com tomografias computadorizadas de feixe cônico (CBCT). Em uma amostra de 31 pacientes foram feitas mensurações a 2 mm, 5 mm, $8 \mathrm{~mm}$ e $12 \mathrm{~mm}$ da margem gengival palatina (4 distâncias), perpendiculares aos 
caninos, primeiros e segundos pré-molares e primeiros e segundos molares (5 dentes), de ambos os lados, totalizando 40 medidas. Concluíram que a espessura média da mucosa palatina era de 2,92 $\mathrm{mm}$ na região canina, 3,11 $\mathrm{mm}$ na região do primeiro pré-molar, 3,28 $\mathrm{mm}$ na região do segundo pré-molar, 2,89 $\mathrm{mm}$ na região do primeiro molar e $3,15 \mathrm{~mm}$ na região do segundo molar (Tabela 1). Não foram encontradas diferenças estatísticas entre os sexos, mas foram observadas em diferentes idades e alturas de mensuração. Espessuras maiores de mucosa foram encontradas em pacientes com mais de 40 anos, que apresentaram mucosa mastigatória mais espessa do que paciente mais jovens, e de maneira geral, quanto mais apical, maior a espessura da mucosa.

Tabela 1 - Espessuras médias em milímetros da mucosa mastigatória palatina de acordo com a distância da cervical do molar em direção à sutura palatina mediana (34).

\begin{tabular}{ccccccccc} 
& \multicolumn{5}{c}{$1^{\circ}$ Molar } & \multicolumn{4}{c}{$2^{\circ}$ Molar } \\
\hline & $2 \mathrm{~mm}$ & $5 \mathrm{~mm}$ & $8 \mathrm{~mm}$ & $12 \mathrm{~mm}$ & $2 \mathrm{~mm}$ & $5 \mathrm{~mm}$ & $8 \mathrm{~mm}$ & $12 \mathrm{~mm}$ \\
\hline Média & 2,11 & 2,34 & 2,92 & 4,21 & 2,22 & 2,28 & 3,08 & 5,02 \\
DP & 0,51 & 0,65 & 0,73 & 0,90 & 0,72 & 0,77 & 1,22 & 1,61 \\
Mediana & 2,06 & 2,20 & 2,91 & 4,02 & 2,15 & 2,15 & 2,97 & 5,24 \\
\hline
\end{tabular}

Gracco et al. (35) avaliaram tomografias volumétricas de 162 pacientes de 10 a 44 anos de idade, de ambos os sexos, com o objetivo de medir a espessura do osso no palato e determinar a melhor localização para instalação de mini-implantes. As medidas foram feitas em cortes paracoronais a 4, 8, 16 e $24 \mathrm{~mm}$ posteriormente ao forame incisivo. Não encontraram diferenças significantes entre os sexos e entre os lados direito e esquerdo. Concluíram que a espessura do osso é maior na região anterior do palato, embora a região posterior também seja adequada para instalação de mini-implantes ortodônticos.

\subsubsection{Importância para condutas seguras na instalação de microparafusos}

\subsubsection{Escolha do sítio}

Poggio et al. (36) analisaram imagens tomográficas de 25 maxilas e 25 mandíbulas, com o objetivo de fornecer um mapa anatômico para ajudar o clínico a instalar mini-implantes em locais seguros entre as raízes. Concluíram que um miniimplante ortodôntico deve ter como características ideais de 1,2 a 1,5 mm de 
diâmetro, com 6 a $8 \mathrm{~mm}$ de rosca e formato cônico, e que os locais mais seguros para instalação na região posterior da maxila são do lado palatino, no espaço interradicular entre (1) o primeiro molar e o segundo pré-molar, de 2 a $8 \mathrm{~mm}$ da crista alveolar; e (2) o segundo molar e o primeiro molar, de 2 a $5 \mathrm{~mm}$ da crista alveolar.

Teixeira (37) ressaltou a importância de se conhecer a topografia do forame palatino maior (FPM), por ser, entre outros aspectos, o ponto de emergência do feixe vásculo nervoso que se distribui para o palato. Em seu trabalho, as medidas de 141 crânios, submetidas a análise estatística, mostraram que na maior parte dos crânios, o FPM estava localizado mais próximo ao terceiro molar e um número pequeno (menos de 1\%) próximo ao segundo molar, distante aproximadamente 1,6 cm lateralmente à sutura interpalatina (Figura 1), concordando de forma unânime com os estudos científicos incluídos em seu trabalho.

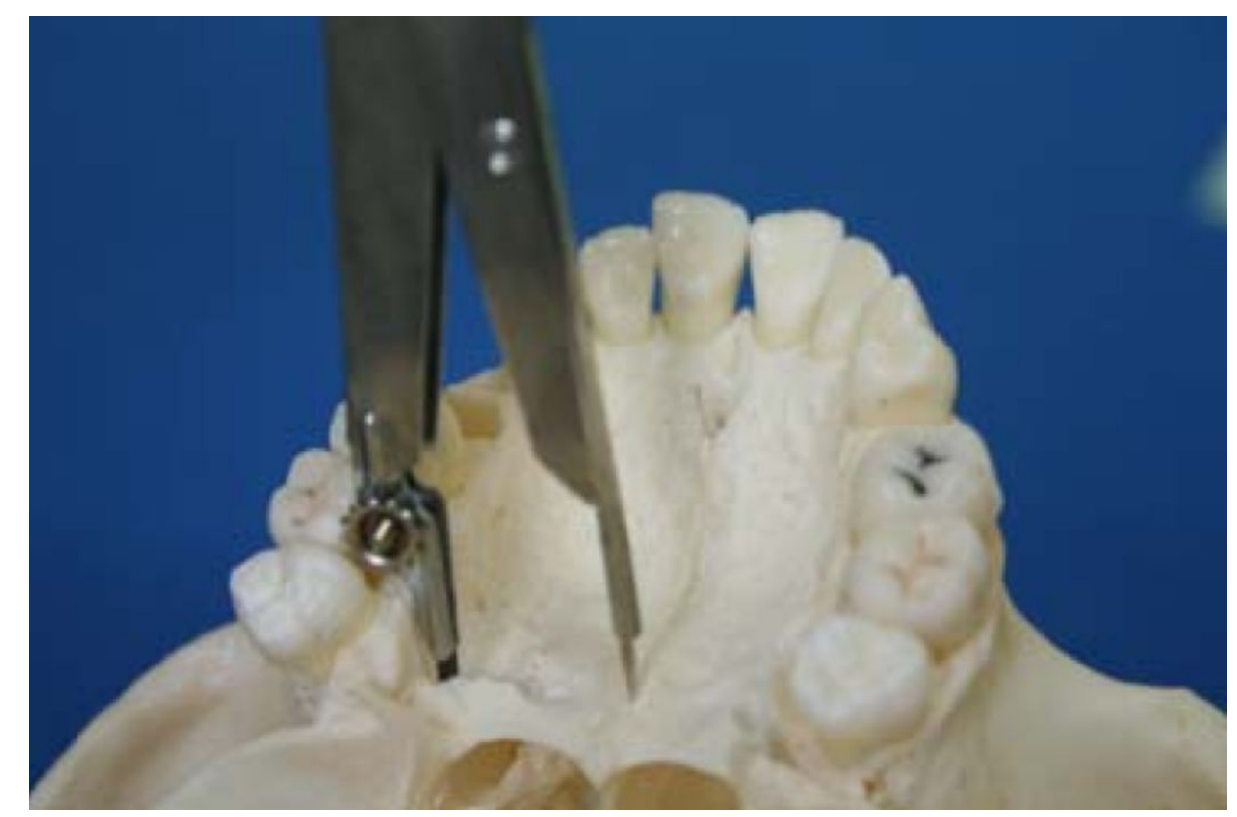

Figura 1 - Mensuração da distância entre o forame palatino maior e a sutura interpalatina. (Teixeira p.39).

Ikuta et al. (38) avaliaram o posicionamento do 100 Forames Palatinos Maiores em adultos, em relação aos molares superiores em 50 Tomografias Computadorizadas de Feixe Cônico. Segundo os autores, a localização do FPM é essencial para a técnica do bloqueio do Nervo Palatino Maior, que é muito utilizada em cirurgias orais menores. O erro da técnica por desconhecimento anatômico pode 
resultar em complicações como diplopia, estrabismo, ptose, injeção intravascular e dano nervoso. Como resultado final, 53\% dos FPMs estavam localizados entre a face mesial do terceiro molar e o seu centro por palatino, 39\% entre o centro da face palatina do segundo molar e a sua face distal, 5\% a distal do terceiro molar, e 3\% entre o centro da face palatina do segundo molar e a sua face distal. Não houve diferença estatisticamente significante entre os lados direito e esquerdo (Teste tpareado, $p>5 \%)$.

\subsubsection{Anestesia}

Marassi (39) recomenda a aplicação de anestesia subperiosteal próxima ao local onde será instalado o mini-implante, com aproximadamente um quinto do conteúdo de um tubete anestésico. Explica que é desejável que os dentes vizinhos ao local de inserção não sejam anestesiados, pois, se o ligamento periodontal dos dentes vizinhos for atingido durante a perfuração, o paciente relatará dor. Caso isso ocorra, o mini-implante poderá ser removido e instalado em uma outra posição.

\subsubsection{Forma de instalação}

Em um estudo retrospectivo, Kuroda et al. (40) analisaram os índices de sucesso de miniplacas e miniparafusos instalados com ou sem rebatimento do retalho. Instalaram 116 miniparafusos de dois tipos e 38 miniplacas em 75 pacientes, que preencheram um questionário que incluía uma escala visual analógica, para que fosse indicada a intensidade do desconforto após a instalação. Encontraram um índice de sucesso superior a $80 \%$ para os miniparafusos e de quase $87 \%$ para as miniplacas, sem diferença significante no índice de sucesso entre eles, assim como também não encontraram correlação entre insucesso e sexo, idade, ângulo do plano mandibular, relação anteroposterior dos maxilares, sintomas de DTM, tempo e intensidade da aplicação da força inicial e comprimento do parafuso. Dor foi relatada por todos os pacientes que foram submetidos a cirurgia com rebatimento do retalho, com intensidade média de 6,5 em 10, uma hora após a cirurgia. A dor foi relatada também em metade dos pacientes que receberam miniparafusos sem retalho, mas com intensidade média de 2 em 10, uma hora após a cirurgia. Também foram encontradas diferenças significantes no desconforto e edema pós-operatório, dificuldade em falar e mastigar entre os procedimentos feitos com ou sem retalho. $O$ que provocou menor transtorno pós-operatório foi o miniparafuso sem retalho, 
seguido pelo miniparafuso com retalho e pela miniplaca. Os autores ressaltaram a vantagem na opção pelo miniparafuso instalado sem retalho, que além de ser o que provocou menor dor e desconforto após a instalação, foi o que teve o melhor índice de sucesso $(89,8 \%)$.

Wilmes et al. (41) analisaram o impacto do desenho e tamanho do miniimplante na estabilidade primária. Após instalar 1050 mini-implantes de vários fabricantes, com 1,4 a 2 mm de diâmetro e 8 a 11 mm de comprimento, com prébrocagem em ossos ilíacos suínos, observaram uma grande variação de torques de inserção. Concluíram que os mini-implantes cônicos obtiveram maior estabilidade primária do que os cilíndricos e que o torque de inserção está relacionado diretamente com o calibre do mini-implante.

Baumgaertel (42) relatou que o mercado oferece mini-implantes com e sem brocagem prévia (nondrill-free e drill free) e revisou a literatura sobre o assunto. Explica que a estabilidade primária é a estabilidade inicial do implante logo após a sua instalação. Ocorre em função da retenção mecânica do implante com o osso e depende do desenho do implante. É importante durante a cicatrização e o período de remodelamento, especialmente quando o implante recebe carga imediata. A estabilidade secundária é a estabilidade após a cicatrização do sítio de instalação. Ocorre em consequência da formação óssea e remodelamento do osso circundante na interface implante-osso. É resultado da resposta do hospedeiro, determinada por reações biológicas e retenção mecânica. Também é um fator determinante para o sucesso durante a maior parte do período da aplicação de força. Concluiu que um fator importante no índice de sucesso dos mini-implantes é o torque de inserção, que teve mais sucesso entre 5 e $10 \mathrm{Ncm}$, alto o suficiente para fornecer estabilidade primária e baixo o suficiente para manter a vitalidade dos tecidos circundantes e favorecer uma resposta favorável do hospedeiro, melhorando a estabilidade secundária. Portanto, em áreas com alta densidade óssea, a pré-brocagem pode ser recomendada se o objetivo for manter o torque em um nível ideal.

Cho et al. (43) analisaram relação entre a experiência do operador e o contato com a raiz dos dentes vizinhos, durante a instalação de microimplantes autorrosqueantes. Em modelos com dentes de resina, selecionaram seis locais para que 28 dentistas, divididos em dois grupos, realizassem 332 pré-brocagens. O grupo mais experiente foi significativamente mais preciso, contatando em média 13,5\% das raízes (valor similar ao reportado como índice de falha dos microimplantes), versus 
21,3\% de contato com o grupo sem experiência. Em ambos os grupos, a maior quantidade de contatos ocorreu na região posterior. No grupo experiente, os dentes mais suscetíveis a contato foram o 16 e o 36, enquanto que no grupo sem experiência, todos apresentaram risco similar na região posterior. Notaram que os operadores experientes mudaram pouco de posição durante o procedimento, independente do sítio de instalação. Acreditaram que isto indicou que fatores relacionados ao operador, como postura, ângulo de visão e acesso dos instrumentos, têm maior importância do que o espaço interradicular. Concluíram também que atenção especial deve ser dada durante a instalação de microimplantes próxima aos dentes 16 e 36.

\subsubsection{Ativação}

Miyawaki et al. (44) não encontraram associação entre estabilidade e número de dias da implantação até a aplicação de força. Os resultados de seu estudo sugerem que é possível aplicar carga imediata nos mini-implantes se a força for menor que $2 \mathrm{~N}$, provavelmente pela interdigitação mecânica entre o mini-implante e o osso alveolar, ressaltando outros estudos que recomendam a aplicação imediata de carga.

Kuroda et al. (40), estudaram dois tipos de mini-implantes, que receberam carga de 50 a 200 gf (0,5 a 2 N) imediatamente após a instalação ou 4 semanas depois, com cadeias elásticas ou molas fechadas de NiTi. Atingiram um índice de sucesso de aproximadamente 90\%, notaram menor desconforto e dor em pacientes submetidos ao procedimento sem incisão mucoperiosteal ou cirurgia a retalho e não relacionaram o tempo de aplicação de carga com o índice de sucesso. Relataram que a aplicação imediata de carga contribui para o bom prognóstico dos miniimplantes, por poder aumentar a ossificação do osso alveolar em volta do implante.

\subsection{MOVIMENTOS A-P E ANCORAGEM ESQUELÉTICA}

Em 1983, Creekmore e Eklund (45) foram os primeiros ortodontistas a publicar um trabalho clínico com os objetivos de levantar a questão sobre o uso do esqueleto como ancoragem para movimentação ortodôntica e ortopédica e estimular uma investigação apropriada. Reportaram o uso de um pequeno parafuso de vitallium como ancoragem para a intrusão dos incisivos superiores de uma paciente de 25 anos de idade, com relação molar de Classe I e mordida profunda anterior. O 
parafuso foi inserido abaixo da espinha nasal anterior e ativado dez dias depois de sua instalação, com uma cadeia elástica no arco superior. Durante um ano de ativações, o parafuso permaneceu estável e sem complicações, até ser removido. Os incisivos foram intruídos aproximadamente $6 \mathrm{~mm}$ e lingualizados cerca de 25 graus.

Em 1990, Roberts et al. (46) reportaram o primeiro caso clínico de implante osteointegrado na região retromolar com propósito de movimentação A-P. Do lado esquerdo, o paciente apresentava ausência do 36 e presença de uma ponte de 3 elementos, uma relação nos pré-molares de Classe II 1/2 cúspide, ausência do 28 e extrusão do 38. Os autores instalaram um implante na região retromolar esquerda e, após a osteointegração (mínimo de 4 meses, mas o paciente só voltou depois de 9 meses), o usaram como ponto de apoio para aplicação de força de mesialização no 37 e 38 até o fechamento do espaço do 36. Após o tratamento, o implante foi removido com trefina porque não se considerava prudente manter o implante na mandíbula do paciente indefinidamente.

\subsubsection{Movimentos A-P convencionais}

Worms et al. (20) investigaram a relação entre direção dos vetores de força e pontos de aplicação da força extrabucal em superposições de telerradiografias de 15 pacientes, comparando os resultados com os de um modelo biomecânico. Afirmaram que para o uso eficaz da força extrabucal, são necessários quatro elementos: (1) centros de rotação, (2) direção, (3) força, e (4) magnitude. Afirmaram que quando uma força é aplicada a um corpo, ele pode se movimentar por translação (movimento de corpo), rotação (inclinação) ou uma combinação destes, dependendo da distância entre o vetor de força e o centro de resistência do corpo. Se a força passa pelo centro de resistência, o corpo irá transladar. Se a força não passa pelo centro de resistência, um braço de momento é criado, no qual a menor distância perpendicular entre o vetor de força e o centro de resistência causam rotação. Neste caso, o centro de resistência ainda se moverá na direção da força e o corpo sofrerá rotação enquanto se move. O centro de rotação é determinado pela localização do centro de resistência instantâneo. Se o centro de rotação é próximo ao centro de resistência, o movimento predominante será de giro, enquanto que se for distante, aproximando-se do infinito, o movimento predominante será de translação. À medida em que a distância perpendicular do vetor de força ao centro 
de resistência aumenta, o centro de rotação se aproxima do centro de resistência e vice-versa. Se múltiplos vetores de força estão envolvidos, como retração e intrusão, a análise de vetores pode reduzí-los a um único vetor de força resultante. Encontraram que o centro de resistência teórico do primeiro molar superior localizase na trifurcação das raízes e consideraram essencial planejar o vetor de força com aparelhos extrabucais porque a posição vertical do molar superior é importante durante o diagnóstico e o plano de tratamento. Se o sistema extrabucal de forças foi paralelo ao plano oclusal, não ocorreu nem intrusão nem extrusão. Se a força foi direcionada para o molar em um plano abaixo do plano oclusal, o molar extruiu, enquanto que se foi acima do plano oclusal, o molar intruiu. Baseado em seu modelo experimental, observou 5 modelos básicos de movimento, translação e quatro tipos de rotação (Figura 2). Concluíram também que, com a distalização dos primeiros molares, os segundos, terceiros molares e segundos pré-molares distalizaram, os primeiros molares intruíram ou distalizaram, de acordo com a direção do extrabucal, e que os segundos molares e segundos pré-molares não intruíram com a intrusão do primeiro molar.
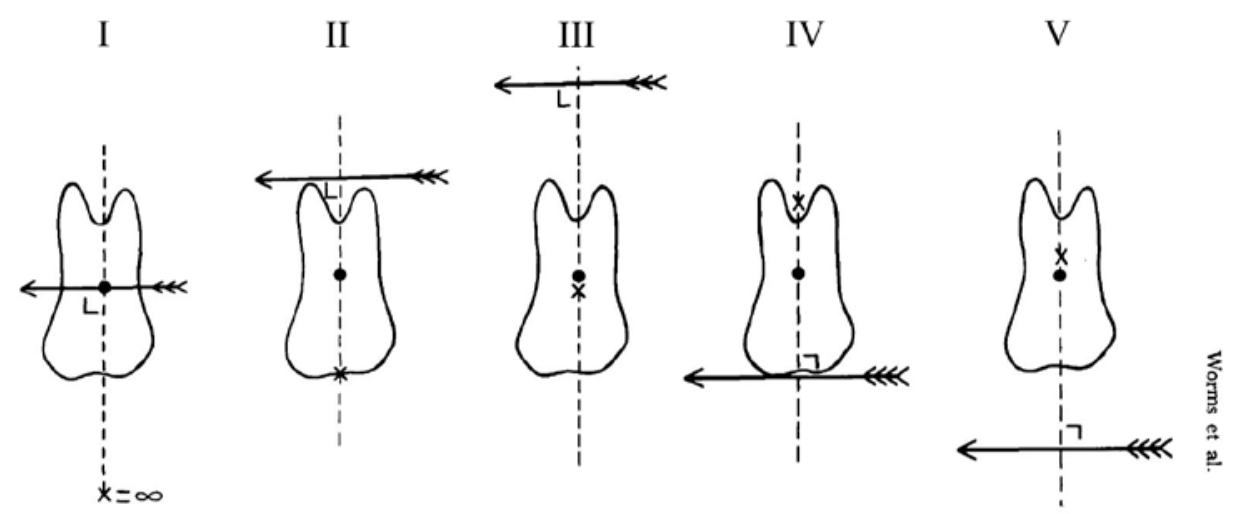

Figura 2 - Vetor de força Tipo I - Passa pelo Cres e produz um Crot (X) no infinito = translação. Vetor de força Tipo II - Passa pelo ápice e produz um Crot na oclusal - rotação. Vetor de força Tipo III - Passa apicalmente duas vezes a distância do ápice ao Cres e produz um Crot próximo ao Cres = rotação. Tipo IV - Passa pela oclusal e produz um Crot no ápice = rotação. Tipo V - Passa oclusalmente duas vezes a distância da oclusal ao Cres e produz um Crot próximo ao Cres = rotação (20).

Dermaut et al. (47) utilizaram interferometria laser para medir e estudar o movimento de molares superiores submetidos à força extrabucal. Para analisar a resistência ao movimento, declarou que parâmetros devem ser considerados, como 
(1) a anatomia dental e a distribuição de massa; (2) a estrutura do ligamento periodontal; (3) o osso circundante; e (4) os dentes adjacentes. A mensuração precisa do movimento dental inicial permitiu a determinação exata da posição do dente antes e depois de aplicação de força, método com número reduzido de possíveis erros quando comparado ao método de sobreposição de traçados. Diminuindo a altura da tração, a resistência às forças diminuiu e a angulação distal aumentou, sendo que com a tração mais baixa ocorreu também uma pequena intrusão. O movimento de corpo do molar ocorreu com a aplicação de força entre os níveis B e C (Figura 3).

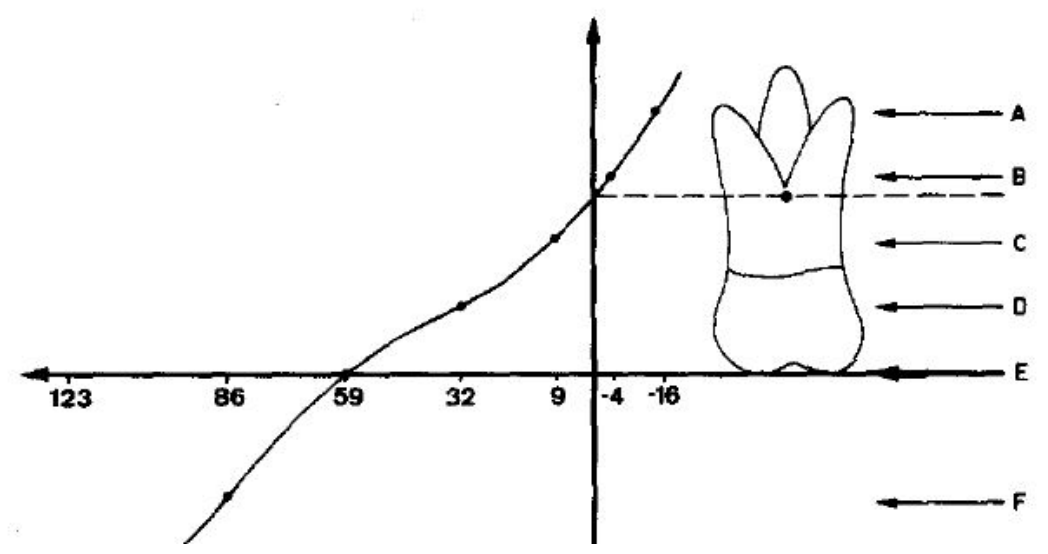

Figura 3 - Média de graus de angulação por nível de linha de tração. Ordenada $=$ Linhas dos níveis de tração. Abscissa $=$ Grau de angulação (a). Os números à esquerda da ordenada representam a angulação distal de coroa, os números à direita indicam angulação distal da raiz. O ponto de intersecção representa movimento de corpo sem rotação (47).

Em um estudo randomizado controlado, Bondemark \& Karlsson (48) compararam os efeitos do aparelho extrabucal cervical (AEB) com os efeitos de um aparelho intrabucal com molas superelásticas de NiTi ancoradas em um Botão de Nance nos segundos pré-molares superiores (AIB), no movimento distal dos primeiros molares superiores em 40 pacientes sem segundos molares erupcionados e com média de idade de 11,5 anos ( $\pm 1,29$ ano). No grupo de AIB, os molares distalizaram em média $3 \mathrm{~mm}$ em 5,2 meses, significantemente mais do que no de AEB com média de 1,7 mm em 6,4 meses. A sobressaliência aumentou $0,9 \mathrm{~mm}$ no grupo de AIB e diminuiu $0,9 \mathrm{~mm}$ no grupo de $A E B$, a sobremordida diminuiu aproximadamente $0,8 \mathrm{~mm}$ e os primeiros molares superiores inclinaram para distal em média $3^{\circ} \mathrm{em}$ ambos os grupos. Os incisivos centrais superiores inclinaram para 
vestibular em média $2^{\circ}$ no grupo de AEB e para lingual em média $0,6^{\circ}$ no grupo AIB.

Antonarakis e Kiliaridis (9) apresentaram uma revisão sistemática com metaanálise que avaliou quantitativamente os efeitos dentários de distalizadores que não necessitam da colaboração do paciente. Analisaram sistemas de forças variados, com aplicação de força vestibular, palatina ou ambas e com atrito (mecânica de deslizamento) ou sem (Hilgers). Na média, ocorreu distalização de 2,9 mm com angulação distal de 5,4 $4^{\circ}$ nos molares. Nos incisivos, a mesialização média foi de 1,8 $\mathrm{mm}$, angulação mesial de $3,6^{\circ}$ e extrusão de $0,4 \mathrm{~mm}$. Nos pré-molares, a mesialização média foi de 1,7 mm e extrusão de 1,1 mm. Os sistemas de força por palatino apresentaram menor angulação radicular que os sistemas de força por vestibular e os botões de Nance não garantiram ancoragem absoluta na distalização de molares, inclusive com vestibularização dos incisivos e aumento da sobressaliência. Os autores encontraram a maior angulação mesial de raiz com o Pendulum de Hilgers, assim como a maior quantidade de movimento distal da coroa. Afirmaram que a distalização é mais eficiente na ausência do segundo molar erupcionado e que um aspecto crítico com o tratamento com estes dispositivos é a recidiva durante a fase de estabilização.

\subsubsection{Tipos de ancoragem esquelética e outras informações relevantes}

Como resultado dos avanços na biocompatibilidade, o titânio têm sido usado em parafusos e miniplacas para fixação rígida em cirurgia ortognática. Após aventar a hipótese de que estes dispositivos também poderiam ser usados como ancoragem em ortodontia, Umemori et al. (18) apresentaram um sistema de ancoragem esquelética (SAS) para correção de mordida aberta. O sistema consistia em miniplacas de titânio, implantadas temporariamente na região entre primeiros e segundos molares inferiores direitos e esquerdos, que serviriam como um ponto imóvel de ancoragem para colocação de cadeias elásticas pela vestibular. Associado à este sistema foram instalados os "Multiloop Edgewise Archwires MEAW", uma barra lingual e posteriormente um arco vestibular rígido, com torque lingual de coroa, para controlar o efeito colateral de vestibularização. Nos dois casos apresentados, obtiveram intrusão de 3,5 e $5 \mathrm{~mm}$ dos molares inferiores, após 5 e 9 meses de tratamento, sem efeitos colaterais significativos e ressaltaram que a estabilidade depende do controle dos fatores etiológicos.

Bernhart et al. (49) buscaram um local alternativo à sutura palatina mediana 
para instalação de implante osteointegrado com propósito de ancoragem ortodôntica, por acreditarem que esta área pode ser caracterizada por relativamente pouco suporte ósseo vertical e limitar a instalação em pacientes sem crescimento, devido a possíveis distúrbios de desenvolvimento da sutura palatina. Utilizaram tomografias computadorizadas para medir a espessura palatina vertical em 22 pacientes e, apesar da grande variação entre as medidas obtidas e do decréscimo de espessura no sentido posterior, encontraram um local adequado para instalação de implantes, identificado entre 6 e $9 \mathrm{~mm}$ posterior ao forame incisivo (região próxima aos primeiros pré-molares) e 3 a $6 \mathrm{~mm}$ paramediano. Recomendaram avaliação pré-operatória para evitar perfurações do ducto nasal inferior, quando for necessária a instalação de implantes ortodônticos.

Dobranszki et al. (10) analisaram a distribuição de tensões ao longo dos filetes de rosca de mini-implantes cilíndricos e cônicos, quando submetidos a carga lateral e de torção de inserção, por meio de análise fotoelástica. Justificaram o estudo da morfologia dos mini-implantes para tentar identificar causas de insucesso, maior nos mini-implantes do que com implantes e miniplacas. A aplicação de cargas laterais provocou momentos fletores nos mini-implantes, aparecimento de franjas isocromáticas ao longo dos filetes do corpo dos mini-implantes e no ápice. Quando foi aplicado o torque de inserção, verificou-se a concentração de tensões próxima ao ápice. Concluiu-se que: (1) o mini-implante cilíndrico apresentou maior concentração de tensões no ápice, e (2) o mini-implante cônico apresentou maior concentração de tensões nos filetes de rosca apicais.

Fudalej e Antoszewska (5) publicaram uma revisão sistemática com metaanálise sobre dispositivos distalizadores com ancoragem esquelética que teve como objetivos comparar a efetividade de distalizadores de molares com ancoragem esquelética com a de distalizadores com ancoragem dentoesquelética. A duração dos tratamentos foi entre 4,6 e 28,9 meses, quantidade de distalização de 3,5 a 6,4 $\mathrm{mm}$, angulação distal de $0,8^{\circ}$ a $12,2^{\circ}$ e média mensal de distalização de $0,7 \mathrm{~mm} / \mathrm{mês}$ ( \pm 0,3 mm). Os sistemas com miniplacas apresentaram as menores taxas de distalização, possivelmente pela força ser aplicada simultaneamente em todos os dentes maxilares, enquanto que o sistema com a distalização mais rápida foi aplicado somente nos molares, pela vestibular e palatina simultaneamente. A diferença na velocidade de distalização não foi significante entre pacientes com segundos molares erupcionados ou não. 
Karagkiolidou et al. (13) estudaram os índices de sucesso de 384 miniparafusos instalados na região paramediana do palato de 196 pacientes, que receberam um ou dois miniparafusos de 1,6x8 mm, de 3 a $6 \mathrm{~mm}$ de distância da sutura palatina mediana e 6 a $9 \mathrm{~mm}$ distal ao forame incisivo. Os miniparafusos utilizados para diversos aparelhos e diferentes mecânicas alcançaram um índice de sucesso de 97,9\%, com 8 perdas, sendo 7 do lado esquerdo 2 no mesmo paciente, sem distinção de sexo.

Dobranszki et al. (50) estudaram se fatores como local de inserção, padrão facial do paciente, comprimento e calibre do MPO, tipo de movimento desejado e experiência do operador, estavam associados a insucesso do MPO. Foram instalados 293 MPOs em 166 pacientes, distribuídos aleatoriamente entre 3 operadores com diferentes níveis de experiência com MPOs. Os MPOs foram observados por 365 dias ou pelo tempo necessário até sua remoção programada ou perda, com índice de sucesso de 87,37\%. Após análises estatísticas, concluíram que o procedimento de instalação de MPOs envolve uma rápida curva de aprendizado para um operador inexperiente, o que justifica sua instalação por ortodontistas e que a única variável associada à perda foi o lado de inserção ( $p=-$ .0022), com 3,088 mais chance de insucesso do lado esquerdo do que do lado direito, talvez pela postura desenvolvida com a experiência clínica, que pode ter impacto negativo nos índices de sucesso.

\subsubsection{Aplicações para movimentos A-P e verticais na maxila}

Kanomi (12) descreveu o tratamento de um paciente de 44 anos, com sobremordida acentuada e ausências posteriores. Com propósito de intrusão, foram instalados três parafusos acima da região alveolar dos incisivos superiores, um parafuso no osso alveolar entre os ápices radiculares dos incisivos centrais inferiores e em ambos os lados dos segundos pré-molares perdidos. Após 4 meses de tratamento, os incisivos inferiores foram intruídos $6 \mathrm{~mm}$, sem intercorrências. Comparou os implantes convencionais, com diâmetro de 3,5 a 5,5 mm e comprimento de 11 a $21 \mathrm{~mm}$ com o pequeno parafuso, com apenas 1,2 $\mathrm{mm}$ de diâmetro e $6 \mathrm{~mm}$ de comprimento, afirmando que o parafuso é pequeno o bastante para ser instalado entre as raízes mesial e distal de um molar para intrusão ou, se colocado no palato, pode promover ancoragem para distalização do mesmo. Declarou que implantes convencionais têm aplicação limitada porque podem apenas 
ser colocados em regiões retromolares ou em áreas desdentadas, com direção de aplicação de força predominantemente horizontal, além do incômodo da severidade da cirurgia, do pós-operatório e da dificuldade de higienização. Previu que o parafuso de ancoragem ortodôntica deveria ser pequeno o bastante para ser colocado em qualquer área do osso alveolar ao nível do osso apical. O processo cirúrgico deveria ser fácil o bastante para um ortodontista ou um clínico geral fazer e o mínimo de tempo para a cicatrização.

Sherwood et al. (17) conseguiram intruir molares superiores em média $2 \mathrm{~mm}$ em 5,5 meses, em quatro pacientes adultos com mordida aberta anterior, com miniplacas instaladas na maxila e mecânica do arco segmentado. A intrusão obtida foi considerada verdadeira, diferente da intrusão relativa, obtida com aparelhos extrabucais de puxada alta, durante a dentadura mista, na qual há retardo do desenvolvimento vertical dentoalveolar posterior. Além da intrusão foram observados diminuição no ângulo do plano oclusal, do plano mandibular, da altura facial ânteroinferior e da sobremordida.

Park et al. (16) quantificaram o movimento A-P dos dentes de 13 pacientes, com mecânica utilizando 30 microparafusos ortodônticos. A força foi aplicada com molas fechadas de NiTi na arcada superior e cadeias elásticas na arcada inferior, ambas com vetor distal e de intrusão. Observaram distalização significante de prémolares e molares, tanto na arcada superior quanto na inferior, mas sem movimento significativo nos incisivos. Obtiveram índice de sucesso de 90\% (27 microparafusos) por um período médio de aplicação de 12,3 \pm 5,7 meses.

Sugawara et al. (4) investigaram a eficiência da ancoragem com miniplacas na distalização e intrusão dos primeiros molares superiores de 25 pacientes adultos. Miniplacas de titânio puro foram fixadas no arco infrazigomático por miniparafusos monocorticais autoperfurantes com $2 \mathrm{~mm}$ de diâmetro e $5 \mathrm{~mm}$ de comprimento, também de titânio puro. Em alguns pacientes foram extraídos os terceiros molares, em outros, os segundos molares. Foi aplicada força de 200 gf para distalizar os molares e 500 gf para retração em massa, com molas abertas ou cadeias elásticas. Telerradiografias com os pacientes de boca aberta foram feitas antes do tratamento e após a remoção e as medidas cefalométricas foram obtidas por um único operador. A média de distalização das coroas foi de 3,78 mm e das raízes de 3,20 $\mathrm{mm}$, sem extrusão e sem efeito colateral de protração dos dentes anteriores. Os autores concluíram que o uso de miniplacas é viável para distalização individual ou 
em massa de molares, apenas com um procedimento cirúrgico pequeno, o que as torna especialmente úteis em tratamentos de más oclusões de Classe II, descompensação para pacientes Classe III cirúrgicos e más oclusões caracterizadas por apinhamento maxilar anterior.

Yamada et al. (6) quantificaram a movimentação de 24 primeiros molares superiores de 12 pacientes, divididos em Classe II (5), I com biprotrusão (4) e III em fase pré-cirúrgica, após ativação com microparafuso interradicular. Nestes casos sem extração os microparafusos foram instalados pela vestibular, na região interradicular entre primeiro molar superior e o segundo pré-molar, após a fase de alinhamento e nivelamento e foram ativados 4 semanas após a instalação, com força aproximada de 200 gf ( $2 \mathrm{~N}$ ) com cadeias elásticas ou com molas fechadas de NiTi. A força foi aplicada o mais paralelo ao plano oclusal possível, em um braço de extensão preso ao fio retangular distal aos caninos, que resultou em distalização sem expansão lateral e com pouca intrusão do molar. Encontraram que as distalizações duraram, em média, 8,4 meses $( \pm 4,2)$, com distalização média das coroas de 2,8 mm $( \pm 1,6)$ e das raízes de 1,2 $\mathrm{mm}( \pm 0,7)$, com angulação distal média de $4,8^{\circ}( \pm 4,5)$ e intrusão média de $0,6 \mathrm{~mm}( \pm 1)$. As coroas dos incisivos distalizaram 2,7 mm $( \pm 2,1)$ e as raízes $1,1 \mathrm{~mm}( \pm 1,7)$, apresentando um pouco de reabsorção radicular $(0,2 \mathrm{~mm} \pm 0,3)$, com inclinação da coroa para lingual de $4,3^{\circ}( \pm$ $7,7)$ e extrusão de $0,2 \mathrm{~mm}( \pm 1,4)$. Não houve alteração no ângulo do plano mandibular

Chung et al. (7) descreveram, por meio de um caso clínico, um conceito de relocar mini-implantes ortodônticos com propósito de distalizar irrestritamente todos os dentes maxilares. Em uma paciente de 18 anos, portadora de apinhamento, biprotrusão dentoalveolar, ANB de $5^{\circ}$ e má oclusão de Classe II, 1 com deficiência mandibular, instalaram mini-implantes com superfície tratada entre os primeiros molares e os segundos pré-molares superiores. Após a remoção dos terceiros molares, executaram um tratamento dividido em 4 fases, (1) iniciaram a retração dos segundos molares inferiores com elásticos em Classe III ancorados nos miniimplantes superiores, (2) usaram sliding jigs para distalizar os primeiros e segundos molares superiores ancorados nos mini-implantes, (3) depois que estes dentes atingiram a relação de Classe I, os mini-implantes foram removidos e instalados entre os primeiros e segundos molares superiores, para retração dos dentes anteriores, com elásticos de Classe I e 150 gf (1,5 N), e (4) coordenação dos arcos e 
finalização. Os autores também reportaram tempo total de tratamento de 30 meses, para o qual foi imprescindível a excelente cooperação da paciente com o uso de elásticos intermaxilares e que o sítio do mini-implante teve cicatrização gengival entre 2 e 3 dias após sua remoção.

Dobranszki (21) apresentou uma forma de distalizar os molares com miniimplantes palatinos associados à barra transpalatina (BTP) e comparou com o AEB e o pêndulo de Hilgers, em trabalhos da literatura. Citou como principais vantagens da técnica a simplicidade do método, a possibilidade de efetuar a distalização simultaneamente com o alinhamento e nivelamento, ser razoavelmente rápida, com um aparelho relativamente pequeno, discreto, fácil de higienizar, não precisa de cooperação do paciente e apresenta vantagens em relação ao AEB e ao pêndulo de Hilgers. As vantagens incluem melhor controle vertical (AEB), não produzir efeitos colaterais na unidade de ancoragem (Hilgers) e distalizar, por efeito das fibras transeptais, todos os dentes da arcada superior (AEB e Hilgers). A técnica apresentou velocidade de distalização um pouco maior que o AEB e com quase a mesma angulação da coroa apresentada como Hilgers. O autor também descreve cuidados que devem ser tomados com esta técnica, como o de calcular a quantidade de distalização necessária para o planejamento do posicionamento do mini-implante, de não deixar a BTP muito próxima ao palato, com risco de pressionar a mucosa palatina, de evitar regiões muito posteriores (qualidade baixa do osso) ou próximas ao forame palatino maior e de aplicar força de forma imediata ou precoce de $50 \mathrm{cN}$.

Choi et al. (8) apresentaram o caso clínico de um paciente com Classe II esquelética, perfil hipodivergente, sobremordida e sobressaliência normais e apinhamento anterior moderado. O desejo do paciente era de resolver 0 apinhamento sem fazer qualquer cirurgia, exceto a remoção dos terceiros molares superiores, que foi feita antes da instalação de um microparafuso na sutura palatina mediana, na altura da mesial dos primeiros molares, que serviu de ancoragem para a distalização inicial dos segundos molares com um pêndulo modificado. Depois de 5 meses, o pêndulo foi removido, foram instalados aparelhos fixos em ambas as arcadas e 2 microparafusos de cada lado, pela vestibular, mesiais aos segundos pré-molares e aos primeiros molares, para retrair os anteriores com elásticos em cadeia até a relação de Classe I molar e canina. Para prevenir a interferência dos microparafusos com a distalização, seu posicionamento foi feito com acentuada 
angulação superior, para que suas extremidades ficassem acima do ápice radicular. Para cancelar o componente expansivo da força, foi instalada uma BTP e o componente intrusivo foi anulado pelos elásticos intermaxilares.

Nur et al. (15) avaliaram os efeitos de uma miniplaca denominada ZygomaGear Appliance (ZGA) nas estruturas dentoalveolares, esqueléticas e nos tecidos moles, após distalização bilateral de molares em 17 pacientes entre 14 e 18 anos. As miniplacas de três furos foram instaladas na borda inferior do arco zigomático e fixadas com 3 parafusos $5 \times 2 \mathrm{~mm}$. Um arco semelhante ao arco interno do aparelho extrabucal foi instalado na arcada superior dos pacientes e ativado 3 meses após a cirurgia, com molas fechadas e força aproximada de $300 \mathrm{gf}(3 \mathrm{~N})$ por lado. O ponto de ancoragem foi a extensão da miniplaca em forma de barra vertical, dobrada para distal em forma de gancho, confeccionado na altura da trifurcação do primeiro molar. Comparações entre traçados cefalométricos iniciais e finais mostraram distalização média de 0,84 mm/mês, com angulação distal média de coroa de $3,30^{\circ} \pm 2,31^{\circ} \mathrm{e}$ intrusão média de $0,50 \mathrm{~mm} \pm 0,46 \mathrm{~mm}$. Semelhante à outros métodos de distalização individual de molares, ocorreu distalização dos pré-molares e retroinclinação dos incisivos.

Bechtold et al. (2) desenharam um estudo com o objetivo de esclarecer o efeito clínico da colocação de múltiplos microparafusos, pela vestibular dos dentes maxilares, sobre a direção e magnitude de força dos vetores da distalização em pacientes adultos portadores de má oclusão de Classe II leve a moderada. Relatam que a força constante contribui para a previsibilidade dos resultados, diferente dos aparelhos extraorais convencionais, com uso colaboração particularmente desfavorável em adultos, e elásticos, dependentes da colaboração do paciente. Mostraram que ao usar dois microparafusos, a magnitude da distalização do molar foi maior do que somente com um, assim como a intrusão e retração dos incisivos, com menor inclinação dos molares. Recomendaram esta técnica para tratamentos até meia Classe II.

Kaya et al. (14) estudaram os efeitos do pêndulo implantossuportado (ISP) e da miniplaca denominada Zygoma Anchorage System (ZAS) nas estruturas dentoalveolares, esqueléticas e nos tecidos moles, após distalização bilateral de molares em 30 pacientes com idade média de 14,5 anos. O pêndulo foi ancorado em dois parafusos palatinos paramedianos e foi aplicada força de 230 gf (2,3 N) por molas de TMA com pré-ativação de verticalização. No sistema ZAS, foram colados 
braquetes nos molares e pré-molares superiores, instalada uma miniplaca na crista inferior do osso zigomático-maxilar e, uma semana após sua instalação, foi aplicada força de 450 gf $(4,5 \mathrm{~N})$ com molas fechadas de NiTi. Comparações entre traçados cefalométricos iniciais e finais mostraram retrusão significante no ponto $A$ no grupo ZAS, enquanto que não houve diferença significante no grupo ISP. O ângulo ANB aumentou no grupo ISP e diminuiu no grupo ZAS, assim como a protrusão dos incisivos superiores. Os incisivos superiores retroinclinaram e extruíram no grupo ZAS, o que não ocorreu no grupo ISP. No sentido vertical, ocorreu intrusão média de $1,4 \mathrm{~mm}( \pm 1,24 \mathrm{~mm})$ no grupo ZAS, enquanto foi insignificante no grupo ISP. Em ambos os grupos ocorreu angulação do primeiro molar para distal, sendo menor no grupo ZAS $\left(5,77^{\circ} \pm 4,99^{\circ}\right.$ versus $\left.8,80^{\circ} \pm 6,54^{\circ}\right)$ pequena rotação posterior mandibular, sem diferença entre os grupos, provavelmente a causa da retração do ponto $B$ e aumento vertical do terço inferior da face. A distalização foi maior no grupo ZAS, com média de 0,5-0,6 mm/mês, enquanto que no grupo ISP a média foi de 0,1-0,37 $\mathrm{mm} / \mathrm{mês}$.

\subsection{ANÁLISE DE ELEMENTOS FINITOS}

\subsubsection{Entendimento da elaboração do modelo de Elementos Finitos}

Embora o termo "Finite Element Method" (Análise de Elementos Finitos - AEF ou Método de Elementos Finitos - MEF) tenha aparecido em 1960 para análise de tensões em aviões (51), a idéia é de 1943, quando Courant (52) utilizou vários elementos triangulares para estudar um problema de torção, baseado em trabalhos de Gauss do século XVIII, que propôs a funções de aproximação para solução de problemas matemáticos (22). Em 1959, Greenstadt (53) sugeriu separar o domínio da solução em células, cada uma com sua função matemática independente. Atribuindo funções de aproximação e avaliando o princípio de variação de cada célula, ele utilizou fórmulas de continuidade para amarrar as equações de todas as células. Com isso ele reduziu um problema contínuo a um problema discreto, base matemática do que é a AEF de hoje. A discretização reduz um problema complexo a vários problemas mais simples, ou seja, a região a ser estudada é dividida em um número finito de elementos, unidos por funções de aproximação (funções de interpolação) em alguns pontos específicos (nós ou pontos nodais) nas fronteiras onde os elementos se conectam. O comportamento destes pontos é expresso por 
matrizes que contém as características dos elementos estudados $(22,54)$.

O primeiro programa desenvolvido para este fim foi o NASTRAN (Nasa Structural Analysis), em 1968. Na área odontológica, o método foi empregado pela primeira vez por Huang e Ledley (55) que elaboraram um modelo linear de um dente, avaliaram seu deslocamento de acordo com a magnitude e direção de uma força aplicada na coroa e também discutiram os erros e limitações do método.

Ribeiro (56) analisou a distribuição de tensões em um modelo de um incisivo central inferior com cinco sistemas de pinos intra-radiculares por meio de Análise de Elementos Finitos utilizando o programa ANSYS ${ }^{\circledR}$. O autor descreve o método de elementos finitos em três etapas: (1) Pré-processamento: construção do modelo geométrico e inserção das propriedades dos materiais no programa de análise, que divide a estrutura do modelo em um número finito de elementos (discretização) que são interconectados por pontos nodais dentro das coordenadas $X, Y$ e $Z$, resultando em uma rede de elementos geométricos denominada "malha". Também são aplicadas as restrições do modelo físico, denominadas condições de contorno, que são os pontos de fixação do modelo (engastamento) e de aplicação do carregamento (pontos de aplicação de força). (2) Processamento: Após a criação do modelo e da inserção das variáveis, o operador dispara a solução computacional para obter os resultados dos campos de tensões e deformações. A velocidade da resposta dependerá da complexidade do modelo e do poder de processamento computacional. (3) Pós-processamento: Análise dos resultados obtidos, que pode ser feita pela comparação dos componentes de tensões normais, tensões principais, tensão equivalente de Von Mises, deslocamento e deformação.

Clement et al. (57) geraram um modelo tridimensional de um dente unirradicular humano utilizando um fluxo de trabalho automático que pode ser implementado na simulação de movimento dental com elementos finitos. Os dados de uma tomografia computadorizada foram usados para obtenção de coordenadas globais da superfície dental e para manter a geometria do dente real, considerando somente a dentina, o ligamento periodontal e o osso alveolar circundante. Foram utilizados os softwares Rhinoceros ${ }^{\circledR}$ e Surfacer ${ }^{\circledR}$ para gerar a geometria, que foi exportada para o software Ansys ${ }^{\circledR}$ para análise. Os autores concluíram que 0 sistema de modelagem apresenta uma alternativa viável para a geração de modelos para análise por meio do método dos elementos finitos. 
Lotti et al. (22) explicaram que os modelos matemáticos criados na análise de elementos finitos podem representar situações in vivo, de forma simplificada e com algumas limitações, pela dificuldade em se simular um ligamento periodontal e principalmente pela grande variabilidade entre indivíduos. Descreveram detalhadamente a aplicação da análise de elementos finitos em odontologia, afirmando que quanto maior o número de elementos, mais preciso será o modelo. O pesquisador determina a direção e o sentido da coordenadas, assim como a liberdade que os pontos terão para se deslocar nas três dimensões espaciais ( $\mathrm{X}, \mathrm{Y}$ e $Z$ ). Os programas exibem os resultados atribuindo tons a regiões do modelo que correspondem a uma quantidade de deslocamento ou tensão, de acordo com uma escala de cores. Enfatizam a importância do ortodontista e do clínico geral de conhecerem o método de elementos finitos, para que os resultados das crescentes pesquisas possam ser mais bem entendidos, interpretados e empregados no diagnóstico, planejamento e tratamento das más oclusões.

Ichim et al. (58) investigaram a influência da forma e profundidade de lesões cervicais bem como a direção das forças oclusais nas respostas mecânicas das restaurações cervicais em ionômero de vidro. Utilizaram um Microtomógrafo para escanear um primeiro pré-molar inferior, criaram um modelo tridimensional no programa Rhinoceros e exportaram o arquivo para o software de elementos finitos Cosmos Design Star. Modelaram lesões cervicais anguladas e arredondadas com diferentes profundidades e aplicaram carregamentos verticais e oblíquos. Os resultados mostraram que nos dentes que recebem forças oblíquas, a tensão na região da cervical das restaurações foi significantemente maior, por outro lado, a forma e a profundidade das lesões tiveram pequena influência no desenvolvimento das tensões na interface das restaurações. Concluíram que o diagnóstico oclusal e subsequente ajuste dos contatos são uma parte crítica do tratamento de lesões cervicais não cariosas.

\subsubsection{Limitações do estudo da mecânica ortodôntica in vivo e a evolução da tecnologia, geração e trabalho das imagens in silico}

Reimann et al. (59) introduziram um interessante exemplo do uso de modelos biomecânicos teóricos com implicações e relevância clínica diretas. Utilizaram um programa de elementos finitos para determinar numericamente o Cres (centro de resistência) dos 4 incisivos superiores combinados, em um modelo de maxila com 16 
dentes disponível comercialmente. Após aplicação de carga de $10 \mathrm{~N}$ nos incisivos laterais superiores, o modelo com 150.000 elementos indicou que os 4 incisivos não se comportam como um bloco único, pela diferença na morfologia radicular. Observaram que a tensão no ligamento periodontal dos incisivos laterais foi significantemente maior que nos incisivos centrais e que o Cres dos 4 incisivos não coincide com o reportado na literatura, por isso a divergência entre as conclusões teóricas e os resultados clínicos. Concluíram que, embora os modelos numéricos teóricos tenham restrições em relação à representação de estruturas biológicas vivas, parece que a grande quantidade de tempo e poder de processamento necessários para a análise de elementos finitos justifica o resultado. Como consequência direta das simulações, recomenda que o clínico aplique os conhecimentos obtidos com FEM.

Motoyoshi et al. (60) usaram tomografias computadorizadas para avaliar a espessura da cortical óssea próxima a 209 microparafusos ortodônticos instalados em 65 pacientes ortodônticos e sua associação com o índice de sucesso. Não encontraram diferença significante nos índices de sucesso da maxila e mandíbula ( $p$ $=0,549)$, lado direito ou esquerdo $(p=0,250)$ ou sexo feminino ou masculino $(p=$ 0,192), mas ao comparar o índice de sucesso em locais com osso cortical de espessura $\geq 1 \mathrm{~mm}(91,5 \%)$ e menor que $1 \mathrm{~mm}(80,4 \%)$, a diferença foi estatisticamente significante $(p=0,027)$. Para examinar os efeitos biomecânicos, elaboraram modelos com elementos finitos de um microparafuso ortodôntico de 1,6 $\mathrm{mm}$ de diâmetro e $8 \mathrm{~mm}$ de comprimento instalado em cubos de osso com corticais variando de $0,5 \mathrm{~mm}$ a $1,5 \mathrm{~mm}$ com e sem osso medular. As paredes laterais e inferior dos cubos foram engastadas e foi aplicada carga de $2 \mathrm{~N}$ na cabeça do parafuso. A tensão máxima von Mises no osso medular diminuiu linearmente com o aumento da espessura do osso cortical, mas no osso cortical permaneceu constante e abaixo do limite para reabsorção óssea. Nos modelos com osso cortical < $1 \mathrm{~mm}$, a presença do osso medular diminuiu a tensão von Mises no osso medular de $28 \mathrm{MPa}$ para $6 \mathrm{MPa}$.

Sung et al. (61) afirmaram que fatores importantes podem afetar a acurácia de uma análise de elementos finitos, como a precisão anatômica do modelo e incertezas sobre as propriedades dos materiais e condições de contorno. Modelos analisados em trabalhos anteriores ao dele, foram obtidos de geometrias modeladas manualmente, o que deu lugar aos modelos produzidos a partir de digitalizações 3-D 
a laser. A precisão dos modelos também melhorou com o aumento da velocidade dos processadores, que permitiu modelamento mais rápido e preciso com elementos tetraédricos do que com as malhas mapeadas. A precisão dos modelos aumentou ainda mais com a descoberta e divulgação das propriedades do ligamento periodontal, obtidas em estudos em animais e em cadáveres.

Jasmine et al. (62) afirmam que é virtualmente impossível a medição precisa da tensão próxima aos microimplantes in vivo, além de ser difícil se obter uma solução analítica para problemas envolvendo geometrias complexas, como a maxila ou a mandíbula, que são expostas a vários tipos de carregamentos. Por este motivo, estudaram a influência do ângulo de inserção $\left(30^{\circ}, 45^{\circ}, 60^{\circ}\right.$ e $\left.90^{\circ}\right)$ dos microimplantes na distribuição de tensões em um modelo virtual do osso alveolar maxilar e mandibular, ao simular uma retração em massa e analisar pelo método de elementos finitos. Os resultados mostraram que a tensão diminui no microimplante e no osso cortical com o aumento da angulação. Encontraram a maior concentração de tensões no pescoço do microparafuso, mas também grandes concentrações de tensões na cabeça do microimplante, no ponto de contato entre o microimplante e o osso cortical e no osso cortical ao redor do microimplante. Sugerem que, mesmo com menor área de contato entre a interface microimplante/osso cortical, o microimplante seja inserido o mais perpendicular possível.

Duaibis et al. (63) utilizaram um programa de análise de elementos finitos para (a) avaliar os efeitos do desenho (forma) dos microparafusos e de diferentes fatores relacionados ao osso de suporte nos picos de tensões na superfície do osso cortical e (b) determinar o risco de falha mecânica (fratura) do osso cortical periimplantar. Para isto eles elaboraram blocos de osso nos quais foram inseridos os microparafusos. Os blocos foram seccionados em 2 camadas de osso, o cortical (1 $\mathrm{mm}$ ) e o medular, a malha foi criada com elementos tetraédricos e a interface de contato entre o microparafuso e osso foi refinada. Condições de contorno foram aplicadas para imobilizar as superfícies laterais e inferior do bloco de osso antes da aplicação de carga de $2 \mathrm{~N}$ na cabeça do microparafuso. Considerou-se 170-190 MPa o limite máximo de tensão de compressão, quando ocorreria falha mecânica do osso cortical. Os resultados mostraram que os picos de tensões foram localizadas na borda do osso cortical próxima ao pescoço do microparafuso, do lado de compressão. O comprimento intraósseo do microparafuso, a forma da rosca e o passo da rosca não apresentaram efeitos significativos no osso cortical, assim como 
não houve diferença significativa na tensão máxima provocada pela variação na espessura da cortical $(0,5 \mathrm{~mm}=10,53 \mathrm{MPa}$ e $2 \mathrm{~mm}=9,94 \mathrm{MPa})$ ou no aumento do módulo de elasticidade do osso medular, exceto em ossos com menos de $700 \mathrm{MPa}$ (pouco resistentes). Os diferentes formatos resultaram em diferenças mínimas, com pequena desvantagem para os cônicos em relação aos cilíndricos (11,7 MPa e 10,6 $\mathrm{MPa}$ ), mas a variação no diâmetro foi significativa e inversamente proporcional à tensão na superfície $(1,4 \mathrm{~mm}=10,6 \mathrm{MPa}$ e 2,0 mm = 3,7 MPa) e a cabeça mais alta produziu maior pico de tensão do que a mais baixa (6 mm = 18,9 MPa e $2 \mathrm{~mm}=7,9$ MPa). Recomenda, portanto, que os clínicos instalem microparafusos com o maior diâmetro e a menor cabeça possíveis.

Dobranszki et al. (64) ressaltaram que a evolução da Ciência da Computação e sua interação com as Ciências da Saúde, permitiram que situações clínicas pudessem ser simuladas em modelos computacionais, com elevada precisão, o que vem a eliminar grande parte das desvantagens de experimentos envolvendo seres vivos. Programas podem ser alimentados com os dados dos elementos estruturais necessários para simulação virtual da movimentação ortodôntica e oferecem respostas com acurácia proporcional à do modelo. Neste estudo, obtiveram medidas das tomografias volumétricas de pacientes com características esqueléticas de um paciente Classe II, com ANB entre 4 e 6 graus, para criar uma maxila hipotética com valores médios das mensurações feitas nas tomografias. Este modelo poderia ser utilizado em situações onde se deseja simular resposta à força ortodôntica em um indivíduo portador de relação maxilomandibular de Classe II esquelética típico.

\subsubsection{Elementos Finitos em Ortodontia}

De acordo com Lotti et al. (22), há grande interesse científico no estudo do efeito das cargas (forças) aplicadas aos dentes. Vários métodos podem ser usados para análise de tensões, como análise fotoelástica, laser holográfico, modelos matemáticos analíticos análises experimentais em humanos e/ou animais e a análise com elementos finitos. Depois do primeiro estudo com elementos finitos no Brasil, realizado por Correa e Matson (1977), vários autores contribuíram para elucidar como as tensões são distribuídas em dentes, estruturas de suporte, implantes, elementos protéticos e em simulações de situações ortodônticas.

Kojima e Fukui (23) analisaram, por meio de elementos finitos, a mecânica de deslizamento em massa a longo prazo em um caso típico de fechamento de espaço 
com retração anterior ancorada nos segundos molares superiores. Observaram que com o sistema inicial de forças, ocorreu inclinação dos dentes anteriores, movimento que após algum tempo deu lugar ao movimento de corpo e ocorreu atrito na interface braquete-fio. A quantidade total de força transferida aos dentes anteriores foi igual à transferida aos dentes posteriores, um quarto do valor total da força aplicada. A outra metade foi dissipada no atrito, que diminui a velocidade do movimento dentário. O aumento da intensidade de força ou diminuição do atrito provocaram maior inclinação dos anteriores devido à deflexão elástica do fio. Concluíram que não é possível prever movimento ortodôntico a longo prazo a partir do sistema inicial de forças.

Sung et al. (61) utilizaram a análise de elementos finitos para identificar qual a melhor combinação entre altura do mini-implante e gancho de retração, para o movimento de retração em massa. Para tanto, elaboraram um modelo virtual de uma maxila com incisivos inclinados para vestibular e lingual, com o Cres situado $9 \mathrm{~mm}$ acima e 13,5 mm atrás do ponto médio do arco vestibular. Os modelos foram criados a partir de uma combinação entre 3 variáveis, a posição do mini-implante, o calibre do arco vestibular e a altura do gancho. Os mini-implantes foram instalados nas posições de 10 e 12 mm de distância do arco vestibular, no sentido apical. Os elásticos foram ativados em ganchos instalados nos arcos vestibulares de aço de $0,019 " \times 0,025$ " ou $0,016 " x 0,022 "$, distais aos incisivos laterais superiores, nas alturas de $0,2,4$ e $8 \mathrm{~mm}$. Concluíram que a inclinação lingual da coroa dos incisivos diminuía na medida em que se aumentava a altura do gancho de retração anterior, que o controle de inclinação dos incisivos foi pior com o arco menos calibroso, que nenhuma das combinações promoveu movimento de translação do segmento anterior e que um mini-implante adicional instalado na linha média superior pode promover movimento intrusivo e leve inclinação vestibular de coroa dos dentes anteriores, simultâneo à retração.

Dobranszki (65) comparou a resposta mecânica dos microparafusos ortodônticos (1) cônico e cilíndrico de mesmo calibre e comprimento; e (2) cônicos de mesmo comprimento, com calibres de $1,4 \mathrm{~mm}$ e $1,8 \mathrm{~mm}$, sob carga lateral de $5 \mathrm{~N}$, por meio de análise de elementos finitos. Afirmam que a simulação computacional já é aceita na indústria mundial como substituta de vários ensaios mecânicos em elementos inanimados e com vantagens, por fornecer valores muito precisos nos resultados e por não ser necessário fabricar nem destruir o elemento de estudo. Nas 
ciências biológicas, ainda há um longo caminho a percorrer, pois existe uma grande variabilidade estrutural entre os indivíduos e suas respostas biológicas, pela falta de padronização entre os modelos estudados por parte dos pesquisadores e por uma temporária limitação computacional. A vantagem mais nítida do emprego do método é a grande aproximação dos resultados computacionais com os reais, o que torna cada vez menos necessário o comprometimento de grande número amostral de estruturas biológicas. Neste trabalho, foram gerados 4 modelos de microparafusos no programa COSMOSXpress ${ }^{\circledR}$ e foi aplicada carga de $5 \mathrm{~N}$ normal ao eixo axial na cabeça dos microparafusos. A AEF evidenciou maior concentração de tensão de tração na região do perfil transmucoso de ambos os tipos de microparafusos e, no cilíndrico de 1,4 mm de diâmetro, a tensão de tração foi quase duas vezes maior que no de 1,8 mm de diâmetro, quando submetidos à mesma carga.

Ueno et al. (19) estudaram o movimento distal de primeiros molares superiores em um sistema de forças utilizando uma BTP e mini-implantes, instalados na linha mediana palatina, por meio de análise de elementos finitos. Construíram oito modelos, incluindo osso maxilar, os primeiros molares, ligamento periodontal e uma BTP, utilizando o programa SOLIDWORKS, com aproximadamente 170.000 elementos tetraédricos cada. Nos três primeiros modelos, variaram o ponto de aplicação de força na BTP (Figura 4). Com o mini-implante instalado aproximadamente $5 \mathrm{~mm}$ distal à barra, no centro do palato, a ativação $A$ foi no centro da BTP, a ativação B foi na altura da crista alveolar e a ativação $C$ foi na altura do centro da coroa do molar. Descrevendo os 3 modelos seguintes, na ativação I o mini-implante foi instalado na linha média do palato, na ativação II foi instalado $2 \mathrm{~mm}$ à esquerda da linha média e na ativação III foi instalado $4 \mathrm{~mm}$ à esquerda da linha média. Os últimos dois modelos foram baseados no modelo $B$, variando a posição do molar esquerdo no sentido A-P, sendo o modelo B' construído com o molar esquerdo 2,5 mm mais mesial do que o esquerdo e o modelo B" construído como molar esquerdo $5 \mathrm{~mm}$ mais mesial do que o esquerdo. Como resultado, no modelo $A$ ocorreu movimento para distal da raiz e mesial da coroa, com grande rotação mesial de coroa e sem componente vertical. O modelo B apresentou os números mais próximos de um movimento de translação, ainda com maior movimento distal da coroa do que da raiz e considerável movimento intrusivo. No modelo C, ocorreu grande movimento distal da coroa, pouco movimento mesial da raiz e movimento intrusivo ainda maior do que no modelo $B$, com rotação distal 
da coroa. Ao se alterar a posição do mini-implante em relação à linha média, quanto mais distante para a esquerda, maior a força de distalização no molar esquerdo e menor no molar direito. Ocorreu deslocamento lateral dos molares proporcional à variação da posição de instalação dos mini-implantes e à posição mesial do molar, ou seja, quanto mais longe o mini-implante foi instalado do centro do palato e quanto mais mesial o molar foi posicionado, maior o deslocamento lateral dos molares (Figura 5). Em relação ao movimento vertical, quando o mini-implante foi instalado mais à esquerda da linha média, ocorreu aumento do movimento intrusivo no molar esquerdo e diminuição no molar direito, enquanto que quando o molar esquerdo foi posicionado mais mesialmente, ocorreu o inverso.
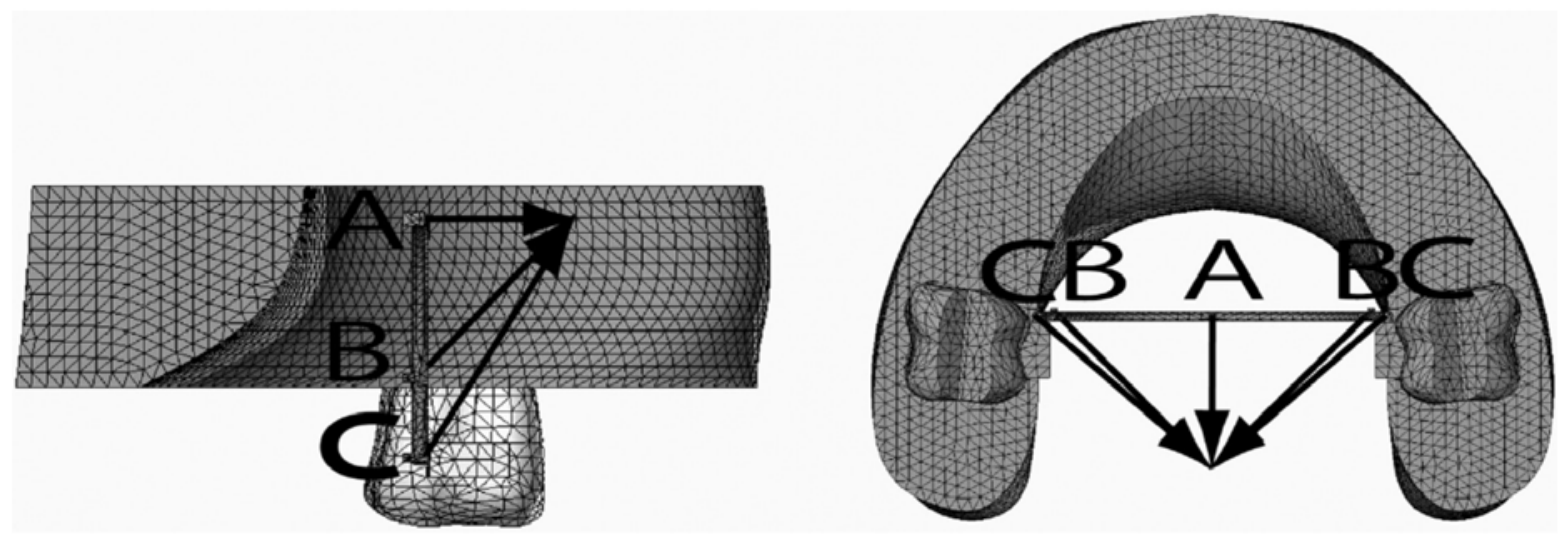

Figura 4 - No modelo A, o gancho foi fixado ao centro da BTP; no modelo B, os ganchos foram fixados na altura da crista alveolar; e no modelo $\mathrm{C}$, os ganchos foram fixados na altura do centro da coroa do primeiro molar (19).

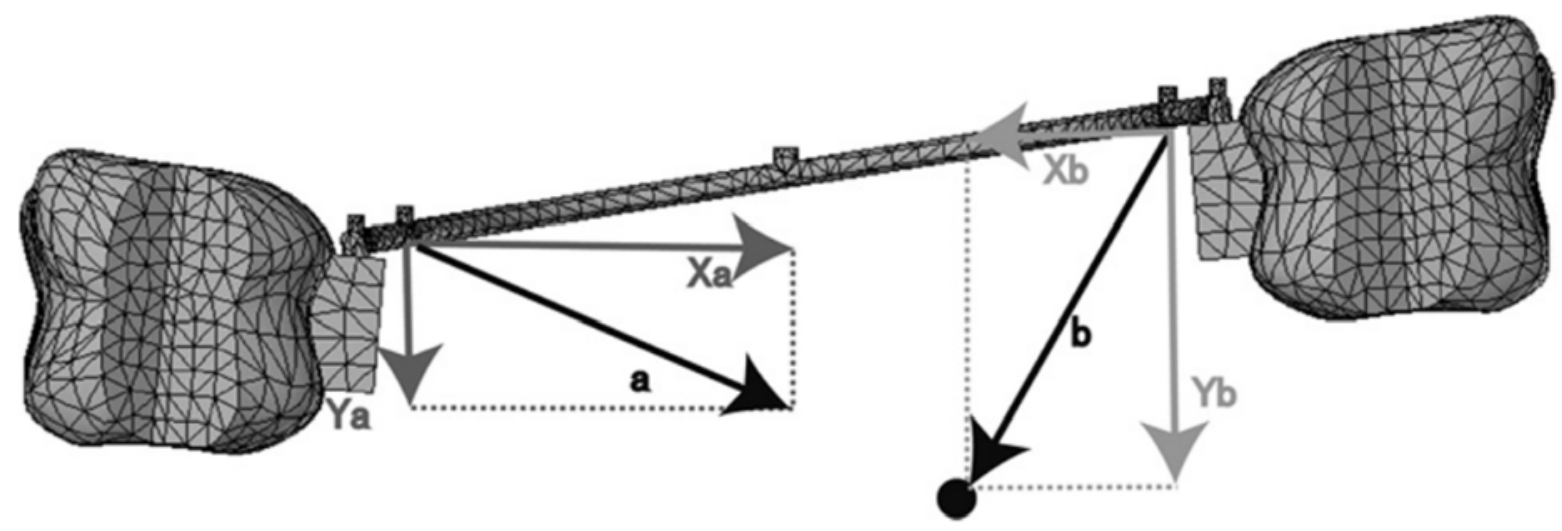

Figura 5 - (a) Força de tração aplicada ao molar direito. (b) força de tração aplicada ao molar esquerdo. Ya, Yb: elementos $Y$ (direção distal) dos molares direito e esquerdo. Xa, Xb: elementos X (direção lateral) dos molares direito e esquerdo (19). 
Viecilli et al. (66) testaram a hipótese de que os centros de resistência dentários não existem no espaço como pontos tridimensionais, primariamente por causa da assimetria geométrica do ligamento periodontal e do dente, secundariamente pela dificuldade de sua determinação técnica, que é um problema diferente da sua determinação com propósito clínico. Os autores explicam que a determinação científica do centro de resistência é limitada ao deslocamento instantâneo do dente, antes do modelamento ósseo, enquanto que a aplicação clínica do conceito é o planejamento da movimentação a longo prazo. Em espécimes de autópsia, a maior fraqueza do método é que o medidor do deslocamento do dente já aplicaria carga no dente, causando erros de leitura. Esta dificuldade foi superada por ajustes matemáticos, com o uso de sensores de interferometria com laser holográfico e sensores magnéticos. Atualmente, o método mais comumente usado e confiável é o MEF, que pode atribuir o comportamento não-linear ao ligamento periodontal. Enfatizaram que trabalhos anteriores utilizavam desenhos de raízes simétricas a partir de revoluções de um parabolóide e calculavam o centróide, mas estas simplificações demasiadas comprometiam os resultados. As deformações no ligamento periodontal são os maiores determinantes no padrão do deslocamento dental e, se a anatomia radicular e o ligamento periodontal forem assimétricos, também será o padrão de deslocamento. Desta forma, os eixos de rotação gerados por momentos ortogonais em 3-D não interseccionarão em apenas um ponto de centro de resistência. Neste trabalho, os autores digitalizaram e reconstruíram o segmento maxilar do primeiro pré-molar ao segundo molar a partir da imagem tomográfica computadorizada de um crânio seco e usaram algoritmos para criar um ligamento periodontal assimétrico. O modelo foi importado pelo programa ANSYS ${ }^{\circledR}$ e neste foram aplicadas forças perpendiculares aos três planos cartesianos ( $x, y$ e $z$ ). Para determinar os eixos de rotação, quantificaram o menor deslocamento nos outros dois planos e a menor diferença de deslocamento entre o ápice radicular e a coroa, ou seja, o mais próximo da translação do dente. Após encontrarem os eixos de resistência, aplicaram forças nos dois centros de resistência hipotéticos para cada plano, totalizando 6 combinações. Concluíram que por causa da assimetria do dente e do ligamento periodontal, os eixos de resistência não coincidem, portanto o centro de resistência não pode ser definido como um ponto 3D, mas como uma área, que neste estudo foi pequena o suficiente para ser clinicamente insignificante no planejamento do movimento 
dentário. Para obter translação pura em uma direção (por exemplo, x), um ponto do centro de resistência projetado em 2D pode ser derivado de intersecções dos eixos de resistência de projeções ortogonais no plano determinado pelas outras duas direções perpendiculares (por exemplo, y e z), por isso as representações didáticas dos centros de resistência projetados em 2D devem ser construídos em um plano perpendicular ao vetor da força, como na Figura 6.

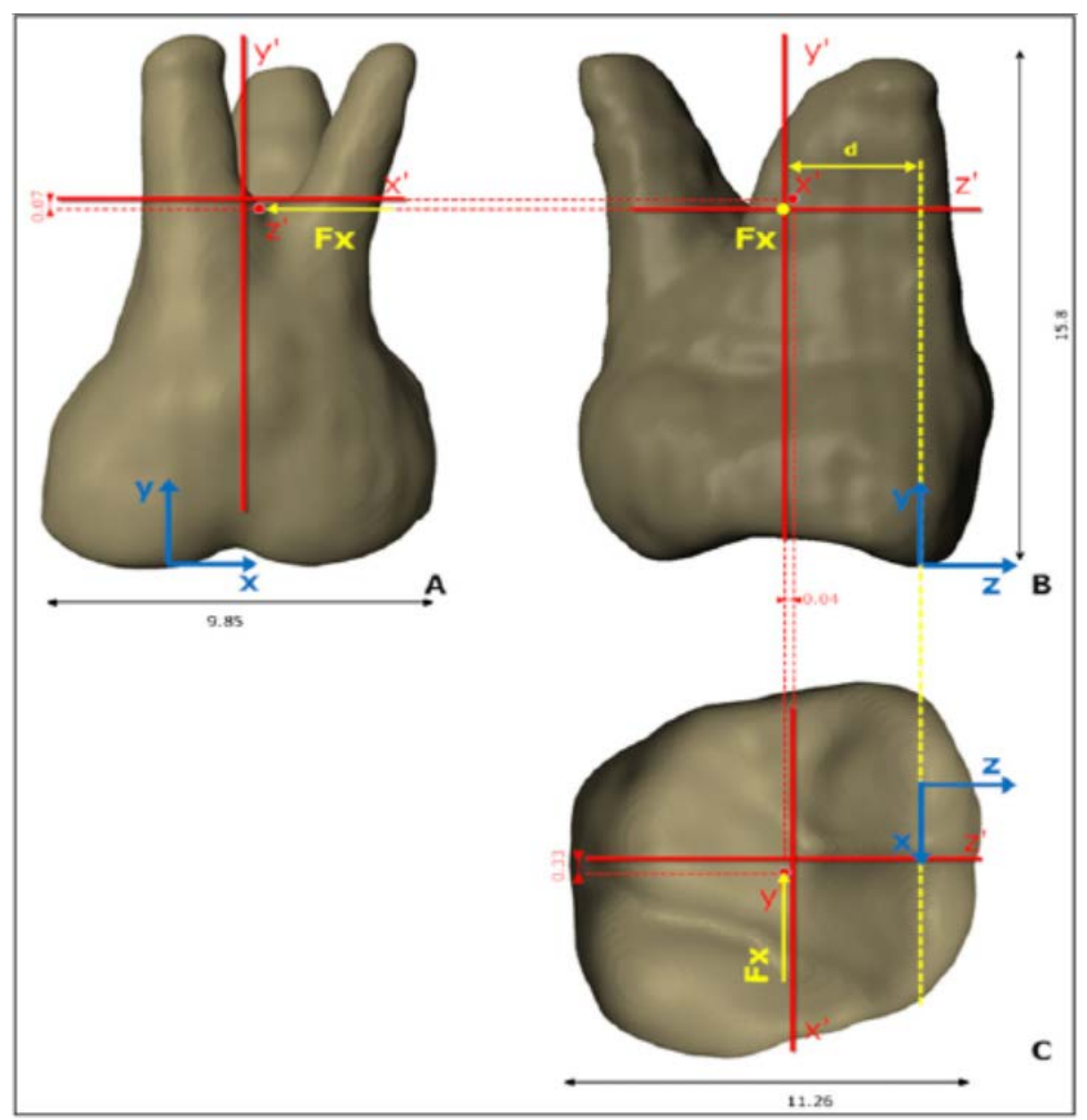

Figura 6 - Representação alternativa do ponto do centro de resistência projetado em 2D, compatível com a teoria dos eixos de resistência em 3D. Para translação no eixo $x$, a força pode ser aplicada no eixo de resistência $z^{\prime}$ em $A$, mas a coordenada em $z$ do vetor de força deve ser fornecido (B e C). A informação seria ausente se fosse usada somente a projeção em A (66).

Xue et al. (24) compararam diferentes métodos de redução de resistência óssea (corticotomias) para retração rápida do canino pela análise de elementos finitos, com o programa Ansys ${ }^{\circledR}$ 13.0. Simularam uma maxila com dentes, ligamento 
periodontal, osso alveolar e para retração, foi aplicada carga de 1,5 $\mathrm{N}$ no centro da coroa, sendo $0,75 \mathrm{~N}$ no centro da face vestibular e $0,75 \mathrm{~N}$ no centro da face palatina, no sentido distal. No molar, foi aplicada carga da mesma forma, no sentido mesial. O valor do deslocamento total foi usado para avaliar o deslocamento inicial do canino e do molar no início do carregamento da força. Encontraram o maior valor de deslocamento total na distal da coroa do canino, com diminuição gradativa até o ápice. A menor tensão equivalente (von Mises) e a menor tensão máxima de cisalhamento foi concentrada principalmente no lado distal da raiz do canino no modelo 2, o qual também apresentou maior deslocamento. Nos três modelos, a distribuição da tensão equivalente e a maior tensão máxima de cisalhamento, no ligamento periodontal, concentraram-se na borda distal do cervix do canino. Concluíram que a remoção do osso do caminho do canino resulta em intensidade menor de tensão, para o movimento do canino durante a retração e que a distração periodontal, assistida pelo enfraquecimento do osso interseptal, reduziria a resistência e efetivamente aumentaria a velocidade de retração do canino. 


\section{OBJETIVOS}

- Encontrar e descrever, por meio de mensurações tomográficas e análise estatística, medidas da maxila de um indivíduo médio dentro do universo dos pacientes com características de uma má oclusão de Classe II esquelética não cirúrgica.

- Criar um modelo virtual da maxila deste paciente, a partir das medidas obtidas.

- Avaliar neste modelo a distribuição de tensões, após aplicação de 9 carregamentos com diferentes vetores de força, nos primeiros molares superiores, nos elementos constituintes ortodônticos e nas estruturas biológicas adjacentes, nos três planos do espaço, pelo método de elementos finitos (MEF).

- Sugerir a indicação clínica para cada tipo de ativação. 


\section{MÉTODOS}

O projeto de pesquisa deste trabalho foi submetido ao Comitê de Ética em Pesquisa da Faculdade de Medicina da UnB (CEP-FM-UnB) sob o no. 099/2010 e foi aprovado no dia 30/03/2011. O Termo de Consentimento Livre e Esclarecido (TCLE) encontra-se no APÊNDICE A e a digitalização do Documento de Aprovação pelo Comitê de Ética em Pesquisa em Seres Humanos encontra-se no ANEXO A.

O Método de Elementos Finitos (MEF) é uma técnica que simula computacionalmente o comportamento de um sistema físico determinado. O programa de computador transforma este modelo virtual em equações matemáticas que, quando resolvidas, produzem o resultado da análise. Ribeiro (56) explica que o processo de simulação tem três etapas básicas: a construção do modelo, a solução do problema e a análise dos resultados. Estas três etapas comumente também são identificadas respectivamente como: pré-processamento, processamento e pósprocessamento. O pré-processamento consiste em modelagem da geometria, aplicação das condições de contorno (fixação do modelo, aplicação das cargas) e inserção das propriedades dos materiais empregados.

Para modelagem da geometria definitiva, os passos foram descritos abaixo detalhadamente como: 4.1 Cálculo amostral e critérios para inclusão das imagens tomográficas na amostra; 4.2 Mensurações nas tomografias; 4.3 Método estatístico para avaliação de erro de mensuração intra-operador; 4.4 Escolha da tomografia do indivíduo médio (64); 4.5 Tratamento da imagem tomográfica (segmentação da reconstrução tridimensional); 4.6 Adaptação e compatibilização das medidas; 4.7 Alimentação de dados dos elementos anatômicos e ortodônticos constituintes - teste preliminar; 4.8 Avaliação de parâmetros de comparação clínica com pilotos; e 4.9 Definição dos parâmetros primários de otimização (distalização bilateral simétrica).

\subsection{CRITÉRIOS PARA INCLUSÃO DAS IMAGENS TOMOGRÁFICAS NA AMOSTRA}

As imagens tomográficas foram obtidas a partir do banco de dados da Clínica Radiológica Fenelon Ltda., com anuência do Responsável Técnico, Dr. Maurício Barriviera, conforme descrito no projeto 099/2010 submetido ao CEP-FM. As 2225 tomografias foram avaliadas consecutivamente, iniciando no mês de outubro de 
2010 até o mês de janeiro de 2011 .

As tomografias foram obtidas a partir de uma unidade iCAT (Imaging Sciences International Inc., Hatfield, PA, USA) e processadas pelo software da iCAT em computador dedicado. A posição de aquisição foi sentada, com o queixo e cabeça estabilizados (34).

O primeiro critério de exclusão foi o tamanho da imagem adquirida, que deveria ter $14 \mathrm{~cm}$ de altura e $17 \mathrm{~cm}$ de profundidade, desta forma seria possível visualizar os pontos Násio, A e B, necessários para mensuração do ângulo ANB, e a dimensão total da maxila no sentido A-P. Todas as tomografias foram obtidas com tempo de $20 \mathrm{~s}$ com o protocolo da aquisição do tomógrafo iCAT: tamanho de voxel de 0,3 mm; escala de cinza: 14 bits; ponto focal $0.5 \mathrm{~mm}$; detector de imagem: painel plano de silicone amorfo; aquisição de imagem: rotação única 3601. As imagens foram geradas em formato XORAN e os arquivos de cada paciente foram salvos.

O segundo critério de exclusão foi a idade dos pacientes, que deveria ser entre 18 e 50 anos. O terceiro critério de exclusão foi a presença de todos os dentes superiores, independente da presença ou ausência dos terceiros molares. Com isso, a amostra inicial de 2225 tomografias foi reduzida a 54.

O quarto critério de exclusão foi o ângulo ANB entre 4 e 6 graus. De cada uma das 54 tomografias foi impresso um corte sagital passando pelo ponto N. Com um transferidor, um único operador mensurou manualmente o ângulo ANB e as tomografias com valores entre 4 e 6 graus foram selecionadas, reduzindo a amostra a 20 tomografias.

\subsection{MENSURAÇÕES NAS TOMOGRAFIAS}

As 20 tomografias selecionadas foram convertidas para o formato DICOM e importadas pelo software gratuito Invesalius 3.0, baixado pelo site (http://svn.softwarepublico.gov.br/trac/invesalius/wiki/InVesalius/pt/Download).

Dentro deste programa, a importação dos dados se deu pelo ícone "importar imagens médicas”. Após a importação, é necessária a seleção dos cortes (fatias), onde foi optado por "manter todas as fatias" e "OK". O programa gerou uma visualização multiplanar, que necessitou da correção do limiar threshold, para que houvesse a visibilização dos tecidos duros e moles, para tanto manteve-se o limiar mínimo em 226 e moveu-se o limiar máximo para o maior valor possível na escala. Para simples padronização, foi escolhida a cor "verde sólida", com matiz 80, sat 240 
e Lum120, Vermelho 0, Verde 255 e Azul 0, quando foi clicado no botão "Gerar superfície".

Dentro da janela "Fatia Axial", buscou-se a fatia que melhor evidenciasse a ponta das cúspides mésio-vestibulares dos primeiros molares superiores e as coroas dos incisivos centrais superiores. A ferramenta "medições" foi utilizada para mensurar duas distâncias: a primeira unindo os pontos dos vértices das cúspides mésio-vestibulares dos primeiros molares superiores permanentes (medida transversal) e a segunda unindo o ponto da linha média dentária e o centro da linha transversal entre as cúspides dos molares, traçada anteriormente (medida ânteroposterior), de forma semelhante ao trabalho de Esteves \& Bommarito (31).

Dentro da janela "Fatia Coronal", buscou-se a fatia que melhor evidenciasse a ponta das cúspides mésio-vestibulares dos primeiros molares superiores. A ferramenta "medições" foi utilizada para mensurar duas distâncias: a primeira unindo os pontos dos vértices das cúspides mésio-vestibulares dos primeiros molares superiores permanentes (medida transversal) e a segunda unindo o ponto mais superior da sutura palatina mediana e o centro da linha transversal entre as cúspides dos molares, traçada anteriormente (medida ântero-posterior), de forma semelhante ao trabalho de Esteves \& Bommarito (31). A imagem exibida na tela neste ponto das mensurações é representada pela Figura 7. 


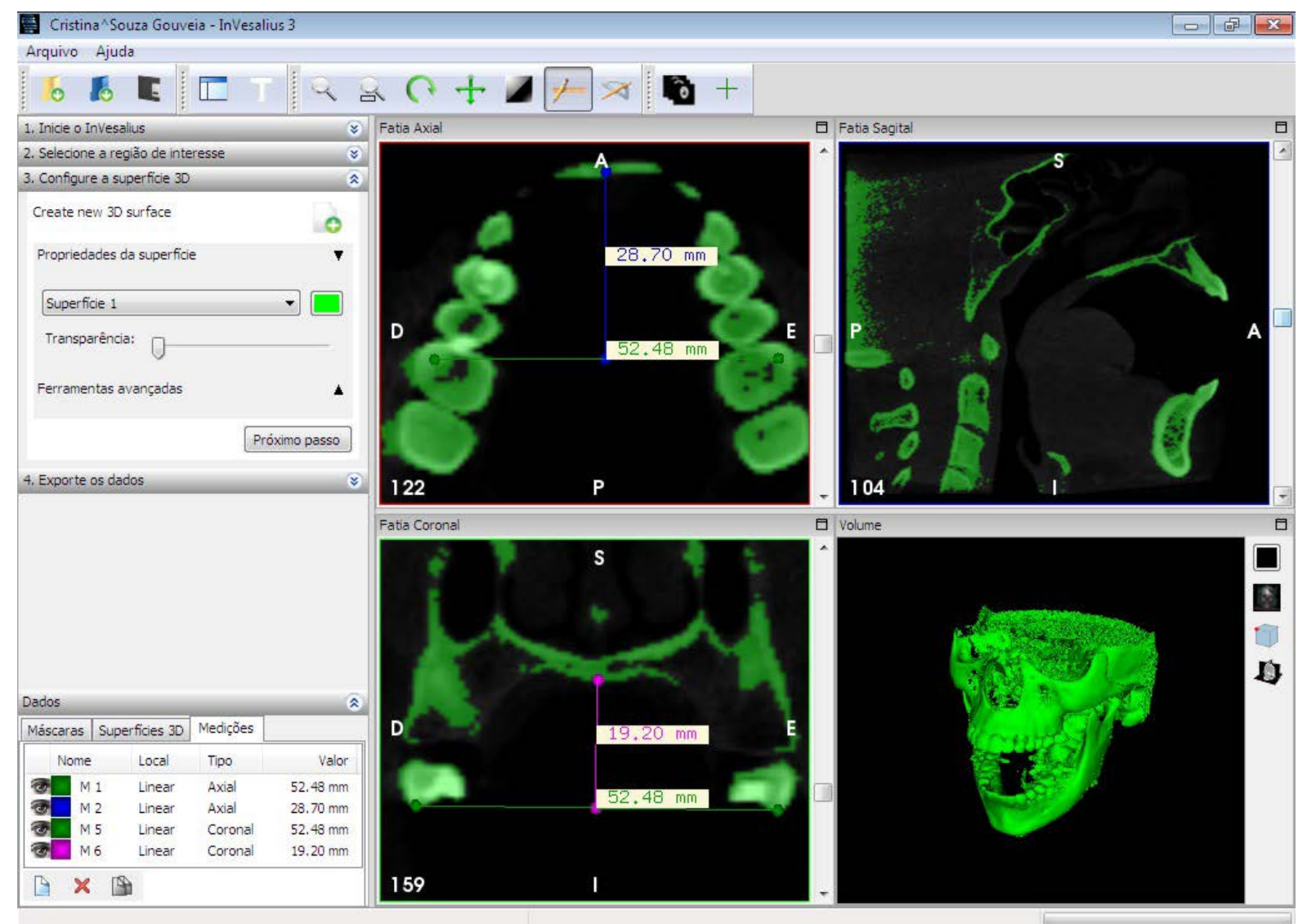

Figura 7 - Tela capturada após mensurações lineares axiais e coronais com software Invesalius 3.0.

Em uma planilha criada no Microsoft Excel® (Tabela 2), as tomografias dos pacientes foram numeradas de 1 a 20 e as medidas foram transferidas, anotando-se o número da fatia coronal e axial nas quais fosse mais nítida a visualização anatômica dos pontos desejados. Nestas fatias foram feitas a 1a. e a 2a. medições lineares em milímetros, com intervalo de 30 dias entre as mensurações. As colunas representam respectivamente: o número do paciente, o número da fatia coronal na qual foram feitas as medições, a medida em milímetros da primeira e da segunda mensurações da distância entre a linha que une as pontas das cúspides mésiovestibulares dos primeiros molares superiores até a sutura palatina mediana (6-6palato), o número da fatia axial na qual foram feitas as medições, a medida em milímetros da primeira e da segunda mensurações da distância entre a linha que une as pontas das cúspides mésio-vestibulares dos primeiros molares superiores (16-26), a medida em milímetros da primeira e da segunda mensurações da distância entre a linha que une as pontas das cúspides mésio-vestibulares dos primeiros molares superiores e o ponto da linha média dentária entre incisivos 
centrais superiores (6-6-ICS). O diagrama com a explicação do título das colunas está no APÊNDICE B.

Tabela 2 - Número da tomografia, número das fatias coronais e axiais nas quais foram feitas a 1a. e a 2a. medição linear em milímetros com intervalo de 30 dias, da profundidade do palato (vertical, 6-6-palato), distância entre as cúspides MV do 16 e 26 (transversal, 16-26) e da distância entre a linha 16-26 e a linha média entre os incisivos centrais superiores (anteroposterior, 6-6-ICS).

\begin{tabular}{|c|c|c|c|c|c|c|c|c|}
\hline \multirow{2}{*}{$\begin{array}{c}\text { Tomo } \\
\text { No. }\end{array}$} & \multirow{2}{*}{$\begin{array}{c}\text { Fatia } \\
\text { Coronal }\end{array}$} & \multicolumn{2}{|c|}{ 6-6-palato } & \multirow{2}{*}{$\begin{array}{l}\text { Fatia } \\
\text { Axial }\end{array}$} & \multicolumn{2}{|c|}{$16-26$} & \multicolumn{2}{|c|}{ 6-6-ICS } \\
\hline & & 1a.Med & 2a.Med & & 1a.Med & 2a.Med & 1a.Med & 2a.Med \\
\hline 1 & co152 & 19,32 & 19,36 & $a \times 128$ & 44,68 & 45,56 & 28,04 & 27,48 \\
\hline 2 & co158 & 24,4 & 23,98 & $a \times 119$ & 49,26 & 48,89 & 28,79 & 28,07 \\
\hline 3 & $\operatorname{co162}$ & 22,95 & 23,61 & $a \times 118$ & 45,8 & 46,29 & 24,65 & 24,68 \\
\hline 4 & co169 & 25,78 & 25,65 & ax90 & 51,08 & 51,27 & 32,11 & 31,8 \\
\hline 5 & co159 & 19,24 & 19,2 & $a \times 122$ & 52,48 & 52,48 & 28,55 & 28,7 \\
\hline 6 & co144 & 24,42 & 24,64 & $a \times 119$ & 49,46 & 49,67 & 25,22 & 25,77 \\
\hline 7 & co161 & 22,22 & 22,1 & $a \times 132$ & 47,47 & 47,6 & 24,31 & 24,13 \\
\hline 8 & co159 & 25,11 & 25,14 & ax155 & 45,53 & 45,53 & 23,43 & 23,57 \\
\hline 9 & co147 & 21,35 & 21,27 & $a \times 127$ & 53,09 & 53,22 & 29,12 & 29,08 \\
\hline 10 & $\operatorname{co166}$ & 19,78 & 19,63 & $a \times 119$ & 40,7 & 40,32 & 22,57 & 22,45 \\
\hline 11 & co167 & 18,83 & 19,29 & $a \times 136$ & 45,21 & 45,26 & 24,41 & 24,36 \\
\hline 12 & $\operatorname{co170}$ & 23,22 & 22,94 & $a \times 124$ & 53,8 & 53,6 & 31,15 & 30,93 \\
\hline 13 & co157 & 21,81 & 22,31 & $a \times 113$ & 49,47 & 49,66 & 26,58 & 26,35 \\
\hline 14 & co141 & 22,99 & 22,71 & $a \times 130$ & 53,26 & 53,04 & 30,21 & 29,83 \\
\hline 15 & co175 & 25,83 & 26,23 & $a \times 143$ & 47,48 & 47,68 & 24,99 & 24,67 \\
\hline 16 & co163 & 20,24 & 20,17 & ax133 & 51,16 & 51,23 & 25,47 & 25,62 \\
\hline 17 & co183 & 16,94 & 16,79 & $a \times 137$ & 49,08 & 49,34 & 27,03 & 27,11 \\
\hline 18 & co146 & 19,12 & 19,02 & $a \times 135$ & 54,57 & 54,38 & 28,91 & 28,68 \\
\hline 19 & co154 & 25,3 & 25,21 & $a \times 125$ & 47,71 & 48,04 & 28,68 & 28,76 \\
\hline 20 & co154 & 22,53 & 22,85 & $a \times 123$ & 44,99 & 45,08 & 26 & 25,73 \\
\hline média & & 22,07 & 22,11 & & 48,81 & 48,91 & 27,01 & 26,89 \\
\hline $\begin{array}{l}\text { desvio } \\
\text { padrão }\end{array}$ & & 2,64 & 2,66 & & 3,67 & 3,61 & 2,65 & 2,56 \\
\hline máximo & & 25,83 & 26,23 & & 54,57 & 54,38 & 32,11 & 31,80 \\
\hline mínimo & & 16,94 & 16,79 & & 40,70 & 40,32 & 22,57 & 22,45 \\
\hline
\end{tabular}




\subsection{MÉTODO ESTATÍSTICO PARA AVALIAÇÃO DE ERRO DE MENSURAÇÃO INTRA-OPERADOR}

Após a obtenção de todos os valores médios e desvios-padrões, foi calculada a média dos desvios na primeira e segunda mensurações das 3 medidas (a distância axial entre as pontas das cúspides dos primeiros molares superiores (6-6), a distância axial desta linha (6-6) e o ponto mediano dentário entre os incisivos centrais superiores (ICS) e a distância coronal desta linha (6-6) e a sutura palatina mediana), descrita na Tabela 3. Para se avaliar o erro sistemático intra-operador, foi utilizado o teste t pareado, comparando-se o valor obtido (t calculado) com o valor tabelado para 19 Graus de Liberdade (GL). Na determinação do erro casual utilizouse o cálculo de erro proposto por Dahlberg (67), cuja fórmula é:

$$
\text { Erro }=\sqrt{\sum d^{2}} / 2 n
$$

onde $d=$ diferença entre $1^{\mathrm{a}}$ e $2^{\mathrm{a}}$ medições e $\mathrm{n}=$ número de sujeitos repetidos.

Tabela 3 - Número da tomografia, diferenças entre as duas medições (2a. med - 1a. med) 6-6-palato (vertical), 16-26 (transversal), 6-6-ICS (A-P) e valores do teste t de Student, com 19 graus de liberdade (GL), erro casual e p-valor.

Diferença entre 2a.Med Diferença entre 2a.Med Diferença entre 2a.Med

\begin{tabular}{cccc}
$\begin{array}{c}\text { Tomo } \\
\text { No. }\end{array}$ & $\begin{array}{c}\text { e 1a.Med } \\
\text { 6-6-palato (vertical) }\end{array}$ & $\begin{array}{c}\text { e 1a.Med } \\
\text { 16-26 (transversal) }\end{array}$ & $\begin{array}{c}\text { e 1a.Med } \\
\text { 6-6-ICS (A-P) }\end{array}$ \\
\hline 1 & 0,04 & 0,88 & $-0,56$ \\
2 & $-0,42$ & $-0,37$ & $-0,72$ \\
3 & 0,66 & 0,49 & 0,03 \\
4 & $-0,13$ & 0,19 & $-0,31$ \\
5 & $-0,04$ & 0 & 0,15 \\
6 & 0,22 & 0,21 & 0,55 \\
7 & $-0,12$ & 0,13 & $-0,18$ \\
8 & 0,03 & 0 & 0,14 \\
9 & $-0,08$ & 0,13 & $-0,04$ \\
10 & $-0,15$ & $-0,38$ & $-0,12$ \\
11 & 0,46 & 0,05 & $-0,05$ \\
12 & $-0,28$ & $-0,2$ & $-0,22$ \\
13 & 0,5 & 0,19 & $-0,23$ \\
14 & $-0,28$ & $-0,22$ & $-0,38$ \\
& & & continua
\end{tabular}


conclusão

\begin{tabular}{|c|c|c|c|}
\hline $\begin{array}{c}\text { Tomo } \\
\text { No. }\end{array}$ & $\begin{array}{c}\text { Diferença entre 2a.Med } \\
\text { e 1a.Med } \\
\text { 6-6-palato (vertical) }\end{array}$ & $\begin{array}{c}\text { Diferença entre 2a.Med } \\
\text { e 1a.Med } \\
\text { 16-26 (transversal) }\end{array}$ & $\begin{array}{c}\text { Diferença entre 2a.Med } \\
\text { e 1a.Med } \\
\text { 6-6-ICS (A-P) } \\
\end{array}$ \\
\hline 15 & 0,4 & 0,2 & $-0,32$ \\
\hline 16 & $-0,07$ & 0,07 & 0,15 \\
\hline 17 & $-0,15$ & 0,26 & 0,08 \\
\hline 18 & $-0,1$ & $-0,19$ & $-0,23$ \\
\hline 19 & $-0,09$ & 0,33 & 0,08 \\
\hline 20 & 0,32 & 0,09 & $-0,27$ \\
\hline média & 0,036 & 0,093 & $-0,1225$ \\
\hline desvio padrão & 0,29245602 & 0,292846286 & 0,284102928 \\
\hline variância & 0,08553053 & 0,085758947 & 0,080714474 \\
\hline máximo & 0,66 & 0,88 & 0,55 \\
\hline mínimo & $-0,42$ & $-0,38$ & $-0,72$ \\
\hline t calculado & 0,5504995 & 1,420228507 & $-1,92830344$ \\
\hline $\begin{array}{l}\mathrm{t} \text { tabelado com } \\
19 \mathrm{GL}\end{array}$ & 2,09 & 2,09 & 2,09 \\
\hline conclusão & $\mathrm{H}_{0}$ aceita & $\mathrm{H}_{0}$ aceita & $\mathrm{H}_{0}$ aceita \\
\hline $\begin{array}{l}\text { Erro Dahlberg } \\
(\mathrm{mm})\end{array}$ & 0,20679764 & 0,202994361 & 0,207073595 \\
\hline p-valor & $<.001$ & $<.001$ & $<.001$ \\
\hline
\end{tabular}

\subsection{ESCOLHA DA TOMOGRAFIA DO INDIVÍDUO MÉDIO}

Sendo constatada a ausência de significância estatística na diferença entre as mensurações, calculou-se a média das variações das três medidas, nas duas medições, em relação ao Desvio Padrão Tabela 4. O cálculo foi executado atribuindo-se um valor absoluto à diferença entre o valor encontrado individualmente e o valor médio de todas as tomografias (=ABS(D-Dmédia)) para cada uma das três medidas (vertical 6-6-palato, transversal 16-26 e anteroposterior 6-6-ICS). Para cada tomografia foi obtido um valor médio de desvios, calculado pela média dos desvios das 3 medidas, na primeira e na segunda mensurações.

A maxila que exibiu a menor variação nas duas medições teve a coluna marcada em negrito e escolhida como modelo para a criação do modelo computacional. 
Tabela 4 - Média das variações das duas medições em relação ao desvio padrão.

\begin{tabular}{ccccrcrrr} 
& $\begin{array}{c}\text { Coronal } \\
\text { 1a. }\end{array}$ & $\begin{array}{c}\text { Axial } \\
\text { 1a. }\end{array}$ & $\begin{array}{c}\text { Axial } \\
\text { 1a. }\end{array}$ & Média & $\begin{array}{c}\text { Coronal } \\
\text { 2a. } \\
\text { Vertical }\end{array}$ & $\begin{array}{c}\text { Axial } \\
\text { 2a. }\end{array}$ & $\begin{array}{c}\text { Axial } \\
\text { Transv. }\end{array}$ & A-P \\
Tomo & Vertical & Transv. & A-P & & Vertia \\
\hline 1 & 2,749 & 4,134 & 1,029 & 2,637333 & 2,745 & 3,347 & 0,5915 & 2,227833 \\
2 & 2,331 & 0,446 & 1,779 & 1,518666 & 1,875 & 0,017 & 1,1815 & 1,0245 \\
3 & 0,881 & 3,014 & 2,361 & 2,085333 & 0,76 & 2,617 & 2,2085 & 1,861833 \\
4 & 3,711 & 2,266 & 5,099 & 3,692 & 3,545 & 2,363 & 4,9115 & 3,6065 \\
5 & 2,829 & 3,666 & 1,539 & 2,678 & 2,905 & 3,573 & 1,8115 & 2,763167 \\
6 & 2,351 & 0,646 & 1,791 & 1,596 & 2,535 & 0,763 & 1,1185 & 1,472167 \\
7 & 0,151 & 1,344 & 2,701 & 1,398666 & 0,005 & 1,307 & 2,7585 & 1,356833 \\
8 & 3,041 & 3,284 & 3,581 & 3,302 & 3,035 & 3,377 & 3,3185 & 3,2435 \\
9 & 0,719 & 4,276 & 2,109 & 2,368 & 0,835 & 4,313 & 2,1915 & 2,4465 \\
10 & 2,289 & 8,114 & 4,441 & 4,948 & 2,475 & 8,587 & 4,4385 & 5,166833 \\
11 & 3,239 & 3,604 & 2,601 & 3,148 & 2,815 & 3,647 & 2,5285 & 2,996833 \\
12 & 1,151 & 4,986 & 4,139 & 3,425333 & 0,835 & 4,693 & 4,0415 & 3,189833 \\
13 & $\mathbf{0 , 2 5 9}$ & $\mathbf{0 , 6 5 6}$ & $\mathbf{0 , 4 3 1}$ & $\mathbf{0 , 4 4 8 6 6 6}$ & $\mathbf{0 , 2 0 5}$ & $\mathbf{0 , 7 5 3}$ & $\mathbf{0 , 5 3 8 5}$ & $\mathbf{0 , 4 9 8 8 3 3}$ \\
14 & 0,921 & 4,446 & 3,199 & 2,855333 & 0,605 & 4,133 & 2,9415 & 2,559833 \\
15 & 3,761 & 1,334 & 2,021 & 2,372 & 4,125 & 1,227 & 2,2185 & 2,5235 \\
16 & 1,829 & 2,346 & 1,541 & 1,905333 & 1,935 & 2,323 & 1,2685 & 1,842167 \\
17 & 5,129 & 0,266 & 0,019 & 1,804666 & 5,315 & 0,433 & 0,2215 & 1,989833 \\
18 & 2,949 & 5,756 & 1,899 & 3,534666 & 3,085 & 5,473 & 1,7915 & 3,449833 \\
19 & 3,231 & 1,104 & 1,669 & 2,001333 & 3,105 & 0,867 & 1,8715 & 1,947833 \\
20 & 0,461 & 3,824 & 1,011 & 1,765333 & 0,745 & 3,827 & 1,1585 & 1,910167 \\
\hline DP & 1,36 & 2,04 & 1,31 & 1,02 & 1,42 & 2,07 & 1,29 & 1,05 \\
variância & 1,86 & 4,18 & 1,73 & 1,03 & 2,02 & 4,30 & 1,67 & 1,09
\end{tabular}

O paciente número 13 apresentou valores para as 3 medidas (vertical, transversal e A-P) entre média $\pm 0,14 \mathrm{DP}$ e média \pm 0,47 DP.

Uma análise de agrupamento foi gerada no software SPSS 18 para identificar o indivíduo que mais se aproximaria da média dos valores nas variáveis estudadas. Para tanto, além dos 20 pacientes estudados, foi incluído um indivíduo hipotético com os valores médios de cada variável. Em seguida, foi gerada a análise de agrupamento hierarquizada utilizando o centróide como referência para a formação dos grupos, evidenciado na Tabela 5 e nas Figura 8 e Figura 9. O indivíduo mais próximo da média das três variáveis (indivíduo hipotético) foi identificado e a geometria de sua tomografia foi exportada em formato .STL. 
Tabela 5 - Saída do SPSS - Análise de agrupamento hierarquizada utilizando o centróide das médias como referência para a formação dos grupos.

\begin{tabular}{|c|c|c|c|c|c|}
\hline \multicolumn{6}{|c|}{ Cases } \\
\hline \multicolumn{2}{|c|}{ Valid } & \multicolumn{2}{|c|}{ Missing } & \multicolumn{2}{|c|}{ Total } \\
\hline $\mathrm{N}$ & Percent & $\mathrm{N}$ & Percent & $\mathrm{N}$ & Percent \\
\hline 21 & 100,0 & 0 &, 0 & 21 & 100,0 \\
\hline
\end{tabular}

a. Squared Euclidean Distance used

b. Centroid Linkage

\section{Centroid Linkage}

Agglomeration Schedule

\begin{tabular}{|c|c|c|c|c|c|c|}
\hline \multirow[t]{2}{*}{ Stage } & \multicolumn{2}{|c|}{ Cluster Combined } & \multirow[b]{2}{*}{ Coefficients } & \multicolumn{2}{|c|}{ Stage Cluster First Appears } & \multirow[b]{2}{*}{ Next Stage } \\
\hline & Cluster 1 & Cluster 2 & & Cluster 1 & Cluster 2 & \\
\hline 1 & 13 & 21 & ,688 & 0 & 0 & 9 \\
\hline 2 & 12 & 14 & 1,228 & 0 & 0 & 12 \\
\hline 3 & 3 & 20 & 2,655 & 0 & 0 & 7 \\
\hline 4 & 2 & 19 & 3,225 & 0 & 0 & 15 \\
\hline 5 & 5 & 18 & 4,512 & 0 & 0 & 6 \\
\hline 6 & 5 & 9 & 5,050 & 5 & 0 & 12 \\
\hline 7 & 3 & 7 & 5,606 & 3 & 0 & 10 \\
\hline 8 & 6 & 15 & 5,961 & 0 & 0 & 11 \\
\hline 9 & 13 & 16 & 8,726 & 1 & 0 & 14 \\
\hline 10 & 3 & 8 & 9,202 & 7 & 0 & 11 \\
\hline 11 & 3 & 6 & 10,317 & 10 & 8 & 14 \\
\hline 12 & 5 & 12 & 13,586 & 6 & 2 & 18 \\
\hline 13 & 1 & 11 & 13,698 & 0 & 0 & 16 \\
\hline 14 & 3 & 13 & 17,769 & 11 & 9 & 15 \\
\hline 15 & 2 & 3 & 15,652 & 4 & 14 & 17 \\
\hline 16 & 1 & 17 & 22,304 & 13 & 0 & 17 \\
\hline 17 & 1 & 2 & 27,777 & 16 & 15 & 19 \\
\hline 18 & 4 & 5 & 33,053 & 0 & 12 & 19 \\
\hline 19 & 1 & 4 & 45,723 & 17 & 18 & 20 \\
\hline 20 & 1 & 10 & 100,102 & 19 & 0 & 0 \\
\hline
\end{tabular}




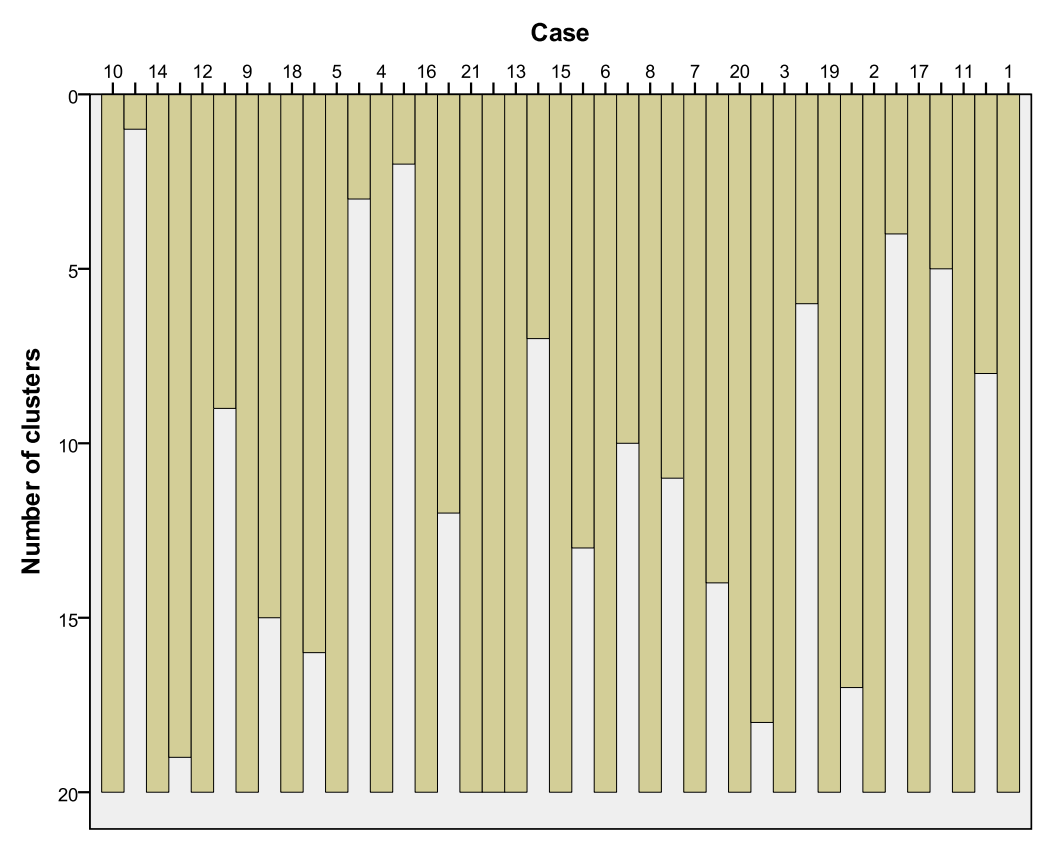

Figura 8 - Saída do SPSS - gráfico de Número de clusters X Caso.

Dendogram using Centroid Linkage / Rescaled Distance Cluster Combine

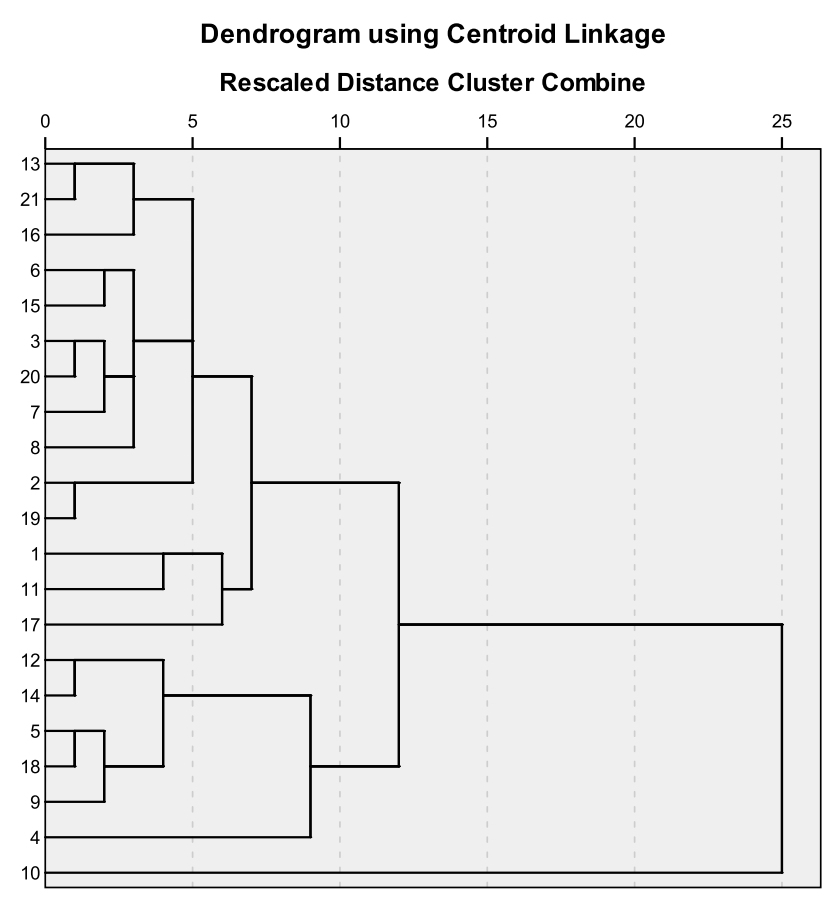

Figura 9 - Saída do SPSS - Dendrograma usando conexão entre o centróide e a distância entre a combinação dos clusters. 


\subsection{TRATAMENTO DA IMAGEM TOMOGRÁFICA (SEGMENTAÇÃO PARA RECONSTRUÇÃO TRIDIMENSIONAL)}

A imagem tomográfica é composta de elementos de tecidos duros e moles. A Segmentação da Reconstrução Tridimensional é o termo usado para separar os elementos de interesse, que para este trabalho foram a maxila e os dentes posteriores superiores.

A tomografia escolhida (em formato DICOM) foi exportada pelo programa INVESALIUS ${ }^{\circledR} 3.0$ em formato .STL, que é o formato nativo dos softwares de estereolitografia criado para sistemas tridimensionais. Este formato descreve somente a geometria da superfície de um objeto tridimensional pela união de vértices de triângulos (malha) usando um sistema de coordenadas cartesianas tridimensionais.

O arquivo foi aberto utilizando-se o programa MESHLAB ${ }^{\circledR}$ v1.3.0a, encontrado gratuitamente no site http://meshlab.sourceforge.net/. Neste programa foi utilizada a ferramenta de corte para segmentar a área de interesse, dentro dos seguintes limites: (1) no plano sagital: acima pelo ponto mais superior da sutura nasal mediana e abaixo pela ponta de cúspide do dente mais extruído; (2) no plano coronal: pela superfície mais vestibular do molar mais lateral (afastado da sutura palatina mediana), dos lados direito e esquerdo; e (3) no plano axial: posterior pela espinha nasal posterior e anterior pela espinha nasal anterior. Após o corte foi selecionado o maior volume e excluídos os ruídos e elementos não aderidos ao maior volume. Esta imagem foi salva também em formato .STL e foi utilizada como "arcabouço ósseo maxilar", ao qual foram incorporados os demais elementos anatômicos.

Para simplificação dos cálculos, a maxila foi segmentada novamente em uma hemimaxila. Para a análise de elementos finitos, se um lado é exatamente o espelho do outro, o programa é capaz de simular a outra hemimaxila por meio da hipótese de simetria e executar os cálculos com metade dos elementos (23). Pelo mesmo motivo, o MPO foi modelado sem as espiras.

\subsection{ADAPTAÇÃO E COMPATIBILIZAÇÃO DAS MEDIDAS}

A imagem maxilar segmentada foi transportada para o programa de modelagem RHINOCEROS ${ }^{2}$ v.3.0 (Figura 10), que pode ser obtido no site 
http://www.rhino3d.com/, cuja licença estava disponível no CTI (CENTRO DE TECNOLOGIA DA INFORMAÇÃO RENATO ARCHER). A partir desta etapa do trabalho, os arquivos digitais foram manipulados pelos engenheiros do CTI, na Divisão de Tecnologias Tridimensionais, chefiada pelo Dr. Jorge Vicente Lopes da Silva e sob supervisão do Dr. Pedro Yoshito Noritomi.

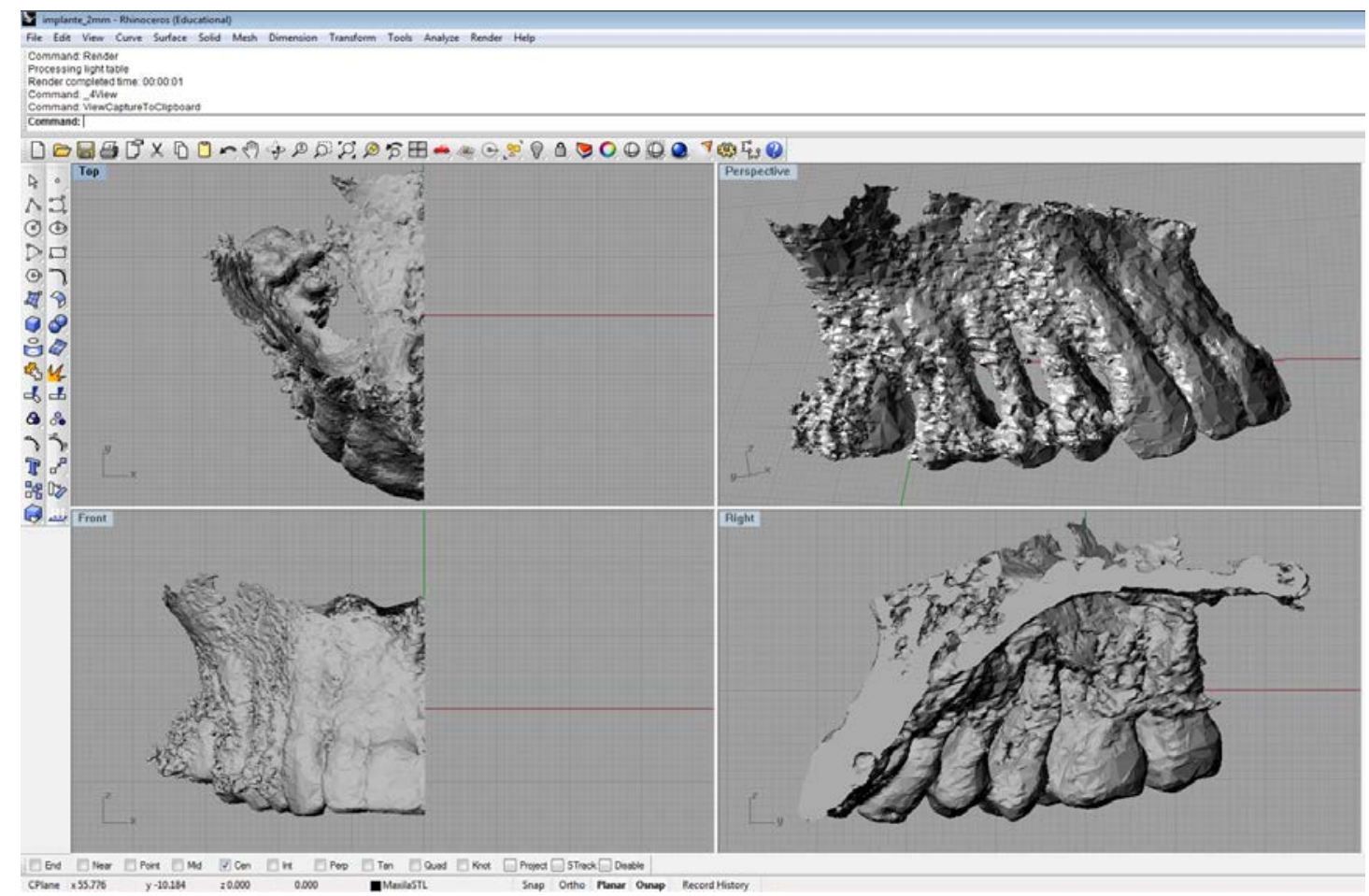

Figura 10 - Arquivo digital importado do MESHLAB para o RHINOCEROS.

Com a "hemimaxila média" identificada, todos os dentes foram removidos e os alvéolos foram delimitados com linhas demarcatórias e fechados, com exceção dos primeiros molares. Os marcos anatômicos principais foram mapeados por entidades geométricas específicas seguindo o protocolo BIOCAD desenvolvido no CTI, um projeto de padronização de geometria das estruturas dentais para fins de pesquisa.

O primeiro molar superior direito foi obtido a partir do banco de dados do CTI, que utilizou referências anatômicas de tomografias para obtenção dos modelos geométricos e foi sobreposto exatamente na posição do primeiro molar original do modelo da tomografia. Ao longo da superfície radicular, foram modelados os outros elementos anatômicos com valores médios encontrados na literatura para ligamento periodontal (0,3 mm) (58), osso cortical (2 mm) (30), cortical alveolar (lâmina dura) (1 $\mathrm{mm}$ ) (26) e mucosa alveolar na região molar (palatina $=3 \mathrm{~mm}$ ) (34) descrito na 
Tabela 6, compatíveis com as dimensões encontradas na tomografia deste paciente (obtidas com mensurações utilizando o programa Invesalius).

Tabela 6 - Descrição das dimensões das estruturas anatômicas e referências:

\begin{tabular}{ccc} 
Estrutura Anatômica & Dimensões & Referência \\
\hline Ligamento periodontal & $0,3 \mathrm{~mm}$ & Ichim et al. (58) \\
Espessura da lâmina dura & $1 \mathrm{~mm}$ & Hubar (26) \\
Espessura do osso cortical & $2 \mathrm{~mm}$ & Deguchi et al. (30) \\
Mucosa alveolar & $3 \mathrm{~mm}$ & Barriviera et al. (34) \\
\hline
\end{tabular}

O engenheiro mediu com um paquímetro e modelou no programa a metade da barra transpalatina (BTP) calibre 0,9 mm (0,036"), presa a uma banda de aço inox pré-soldada com tubo vestibular e lingual, calibre 0,018 " $\times 0,025 "$. O desenho digitalizado do MPO foi gentilmente cedido pelo fabricante SIN, ref. POT1838, com $1,8 \mathrm{~mm}$ de calibre, $3 \mathrm{~mm}$ de perfil transmucoso e $8 \mathrm{~mm}$ de comprimento, sem as espiras, pois a grande quantidade de detalhes aumentaria a demanda de capacidade computacional para uma região de pouco interesse e para evitar singularidades de tensões nas bordas pontudas (63).

\subsection{ALIMENTAÇÃO DE DADOS DOS ELEMENTOS ANATÔMICOS E ORTODÔNTICOS CONSTITUINTES - TESTE PRELIMINAR}

Em um modelo preliminar, o MPO foi inserido perpendicular à superfície do palato, entre o primeiro e o segundo molares, próximo ao local provável da raiz palatina do segundo molar, seguindo a referência de $5 \mathrm{~mm}$ medial à cervical (Figura 11) e, para atribuição dos pontos carregamento (aplicação de força), foi modelada uma haste com as extremidades inseridas na cabeça do MPO e no ponto de menor distância até a BTP. Esta haste simula o efeito do elástico ou mola fechada utilizados em uma situação clínica de aplicação de força ortodôntica. (Figura 12, Figura 13, Figura 14 e Figura 15). 


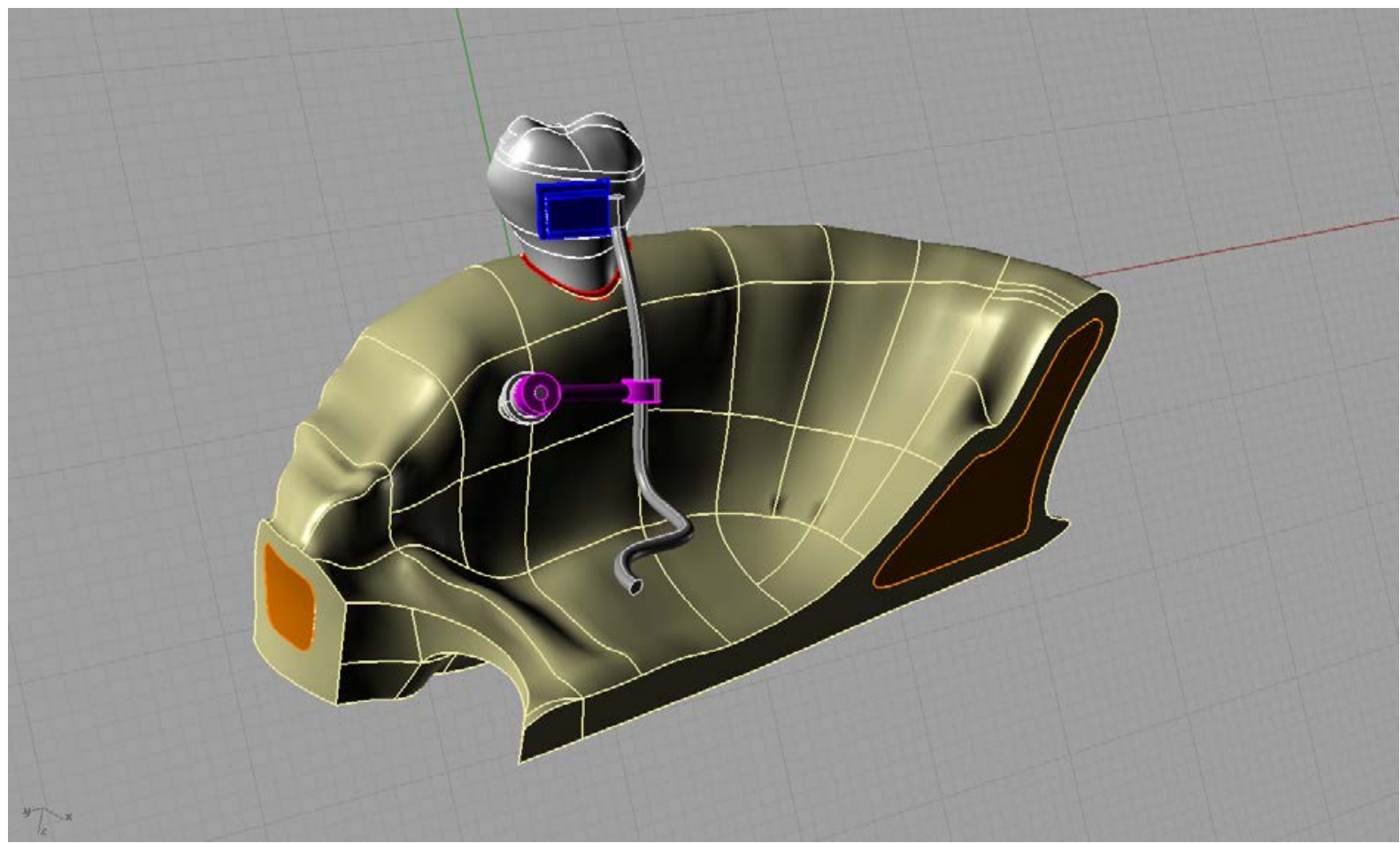

Figura 11 - Visão em perspectiva do modelo da hemimaxila e seus elementos anatômicos constituintes, além do primeiro molar com ligamento periodontal, banda, tubo lingual, BTP, MPO e elástico - Rhinoceros ${ }^{\circledR}$.

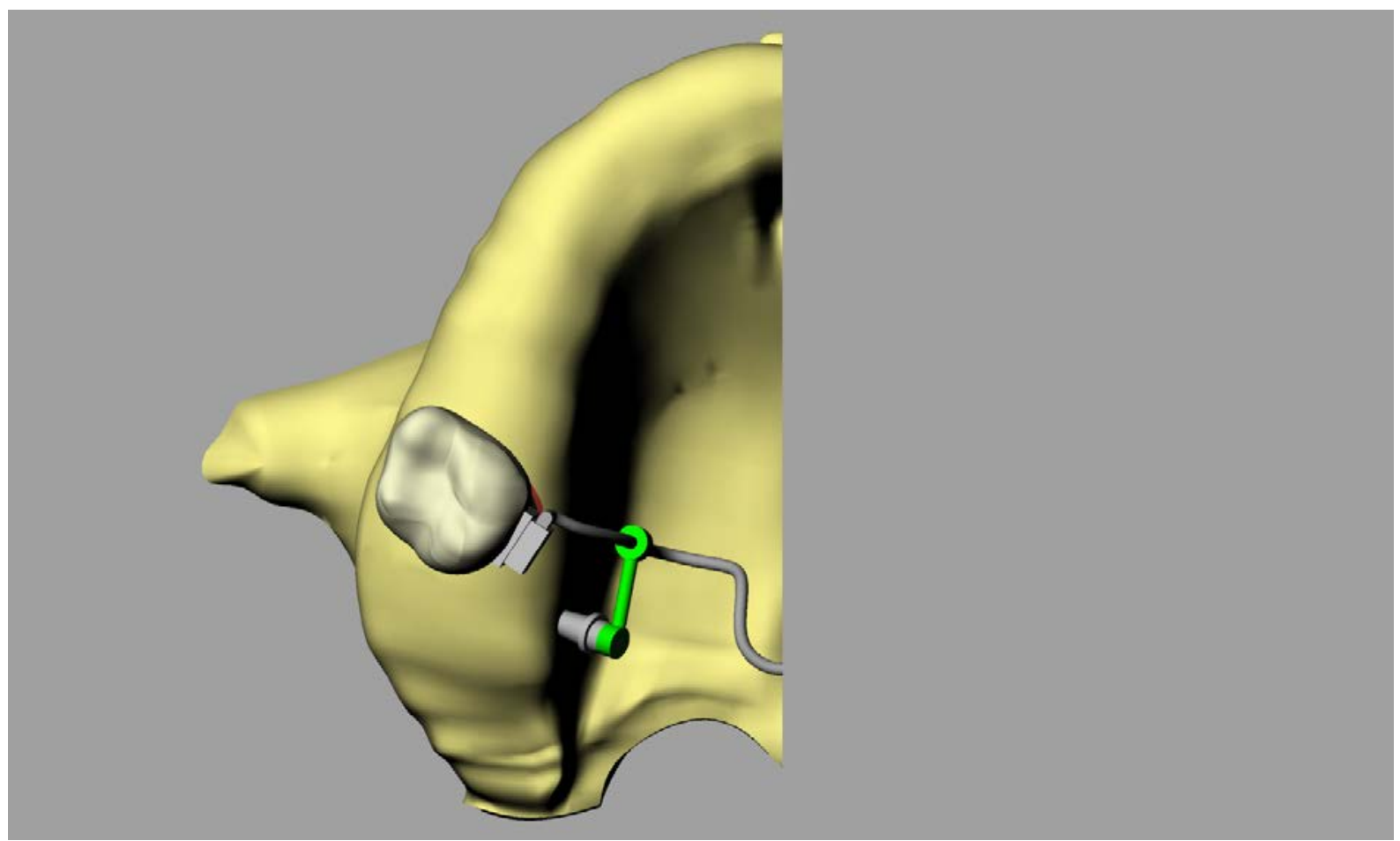

Figura 12 - Visão oclusal do modelo texturizado da hemimaxila e seus elementos anatômicos constituintes, além do primeiro molar com ligamento periodontal, banda, tubo lingual, BTP, MPO e elástico - Rhinoceros ${ }^{\circledR}$. 


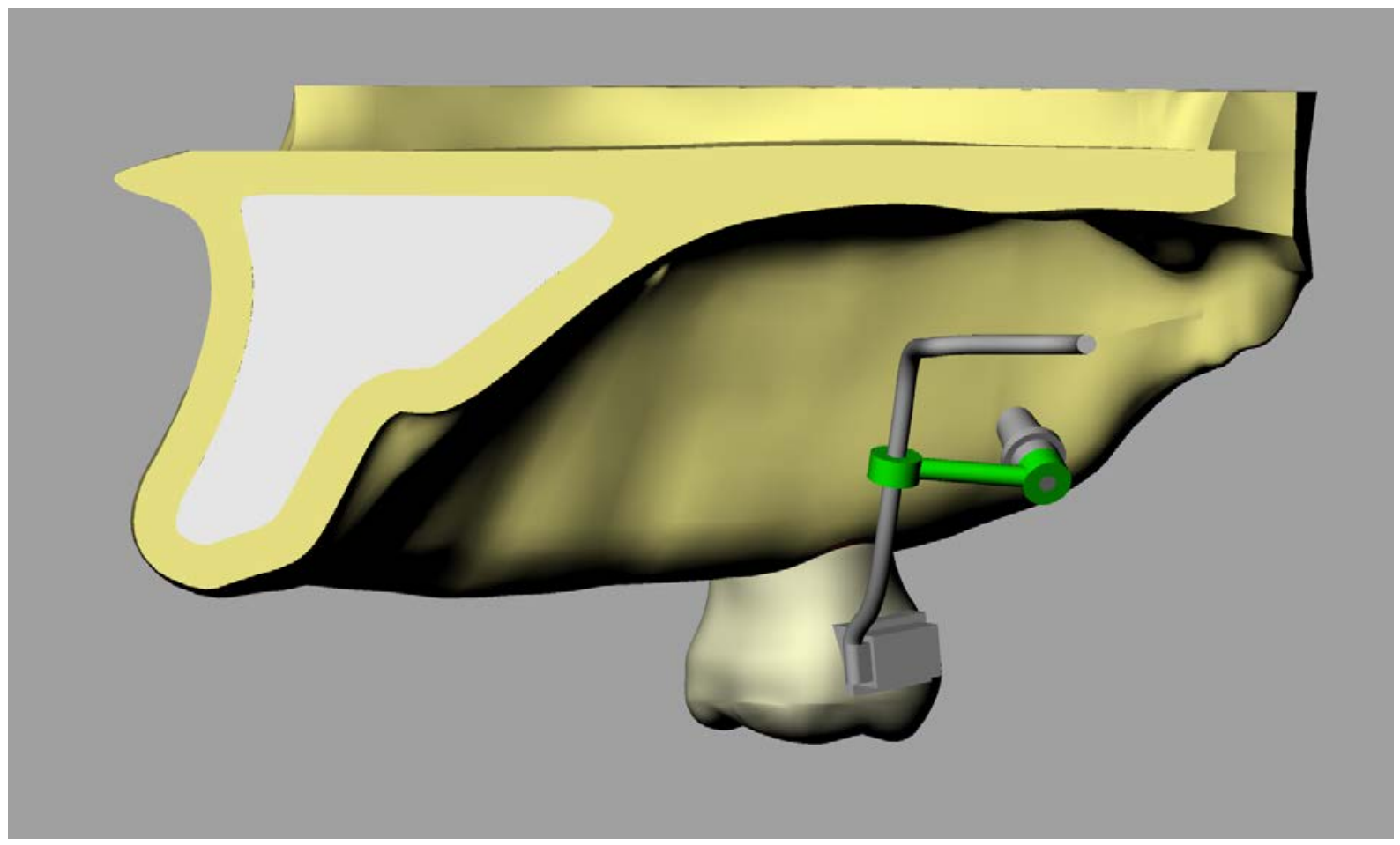

Figura 13 - Visão lingual do modelo texturizado da hemimaxila e seus elementos anatômicos constituintes, além do primeiro molar com ligamento periodontal, banda, tubo lingual, BTP, MPO e elástico - Rhinoceros ${ }^{\circledR}$.

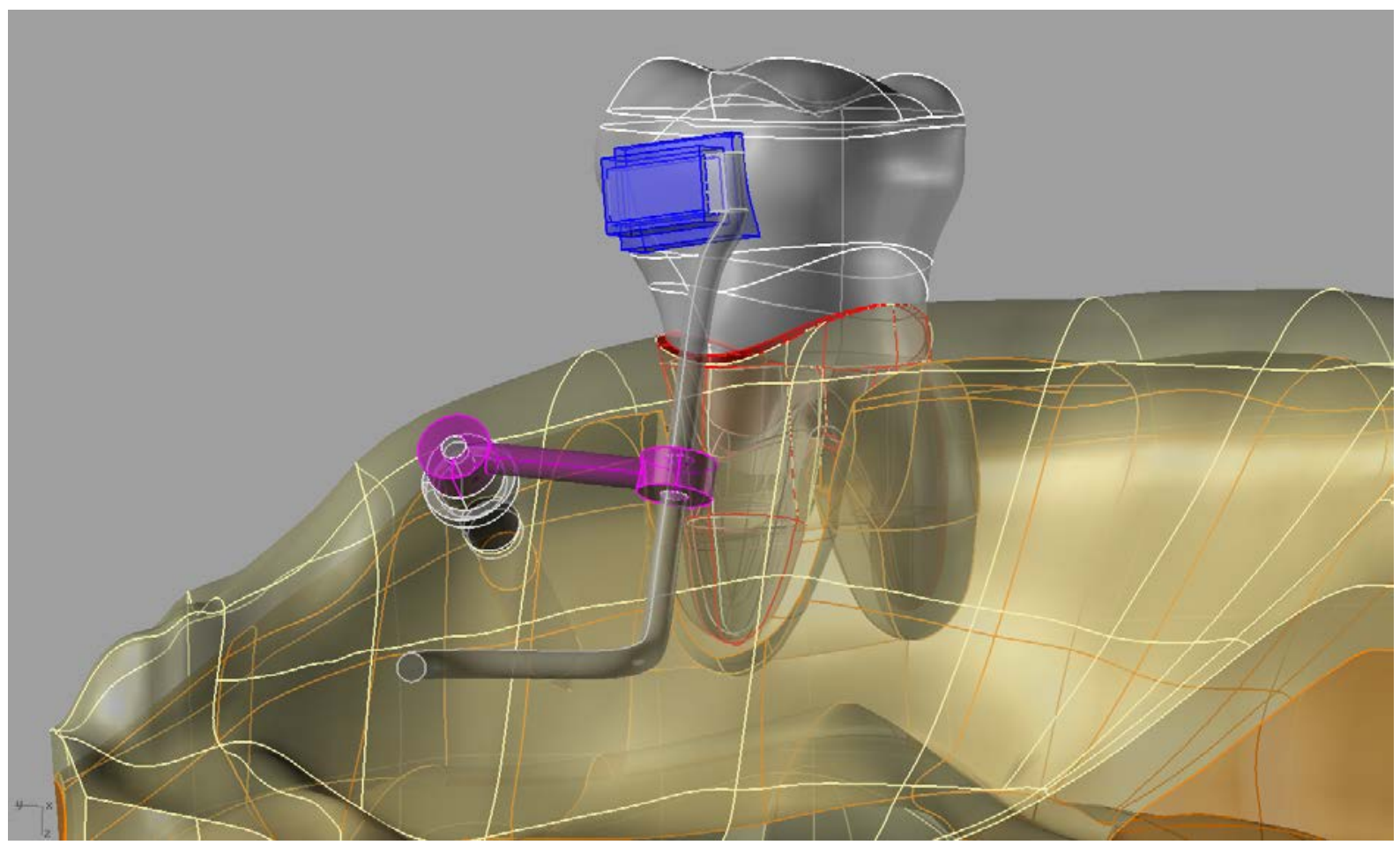

Figura 14 - Visão lingual do modelo texturizado e com transparência da hemimaxila e seus elementos anatômicos constituintes, além do primeiro molar com ligamento periodontal, banda, tubo lingual, BTP, MPO e elástico - Rhinoceros ${ }^{\circledR}$. 


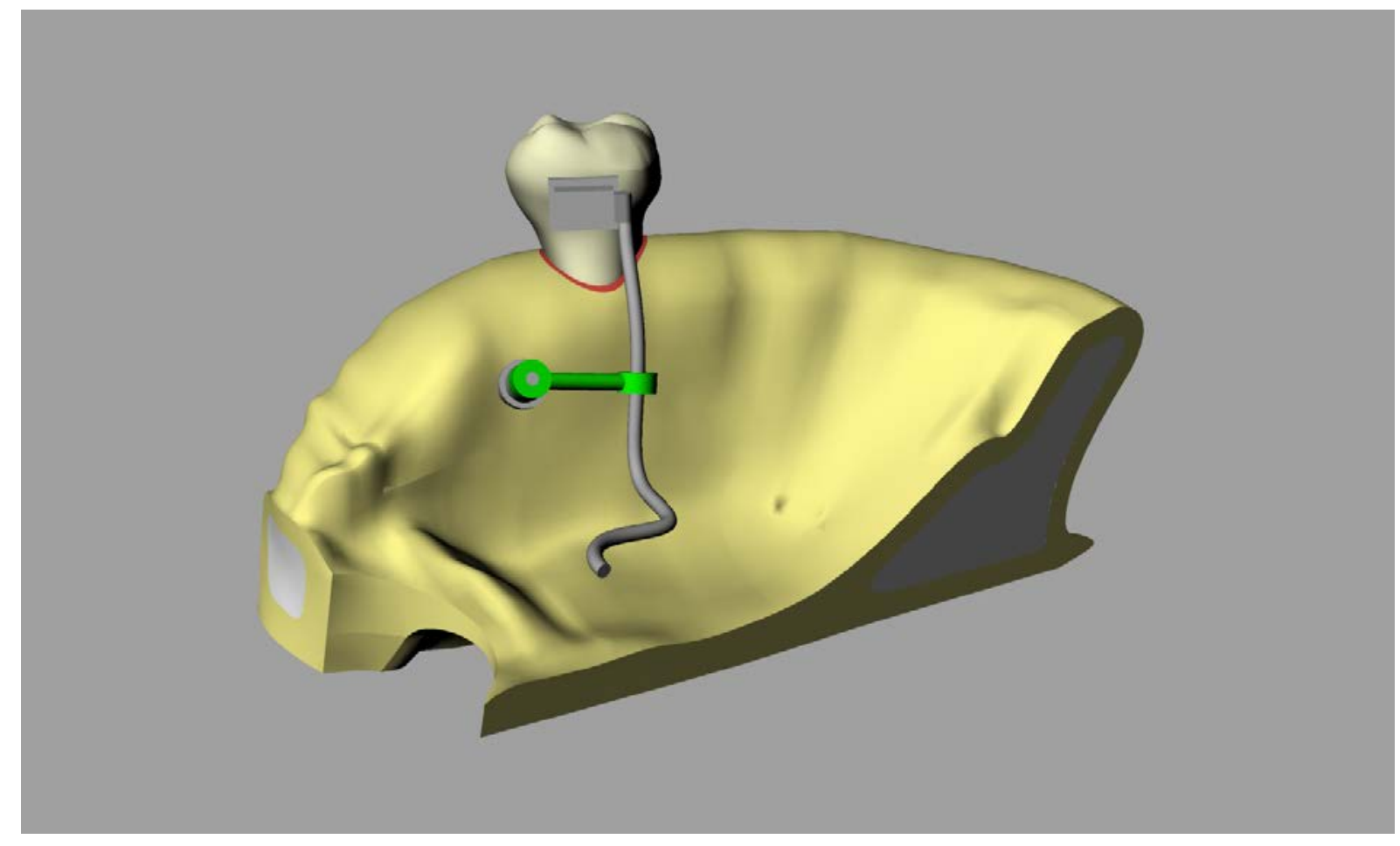

Figura 15 - Visão em perspectiva do modelo texturizado da hemimaxila e seus elementos anatômicos constituintes, além do primeiro molar com ligamento periodontal, banda, tubo lingual, BTP, MPO e elástico - Rhinoceros ${ }^{\circledR}$.

Este modelo foi exportado para o programa ANSYS 12.1® em formato .STP (Standard for The exchange of Product model data), onde foi discretizado (separação de um volume em vários elementos menores) e foi gerada uma malha tetraédrica com mais de 500.000 elementos (Figura 16, Figura 17 e Figura 18) (61, 63). 


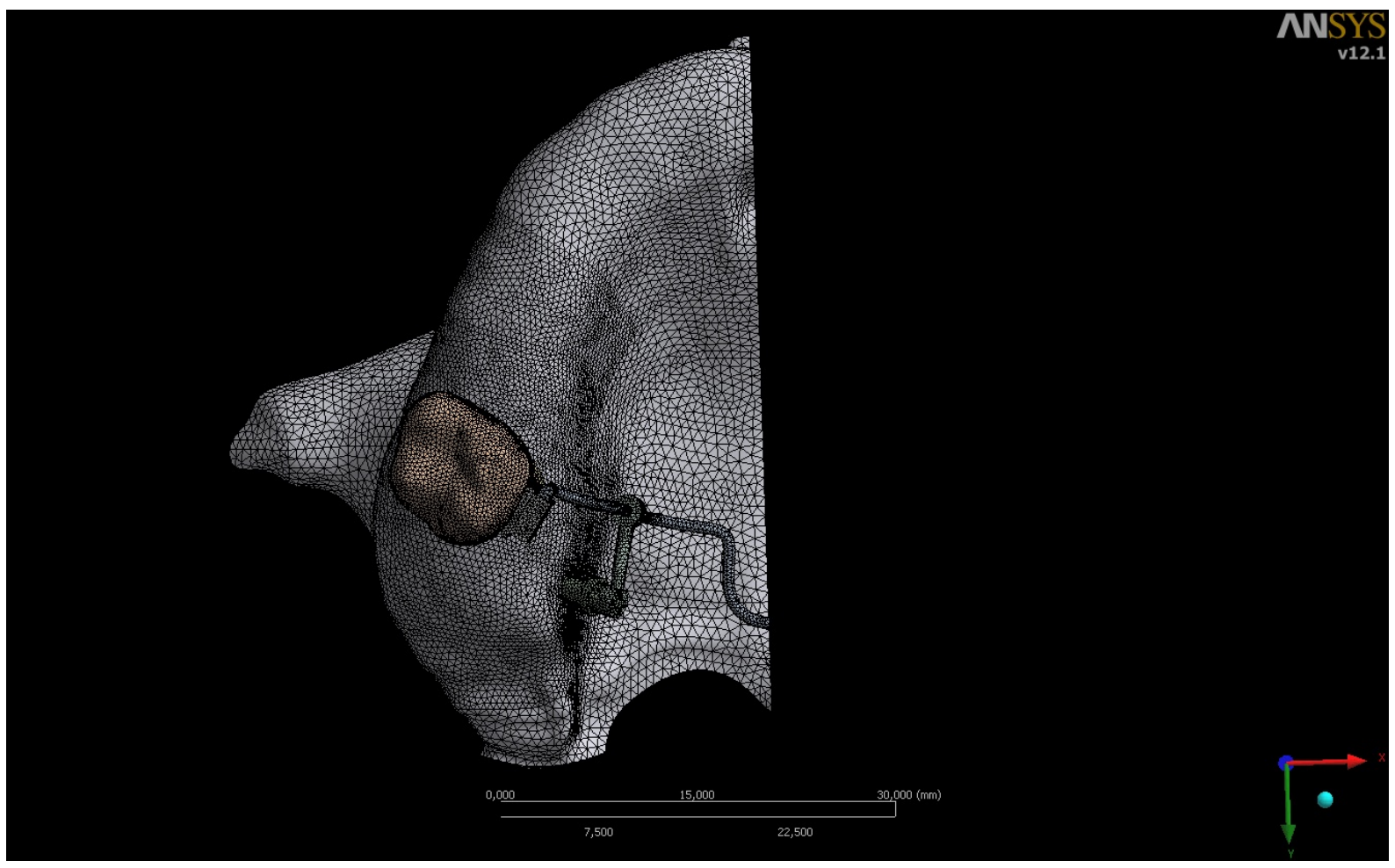

Figura 16 - Visão oclusal do modelo com a malha em tetraedros - ANSYS ${ }^{\circledR} 12.1$.

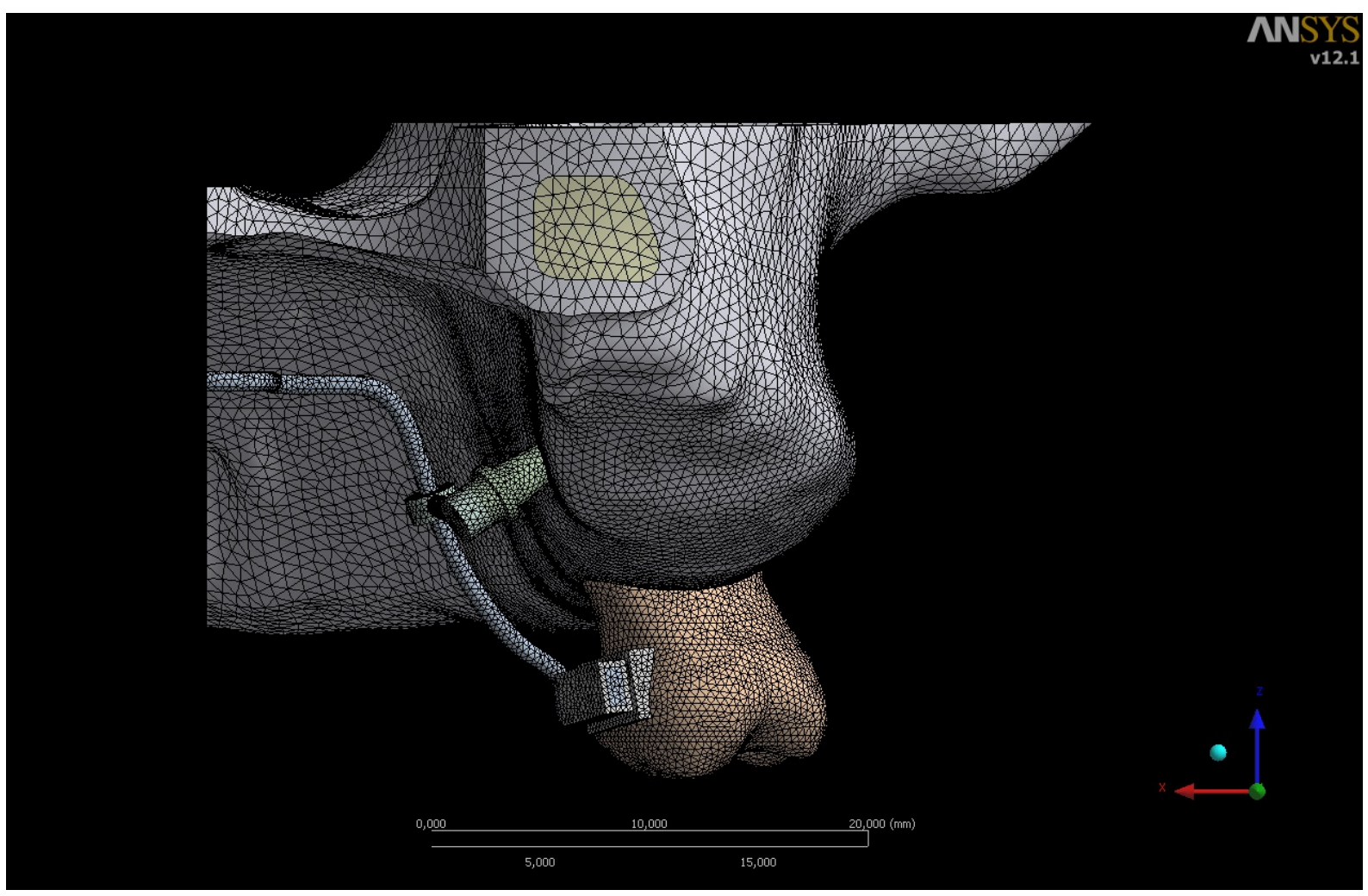

Figura 17 - Visão lingual do modelo com a malha em tetraedros - ANSYS ${ }^{\circ} 12.1$. 


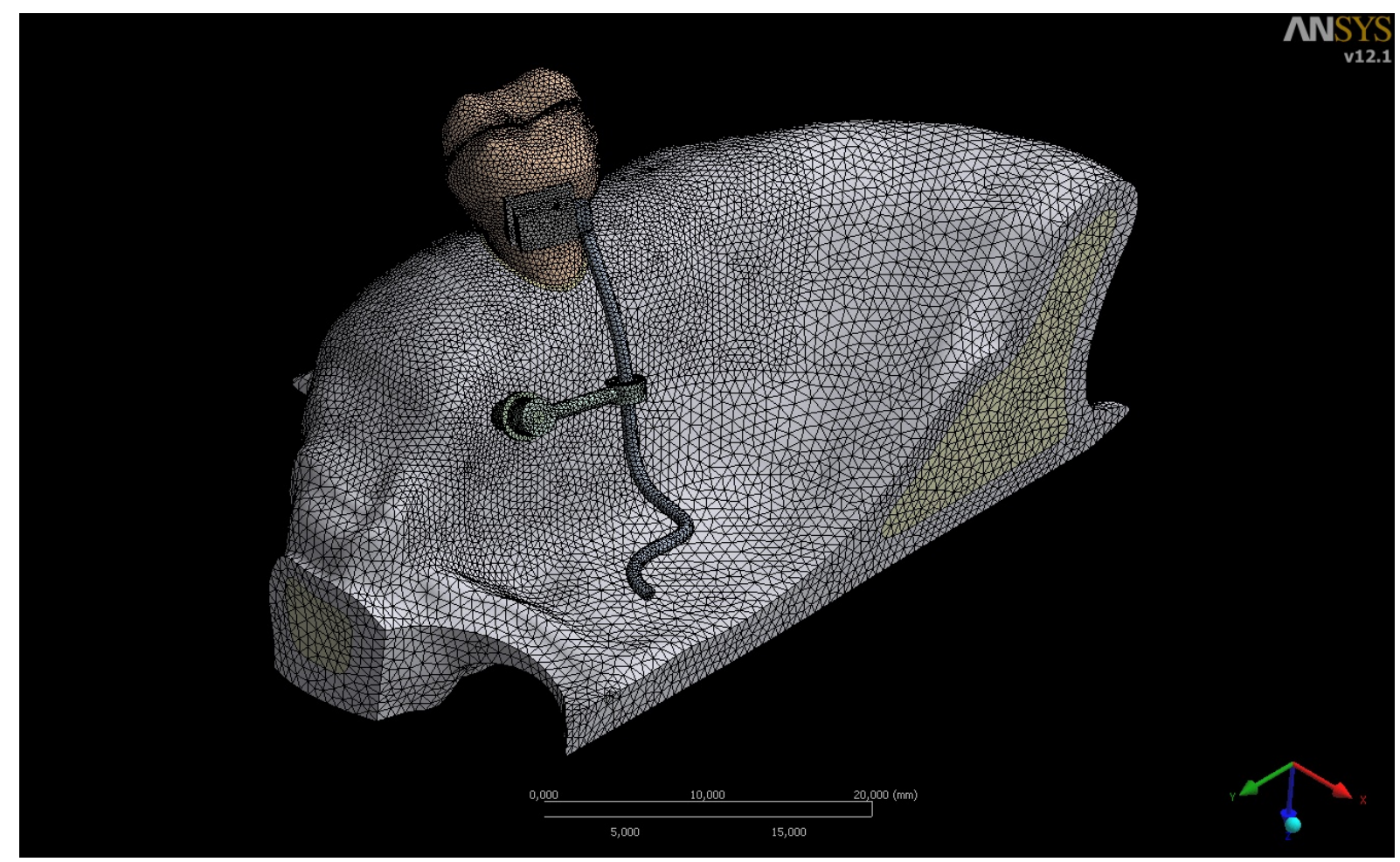

Figura 18 - Visão lingual do modelo com a malha em tetraedros - ANSYS ${ }^{2} 12.1$.

Estabelecido o sistema de coordenadas do modelo, a malha foi refinada nas regiões de maior interesse, sendo aumentado o número de nós ao mesmo tempo em que foi reduzido o tamanho dos elementos, com propósito de aumentar a precisão e detalhamento dos resultados (controle manual da malha) (63). O controle manual é realizado sobre as entidades geométricas dispostas sobre os marcos anatômicos, identificados como protocolo BIOCAD (desenvolvido no CTI). A melhora na quantidade e qualidade nos elementos resultará em uma melhora na quantidade e qualidade das equações, acarretando em aumento no tempo de processamento e em maior qualidade nos resultados (forças, tensões, deslocamentos e deformações).

Para melhor entendimento dos dados obtidos, alguns conceitos básicos de engenharia são relevantes. Quando um corpo sólido está sujeito à ação de forças, um estado de tensão é gerado internamente. A tensão em um ponto específico da estrutura é representada no plano bidimensional por três componentes de tensão, duas componentes perpendiculares entre si, e uma de distorção ou cisalhante. Este estado de tensão, sempre é descrito relativo a um sistema de referência, um eixo de coordenadas com orientação espacial, tradicionalmente o eixo de coordenadas globais $X Y$, sendo $X$ para representar a direção horizontal e $Y$ para representar a direção vertical. O estado de tensão também é representado nestas direções (Sx - 
horizontal, Sy - vertical e Sxy - de distorção ou cisalhante). Os valores destas variáveis de tensão são positivos quando naquele ponto, o material está sendo tracionado e negativo ao ser comprimido, ao longo do eixo de coordenadas específico (X ou Y). Já a tensão cisalhante ou de distorção tende a rotacionar ou distorcer pontualmente a estrutura, sendo positiva no sentido anti-horário e negativo no sentido horário (68).

Em um sistema tridimensional, o sistema de coordenadas inclui mais uma dimensão (Z), perpendicular a X e a $Y$. Os eixos podem ser aleatoriamente designados $e$, para este trabalho a coordenada $X$ foi utilizada para representar 0 eixo horizontal transversal, a coordenada $Y$ para representar 0 eixo horizontal ântero-posterior (A-P) e a coordenada Z para representar o eixo vertical.

Além destes conceitos, é importante citar também a energia de distorção, tensão equivalente (equivalent stress) ou tensão de von Mises. Este conceito está relacionado ao mecanismo de deformação microscópico, o deslizamento relativo dos átomos do material dentro de uma estrutura cristalina. O deslizamento é causado pela tensão de cisalhamento e é acompanhado pela distorção na forma do modelo ou material de estudo. A energia acumulada devido a essa distorção é um indicador da magnitude da tensão de cisalhamento presente. Essa energia acumulada pode ser representada pela tensão equivalente de von Mises ( $\left.\sigma^{\prime}\right)$, que é a somatória das tensões aplicadas normais $\left(90^{\circ}\right)$ e de cisalhamento (Sx, Sy e Sxy) no mesmo ponto. A tensão de von Mises (que é parte de um critério de falha) é indicada para materiais metálicos, ou com comportamento semelhante ao metal (63), pois indica o ponto em que haverá a falha (mudança do regime elástico para o regime plástico, sendo possível uma correlação com o teste de tração com corpo de prova padronizado), geralmente correspondendo a uma fissura, edentação ou trinca do material. Os resultados de von Mises não devem ser extrapolados para indicar um ponto de falha no osso, pela diferença entre os modos de falha dos materiais, pois o cálculo contém valores também de cisalhamento. Os Ossos são mais frágeis (pequena fase plástica) do que os metais, que por sua fez são mais fáceis de cortar (cisalhamento) do que os ossos (esmagamento).

Segundo Anusavice (68), "o Módulo de elasticidade, Módulo de Young ou Módulo elástico (E) descreve a relativa rigidez de um material, que é medida pela porção elástica (reversível) da deformação. Representa a capacidade de recuperação elástica do material. Em outras palavras, para um material isotrópico, é 
a razão entre a tensão por unidade de deformação (Lei de Hooke). É representado também por unidades de força divididas por área. Exemplo: GPa. O Coeficiente de Poisson (v) é a relação da deformação transversal (alongamento ou contração), com a deformação longitudinal (alongamento ou contração) do material, pois em todos os materiais, o alongamento que é produzido por uma força $P$, na direção dessa força, é acompanhado por uma contração em qualquer direção transversal.

As propriedades físicas dos materiais (Módulo de Elasticidade e Coeficiente de Poisson) foram inseridas de acordo com a Tabela 7 e os materiais utilizados foram considerados como: 1) Isotrópicos - apresentam as mesmas propriedades independente da direção considerada; 2) Elásticos - recuperam as dimensões originais quando a carga é retirada; 3) Contínuos - não apresentam espaços vazios $(19,59,61,63)$.

Tabela 7 - Propriedades mecânicas das estruturas dentais, estruturas de suporte e biomateriais.

Material Módulo de Elasticidade

Esmalte $(58,66)$

Ligamento Periodontal (56, $80 \mathrm{GPa}$ Coeficiente de Poisson

58)

Osso cortical $(56,63,24)$
Osso esponjoso $(56,63,24)$

$0,012 \mathrm{GPa}$

0,30

0,45

$13,7 \mathrm{GPa}$

0,30

Aço inoxidável (Fabricante,

$1,37 \mathrm{GPa}$

0,30

23)

$200 \mathrm{GPa} \quad 0,30$

Liga Ti-6Al-4V (Fabricante)

$105 \mathrm{GPa}$

0,31

Para fixar o modelo, foi atribuído engastamento aos nós do osso da parte mais superior e das partes laterais da maxila, na superfície onde haveria continuidade do osso maxilar e arco zigomático $(19,24,63,66)$. Os carregamentos foram aplicados sobre a haste com a mesma direção e intensidade de 1,5 N, mas em sentidos opostos. A haste que simula o elástico foi seccionada transversalmente, as extremidades seccionadas foram afastadas entre si e as cargas foram mantidas, para que não houvesse interferência da deformação da haste nos resultados (como restritora do movimento do dente = pré carga do Ansys $\left.{ }^{\circledR}\right)$.

O pós-processamento evidenciou as tensões principais máximas e mínimas, representando respectivamente as regiões de maior tração e de maior compressão, de acordo com o eixo analisado ( $X, Y$ ou Z), ou pela combinação global do valor absoluto ao quadrado de todas as tensões, a tensão de von Mises (medida da 
energia interna em um dado ponto da estrutura a partir das tensões normais e de cisalhamento, que não determina o estado de tração ou compressão, pois o resultado quadrático é sempre positivo). Na análise de deslocamento, o pósprocessamento evidenciou os valores máximos e mínimos, também de acordo com o eixo ( $X, Y$ ou Z). A solução (resultado) foi submetida a análise qualitativa e quantitativa, expostos na seção 5.1 (Resultados no Modelo de Teste Preliminar).

\subsection{AVALIAÇÃO DE PARÂMETROS DE COMPARAÇÃO CLÍNICA COM PILOTOS}

Para avaliar a fidedignidade do modelo preliminar (piloto), foi feita comparação entre os resultados obtidos no modelo preliminar de elementos finitos com os resultados obtidos nos trabalhos clínicos de Worms (20) e Dobranszki (21), que motivaram este estudo.

No trabalho de Worms et al. (20) os autores elaboraram um sistema de classificação da movimentação dos primeiros molares de acordo com o a relação entre a direção do vetor de força e o centro de resistência do molar. A ativação feita no piloto assemelha-se ao vetor de força Tipo IV, no qual a força passa pela trifurcação do molar (Cres teórico) e promove movimento distal, mas também rotação distal da coroa. Dobranszki (21) descreveu uma técnica para distalização de primeiros molares superiores com dois microparafusos ortodônticos instalados no palato atuando como ponto de ancoragem para ativação de uma BTP. Os microparafusos foram instalados no palato, a uma distância entre 2 e 5 mm medial à cervical dos primeiros molares (referência transversal), distais aos segundos molares superiores (referência A-P) e com a cabeça do parafuso posicionada verticalmente próxima ao suposto centro de resistência do molar, na altura da furca (referência vertical). A BTP foi ativada com "peixinhos" na sua menor distância entre o MPO, de forma semelhante às ativações de $2 \mathrm{~mm}$ médio e $5 \mathrm{~mm}$ médio (modelo do teste preliminar) e os resultados foram semelhantes aos do modelo preliminar em elementos finitos quanto à leve intrusão, angulação da coroa para distal e distalização. O trabalho clínico apresentou uma rotação importante da coroa para distal, provavelmente pela cabeça do MPOs estar deslocada no sentido oclusal do dente, em relação ao Centro de Resistência do dente, assemelhando-se à ativação $2 \mathrm{~mm}$ alto.

Com resultados esperados e compatíveis aos achados clínicos, julgou-se que o modelo estava pronto para ser submetido a diferentes pontos de carregamento na 
BTP e com diferentes posições de instalação dos microparafusos.

\subsection{DEFINIÇÃO DOS PARÂMETROS PRIMÁRIOS DE OTIMIZAÇÃO (DISTALIZAÇÃO BILATERAL SIMÉTRICA)}

O modelo de teste foi usado como base para criação de mais 8 modelos, totalizando uma análise combinatória de 3 locais de instalação do MPO (2, 5 e 8 mm) Figura 19 e 3 pontos de ativação na BTP (próximo ao tubo lingual - alta, na metade do comprimento do braço da barra - média, e próximo ao ômega central baixa). As ativações estão representadas nas figuras a seguir, com o MPO instalado a $2 \mathrm{~mm}$ (Figura 20 e Figura 21), $5 \mathrm{~mm}$ (Figura 22 e Figura 23) e 8 mm (Figura 24 e Figura 25):

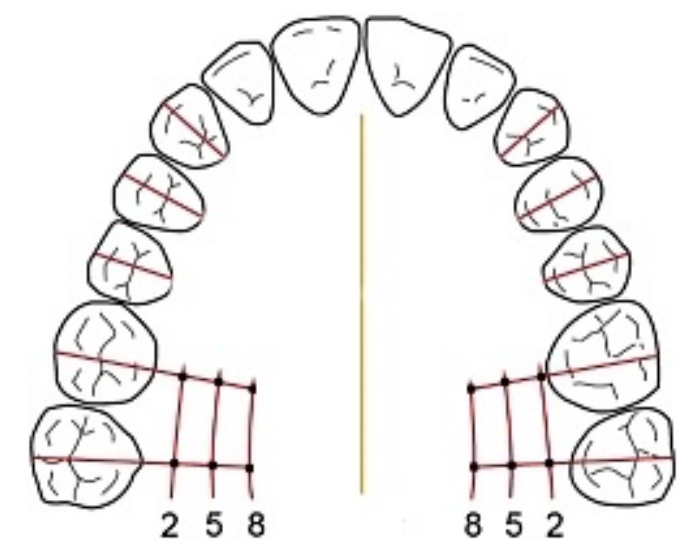

Figura 19 - Diagrama com as distâncias de instalação dos MPOs em relação à cervical do primeiro molar, no plano axial. 


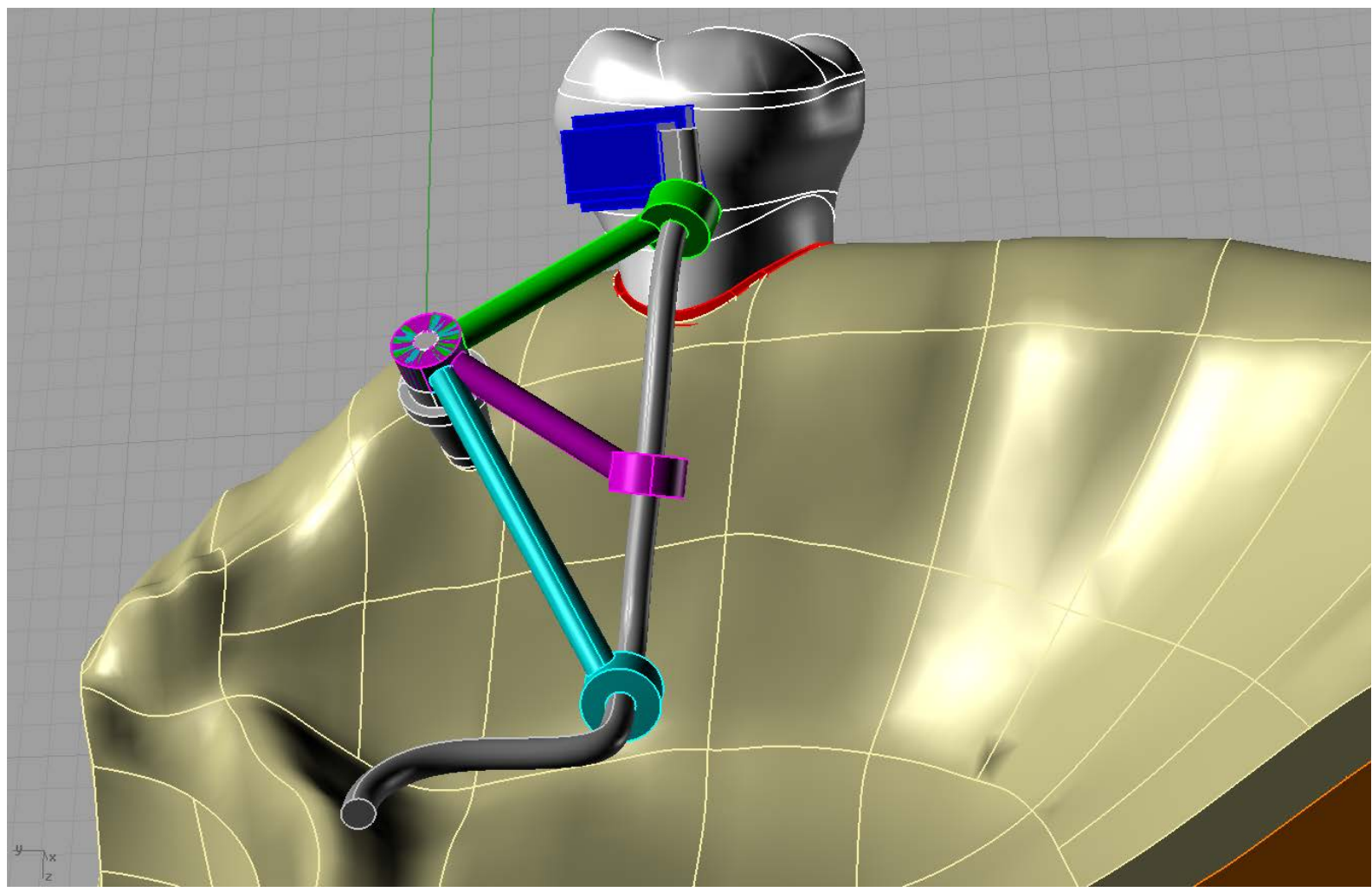

Figura 20 - Imagem do modelo com o MPO instalado a $2 \mathrm{~mm}$ e dos três pontos de ativação na BTP.

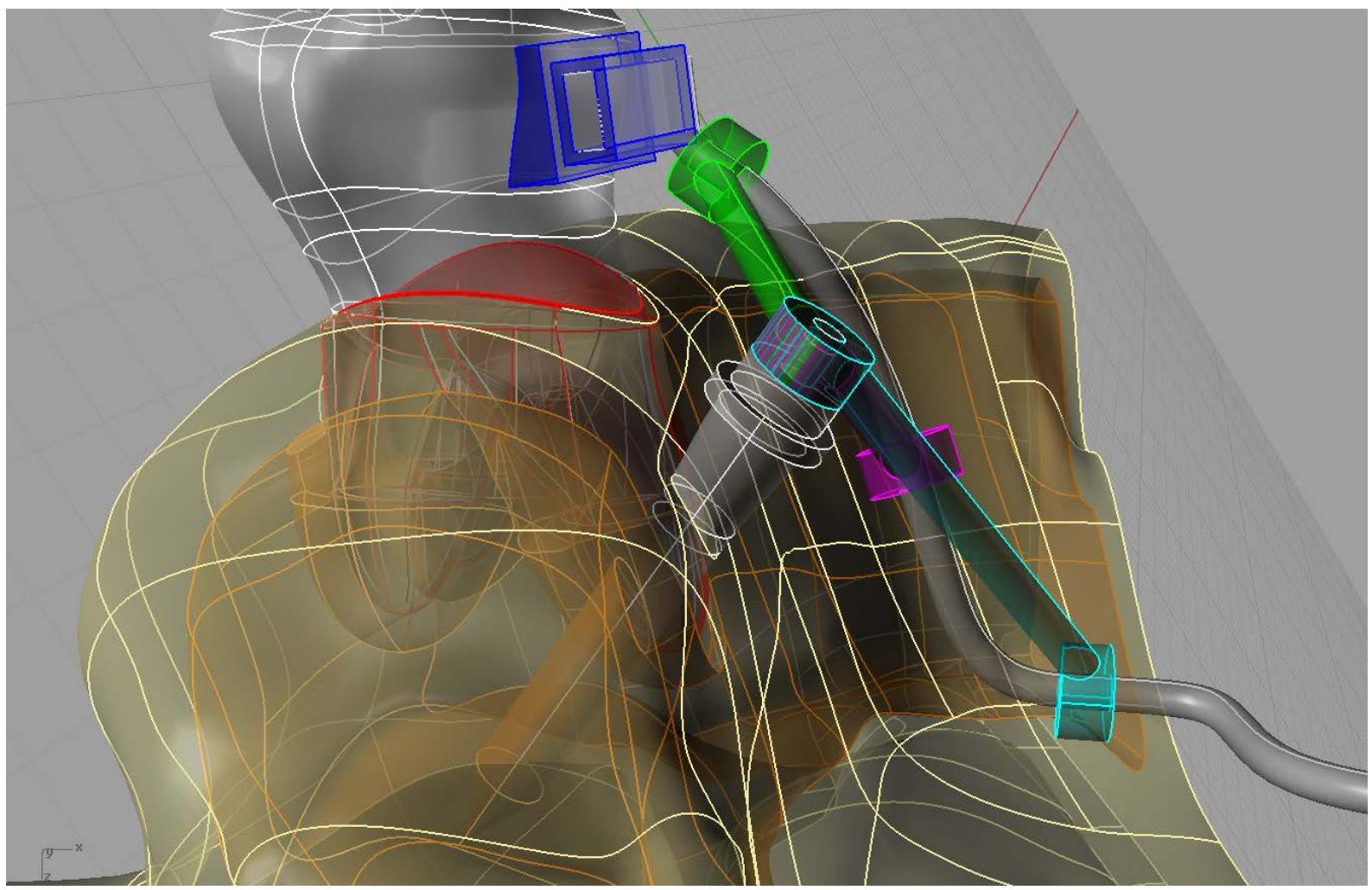

Figura 21 - Imagem do modelo com transparência e MPO instalado a $2 \mathrm{~mm}$ e dos três pontos de ativação na BTP. 


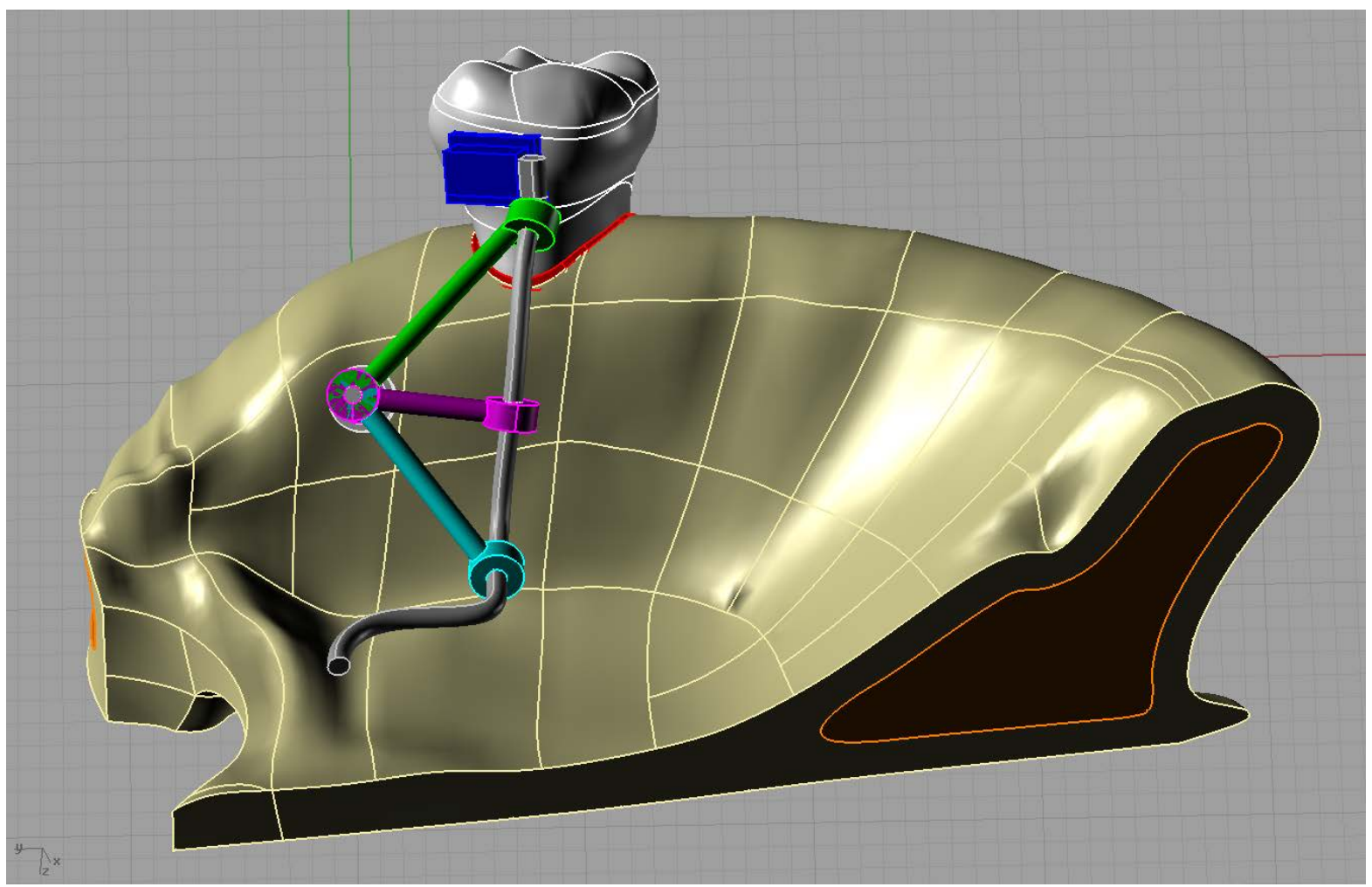

Figura 22 - Imagem do modelo com o MPO instalado a $5 \mathrm{~mm}$ e dos três pontos de ativação na BTP.

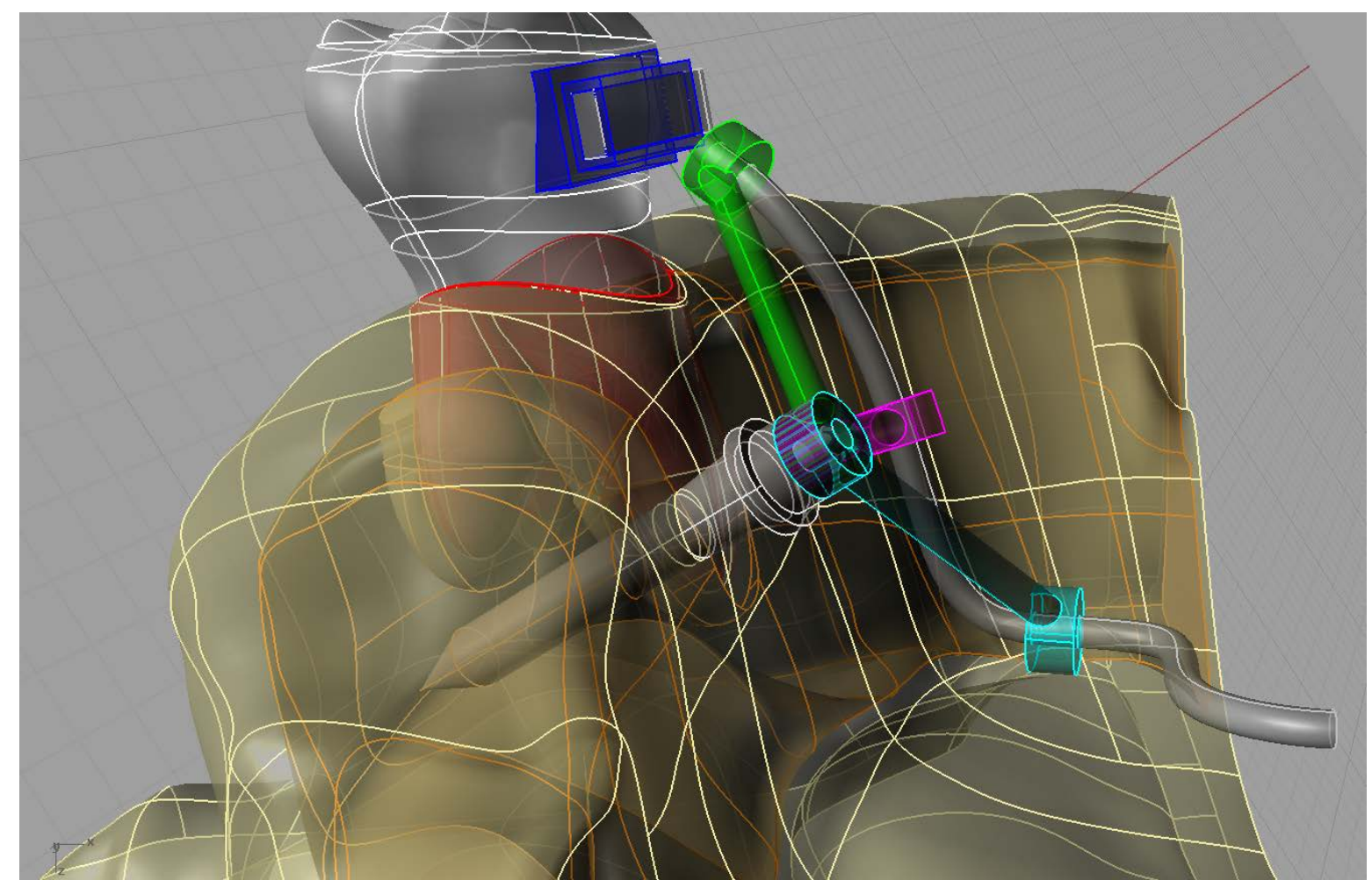

Figura 23 - Imagem do modelo com transparência e MPO instalado a $5 \mathrm{~mm}$ e dos três pontos de ativação na BTP. 


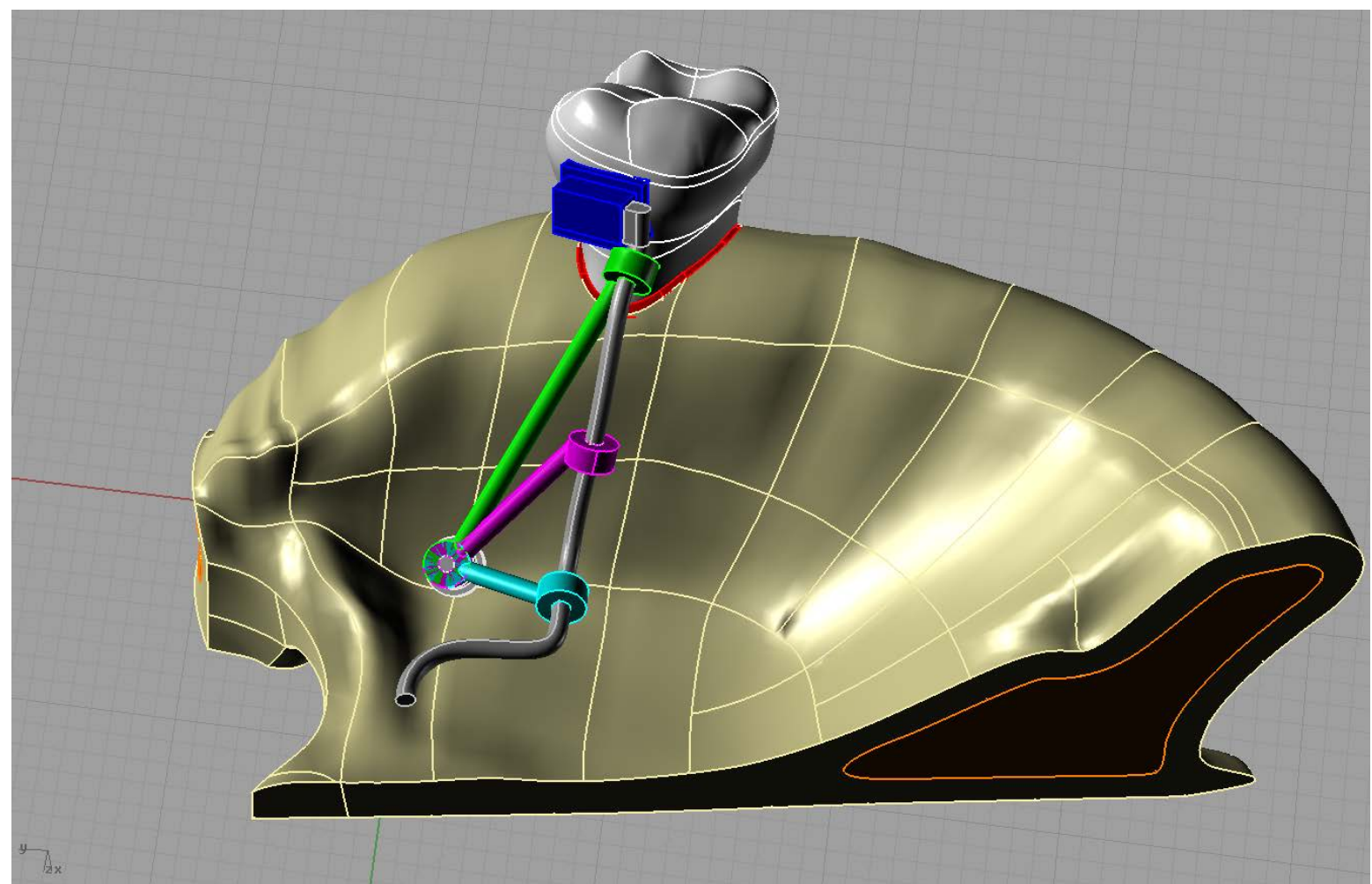

Figura 24 - Imagem do modelo com o MPO instalado a $8 \mathrm{~mm}$ e dos três pontos de ativação na BTP.

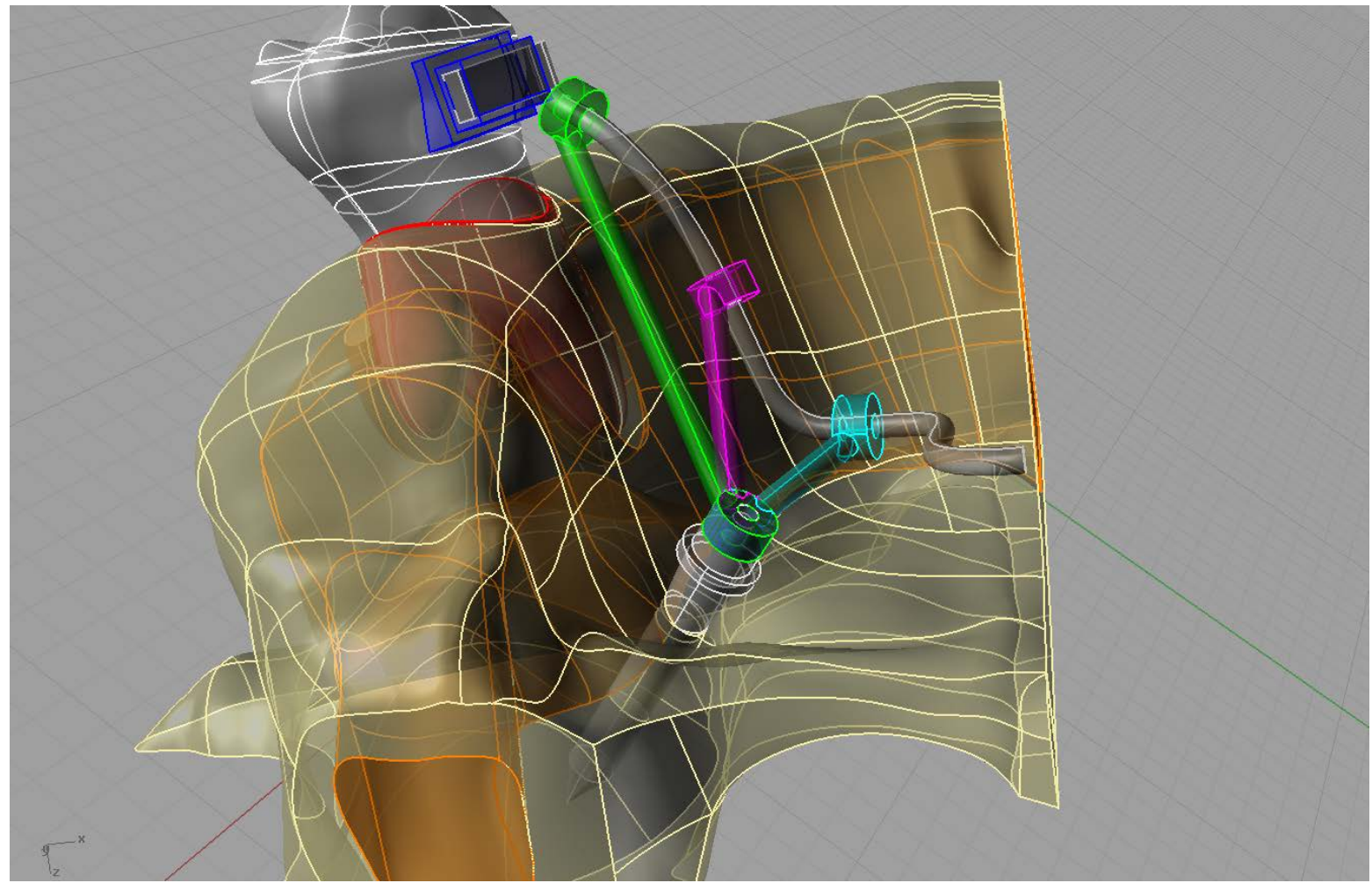

Figura 25 - Imagem do modelo com transparência e MPO instalado a $8 \mathrm{~mm}$ e dos três pontos de ativação na BTP. 


\subsection{ANÁLISE DOS NÚMEROS}

Estes 9 modelos foram submetidos a análise qualitativa e quantitativa. Inicialmente, foram medidos os deslocamentos (deformações) do ponto localizado na trifurcação (Tabela 11) e no centro da fossa principal do molar (Tabela 12), nos eixos $X$ (transversal), $Y(A-P)$ e $Z$ (vertical), com propósito de quantificar o deslocamento nos três planos do espaço, no momento após a ativação. Os cálculos foram feitos no sistemas de coordenadas alinhadas com a movimentação de intrusão (-Z) e distalização do dente (+Y). Para os efeitos da distalização do dente, foi considerada a movimentação da fossa em Y. Para a rotação do dente, foi considerada a rotação do dente no plano $\mathrm{YZ}$ e a quantidade de rotação do molar para distal (angulação) foi medida pela função inversa do seno (arcsen) em um ângulo encontrado pelos dois lados conhecidos do triângulo: (1) distância entre a trifurcação e a fossa principal $(9,147 \mathrm{~mm})$, e (2) projeção em $Y$ do deslocamento do ponto no centro da fossa principal (Tabela 13).

A representação dos resultados foi feita em forma de gráfico de bolhas para visualizar as duas respostas de acordo com a configuração da posição do elástico. A Figura 36 evidencia a intensidade do efeito de deslocamento e a Figura 37 evidencia a intensidade do efeito de rotação, na fossa do primeiro molar, considerando a posição do elástico (1) alto - cervical, (2) médio, (3) baixo - apical e distâncias do parafuso ao rebordo $(2,5$ e $8 \mathrm{~mm})$. A interação da configuração do elástico em função dos efeitos de rotação e translação na fossa são observados na Figura 38. Finalmente, a Tabela 11 apresenta os valores resultantes dos movimentos de Distalização e Intrusão na trifurcação e Rotação do molar, com as intensidades expressas didaticamente em sinais (+). Esta tabela foi dividida em duas, também com propósito didático: A Tabela 8 , que lista os arranjos em que a combinação indica distalização e intrusão e a Tabela 9, que lista os arranjos em que a combinação indica distalização e extrusão. A Figura 36 foi elaborada a partir destes números, na qual foram expressos os valores da deslocamento tanto no sentido vertical quanto horizontal e o sentido e a intensidade da rotação provocada.

\subsection{ANÁLISE DAS IMAGENS}

As ativações apresentadas têm o propósito de servir como embasamento teórico para aplicação clínica e, do ponto de vista clínico, algumas variáveis 
englobam grande parte dos problemas encontrados em relação à posição do primeiro molar permanente. Esta ativações resolveriam problemas verticais (extrusão, intrusão ou manutenção da posição enquanto há movimentação em outro plano), ântero-posteriores (distalização) e de rotação (giro da coroa para distal, mesial ou manutenção da posição enquanto há movimentação em outro plano). Dentro deste conjunto de variáveis, pode-se combinar 5 situações clínicas nas quais é necessário movimento de (1) distalização com extrusão do molar (pacientes com dimensão vertical diminuída e/ou sobremordida diminuída), (2) distalização com angulação distal de coroa (pacientes com perda precoce do segundo molar decíduo, perda do segundo pré-molar ou erupção ectópica do molar, quando o molar sofreu mésio-angulação), (3) distalização em translação (pacientes mesofaciais com sobremordida normal), (4) distalização com intrusão do molar (alguns pacientes dolicofaciais, associados ou não a dimensão vertical aumentada e/ou sobremordida diminuída e/ou molares extruídos por perda do antagonista), e (5) intrusão do molar (em pacientes com extrusão dos molares que não necessitem de distalização).

Após análise numérica da Tabela 11, foram escolhidas as ativações indicadas para cada tipo de movimento desejado, descritas em "5.2.2 Distribuição de tensões em imagens". Cada uma das cinco ativações está detalhada em 7 imagens, sendo 2 do deslocamento em $Y(A-P), 2$ do deslocamento em $Z$ (vertical), 2 do ligamento periodontal e uma da estimativa do Eixo Resistência.

O deslocamento do molar foi avaliado pela análise dos deslocamentos (em milímetros), realizada pela análise dos valores numéricos dos deslocamentos direcionais nos eixos $Y(A-P)$ e $Z$ (vertical). As tensões no ligamento periodontal foram analisadas pelo valor máximo da máxima tensão principal (maximum principal stress), representando o ponto de maior tração e pelo valor mínimo da mínima tensão principal (minimum principal stress), representando o ponto de maior compressão (também em MPa) e as soluções foram apresentadas da seguinte forma:

\section{Deslocamento}

(Imagem 1) Em vista lingual, foram identificados os pontos de maior e menor deslocamento do dente, representados em uma escala com apenas 3 cores, sendo 2 significativas, o azul e o vermelho. A cor intermediária (verde) representa uma 
faixa numérica estreita de $+10^{-6}$ a $-10^{-6} \mathrm{~mm}$, propositalmente para evidenciar em vermelho praticamente todos os valores positivos e em azul, os valores negativos, em outras palavras, no eixo $\mathrm{Y}(\mathrm{A}-\mathrm{P})$ o vermelho representa o que tende a se deslocar para distal (positivo) e em azul o que tende a deslocar para mesial (negativo). (Imagem 2) A mesma imagem foi apresentada em outra escala, com cores intermediárias entre o azul escuro e o vermelho, compatíveis com a intensidade do deslocamento de cada ponto.

Em perspectiva, foram analisadas dos deslocamentos no eixo Z (vertical), (Imagem 3) em 3 cores, onde o que está em vermelho tende a extruir e o que está em azul tende a intruir. (Imagem 4) A mesma imagem foi apresentada também na escala com cores intermediárias.

Distribuição de tensões no ligamento periodontal (Tensões máxima e mínima principal)

As tensões (Imagem 5) de tração (máxima principal) e (Imagem 6) de compressão (mínima principal) foram avaliadas no ligamento periodontal, em vista oclusal (em MPa), também representadas em uma escala colorida.

\section{Rotação e Centro de Resistência}

(Imagem 7) O deslocamento total foi avaliado pela ferramenta isosurface, para evidenciar o eixo de rotação do movimento e o deslocamento tridimensional em camadas. O centro dos círculos representa teoricamente eixo do Centro de Rotação do molar, após cada ativação.

\section{Distribuição de tensões na superfície do alvéolo (Vetores da tensão principal)}

$\mathrm{Na}$ ativação $8 \mathrm{~mm}$ baixa (o de maior componente intrusivo) também foram avaliadas as tensões na superfície da parede alveolar, pelos (8) Vetores da tensão principal (somente para a ativação $8 \mathrm{~mm}$ baixo, para exemplificação da distribuição das tensões de tração e compressão no osso alveolar, quando ocorre efeito intrusivo). 


\section{RESULTADOS}

\subsection{RESULTADOS NO MODELO DE TESTE PRELIMINAR}

A Tensão Máxima Principal foi aplicada para analisar as tensões no MPO (Figura 26 e Figura 27), osso adjacente ao MPO (Figura 28) e ligamento periodontal (Figura 29 e Figura 30). A tensão von Mises foi aplicada para analisar as tensões na barra transpalatina (BTP) (Figura 31) e no osso cortical adjacente ao MPO (Figura 32). O deslocamento foi avaliado nos eixos $X$ (horizontal transversal) (Figura 33), $Y$ (horizontal anteroposterior) (Figura 34) e Z (vertical) (Figura 35).

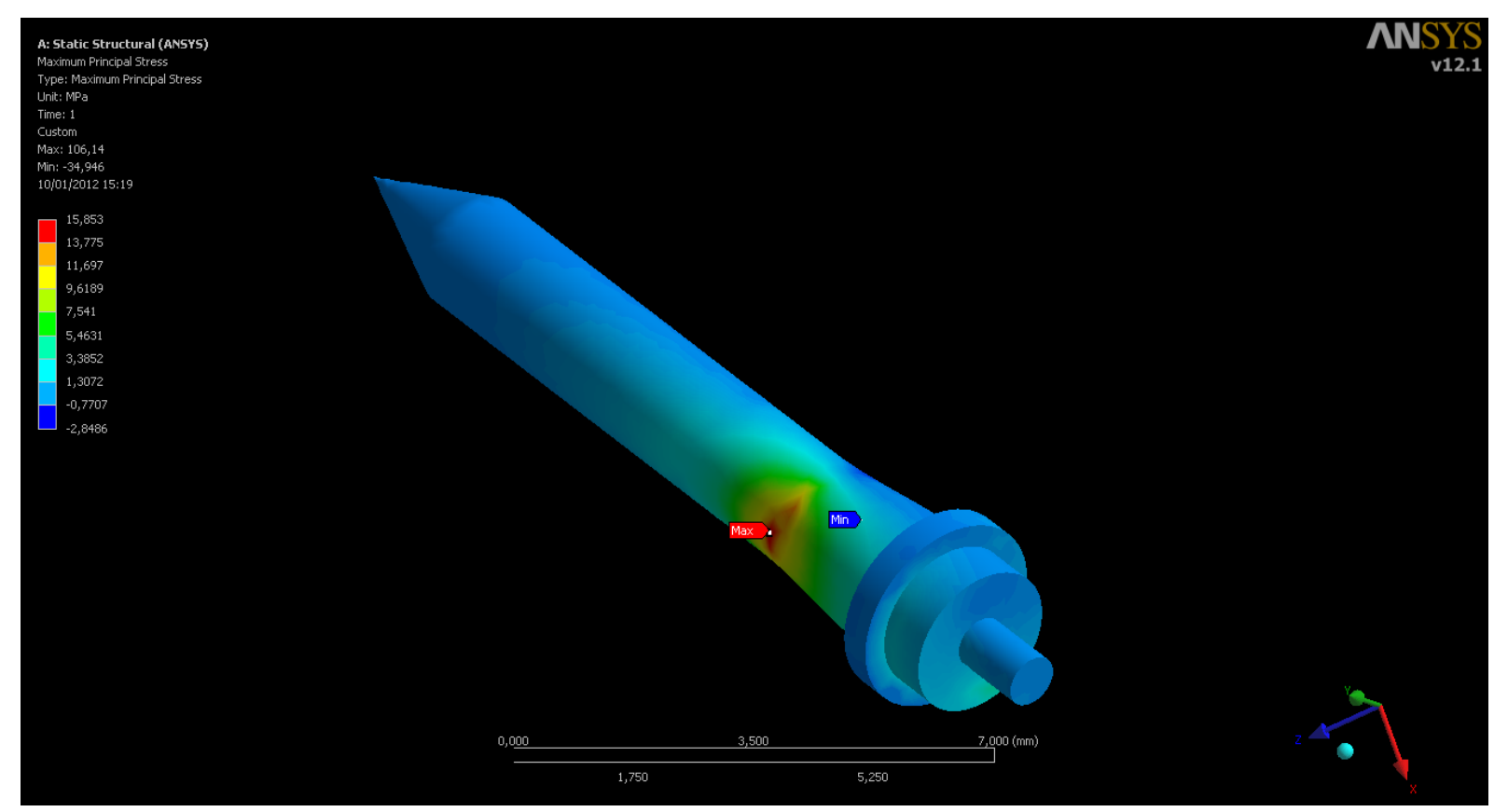

Figura 26 - Tensão Máxima Principal no MPO, indicando o ponto de maior tração. 


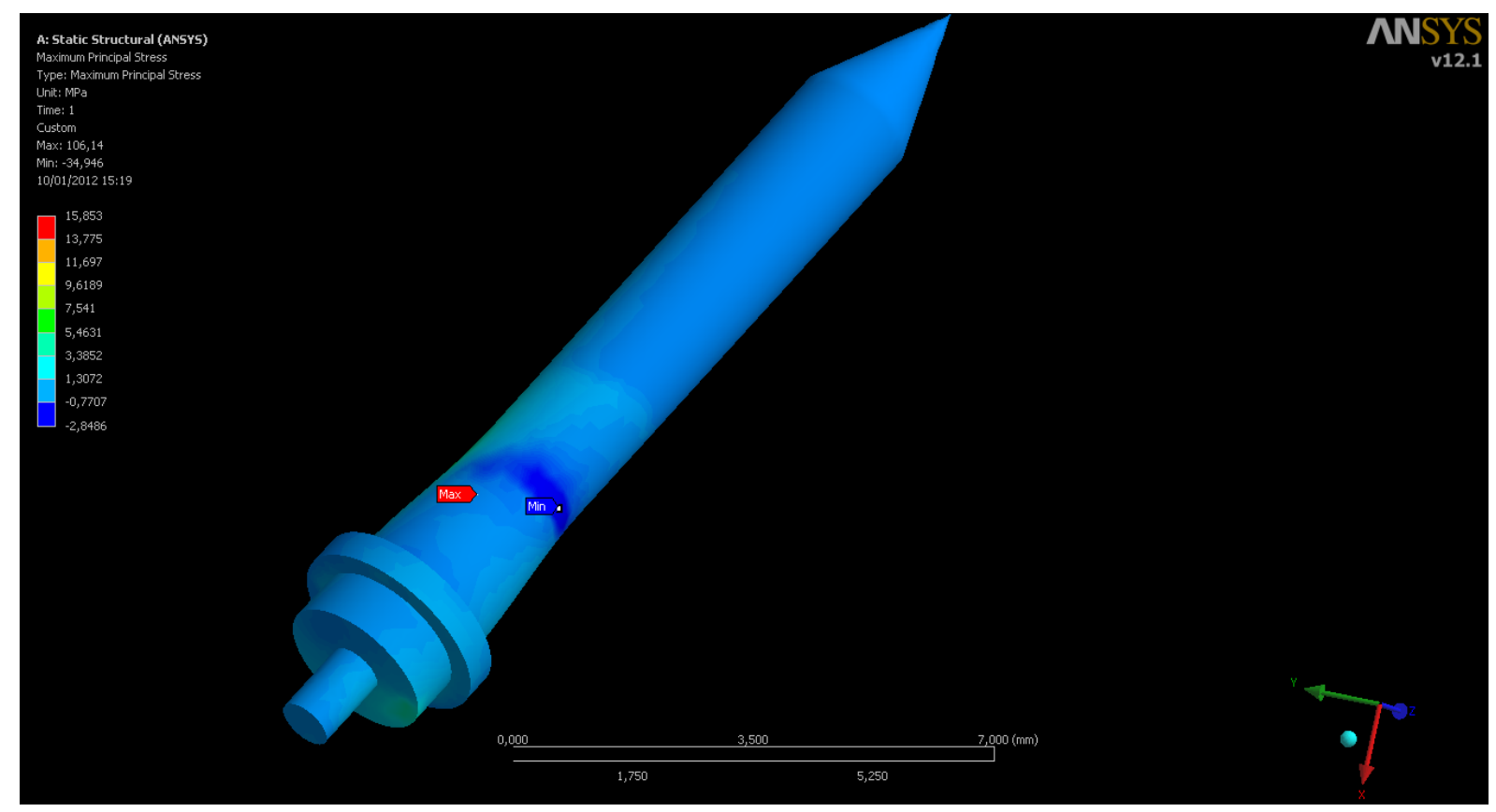

Figura 27 - Tensão Mínima Principal no MPO, indicando o ponto de maior compressão.

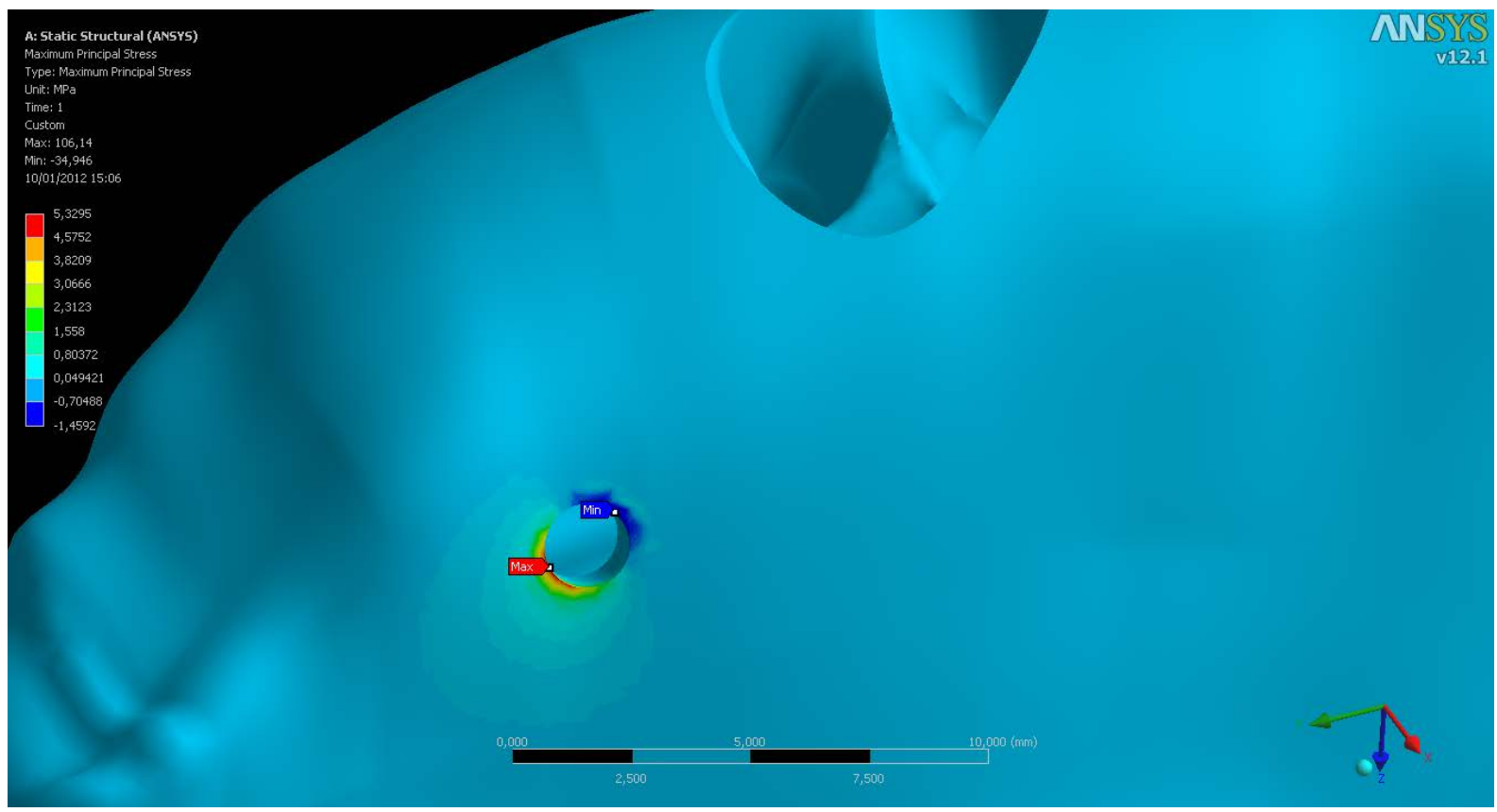

Figura 28 - Tensão Máxima e Mínima Principais no osso adjacente ao MPO 


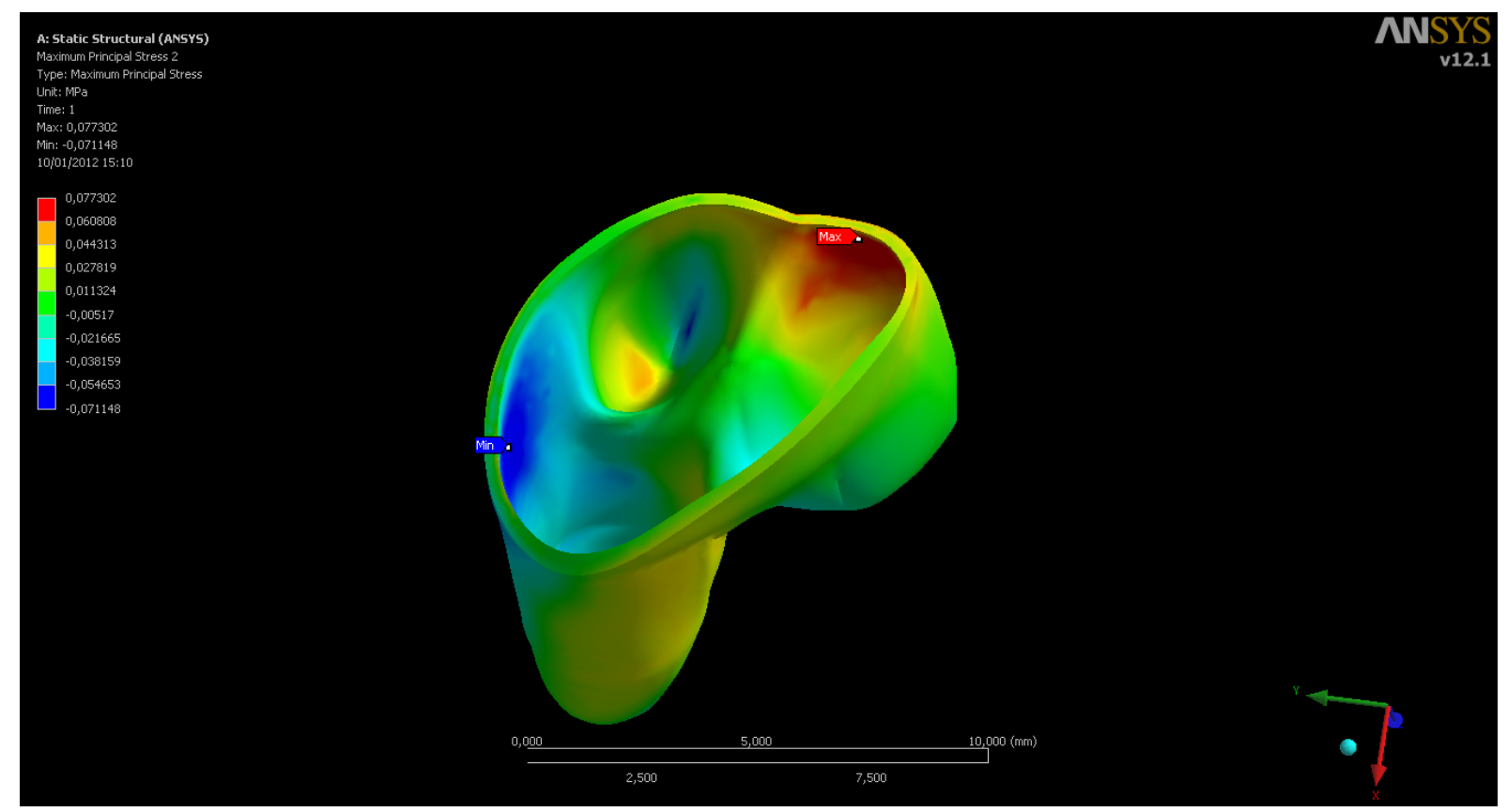

Figura 29 - Tensão Máxima e Mínima Principais no ligamento periodontal.

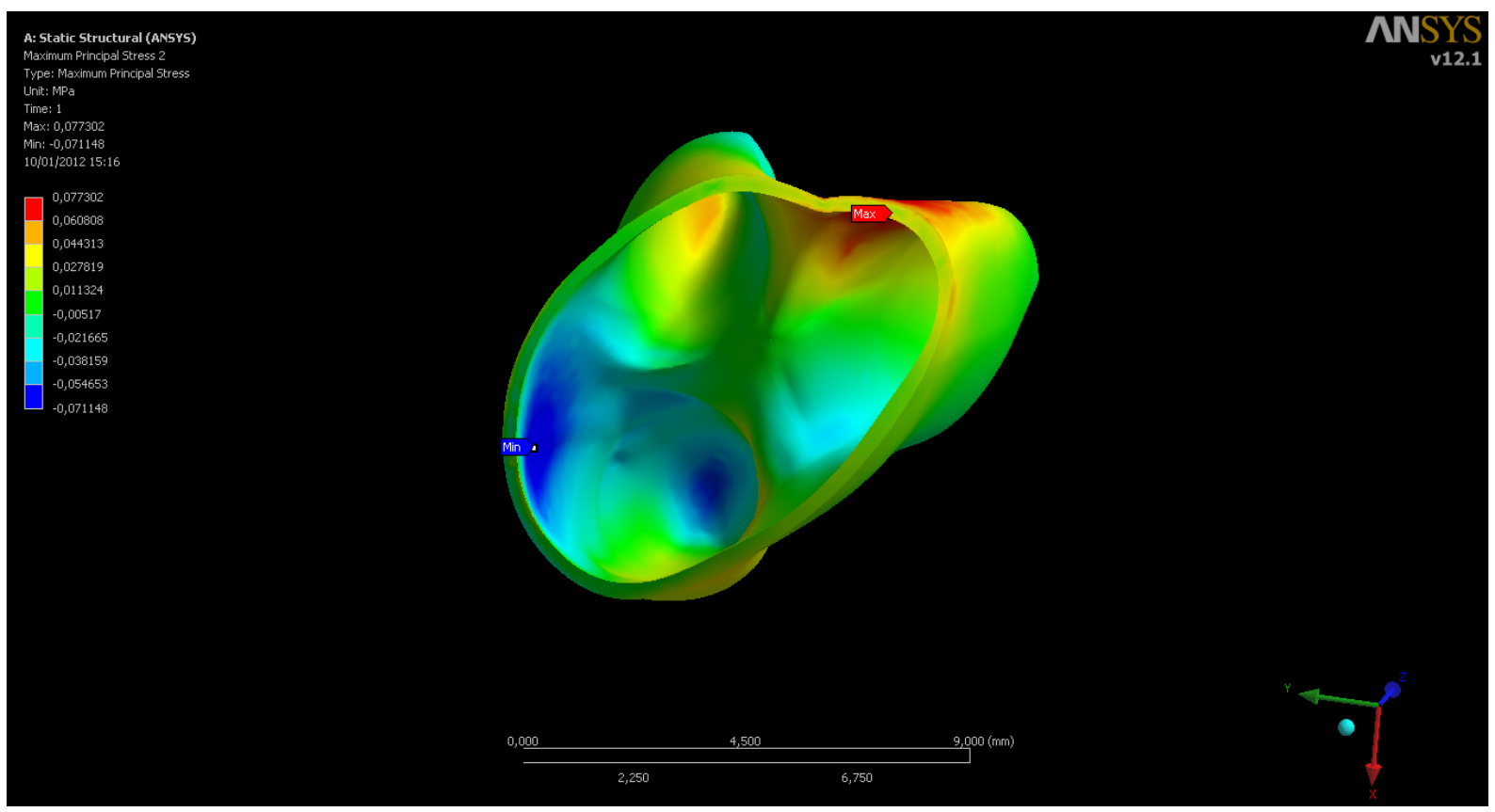

Figura 30 - Tensão Máxima e Mínima Principais no ligamento periodontal. 


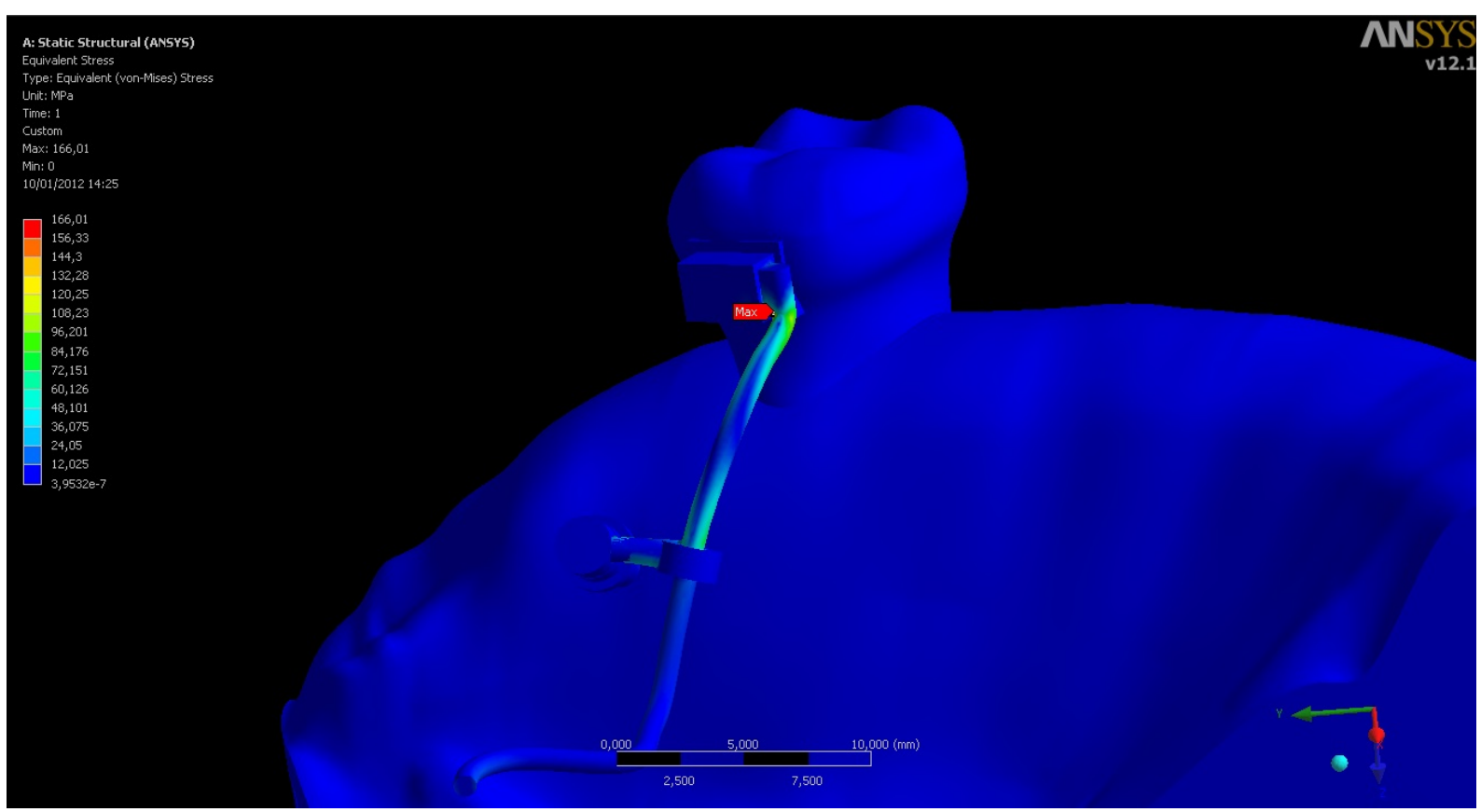

Figura 31 - Tensões de von Mises na BTP.

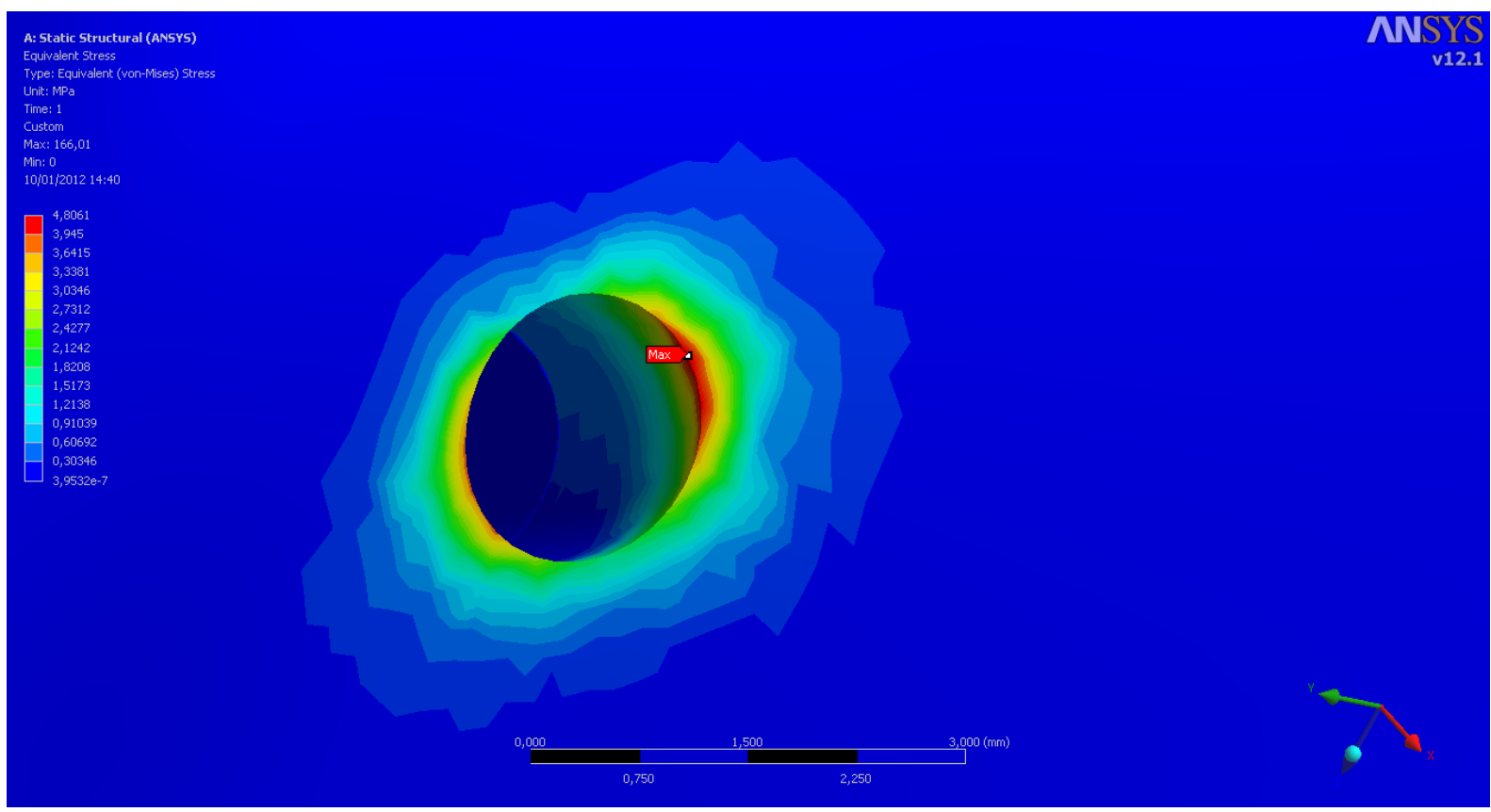

Figura 32 - Tensões de von Mises no osso adjacente ao MPO. 


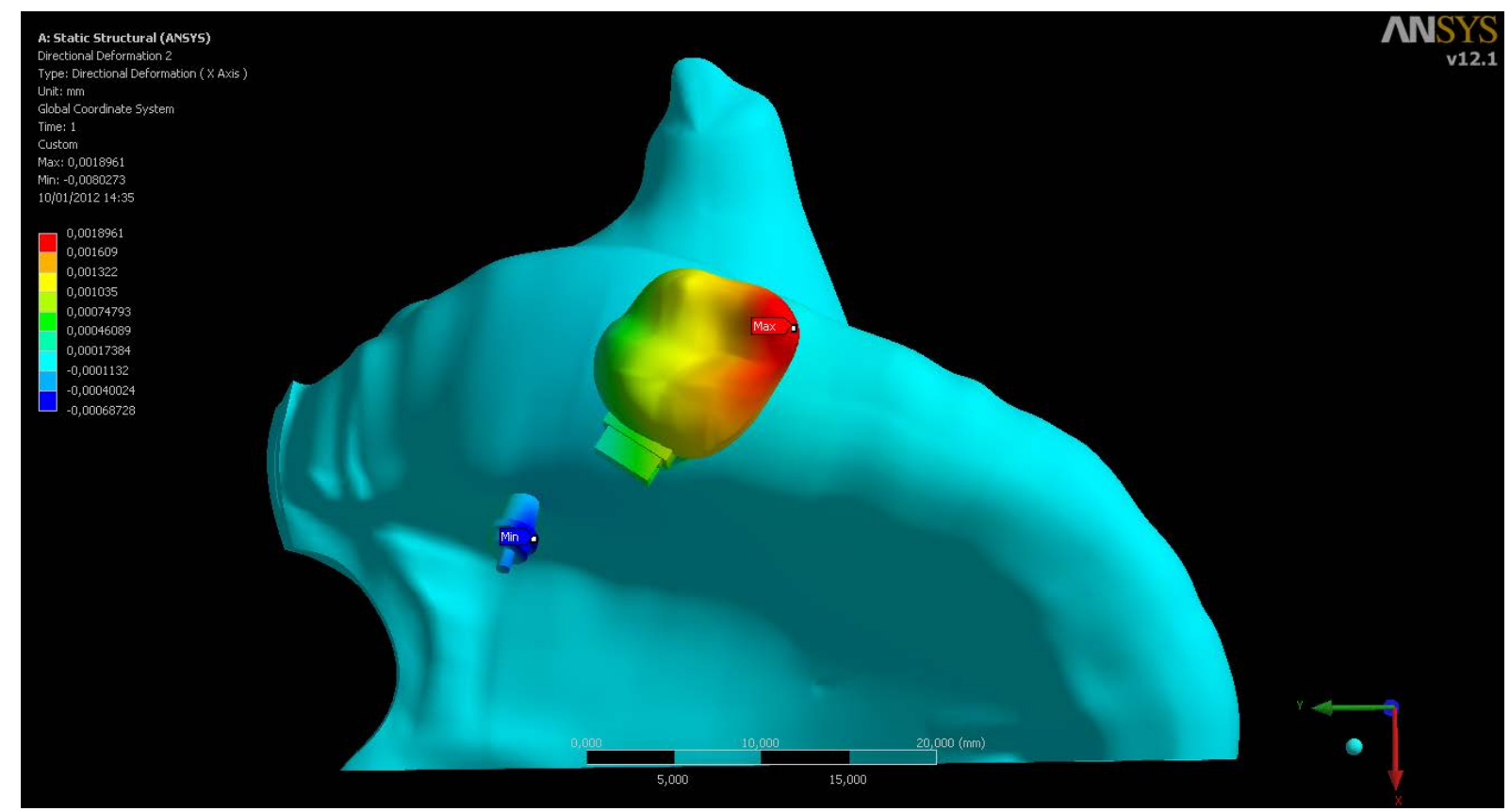

Figura 33 - Deslocamento máximo e mínimo, no eixo X (horizontal transversal).

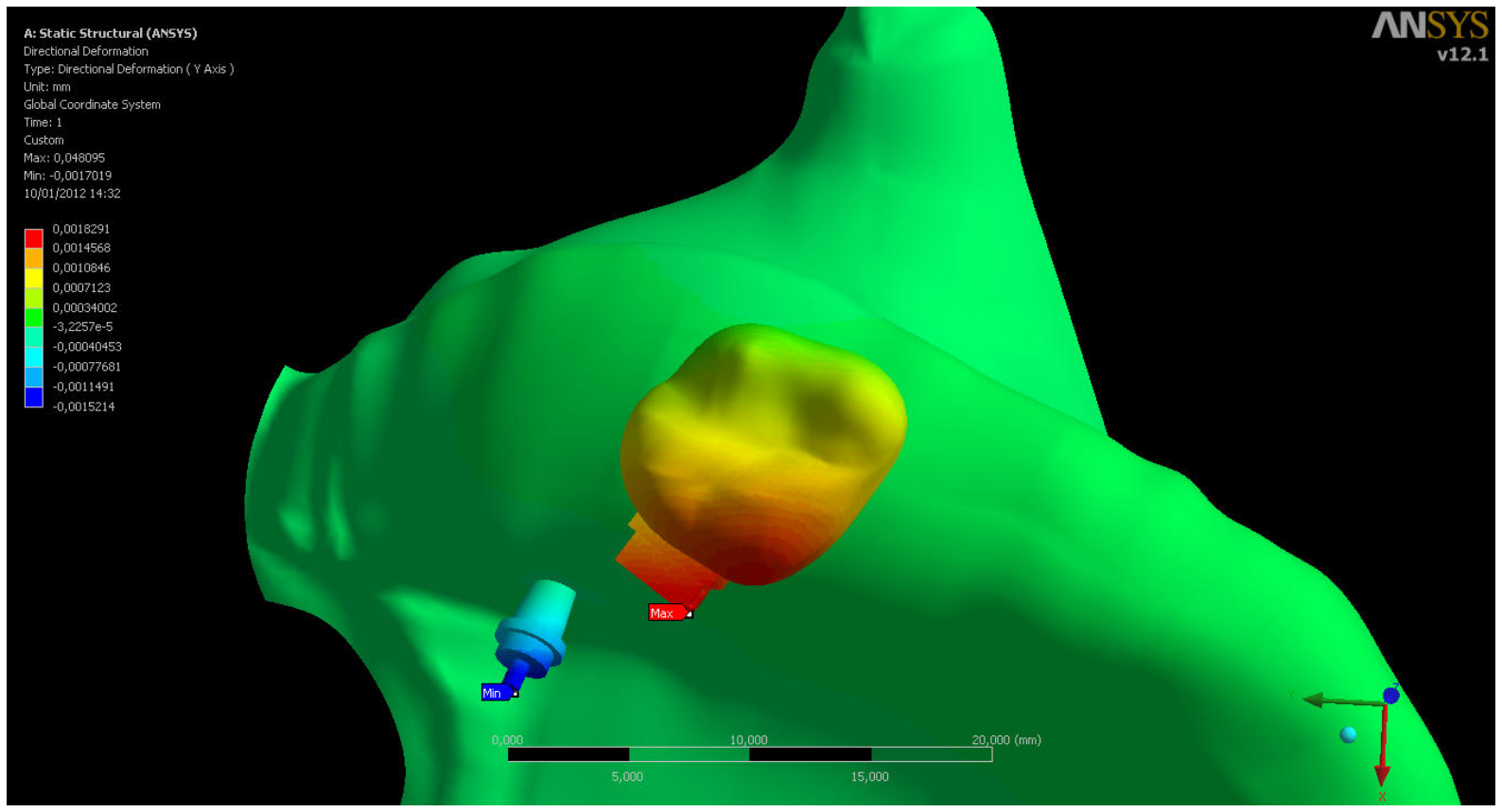

Figura 34 - Deslocamento máximo e mínimo, no eixo Y (horizontal A-P). 


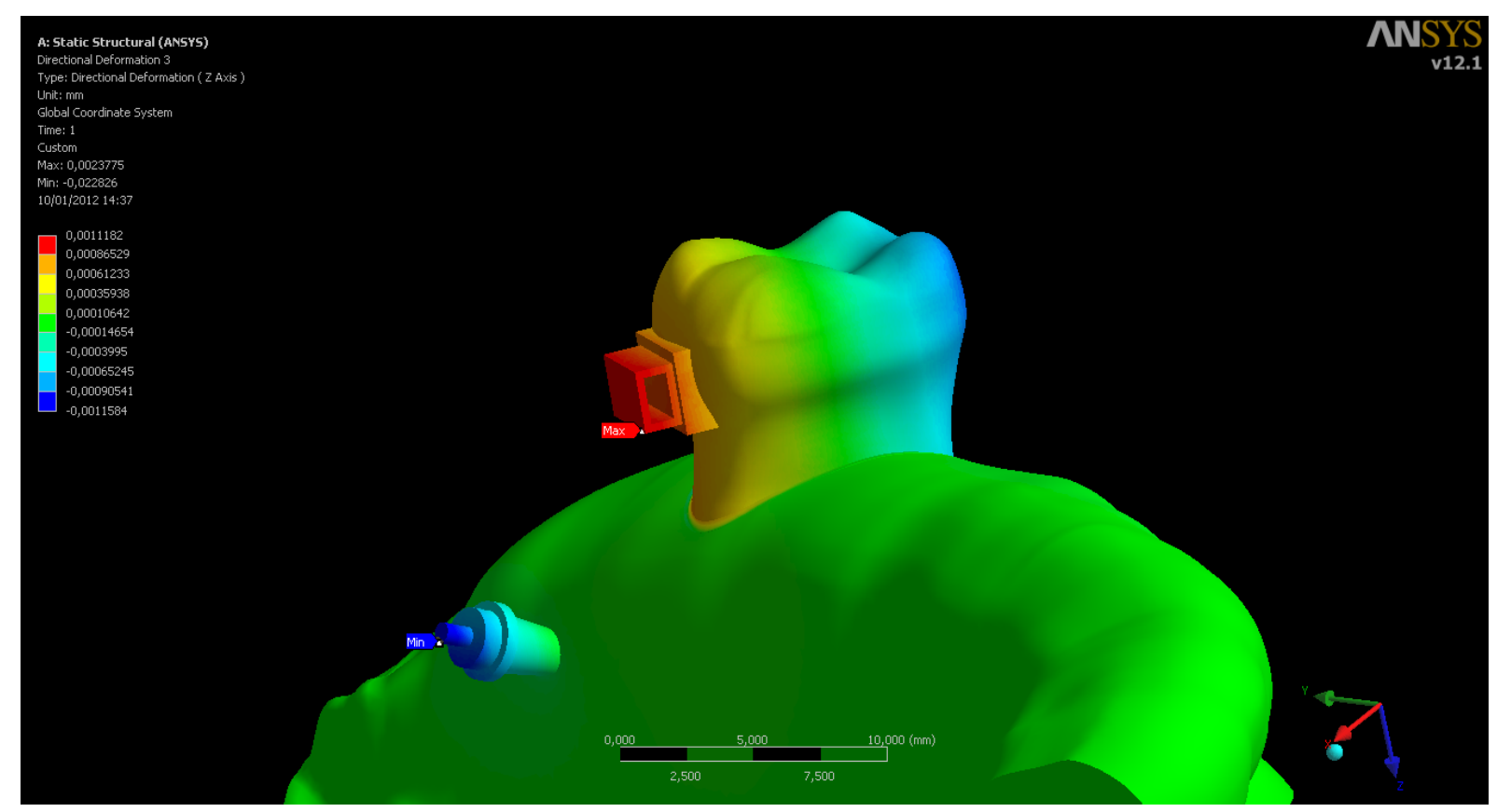

Figura 35 - Deslocamento máximo e mínimo, no eixo Z (vertical).

\subsection{RESULTADOS NO MODELO DEFINITIVO}

\subsubsection{Análise quantitativa da distribuição das tensões (números)}

$\mathrm{Na}$ análise qualitativa e quantitativa dos 9 modelos (convencionado em Materiais e Métodos), valores positivos para $X$ representam deslocamento para lateral (expansão); para Y, deslocamento para distal (distalização); para Z, deslocamento para incisal (extrusão). Valores negativos para $X$ representam deslocamento para medial (contração); para $\mathrm{Y}$, deslocamento para mesial (mesialização); para Z, deslocamento para cervical (intrusão). A Tabela 8 contém os números do deslocamento da trifurcação do molar e a Tabela 09 do centro da fossa principal, nos eixos $X$ (transversal), $Y(A-P)$ e $Z$ (vertical), no momento após a ativação. A Tabela 8 contém as medidas da projeção do centro da fossa principal em Y, em milímetros e da rotação, em graus. 
Tabela 08 - Medidas do deslocamento direcional do ponto na trifurcação do molar, nos eixos $X$ (transversal), Y (A-P) e $Z$ (vertical), em $10^{-3} \mathrm{~mm}$. $O$ * indica os maiores valores de cada categoria.

\begin{tabular}{|c|c|c|c|c|}
\hline $\begin{array}{c}\text { Posição do } \\
\text { MPO e ativação }\end{array}$ & Transversal & $\begin{array}{c}\text { trifurcação } Y \\
\text { A-P }\end{array}$ & $\begin{array}{c}\text { trifurcação } \\
\text { Z } \\
\text { Vertical }\end{array}$ & $\begin{array}{l}\text { Deslocamento } \\
\text { para }\end{array}$ \\
\hline $2 \mathrm{~mm}$ cervical & $-0,278$ & 0,172 & $-0,018$ & medial - distal - cervical \\
\hline 2 mm médio & $-0,256$ & $0,173^{*}$ & 0,004 & medial - distal ${ }^{\star}$ - incisal \\
\hline $2 \mathrm{~mm}$ apical & 0,307 & $-0,069$ & 0,068 & lateral - mesial - incisal \\
\hline $5 \mathrm{~mm}$ cervical & 0,340 & 0,156 & $-0,043$ & lateral - distal - cervical \\
\hline 5 mm médio & $-0,370$ & 0,130 & $-0,048$ & medial - distal - cervical \\
\hline 5 mm apical & 0,293 & $-0,065$ & 0,066 & lateral - mesial - incisal \\
\hline $8 \mathrm{~mm}$ cervical & $-0,348$ & 0,109 & $-0,106$ & medial - distal - cervical \\
\hline 8 mm médio & $-0,397$ & 0,089 & $-0,102$ & medial - distal - cervical \\
\hline $8 \mathrm{~mm}$ apical & $-0,574$ & 0,040 & $-0,210^{*}$ & medial - distal - cervical* \\
\hline
\end{tabular}

Tabela 09 - Medidas do deslocamento direcional do centro da fossa principal do molar, nos eixos $X$ (transversal), $Y(A-P)$ e $Z$ (vertical), em $10^{-3} \mathrm{~mm}$. $O$ * indica os maiores valores de cada categoria.

\begin{tabular}{lcccc}
$\begin{array}{c}\text { Posição do } \\
\text { MPO e } \\
\text { ativação }\end{array}$ & $\begin{array}{c}\text { fossa } X \\
\text { Transversal }\end{array}$ & $\begin{array}{c}\text { fossa } Y \\
\text { A-P }\end{array}$ & $\begin{array}{c}\text { fossa Z } \\
\text { Vertical }\end{array}$ & $\begin{array}{c}\text { Deslocamento } \\
\text { para }\end{array}$ \\
\hline 2 mm cervical & $-1,14$ & $0,914^{*}$ & $-0,018$ & medial - distal - cervical \\
2 mm médio & $-1,01$ & 0,818 & $-0,0001$ & medial - distal - incisal \\
2 mm apical & 1,57 & $-0,288$ & 0,061 & lateral - mesial - incisal \\
5 mm cervical & $-1,46$ & 0,780 & $-0,042$ & medial - distal - cervical \\
5 mm médio & $-1,56$ & 0,534 & $-0,052$ & medial - distal - cervical \\
5 mm apical & 1,48 & $-0,248$ & 0,006 & lateral - mesial - incisal \\
8 mm cervical & $-1,59$ & 0,482 & $-0,103$ & medial - distal - cervical \\
8 mm médio & $-1,89$ & 0,308 & $-0,098$ & medial - distal - cervical \\
8 mm apical & $-2,75$ & 0,894 & $-0,206^{*}$ & medial - distal - cervical \\
\hline
\end{tabular}


Tabela 10 - Medidas da projeção do centro da fossa principal em $\mathrm{Y}$, em milímetros e da rotação, em graus. Valores positivos indicam rotação distal. $O$ * indica os maiores valores de cada categoria (rotação distal ou mesial).

\begin{tabular}{lcc}
$\begin{array}{c}\text { Posição do MPO e } \\
\text { ativação }\end{array}$ & $\begin{array}{c}\text { Projeção } \\
\text { em } \mathrm{Y}\end{array}$ & $\begin{array}{c}\text { Rotação eixo } \\
\text { Fossa- } \\
\text { trifurcação }\end{array}$ \\
\hline $2 \mathrm{~mm}$ cervical & $9,14 \mathrm{E}-04$ & $2,33 \mathrm{E}-03$ \\
$2 \mathrm{~mm}$ médio & $8,18 \mathrm{E}-04$ & $2,02 \mathrm{E}-03$ \\
$2 \mathrm{~mm}$ apical & $-2,88 \mathrm{E}-04$ & $-6,88 \mathrm{E}-04^{*}$ \\
$5 \mathrm{~mm}$ cervical & $7,80 \mathrm{E}-04$ & $1,95 \mathrm{E}-03$ \\
$5 \mathrm{~mm}$ médio & $5,34 \mathrm{E}-04$ & $1,26 \mathrm{E}-03$ \\
$5 \mathrm{~mm}$ apical & $-2,48 \mathrm{E}-04$ & $-5,73 \mathrm{E}-04$ \\
$8 \mathrm{~mm}$ cervical & $4,82 \mathrm{E}-04$ & $1,17 \mathrm{E}-03$ \\
$8 \mathrm{~mm}$ médio & $3,08 \mathrm{E}-04$ & $6,90 \mathrm{E}-04$ \\
$8 \mathrm{~mm}$ apical & $8,94 \mathrm{E}-04$ & $2,67 \mathrm{E}-03^{*}$ \\
\hline
\end{tabular}

A Figura 36 evidenciou a intensidade do efeito de deslocamento e a Figura 37 evidenciou a intensidade do efeito de rotação, na fossa do primeiro molar, no instante imediatamente após a aplicação da força,considerando a posição do elástico (1) apical, (2) médio, (3) cervical e distâncias do parafuso ao rebordo (2, 5 e $8 \mathrm{~mm}$ ). A Figura 38 mostra a interação da configuração do elástico em função dos efeitos de rotação e translação na fossa. O tamanho do círculo indica a posição do elástico: Círculo grande, posição cervical; círculo médio, posição média; círculo pequeno, posição apical. Finalmente, a Tabela 11 apresenta os valores resultantes, com as intensidades expressas em sinais $(+)$, dos movimentos de Distalização e Intrusão na trifurcação e Rotação do molar e a Figura 36 foi elaborada a partir destes números. A forma que a Figura 40 mostra estes valores nos permite inferir que algumas ativações produzem resultados semelhantes. Ao observarmos a intensidade do deslocamento da furca no sentido horizontal (azul) e vertical (vermelho), em milímetros, é possível observar que a ativação "2 mm cervical" e "2 mm médio" são muito semelhantes, assim como as ativações "2 mm apical" e "5 mm apical", as ativações "5 mm apical" e "5 mm médio" e as ativações "8 mm cervical" e "8 mm médio". 


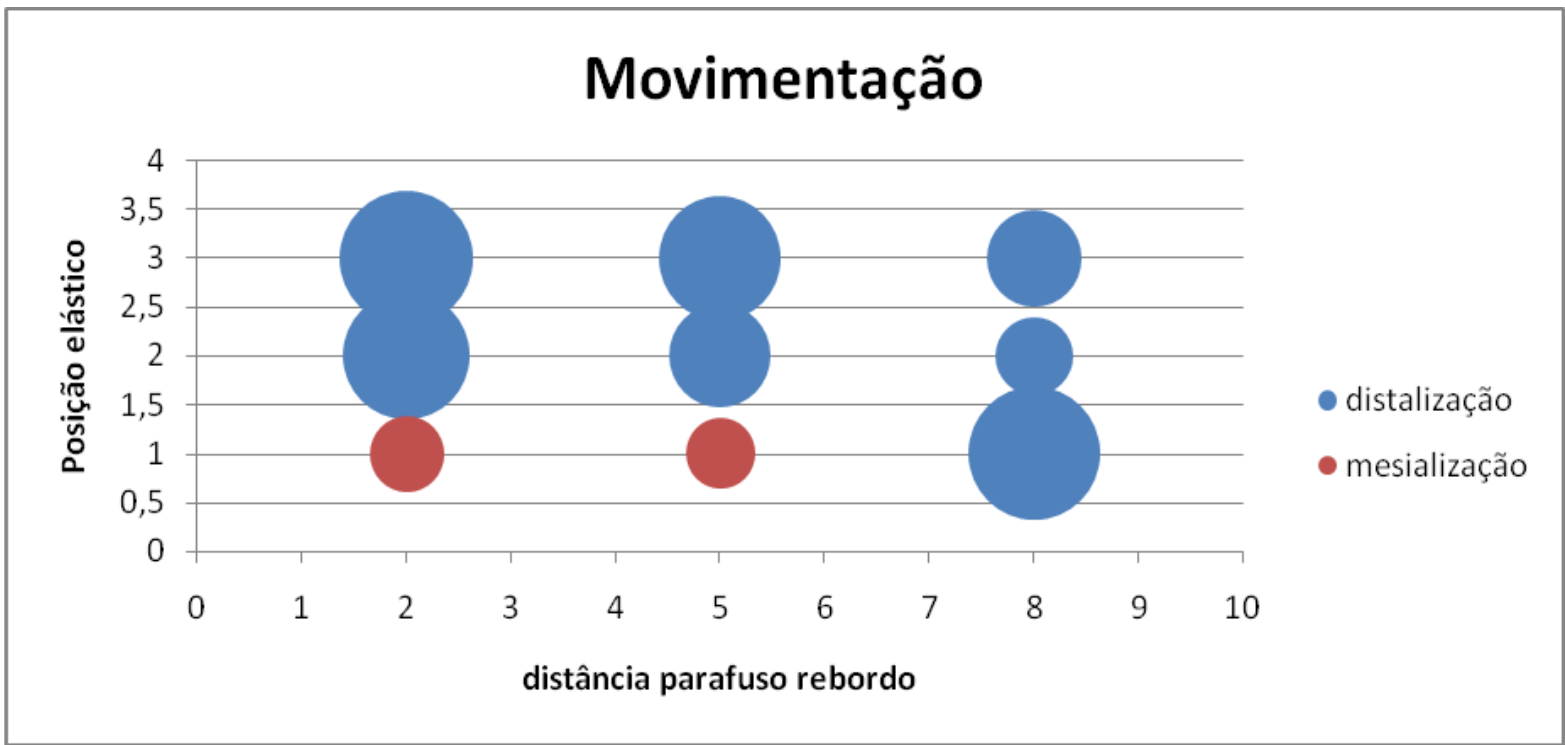

Figura 36 - Posição do elástico (1) cervical, (2) médio, (3) apical. Distâncias do parafuso ao rebordo $(2,5$ e $8 \mathrm{~mm})$. O tamanho do círculo indica a intensidade do deslocamento (movimentação) na fossa principal do molar.

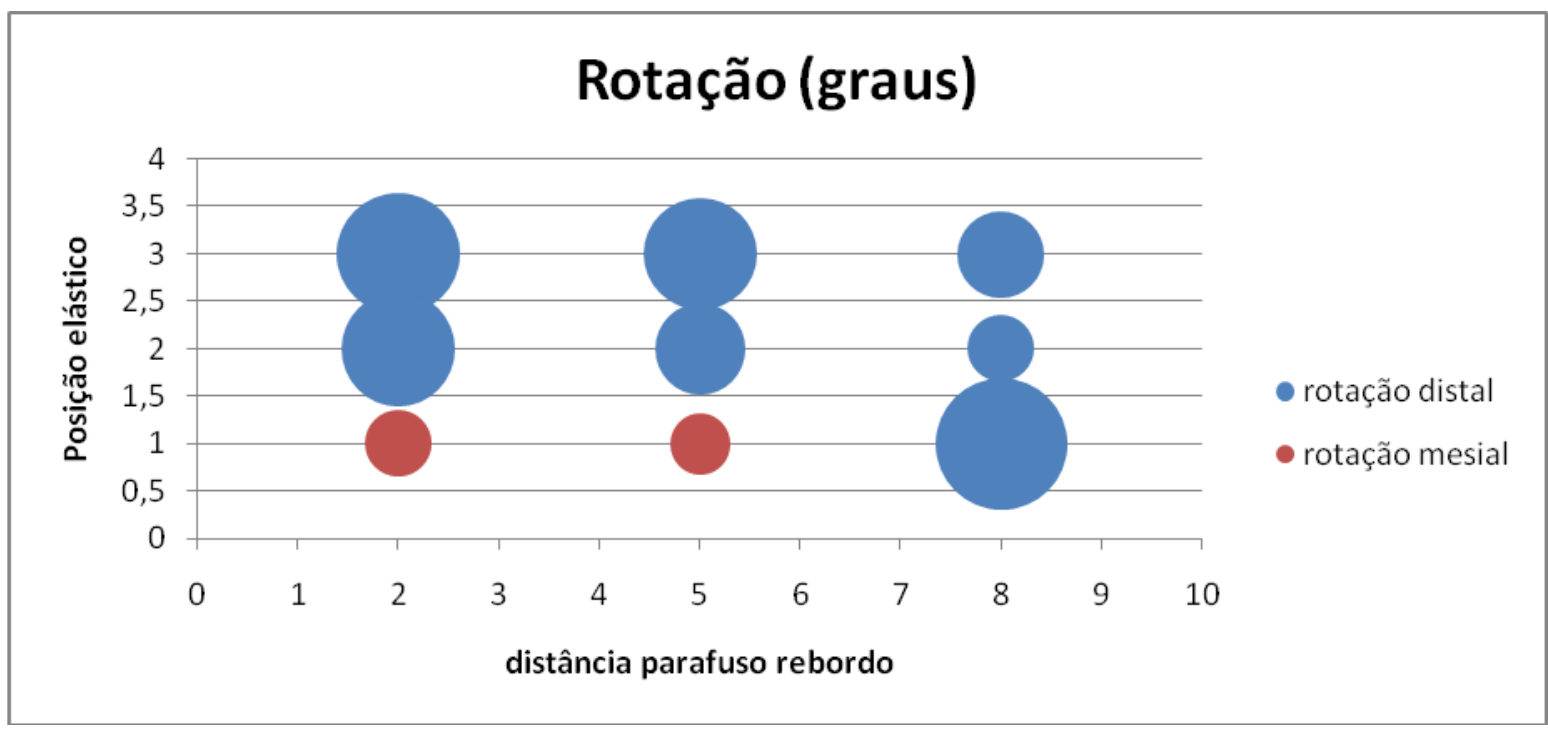

Figura 37 - Posição do elástico (1) cervical, (2) médio, (3) apical. Distâncias do parafuso ao rebordo (2, 5 e $8 \mathrm{~mm}$ ). O tamanho do círculo indica a intensidade da rotação na fossa do primeiro molar. 


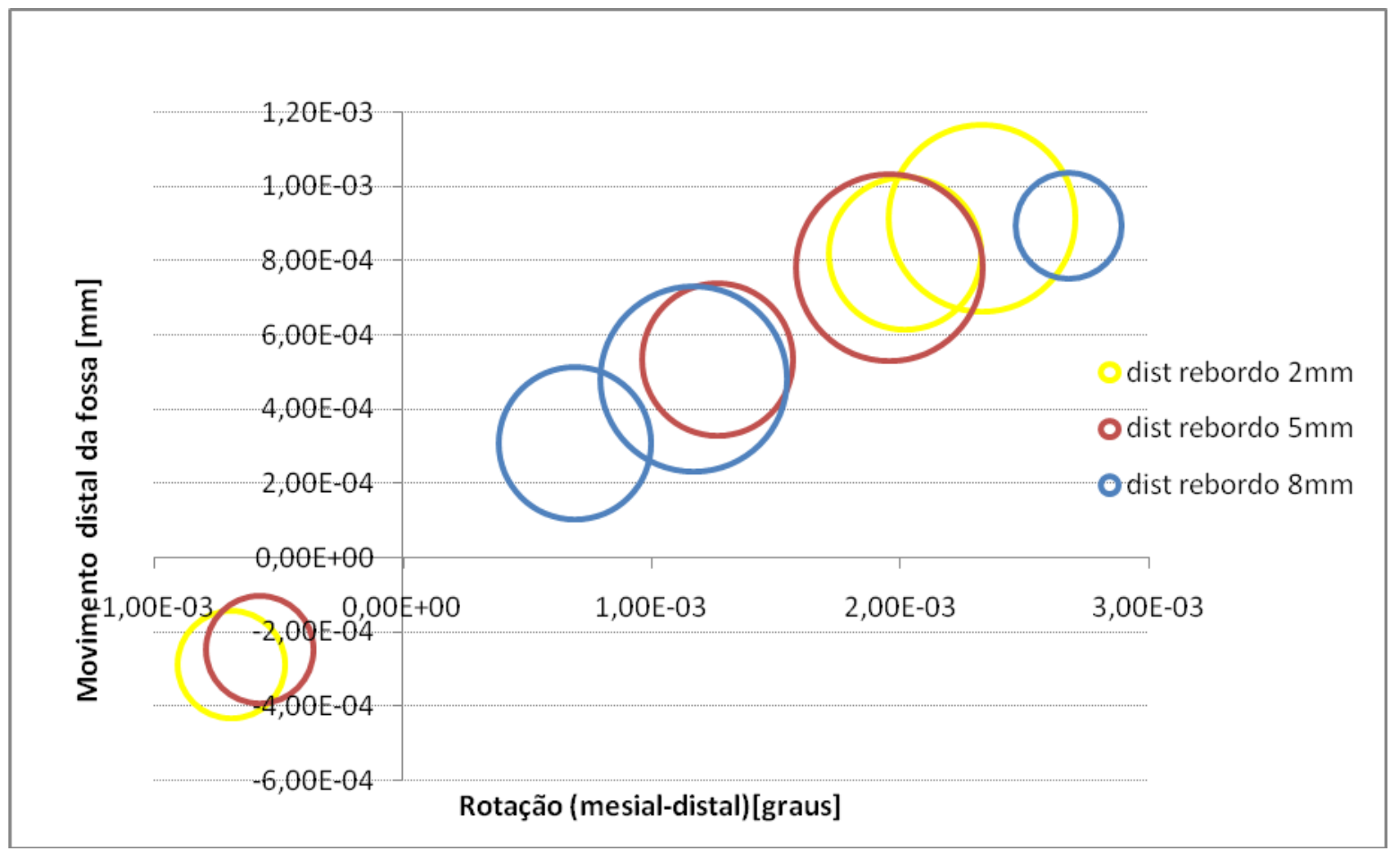

Figura 38 - Configuração do elástico em função dos efeitos de rotação e translação na fossa. O tamanho do círculo indica a posição do elástico. Círculo grande, posição cervical; círculo médio, posição média; círculo pequeno, posição apical. Foi observada semelhança nos gráficos, pois na medida em que a força exercida provoca distalização, ocorre também rotação distal, enquanto que quando o centro da furca se desloca inicialmente para mesial, ocorre também rotação mesial (quando o elástico é instalado próximo ao ômega da BTP, na posição baixa, a 2 e $5 \mathrm{~mm}$ da cervical do molar). 
Tabela 11 - Resultantes dos movimentos de distalização (+ de 0 a 0,6E-04 mm, ++ de 0,6 a 1,2E-04 mm e +++ de 1,2 a 1,8E-04 mm), Intrusão (+ de 0 a 7E-05 mm, ++ de 7 a 14E-05 mm e +++ de 14 a 21E-05 mm) na trifurcação e Rotação (+ de 0 a 1 E-03 grau, ++ de de 1 a 2 E-03 grau, +++ acima de 2 E-03 grau).

\begin{tabular}{|c|c|c|c|}
\hline $\begin{array}{l}\text { Posição do } \\
\text { MPO e } \\
\text { ativação }\end{array}$ & $\begin{array}{c}\text { Resultante do } \\
\text { Movimento A-P } \\
\text { na trifurcação em mm }\end{array}$ & $\begin{array}{l}\text { Resultante do } \\
\text { Movimento Vertical na } \\
\text { trifurcação em mm }\end{array}$ & $\begin{array}{c}\text { Rotação da coroa } \\
\text { em graus }\end{array}$ \\
\hline $2 \mathrm{~mm}$ cervical & Distal +++ (1,72E-04) & Intrusão + (-1,75E-05) & Distal ++ $(2,33 \mathrm{E}-03)$ \\
\hline 2 mm médio & Distal +++ (1,74E-04)* & Extrusão + $(0,41 E-05)$ & $(2,02 \mathrm{E}-03)$ \\
\hline $2 \mathrm{~mm}$ apical & Mesial ++ $(-0,68 E-04)^{\star}$ & Extrusão + $(6,82 \mathrm{E}-05)^{\star}$ & $(-0,68 E-03)^{\star}$ \\
\hline $5 \mathrm{~mm}$ cervical & Distal +++ (1,56E-04) & Intrusão + $(-4,30 E-05)$ & Distal + \\
\hline 5 mm médio & Distal +++ $(1,30 \mathrm{E}-04)$ & Intrusão + $\quad(-4,78 E-05)$ & $(1,26 \mathrm{E}-03)$ \\
\hline $5 \mathrm{~mm}$ apical & Mesial ++ $(-0,52 \mathrm{E}-04)$ & Extrusão + $(6,64 \mathrm{E}-05)$ & $(-0,57 E-03)$ \\
\hline $8 \mathrm{~mm}$ cervical & Distal ++ (1,09E-04) & Intrusão ++ (-10,6E-05) & $(1,17 \mathrm{E}-03)$ \\
\hline $8 \mathrm{~mm} \mathrm{n}$ & Distal $++(0,87 \mathrm{E}-04)$ & Intrusão ++ (-10,2E-05) & $(0,69 E-03)$ \\
\hline $8 \mathrm{~mm}$ apical & Distal $+\quad(0,39 E-04)$ & Intrusão +++ (-21E-05)* & $(2,67 \mathrm{E}-03)^{\star}$ \\
\hline
\end{tabular}

$\mathrm{Na}$ trifurcação do molar, a combinação que resultou no maior valor de distalização foi a de $2 \mathrm{~mm}$ com o elástico ativado no ponto médio da BTP, acompanhado por pouca extrusão (incisal) e contração (medial). O maior valor de intrusão foi na combinação $8 \mathrm{~mm}$ com ativação apical, acompanhado também pelos maiores valor de intrusão (cervical) e contração (medial).

No centro da fossa principal do molar, a combinação que resultou no maior valor de distalização foi a de $2 \mathrm{~mm}$ com o elástico ativado no ponto cervical da BTP, acompanhado por pouca intrusão (cervical) e contração (medial). O maior valor de intrusão foi na combinação $8 \mathrm{~mm}$ com ativação baixa, acompanhado também pelos maiores valor de intrusão (cervical) e contração (medial).

Se o movimento desejado é distalizar e intruir o molar, angulando sua coroa para distal (Tabela 12), observa-se que a combinação que resultou em maior distalização, com pouca intrusão e grande angulação da coroa para distal, foi a de 2 $\mathrm{mm}$ cervical. A intensidade do vetor de distalização diminuiu acompanhando a diminuição da rotação e o aumento da intrusão nas combinações $5 \mathrm{~mm}$ cervical e 5 $\mathrm{mm}$ médio. O MPO instalado a $8 \mathrm{~mm}$ teve maiores componentes intrusivos, sendo o maior com o elástico próximo ao ômega da BTP (8 $\mathrm{mm}$ apical), com menor intensidade de distalização e grande angulação da coroa para distal, seguido pela ativação cervical, próxima ao tubo do molar. 
Tabela 12 - Combinações de distalização e intrusão.

\begin{tabular}{|c|c|c|c|}
\hline $\begin{array}{l}\text { Posição do } \\
\text { MPO e } \\
\text { ativação }\end{array}$ & $\begin{array}{c}\text { Resultante do } \\
\text { Movimento A-P } \\
\text { na trifurcação em mm }\end{array}$ & $\begin{array}{c}\text { Resultante do } \\
\text { Movimento Vertical na } \\
\text { trifurcação em mm }\end{array}$ & $\begin{array}{c}\text { Rotação da coroa } \\
\text { em graus }\end{array}$ \\
\hline $2 \mathrm{~mm}$ cervical & Distal +++ (1,72E-04) & Intrusão + $(-0,17 \mathrm{E}-04)$ & Distal ++ $(2,33 \mathrm{E}-03)$ \\
\hline $5 \mathrm{~mm}$ cervical & Distal +++ (1,56E-04) & Intrusão + $(-0,43 \mathrm{E}-04)$ & Distal $+\quad(1,95 \mathrm{E}-03)$ \\
\hline 5 mm médio & Distal +++ (1,30E-04) & Intrusão + $(-0,47 \mathrm{E}-04)$ & $(1,26 \mathrm{E}-03)$ \\
\hline $8 \mathrm{~mm}$ cervical & Distal ++ $(1,09 \mathrm{E}-04)$ & Intrusão ++ (-1,06E-04) & (1,17E-03) \\
\hline 8 mm médio & Distal ++ $(0,87 \mathrm{E}-04)$ & Intrusão ++ (-1,02E-04) & $(0,69 \mathrm{E}-03)$ \\
\hline $8 \mathrm{~mm}$ apical & Distal + $(0,39 \mathrm{E}-04)$ & Intrusão+++(-2,10E-04) & Distal ++ $(2,67 \mathrm{E}-03)^{\star}$ \\
\hline
\end{tabular}

Se o movimento desejado é distalizar e extruir o molar, angulando sua coroa para distal (Tabela 13), observa-se que a combinação que resultou em maior distalização, com pouca extrusão e grande angulação da coroa para distal foi a de 2 mm médio. A intensidade do vetor de distalização diminuiu acompanhando a diminuição da rotação para distal e o aumento da extrusão nas combinações $5 \mathrm{~mm}$ apical e $2 \mathrm{~mm}$ apical. A trifurcação apresentou movimento resultante e angulação para mesial nas ativações de $2 \mathrm{~mm}$ e $5 \mathrm{~mm}$ apical, que provavelmente apresentaram um ponto fulcral mais apical do que a trifurcação.

Tabela 13 - Combinações de distalização e extrusão.

\begin{tabular}{ccccc}
$\begin{array}{c}\text { Posição do } \\
\text { MPO e } \\
\text { ativação }\end{array}$ & $\begin{array}{c}\text { Resultante do } \\
\text { Movimento A-P } \\
\text { na trifurcação em mm }\end{array}$ & $\begin{array}{c}\text { Resultante do } \\
\text { Movimento Vertical na } \\
\text { trifurcação em mm }\end{array}$ & $\begin{array}{c}\text { Rotação da coroa } \\
\text { em graus }\end{array}$ \\
\hline $2 \mathrm{~mm}$ médio & $\begin{array}{c}\text { Distal +++ (1,74E-04) })^{\star} \\
\text { Extrusão + (0,41E-05) }\end{array}$ & Distal ++ & $(2,02 \mathrm{E}-03)$ \\
$2 \mathrm{~mm}$ apical & Mesial ++ (-0,68E-04) & $\begin{array}{c}\text { Extrusão + (6,82E-05) } \\
5 \mathrm{~mm} \text { apical }\end{array}$ & Mesial + & $(-0,68 \mathrm{E}-03)^{\star}$ \\
\hline
\end{tabular}

A Figura 39 - foi elaborada a partir dos dados obtidos em todas as combinações das posições 2, 5 e $8 \mathrm{~mm}$ nas ativações apical, média e cervical. Foram expressos os valores do deslocamento no instante imediatamente após a aplicação da força, em uma escala de $1 \mathrm{E}-05 \mathrm{~mm}$, tanto no sentido vertical quanto horizontal. Em seguida, o valor do deslocamento foi expresso o sentido e a intensidade da rotação provocada, em uma escala de $1 \mathrm{E}-03^{\circ}$. 


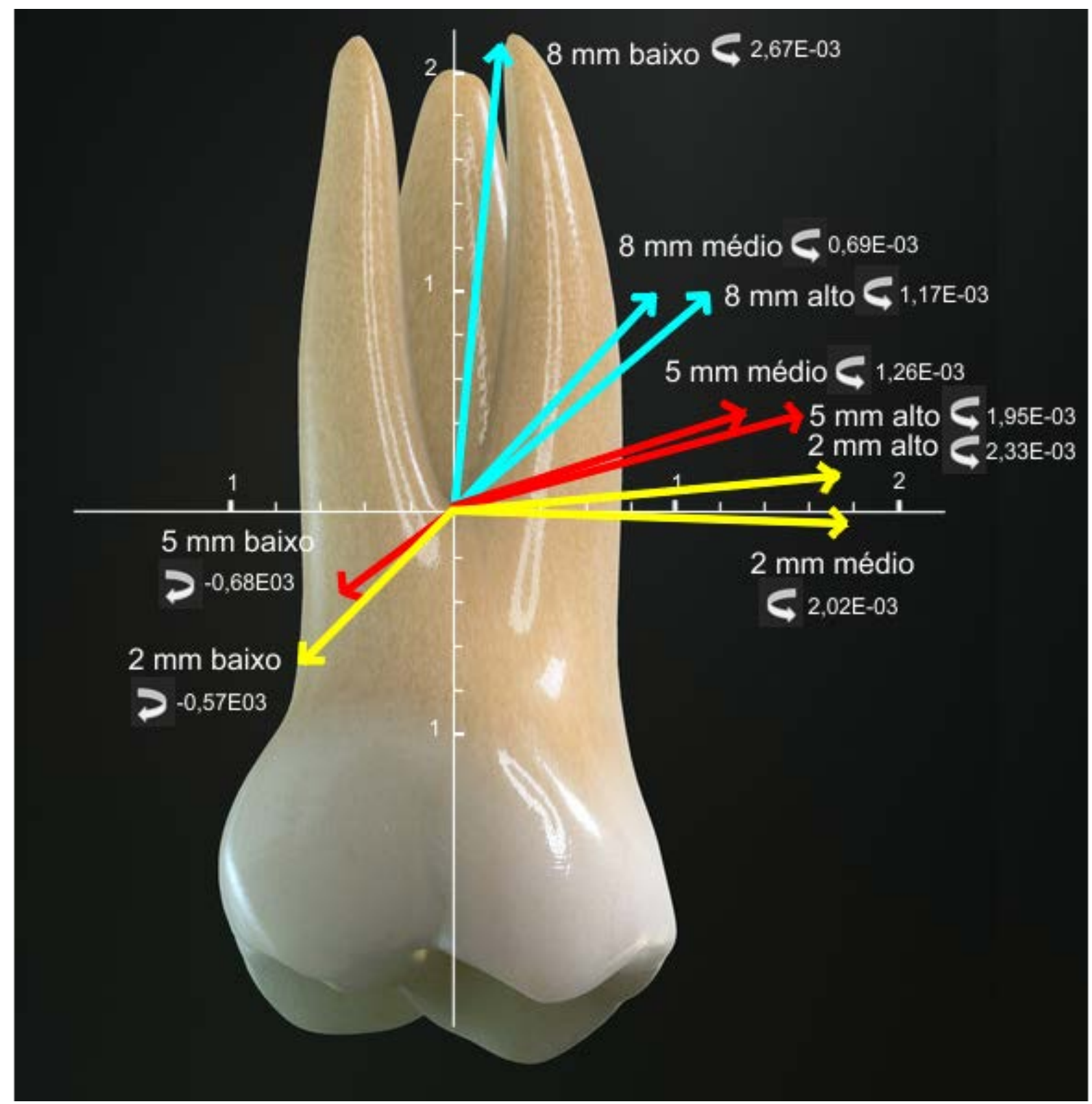

Figura 39 - Diagrama da decomposição dos vetores dos deslocamentos verticais (intrusão e extrusão) e horizontais (distalização: para direita, ou mesialização: para esquerda), seguido pelo sentido e intensidade da rotação. O eixo vertical representa o deslocamento em Z (Vertical, escala de $1 E-05 \mathrm{~mm}$ ) e o eixo horizontal representa o deslocamento em $\mathrm{Y}$ (A-P, escala de 1E-05 mm). As rotações estão em graus, no sentido horário ou anti-horário. As alturas das ativações correspondem a: alto = cervical, baixo = apical. 


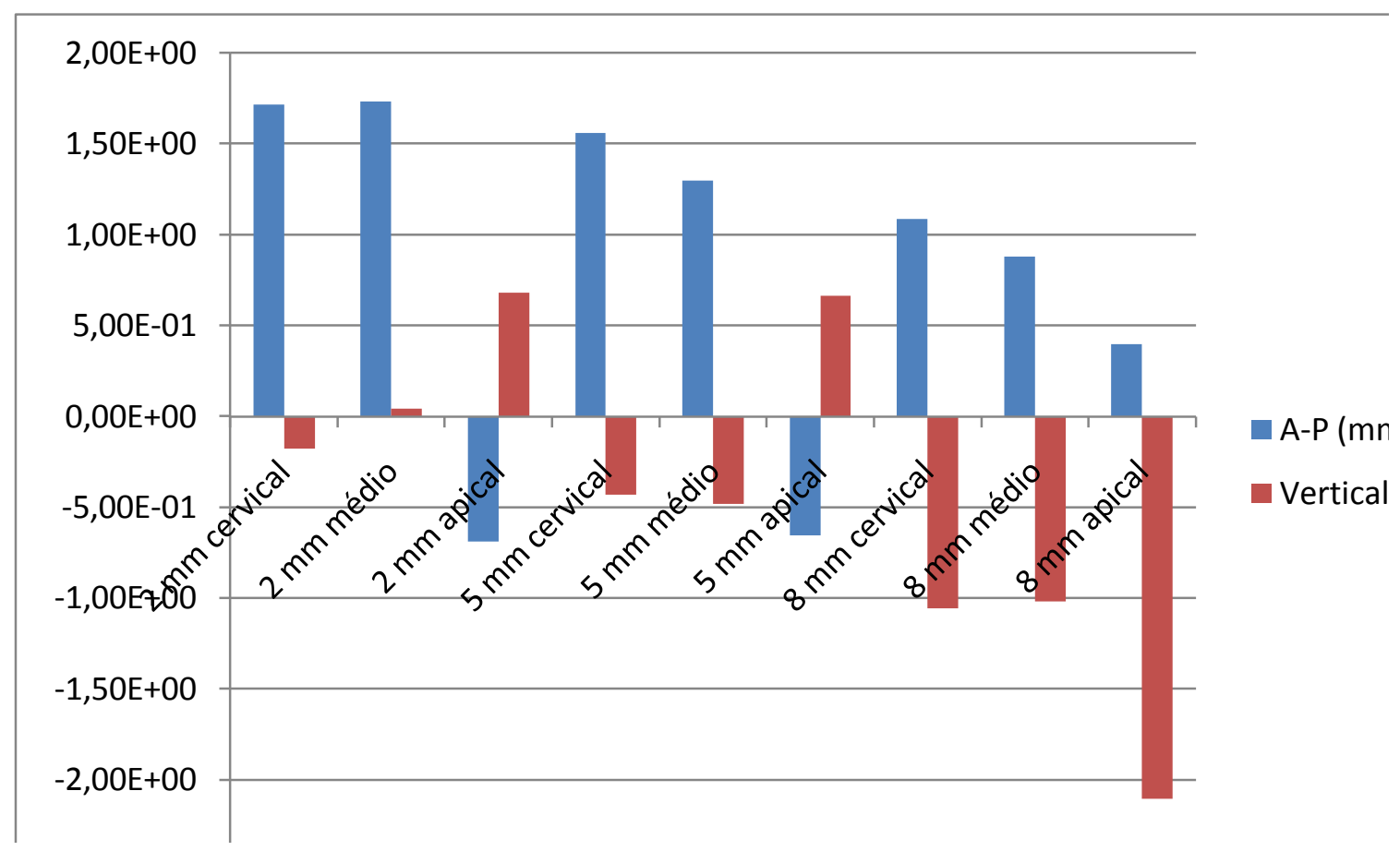

Figura 40 - Intensidade do deslocamento da furca no sentido horizontal (azul) e vertical (vermelho) de acordo com o tipo de ativação, em milímetros.

\subsubsection{Análise qualitativa da distribuição das tensões (imagens)}

\subsubsection{Ativação $2 \mathrm{~mm}$ apical}

Ativação com a cabeça do microparafuso posicionada a $2 \mathrm{~mm}$ medial à cervical do molar e com a inserção do elástico próximo ao ômega da BTP. A Figura 41 e a Figura 42 mostram, em uma vista lingual, o deslocamento direcional A-P (no eixo Y). A cor vermelha indica que as raízes e a furca tendem a se deslocar para distal, enquanto que a coroa, imediatamente após a ativação, tende a se deslocar para mesial (rotação). A Figura 43 e a Figura 44 mostram, em perspectiva, o deslocamento direcional vertical (no eixo Z). A cor vermelha indica que mais da metade medial (palatina) do dente tende a extruir e uma parte da lateral (vestibular) tende a intruir (rotação). A Figura 45 evidencia, em vista oclusal, a distribuição das tensões de tração (Tensão Máxima Principal) e a indicação de que o ponto em que há maior intensidade de tensão de tração está localizado na região do ápice da raiz palatina (Max). A Figura 46 evidencia, em vista oclusal, a distribuição das tensões de compressão (Tensão Mínima Principal) e a indicação de que o ponto em que há 
maior tensão de compressão está localizado na região do ápice da raiz mésiovestibular (Min). A Figura 47 evidencia, com a ferramenta Isosurface, as camadas (superfícies) de pontos com a mesma intensidade de deslocamento, representado pelo eixo de resistência que passa pelo centro dos círculos azuis e um ponto neste eixo em que há o menor deslocamento do dente (Min).

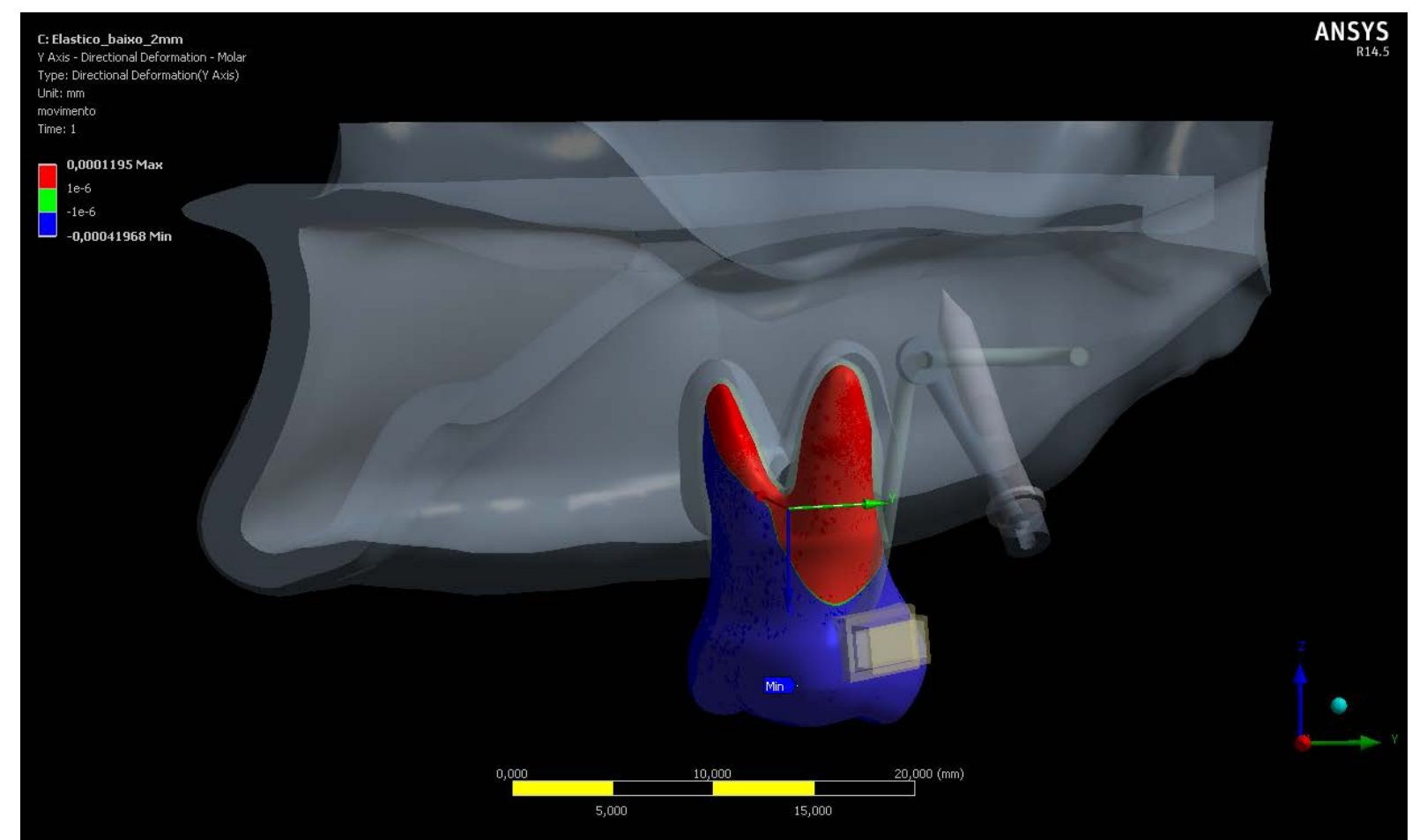

Figura 41 - Deslocamento direcional (eixo Y) com ativação 2 mm apical, 2 cores - vista lingual. 


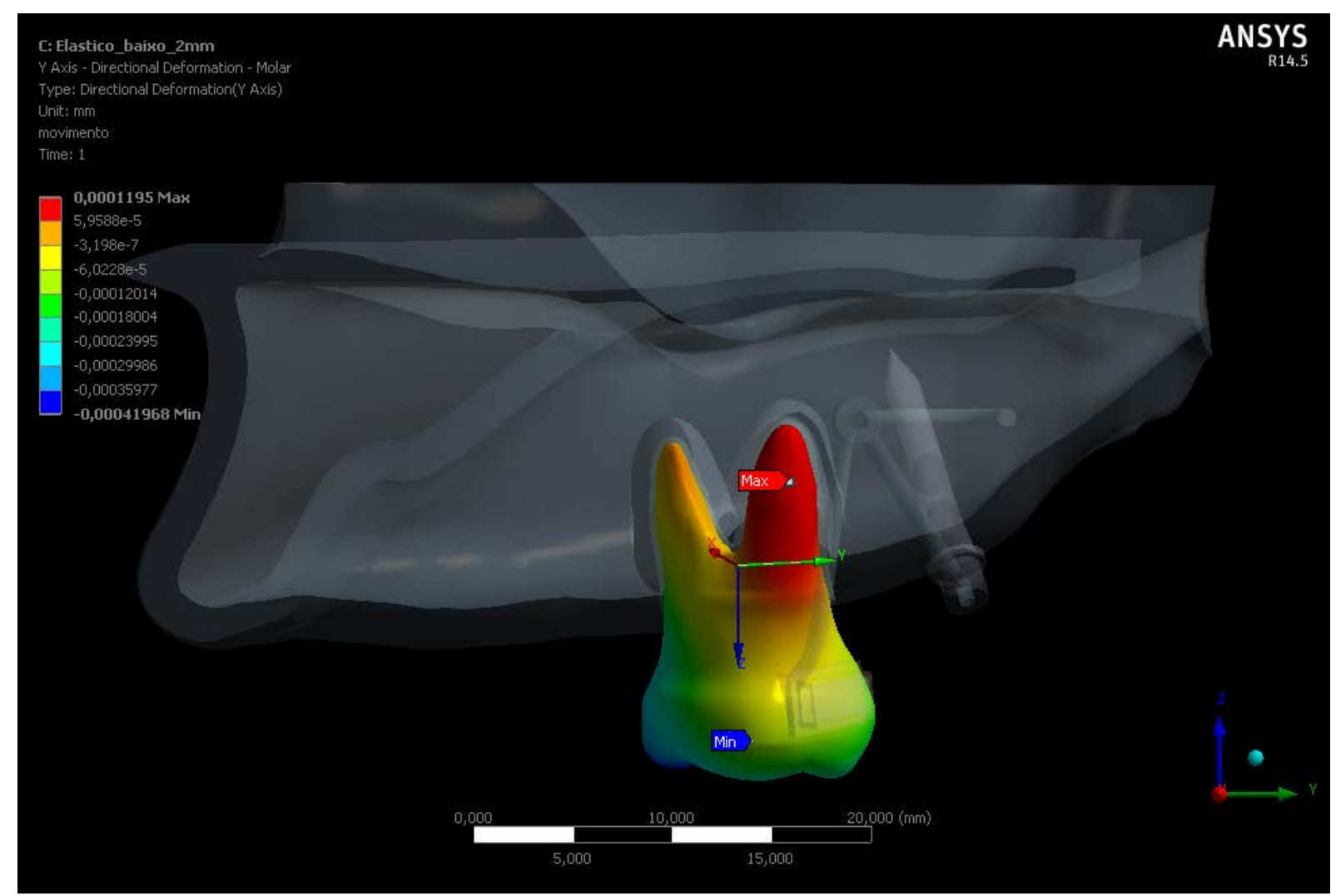

Figura 42 - Deslocamento direcional (eixo Y) com ativação $2 \mathrm{~mm}$ apical - vista lingual.

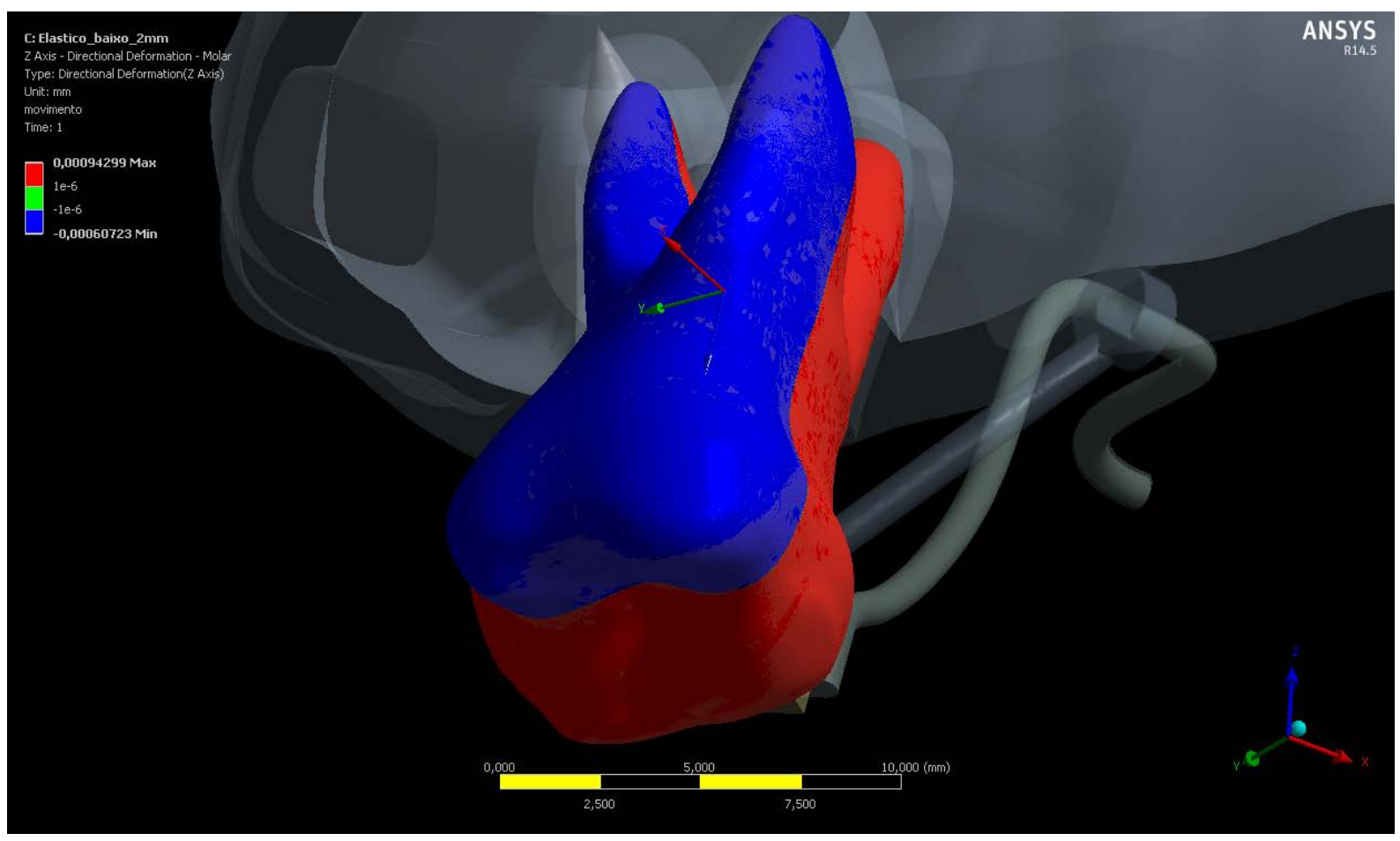

Figura 43 - Deslocamento direcional (eixo Z) com ativação $2 \mathrm{~mm}$ apical, 2 cores - perspectiva. 


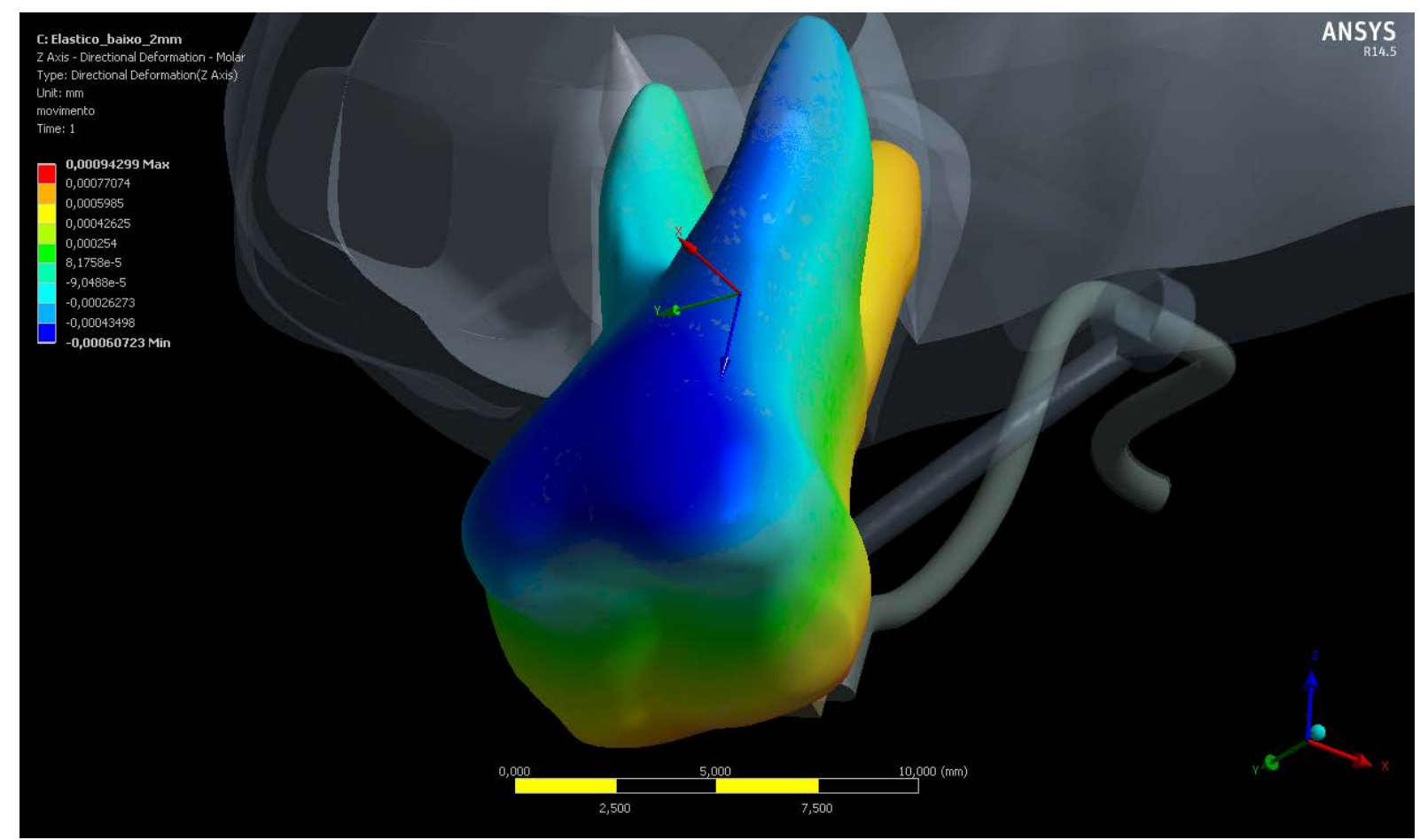

Figura 44 - Deslocamento direcional (eixo Z) com ativação 2 mm apical perspectiva.

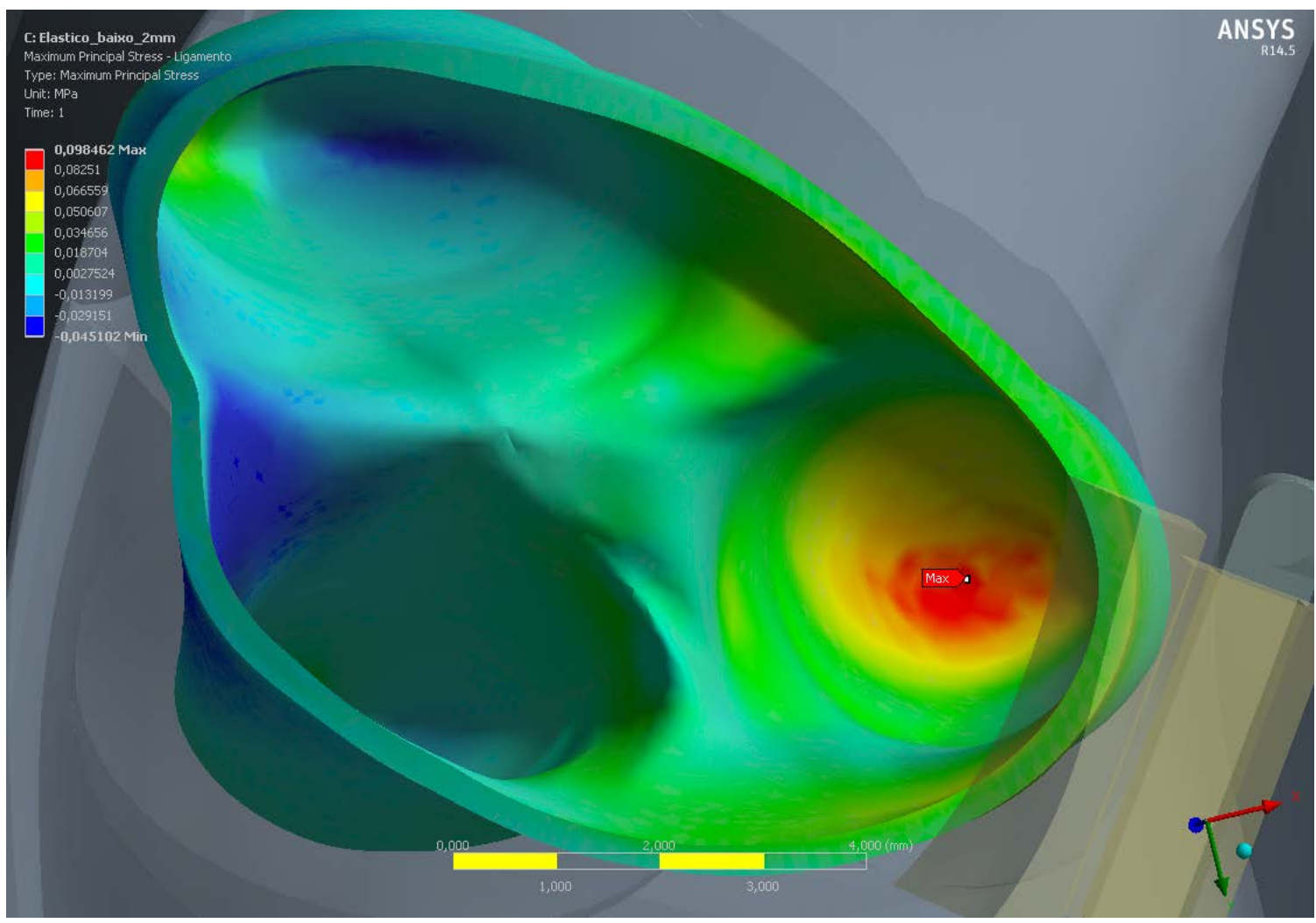

Figura 45 - Tensão Máxima Principal no ligamento periodontal com ativação 2 $\mathrm{mm}$ apical, vista oclusal. 


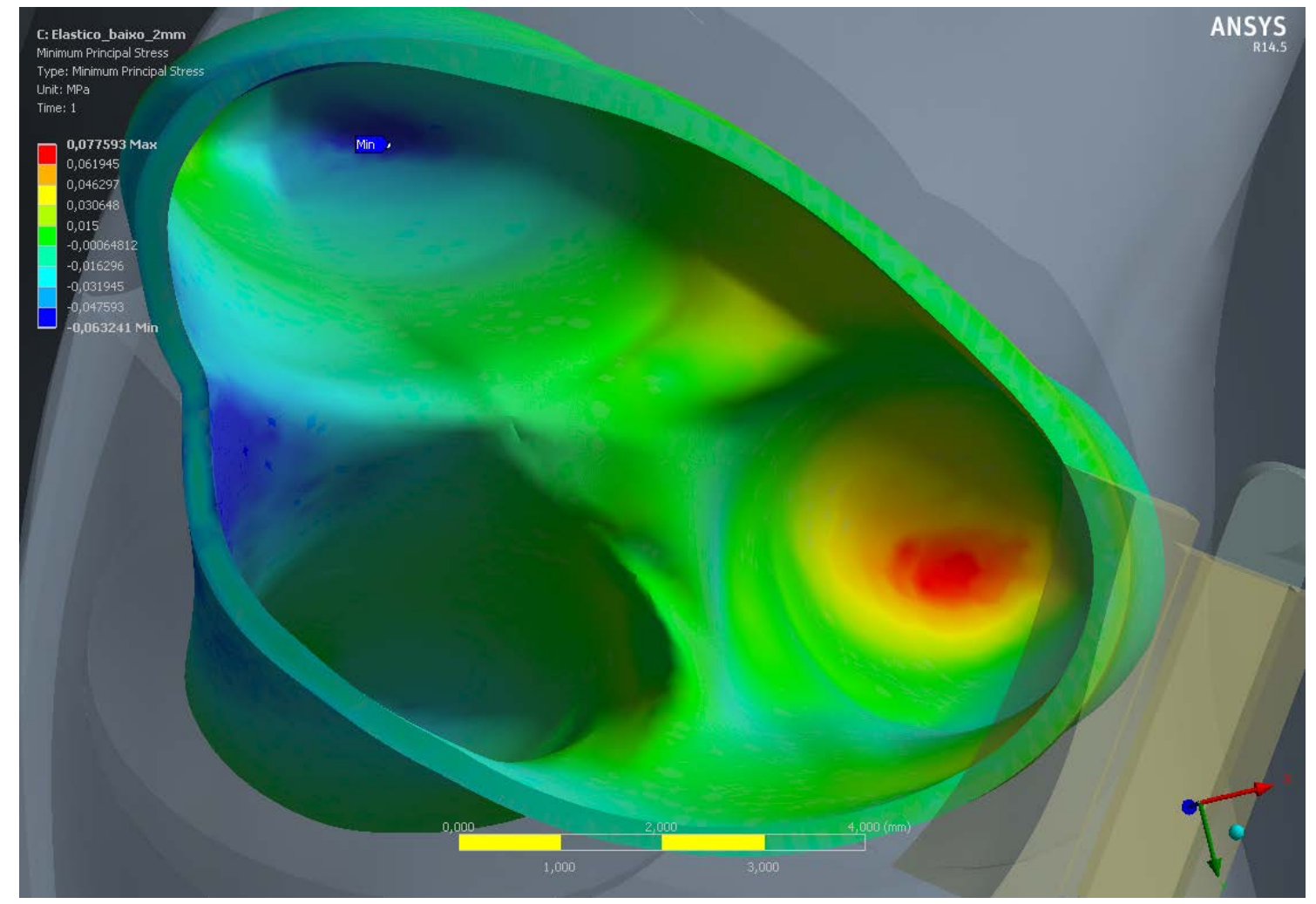

Figura 46 - Tensão Mínima Principal no ligamento periodontal com ativação 2 $\mathrm{mm}$ apical, vista oclusal.

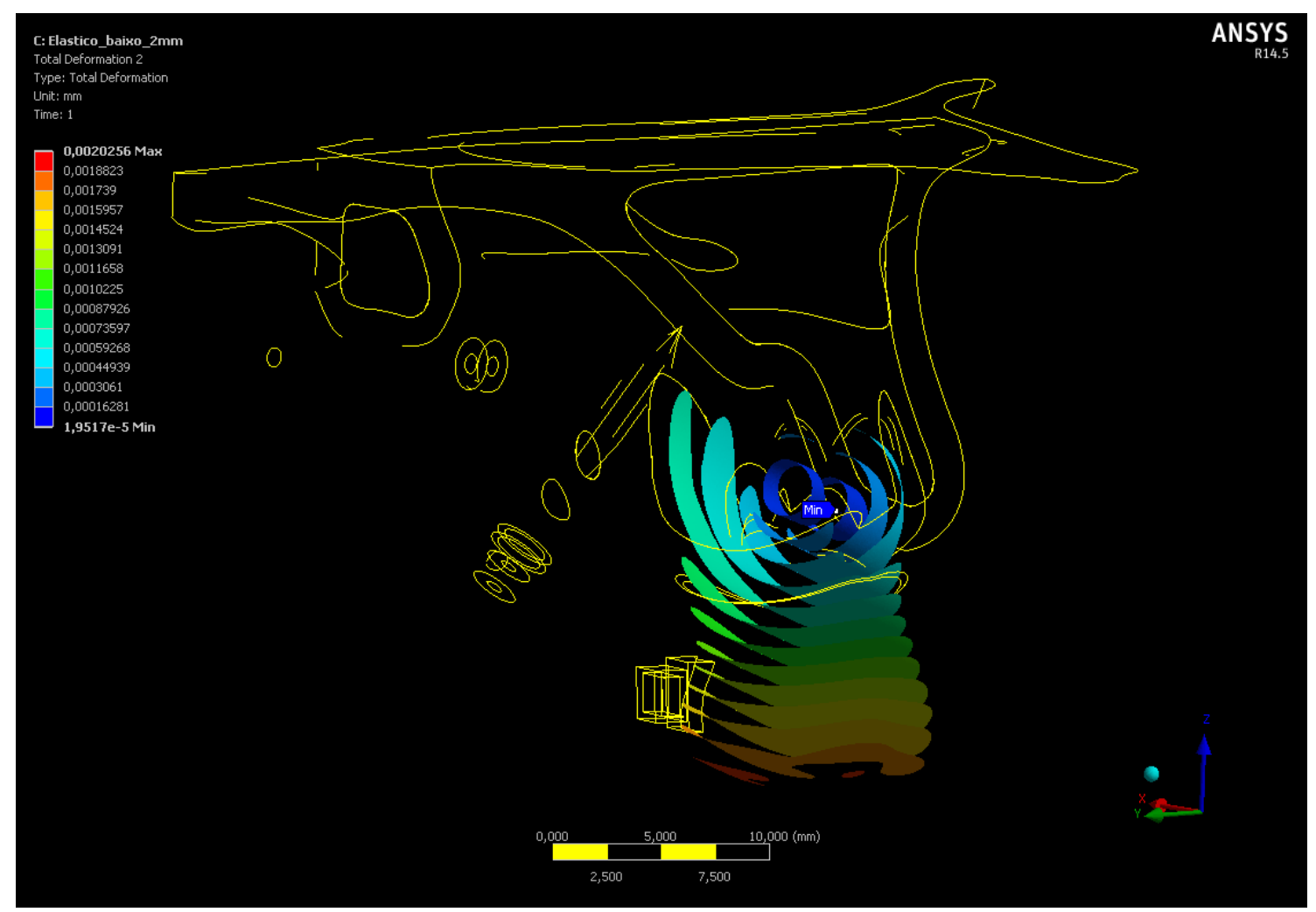

Figura 47 - Deslocamento Total com ativação 2 mm apical - Isosurface.

Resultante $=$ Efeito de extrusão (em maior intensidade no lado palatino) e giro 
da coroa para mesial (horário).

\subsubsection{Ativação $2 \mathrm{~mm}$ cervical}

Ativação com a cabeça do microparafuso posicionada a $2 \mathrm{~mm}$ medial à cervical do molar e com a inserção do elástico no tubo do molar. A Figura 48 e a Figura 49 mostram, em uma vista lingual, o deslocamento direcional A-P (no eixo Y). A cor vermelha indica que a coroa e a furca tendem a se deslocar para distal, enquanto que os terços apicais radiculares, imediatamente após a ativação, tendem a se deslocar para mesial (rotação). A Figura 50 e a Figura 51 mostram, em perspectiva, o deslocamento direcional vertical (no eixo Z). A cor vermelha indica que a raiz mesiovestibular e quase a metade lateral (vestibular) da coroa do dente tendem a extruir e uma parte da medial (palatina) e a raiz distovestibular tendem a intruir (rotação). A Figura 52 evidencia, em vista oclusal, a distribuição das tensões de tração (Tensão Máxima Principal) e a indicação de que o ponto em que há maior intensidade do esforço de tração está localizado na região do ápice da raiz mésiovestibular (Max). A Figura 53 evidencia, em vista oclusal, a distribuição das tensões de compressão (Tensão Mínima Principal) e a indicação de que o ponto em que há maior esforço de compressão está localizado na região do ápice da raiz distovestibular (Min). A Figura 54 evidencia, com a ferramenta Isosurface, as camadas (superfícies) de pontos com a mesma intensidade de deslocamento, o eixo em que se encontra o centro de resistência, representado pelo eixo que passa pelo centro dos círculos azuis (quase perpendicular ao eixo apresentado na ativação $2 \mathrm{~mm}$ cervical) e um ponto neste eixo em que há o menor deslocamento do dente (Min). 
A: Elastico_cima_2mm

movimento

0,0013437 Max

$1 \mathrm{e}-6$
$-1 \mathrm{e}-6$

$-0,00022179$ Min

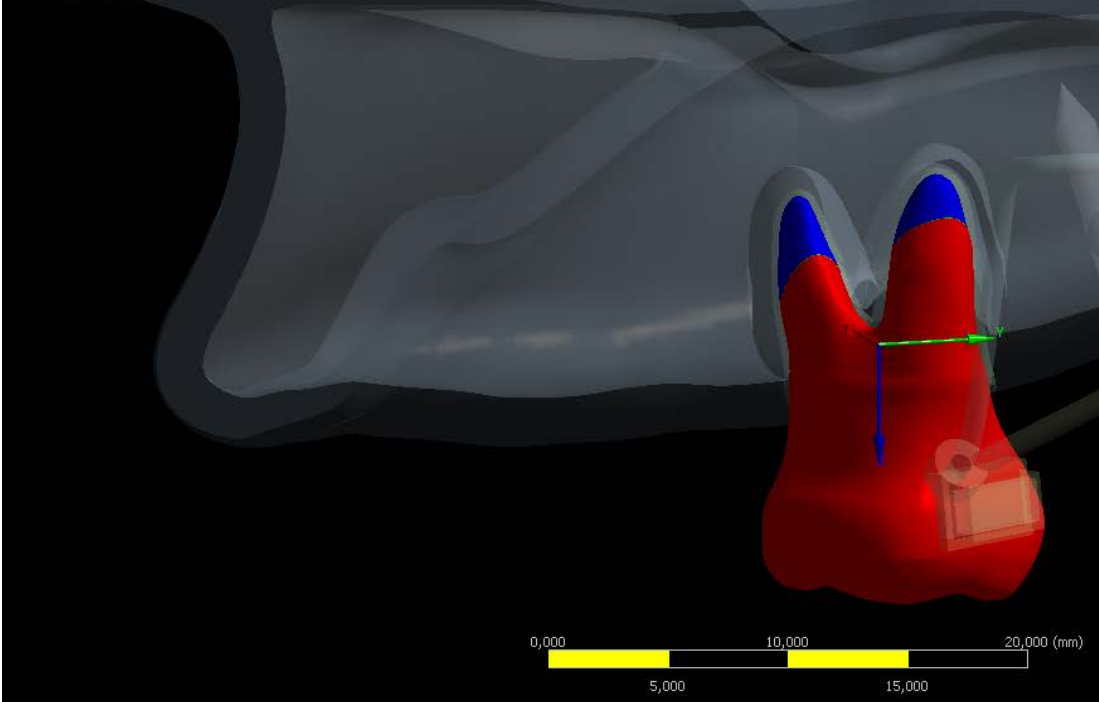

Figura 48 - Deslocamento direcional (eixo Y) com ativação 2 mm cervical, 2 cores - vista lingual.

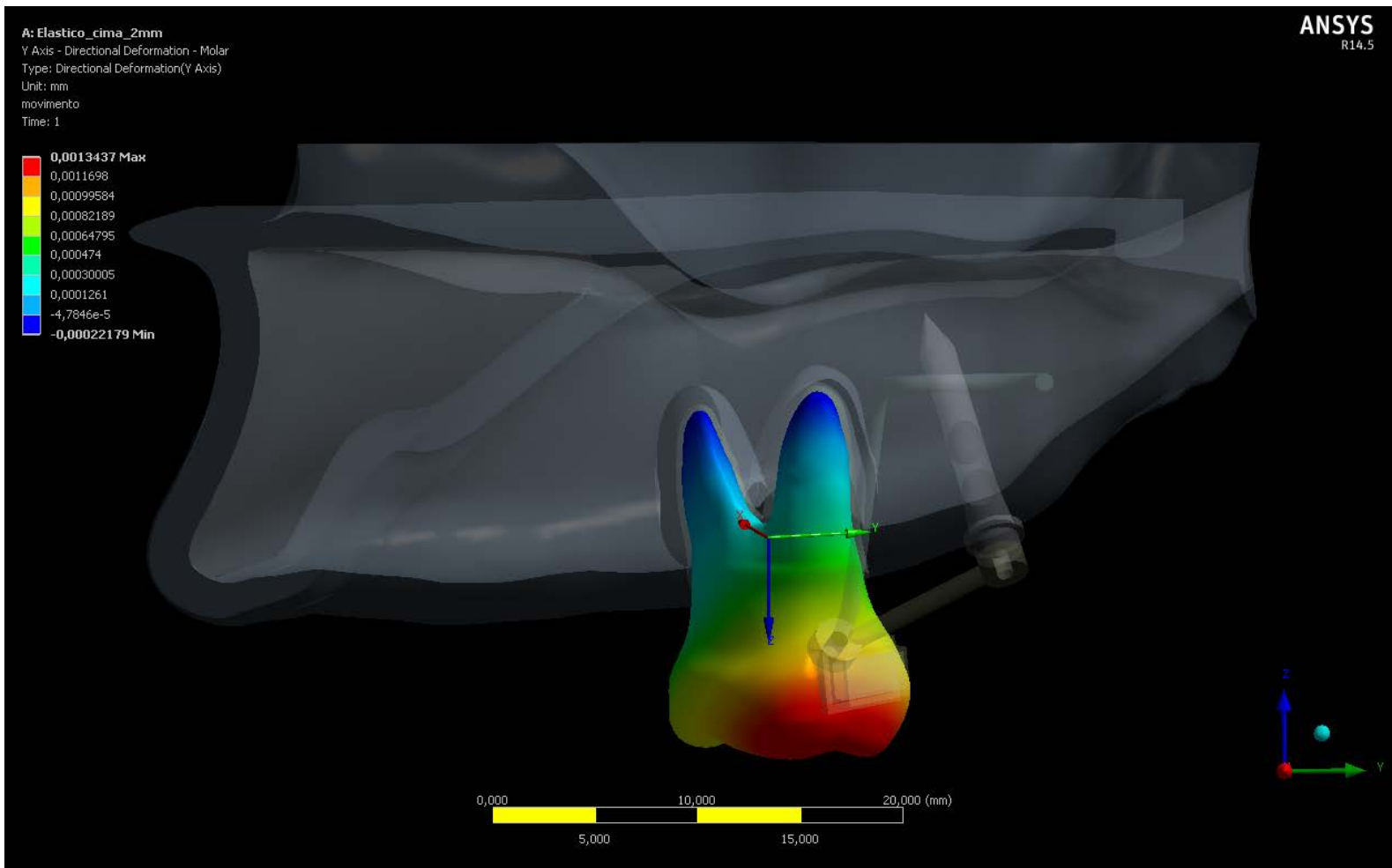

Figura 49 - Deslocamento direcional (eixo Y) com ativação 2 mm "cervical vista lingual. 


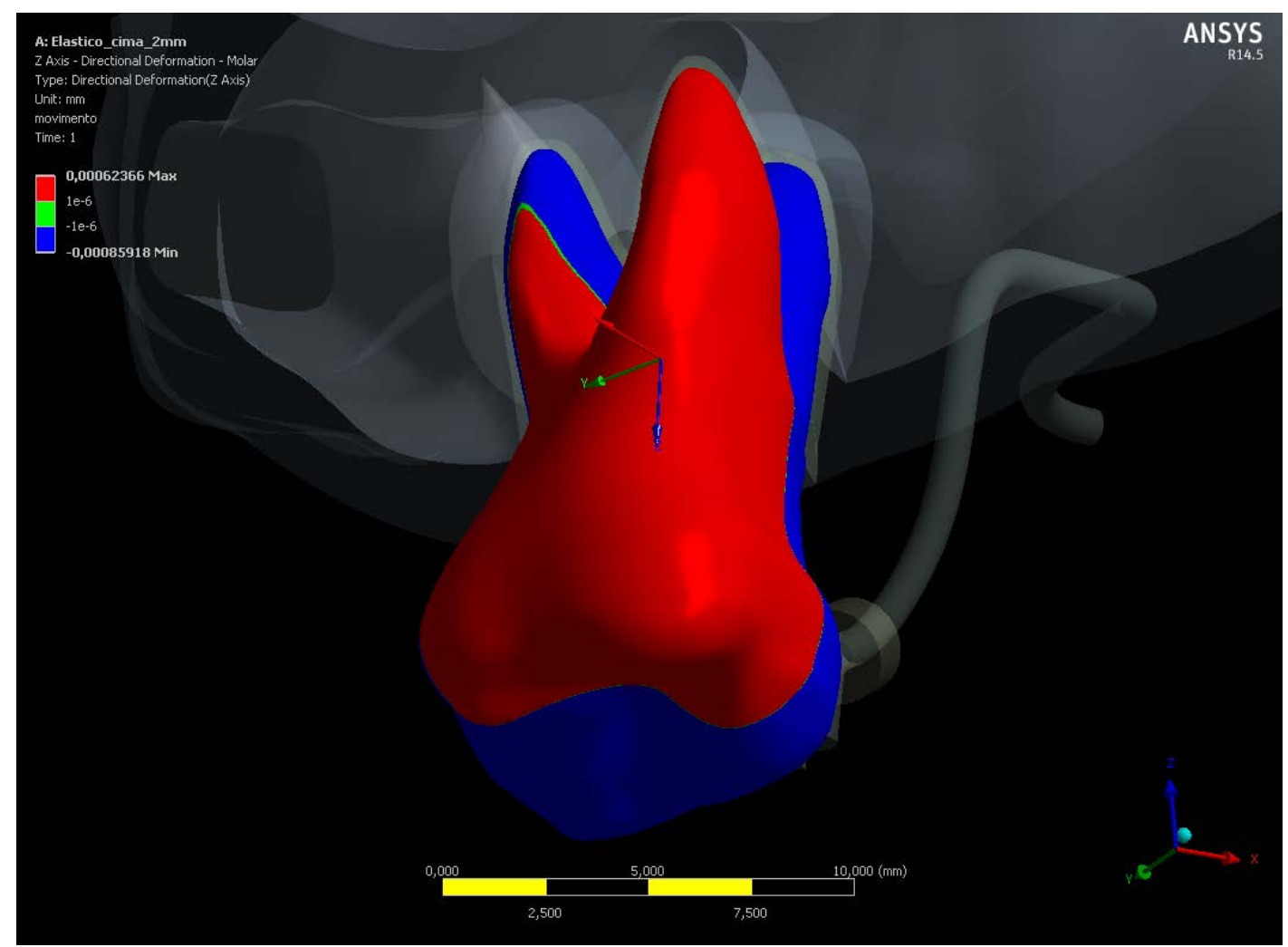

Figura 50 - Deslocamento direcional (eixo Z) com ativação 2 mm cervical, 2 cores - perspectiva.

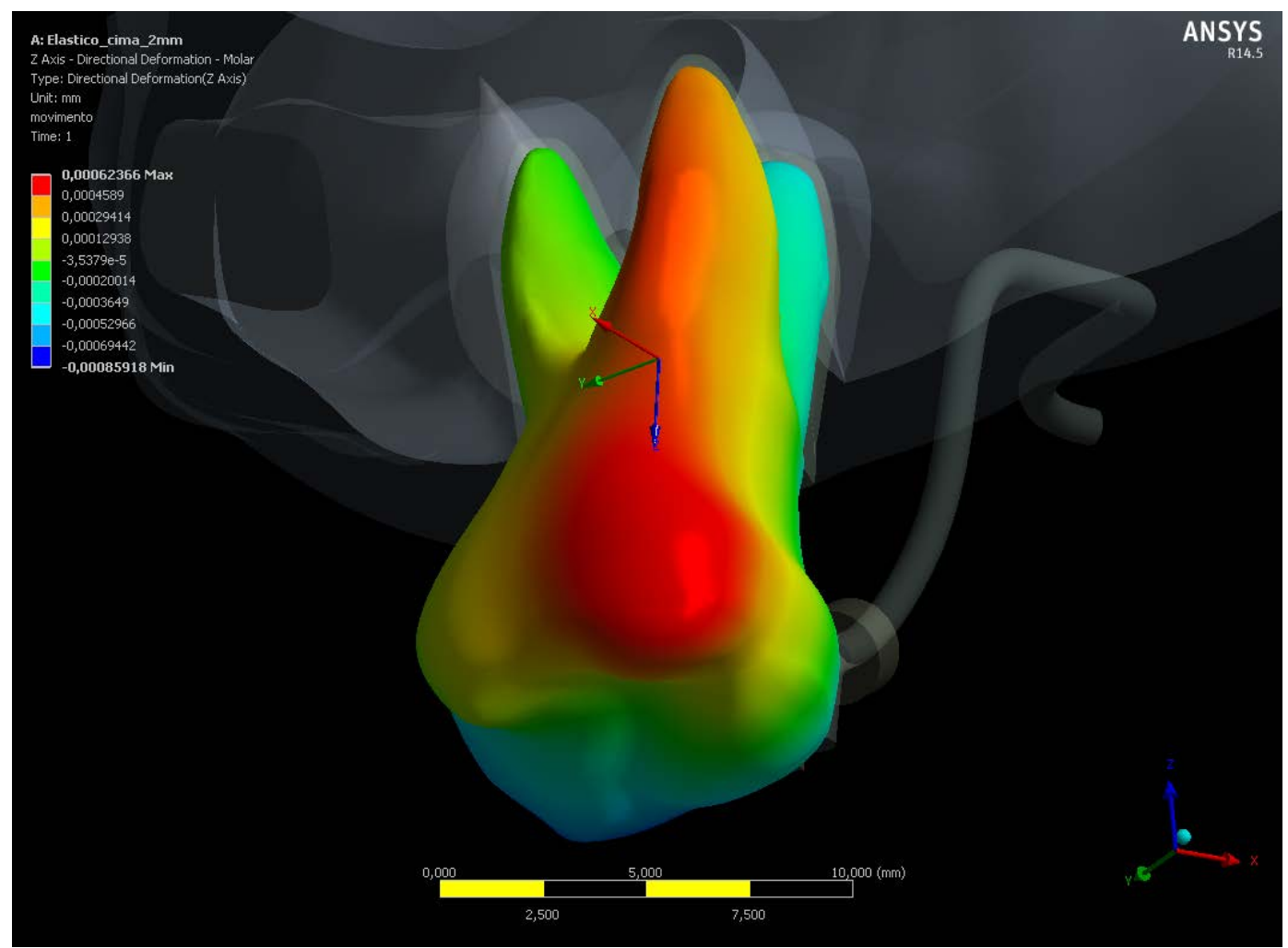

Figura 51 - Deslocamento direcional (eixo Z) com ativação 2 mm cervical perspectiva. 


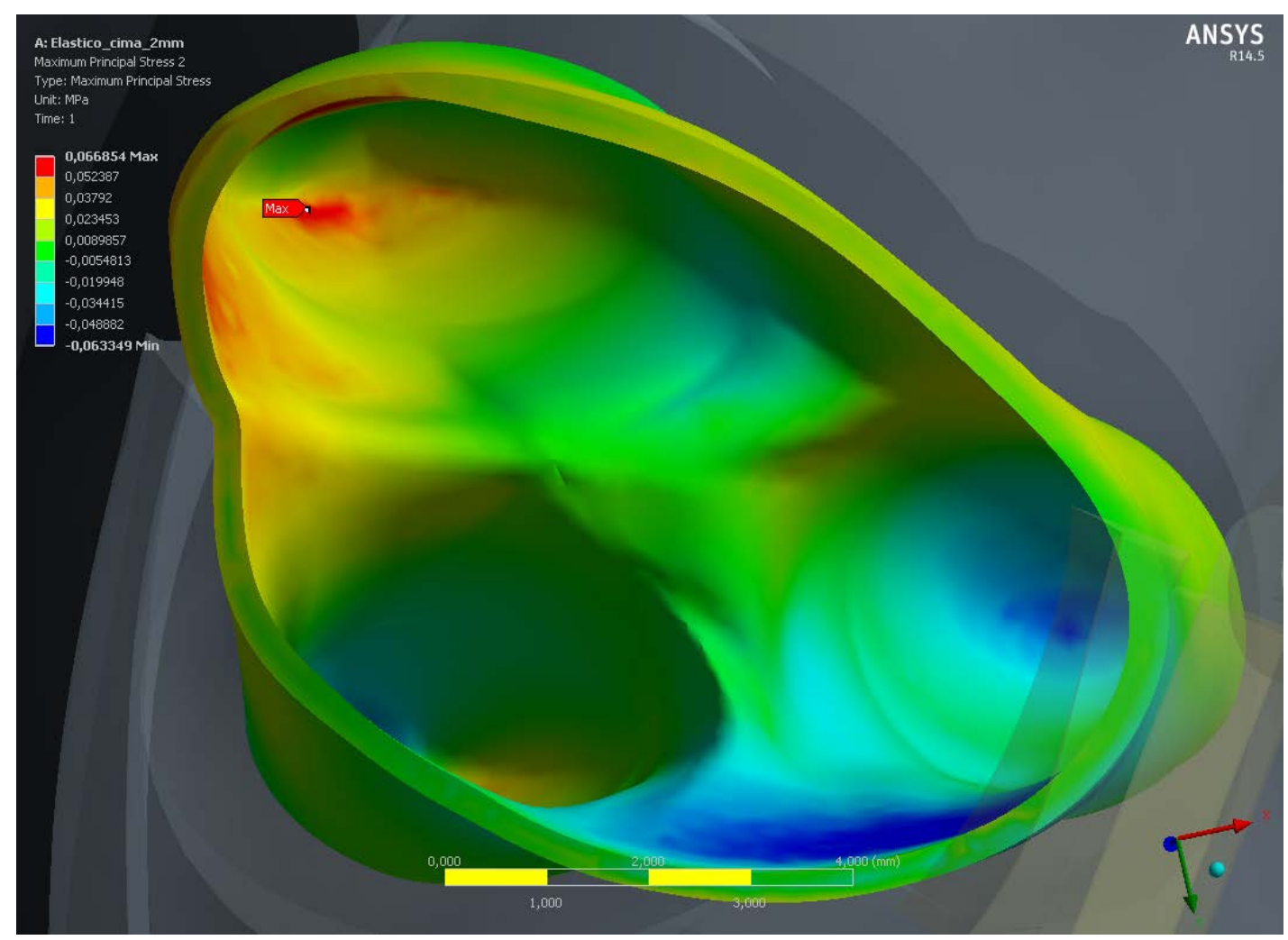

Figura 52 - Tensão Máxima Principal no ligamento periodontal com ativação 2 mm cervical, vista oclusal.

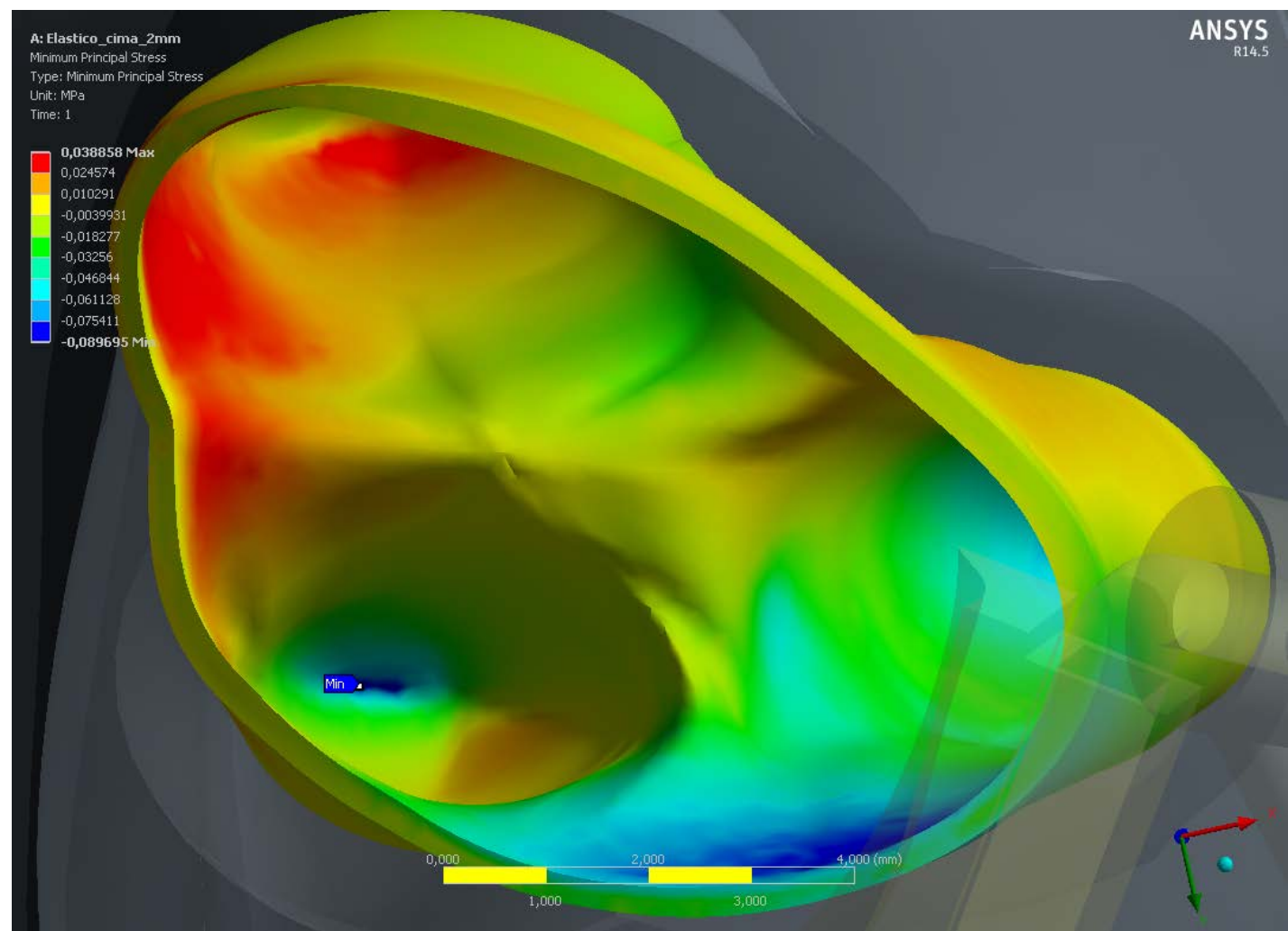

Figura 53 - Tensão Mínima Principal no ligamento periodontal com ativação 2 mm cervical, vista oclusal. 


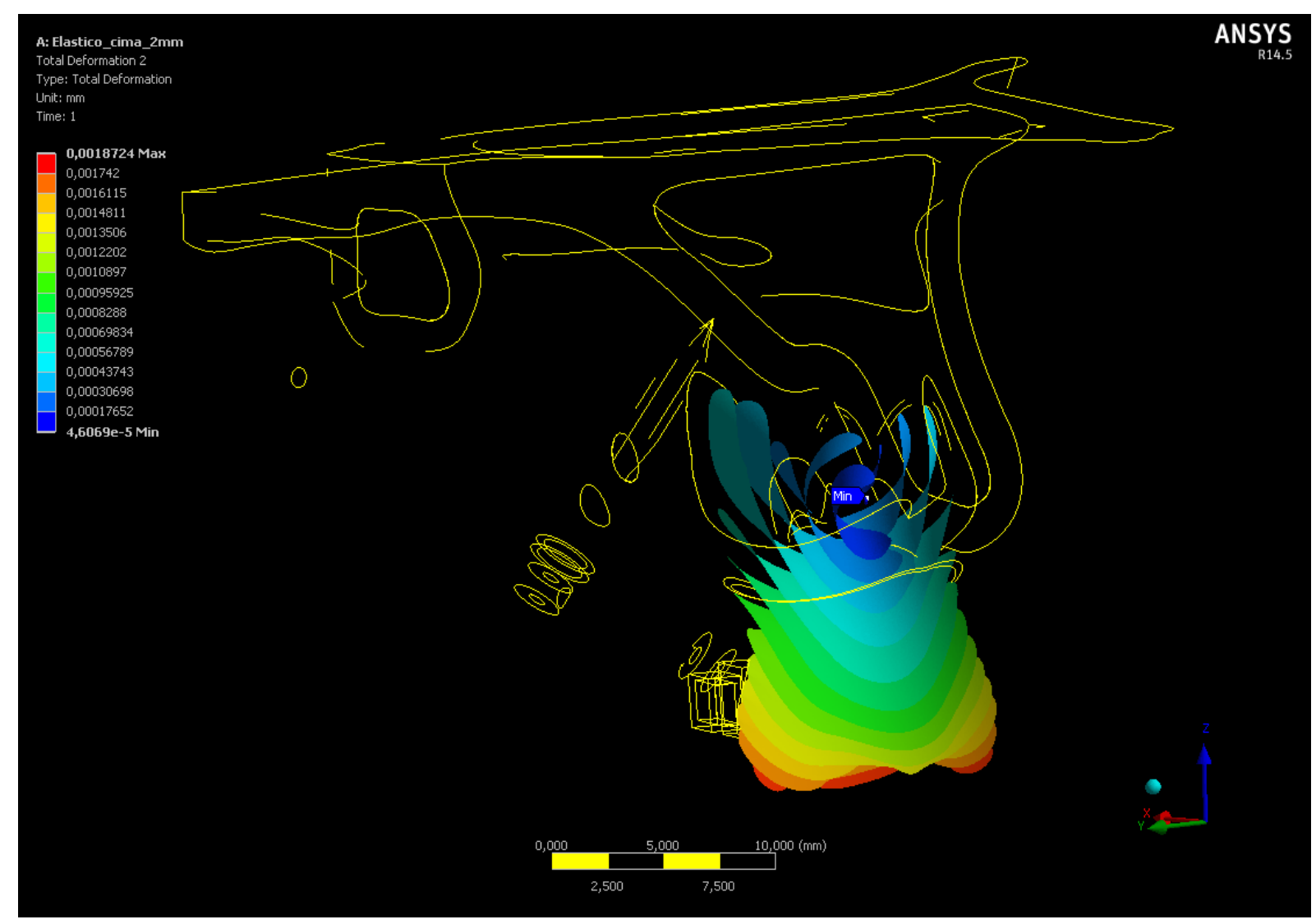

Figura 54 - Deslocamento Total com ativação 2 mm cervical - Isosurface.

Resultante $=$ Efeito de leve intrusão, distalização e muito giro anti-horário (angulação distal da coroa) - indicado para situações de mésio-angulação, como quando ocorreu perda do segundo pré-molar e o primeiro molar mesializou inclinando, ou quando o eixo de erupção do molar está para mesial e impactou no segundo molar decíduo.

\subsubsection{Ativação 5 mm médio}

Ativação com a cabeça do microparafuso posicionada a $5 \mathrm{~mm}$ medial à cervical do molar e com a inserção do elástico na menor distância entre a cabeça do parafuso e a BTP. A Figura 55 e a Figura 56 mostram, em uma vista lingual, o deslocamento direcional A-P (no eixo Y). A cor vermelha indica que a coroa, a furca e a maior parte das raízes tendem a se deslocar para distal, enquanto que os ápices radiculares, imediatamente após a ativação, tendem a se deslocar sutilmente para mesial (rotação). A Figura 57 e a Figura 58 mostram, em perspectiva, o deslocamento direcional vertical (no eixo Z). A cor vermelha indica que quase a 
metade lateral (vestibular) do dente tende a extruir e uma parte da medial (palatina) tende a intruir (rotação), semelhante, mas mais perto da metade do dente do que na ativação $2 \mathrm{~mm}$ alto, com quase a metade de sua intensidade. A Figura 59 evidencia, em vista oclusal, a distribuição das tensões de tração (Tensão Máxima Principal) e a indicação de que o ponto em que há maior intensidade do esforço de tração está localizado na região distovestibular da raiz mésiovestibular (Max). A Figura 60 evidencia, em vista oclusal, a distribuição das tensões de compressão (Tensão Mínima Principal) e a indicação de que o ponto em que há maior esforço de compressão está localizado na região distopalatina da raiz palatina (Min). A Figura 61 evidencia, com a ferramenta Isosurface, as camadas (superfícies) de pontos com a mesma intensidade de deslocamento, o eixo em que se encontra o centro de resistência, representado pelo eixo que passa pelo centro dos círculos azuis (também quase perpendicular ao eixo apresentado na ativação $2 \mathrm{~mm}$ cervical e próximo ao da ativação $2 \mathrm{~mm}$ apical).

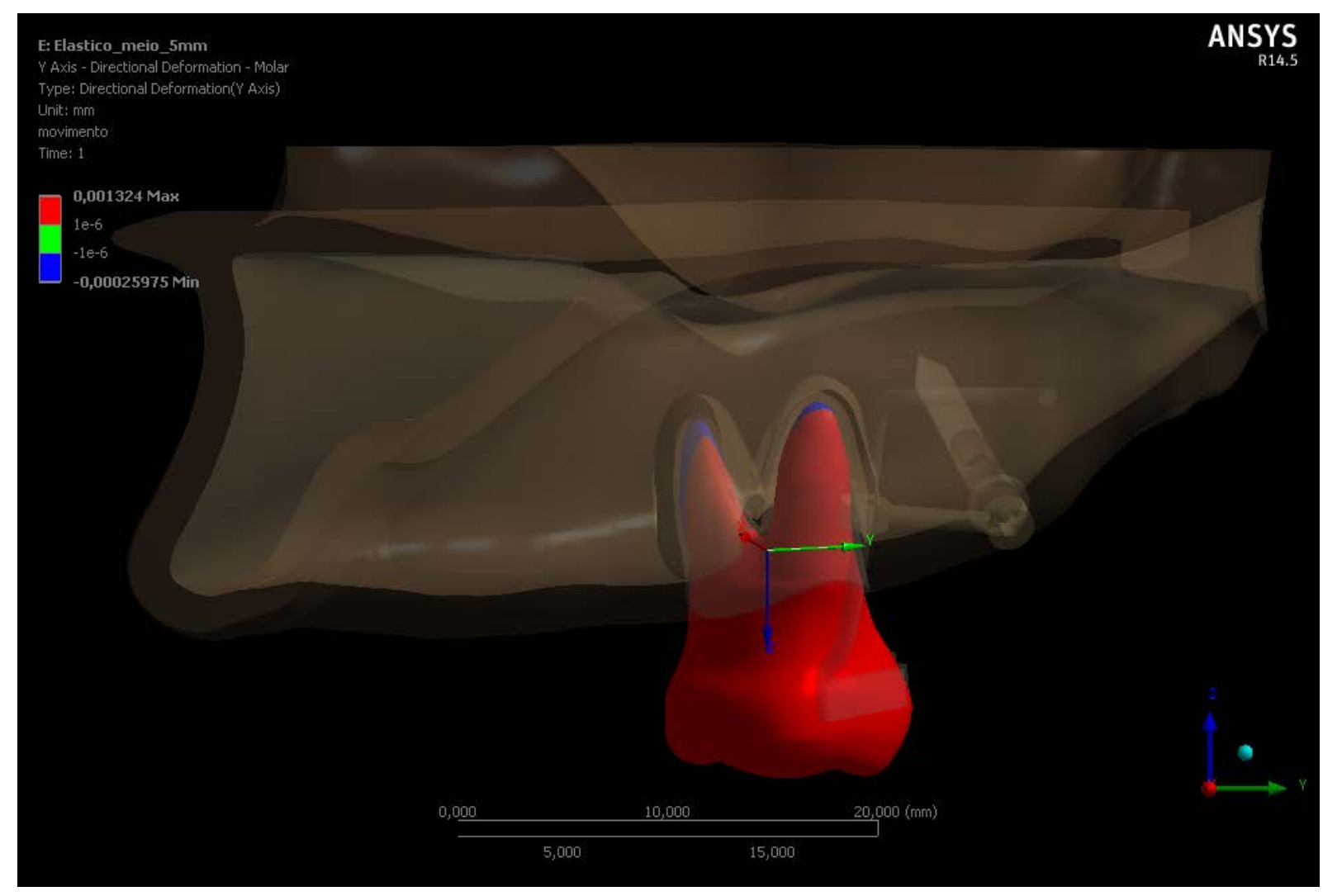

Figura 55 - Deslocamento direcional (eixo Y) com ativação 5 mm médio, 2 cores - vista lingual. 


\section{E: Elastico_meio_5mm}

ANSYS

Y Axis - Directional Deformation - Molar

Type: Directional Deformation(Y Axis)

Unit: $\mathrm{mm}$

movimento

Time: 1

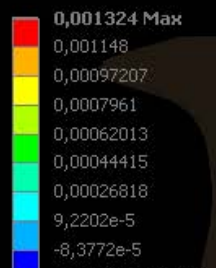

$-0,00025975$ Min

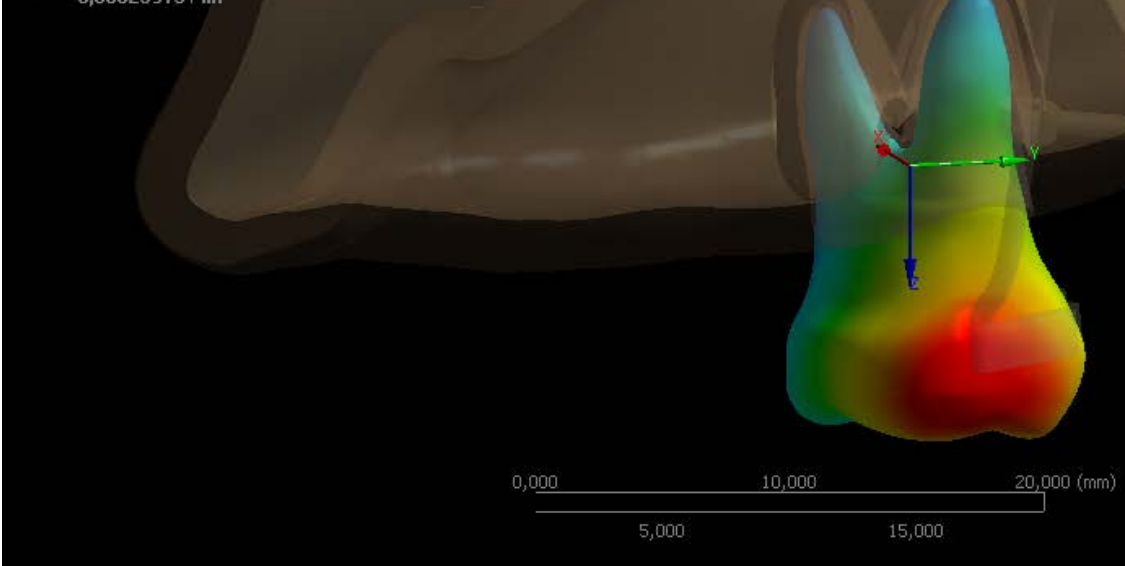

Figura 56 - Deslocamento direcional (eixo Y) com ativação 5 mm médio vista lingual.

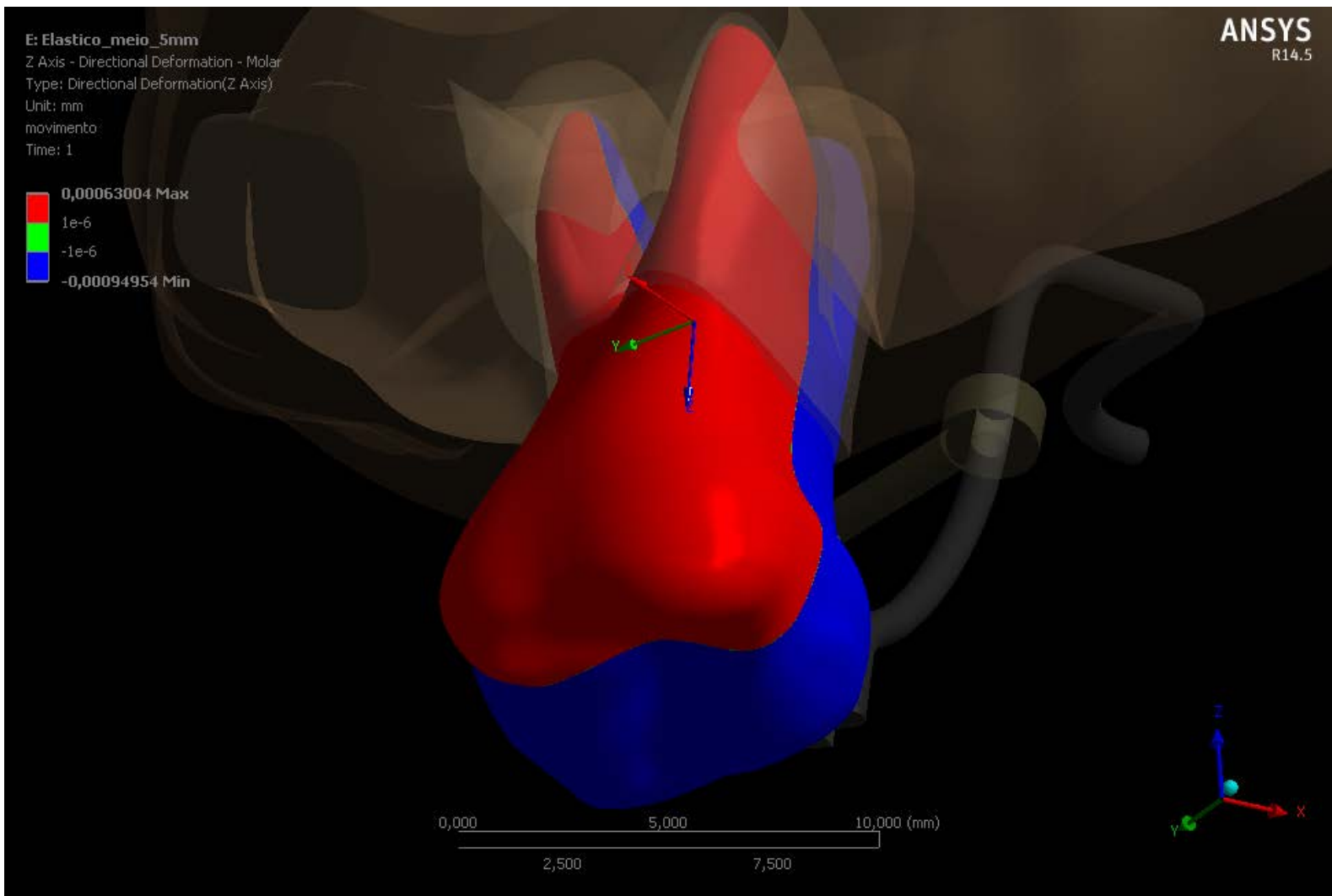

Figura 57 - Deslocamento direcional (eixo Z) com ativação 5 mm médio, 2 cores - perspectiva. 


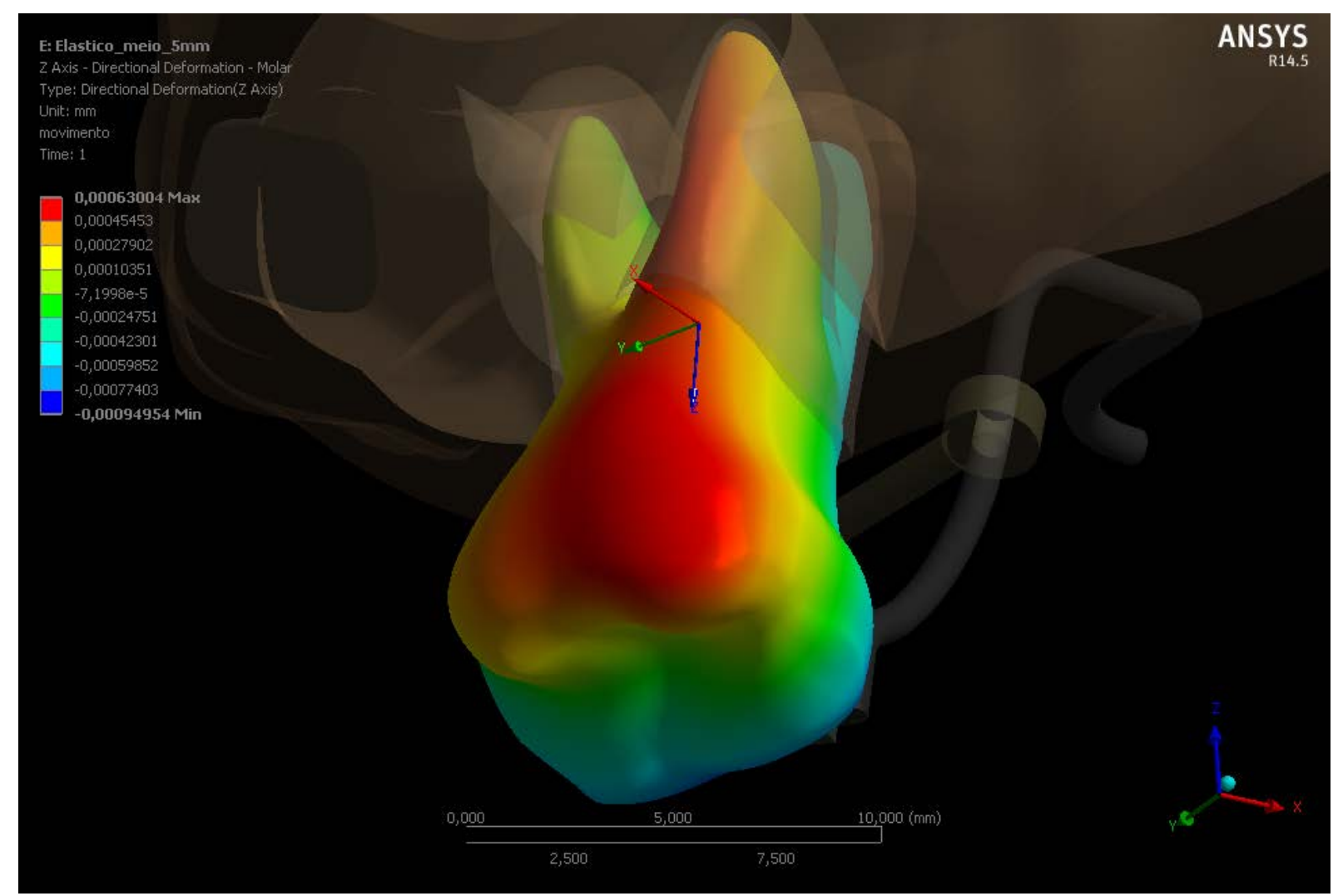

Figura 58 - Deslocamento direcional (eixo Z) com ativação $5 \mathrm{~mm}$ médio perspectiva.

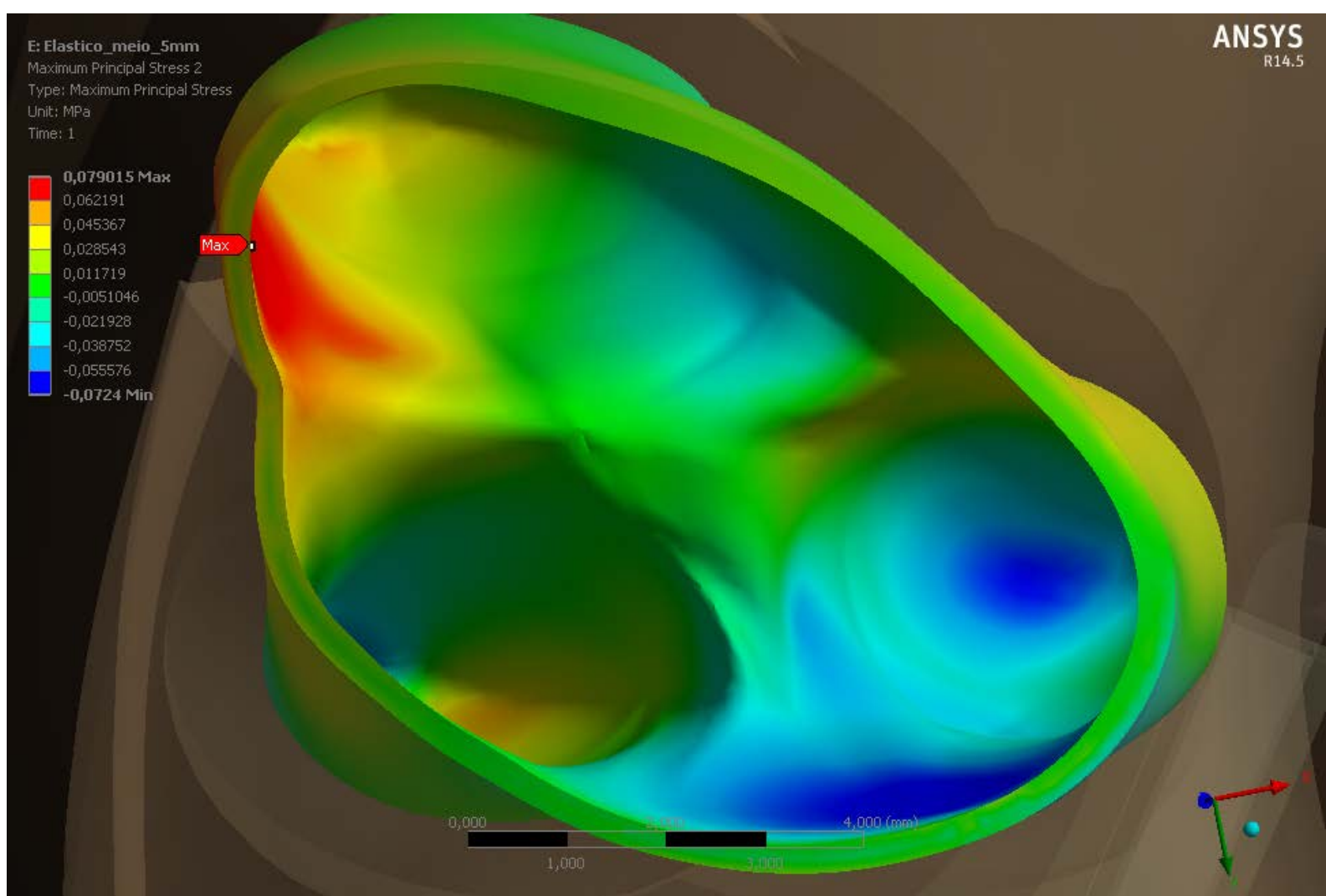

Figura 59 - Tensão Máxima Principal no ligamento periodontal com ativação 5 mm médio, vista oclusal. 


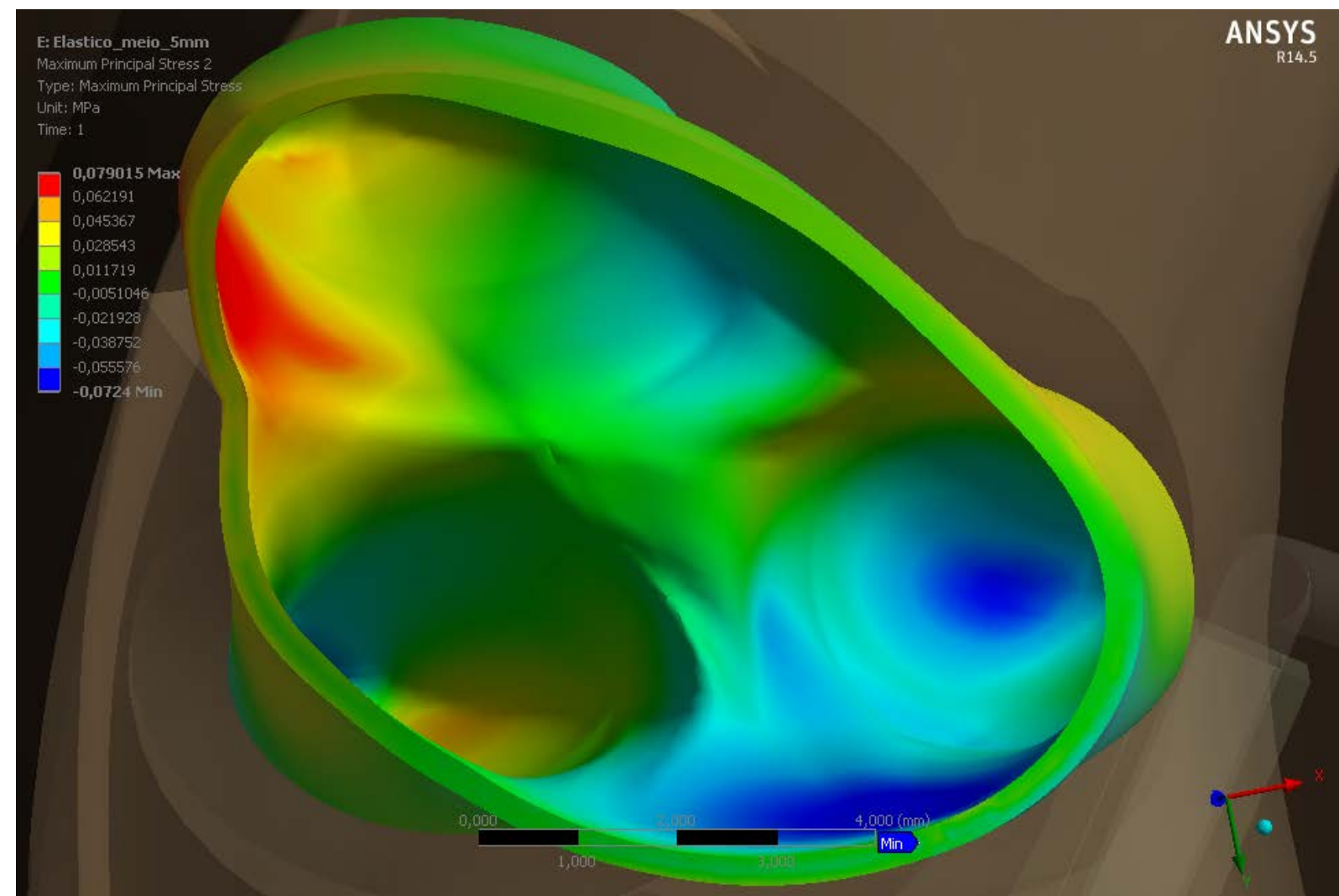

Figura 60 - Tensão Mínima Principal no ligamento periodontal com ativação 5 $\mathrm{mm}$ médio, vista oclusal.

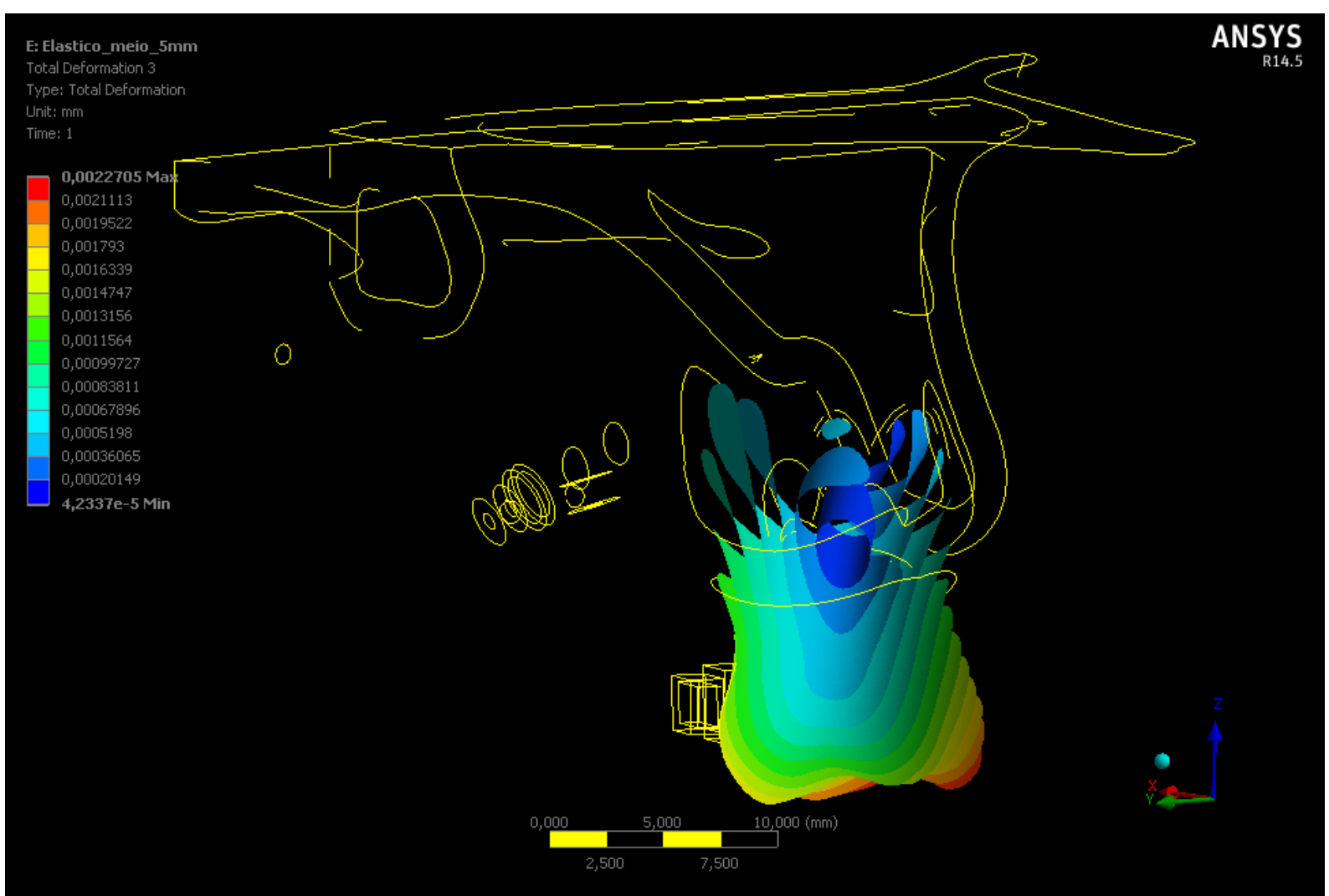

Figura 61 - Deslocamento Total com ativação 5 mm médio - Isosurface.

Resultante $=$ Efeito de pouca intrusão e distalização com giro anti-horário 
(angulação distal da coroa) - indicado para situações onde se deseja distalizar o molar com pouco efeito de giro e um pouco de intrusão, como em casos de overbite normal ou levemente aumentado.

\subsubsection{Ativação 8 mm médio}

Ativação com a cabeça do microparafuso posicionada a $8 \mathrm{~mm}$ medial à cervical do molar e com a inserção do elástico na posição média em relação à BTP. A Figura 62 e a Figura 63 mostram, em uma vista lingual, o deslocamento direcional A-P (no eixo $Y$ ). A cor vermelha indica que a coroa e a furca tendem a se deslocar para distal, enquanto que os terços apicais radiculares, imediatamente após a ativação, tendem a se deslocar para mesial. A Figura 64 e a Figura 65 mostram, em perspectiva, o deslocamento direcional vertical (no eixo Z). A cor vermelha indica que quase a metade lateral (vestibular) do dente tende a extruir e uma parte da medial (palatina) tende a intruir (rotação). A Figura 66 evidencia, em vista oclusal, a distribuição das tensões de tração (Tensão Máxima Principal) e a indicação de que o ponto em que há maior intensidade do esforço de tração está localizado na região mésio-vestibular da raiz disto-vestibular (Max). A Figura 67 evidencia, em vista oclusal, a distribuição das tensões de compressão (Tensão Mínima Principal) e a indicação de que o ponto em que há maior esforço de compressão está localizado no ápice da raiz palatina (Min). A Figura 68 evidencia, com a ferramenta Isosurface, as camadas (superfícies) de pontos com a mesma intensidade de deslocamento, 0 eixo em que se encontra o centro de resistência, representado pelo eixo que passa pelo centro dos círculos azuis (difere dos resultados das ativações anteriores) e um ponto neste eixo em que há o menor deslocamento do dente (Min). 
H: Elastico_meio_8m m

Axis - Directional Deformation - Molar

Type: Directional Deformation $Y$ Axis

Unit: $\mathrm{mm}$

Time: 1

0,00051593 Max

1e-6

$-1 \mathrm{e}-6$

$-8,3832 \mathrm{e}-5 \mathrm{Min}$

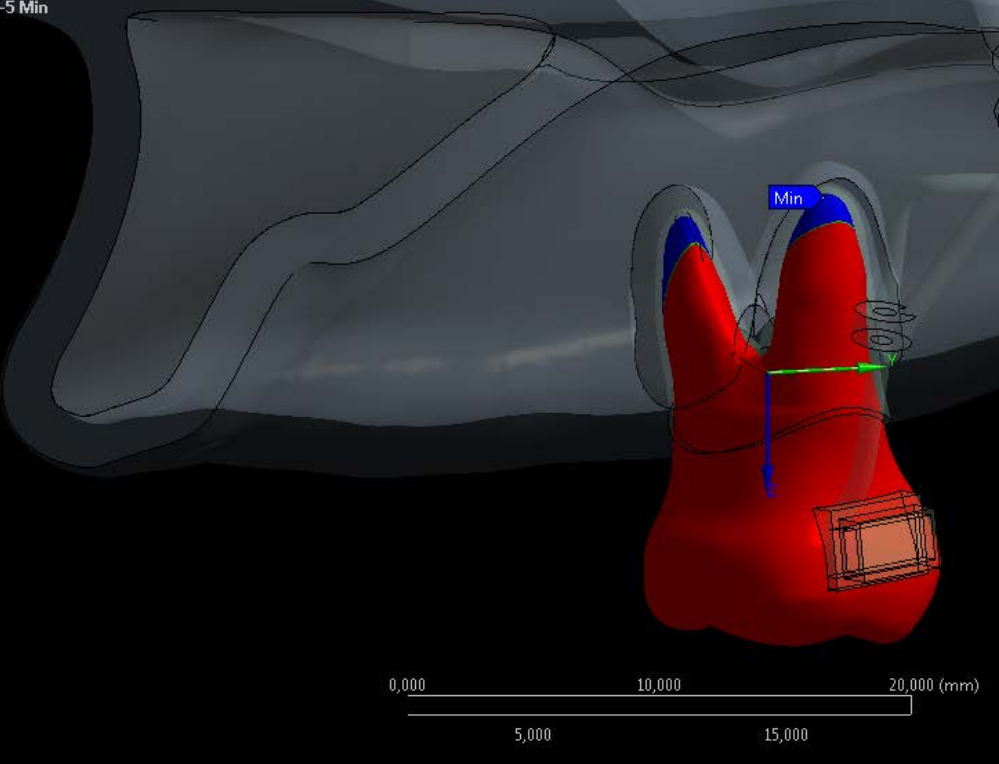

Figura 62 - Deslocamento direcional (eixo Y) com ativação 8 mm médio, 2 cores - vista lingual.

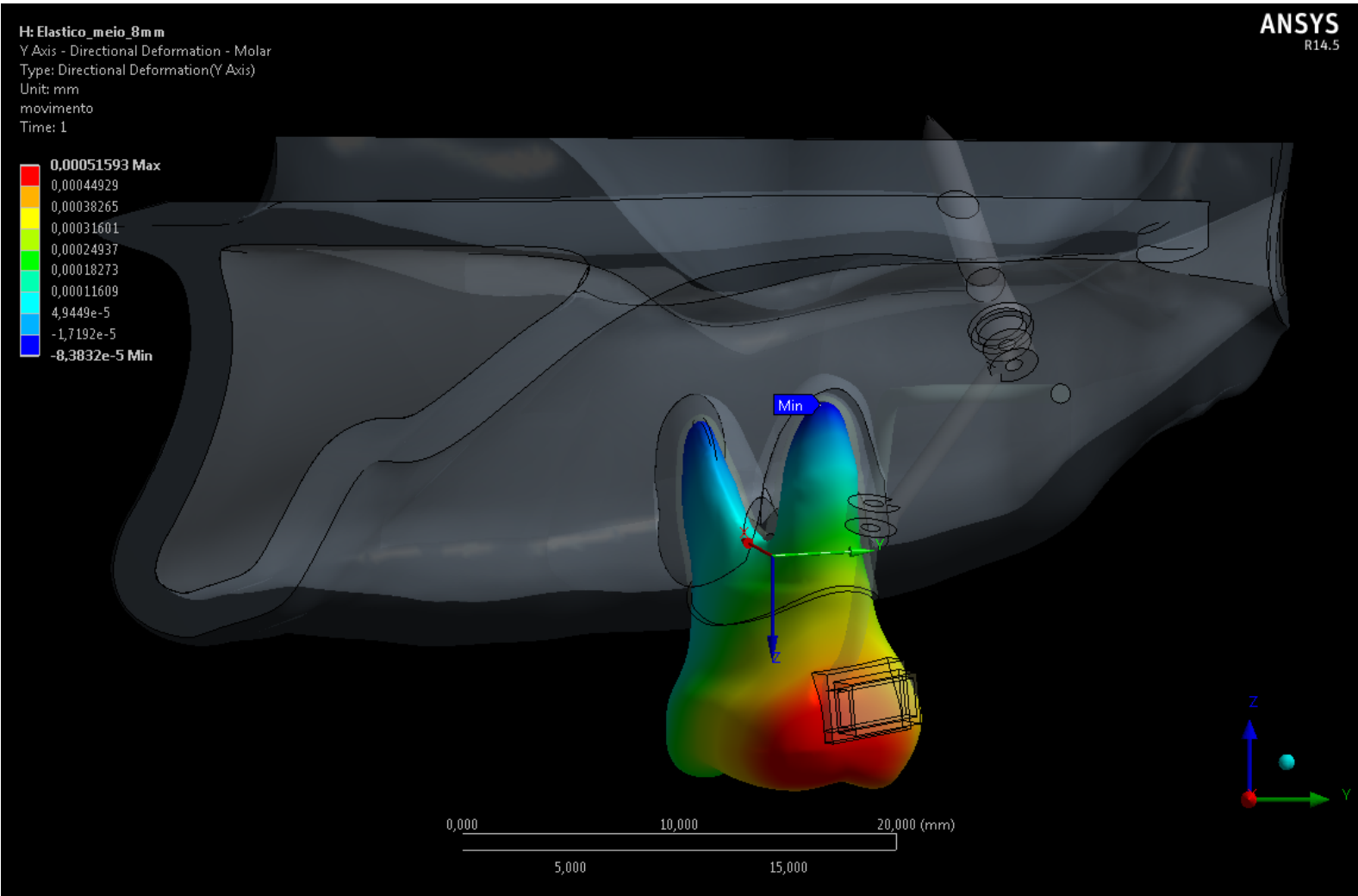

Figura 63 - Deslocamento direcional (eixo Y) com ativação 8 mm médio vista lingual. 


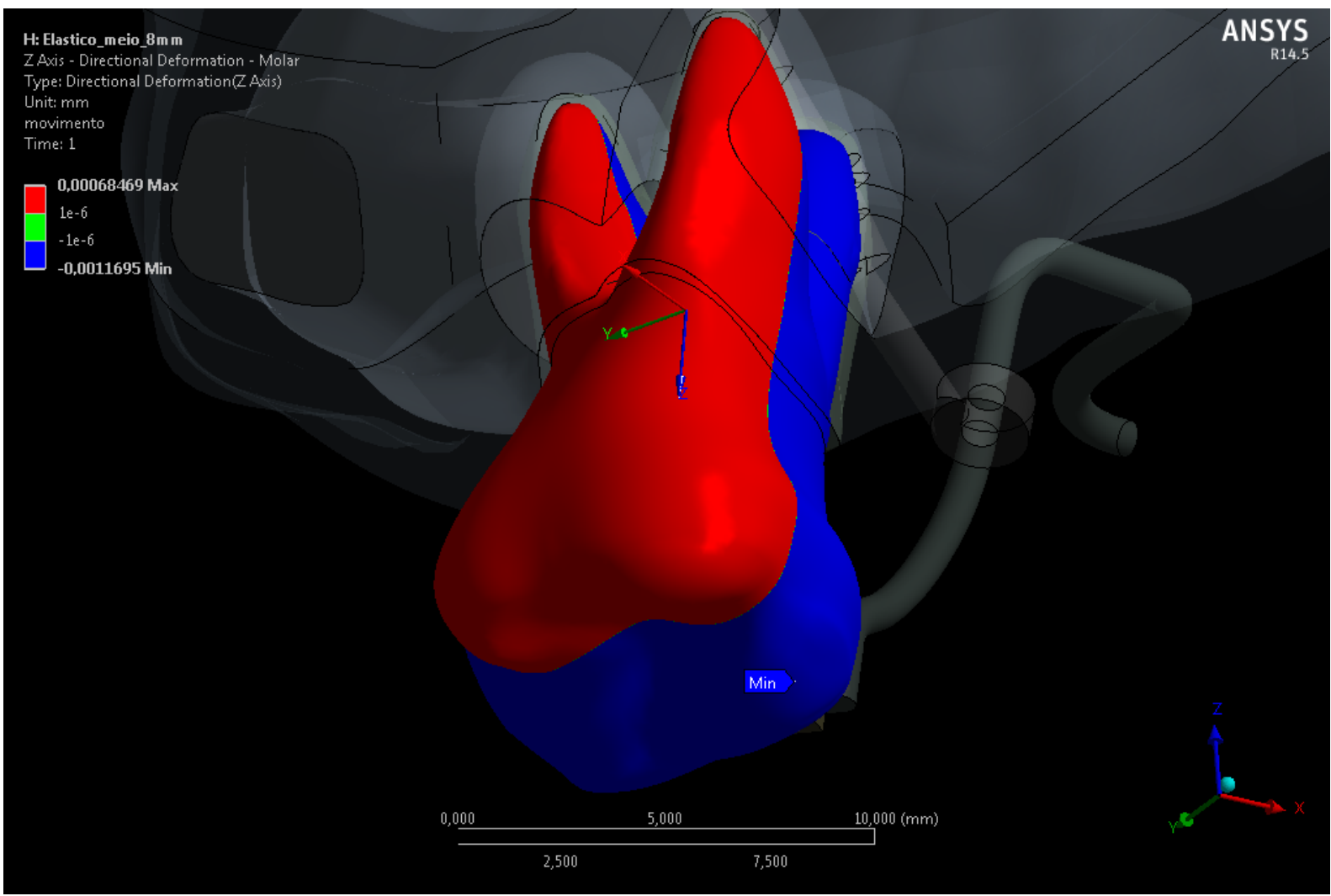

Figura 64 - Deslocamento direcional (eixo Z) com ativação 8 mm médio, 2 cores - perspectiva.

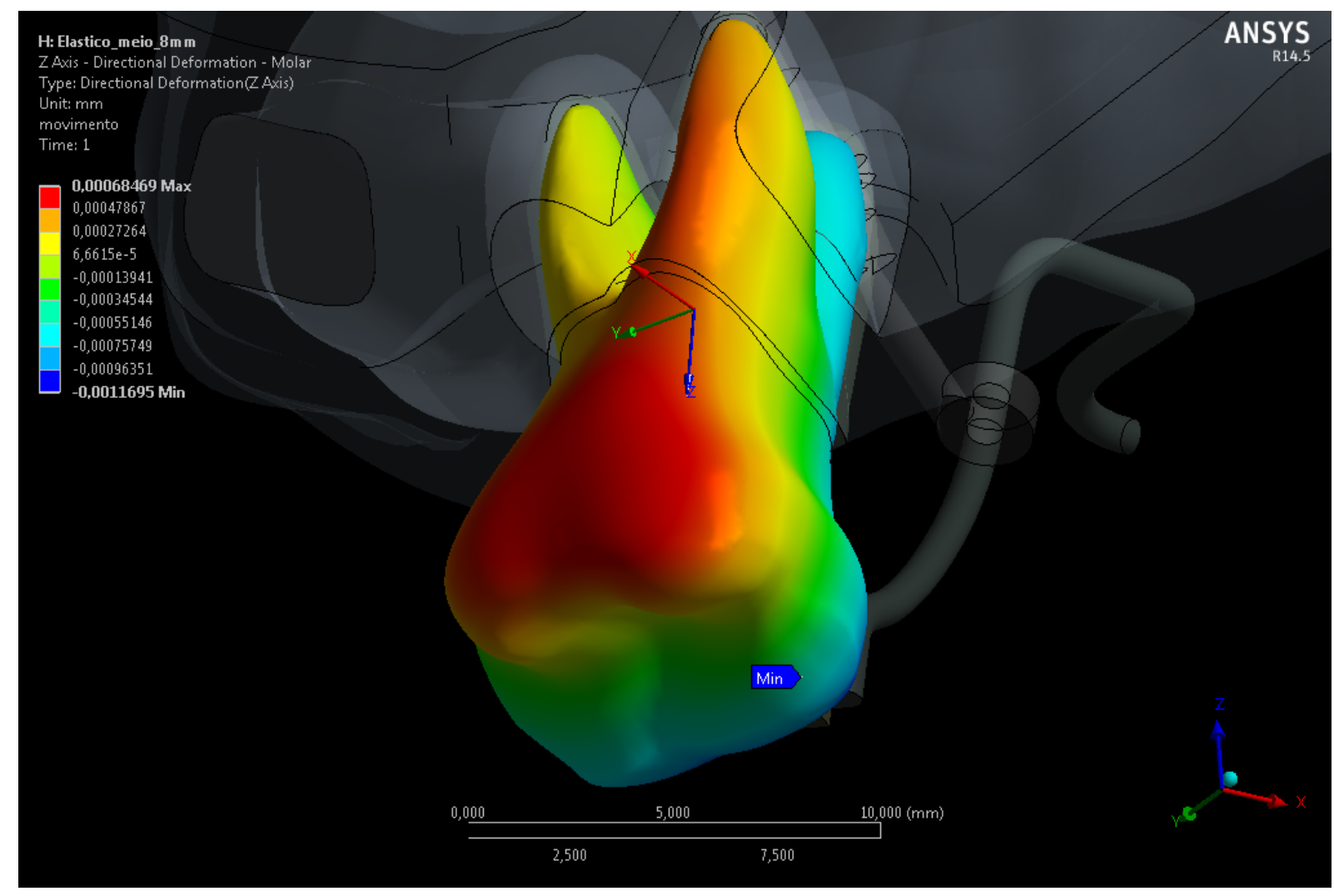

Figura 65 - Deslocamento direcional (eixo Z) com ativação 8 mm médio perspectiva. 


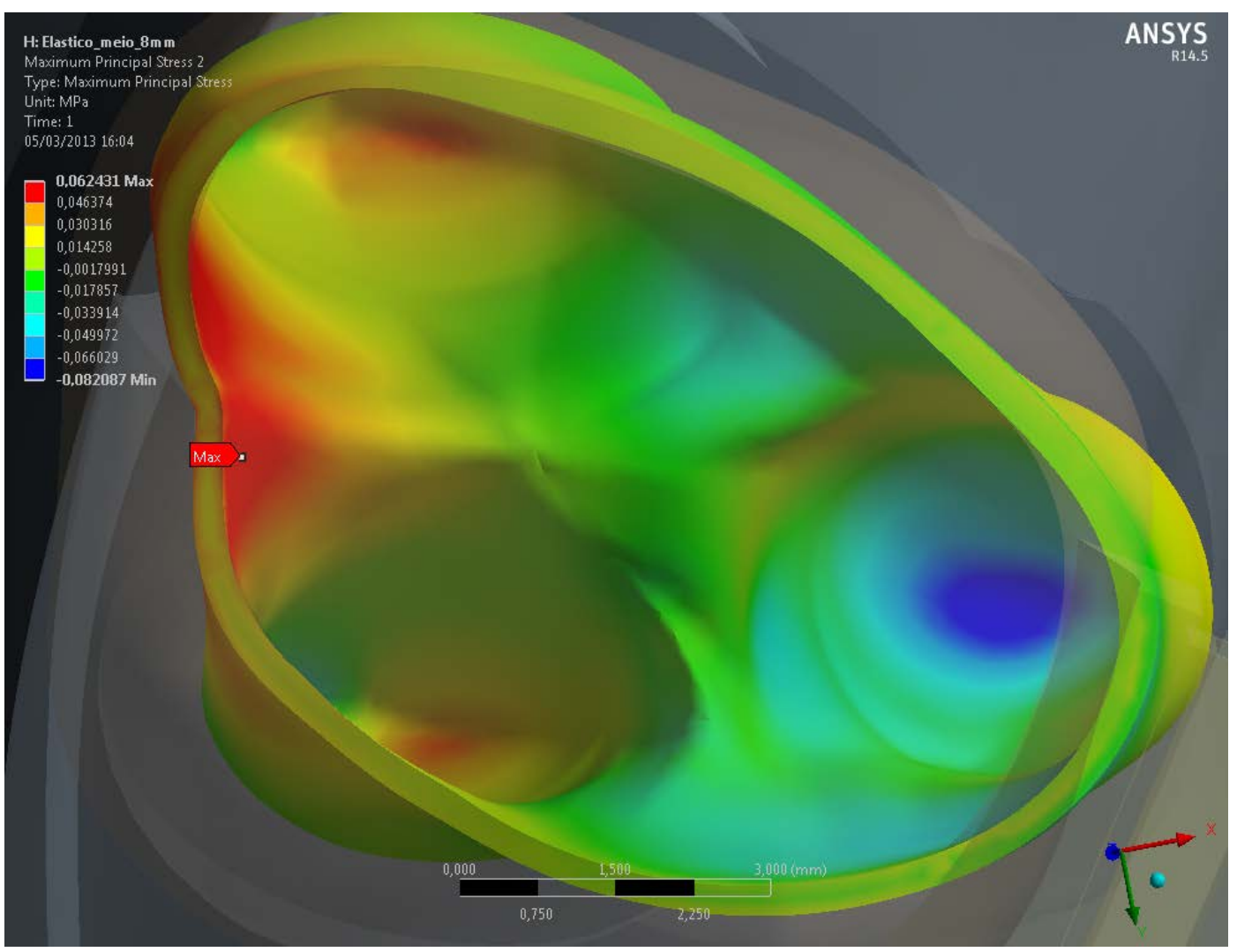

Figura 66 - Tensão Máxima Principal no ligamento periodontal com ativação 8 $\mathrm{mm}$ médio, vista oclusal.

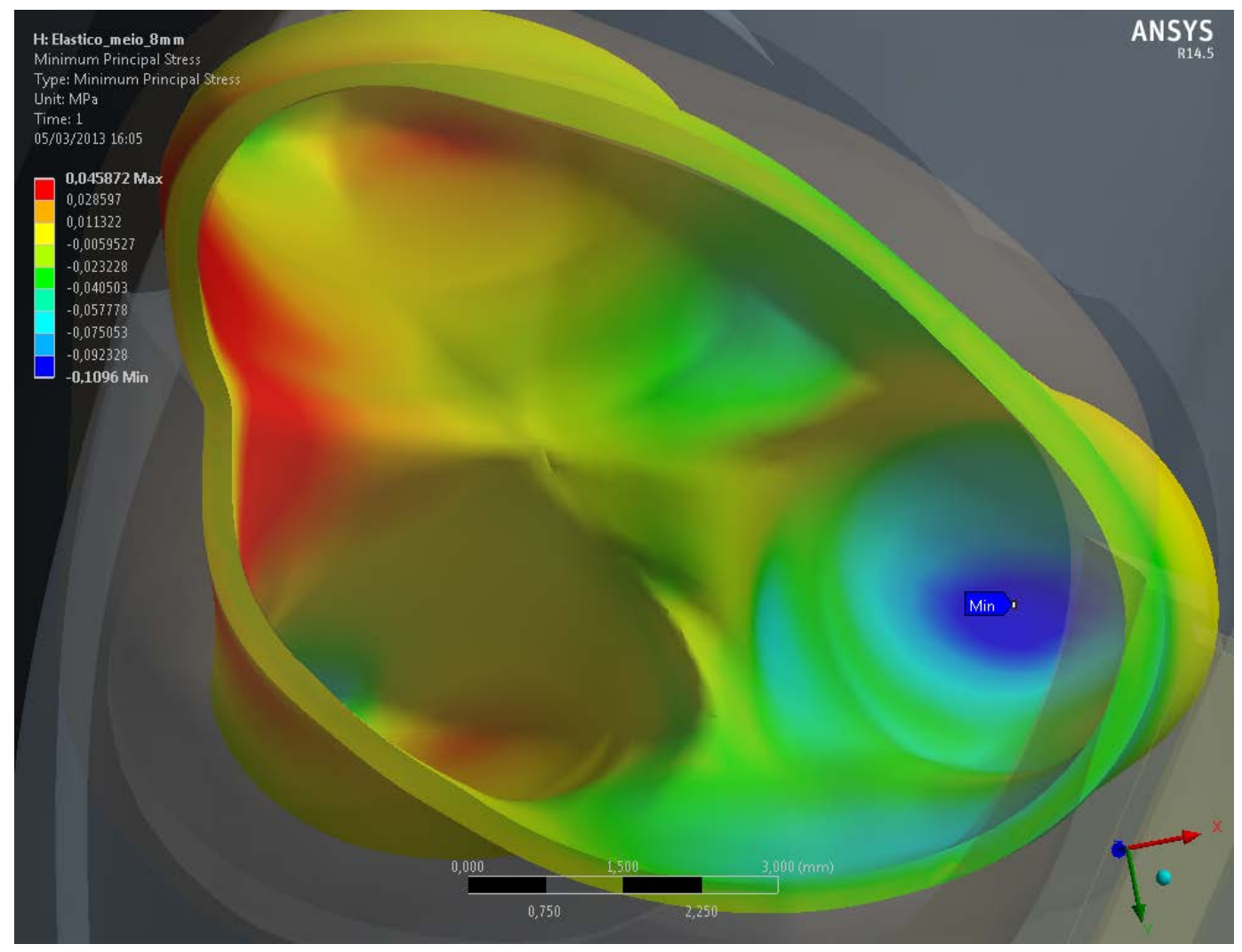

Figura 67 - Tensão Mínima Principal no ligamento periodontal com ativação 8 mm médio, vista oclusal. 


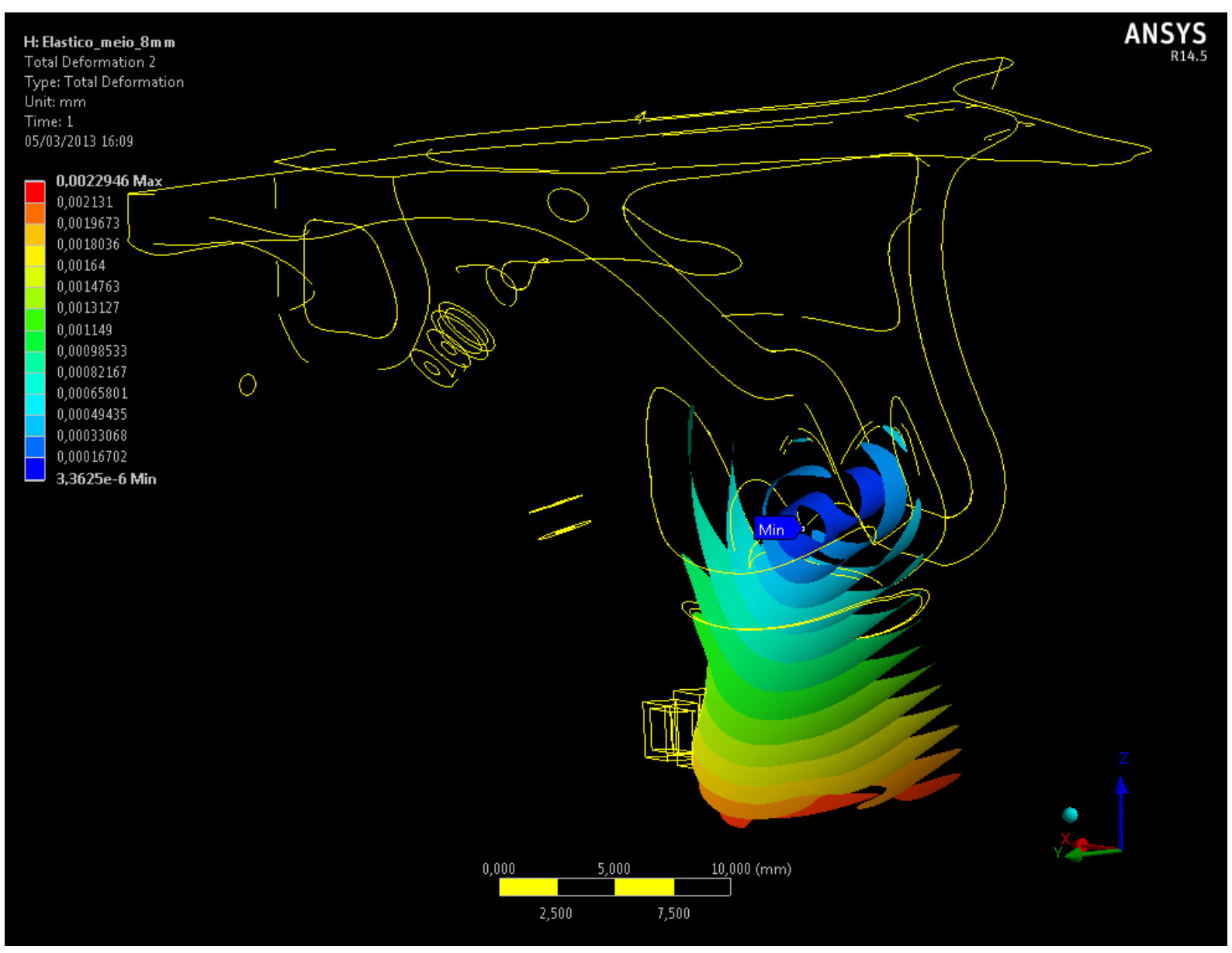

Figura 68 - Deslocamento Total com ativação 8 mm médio - Isosurface.

Resultante $=$ Efeito de muita intrusão, pouca distalização (metade da de $2 \mathrm{~mm}$ alto) e muito pouco giro anti-horário (angulação distal da coroa) - indicado para situações onde se deseja intrusão quase pura do molar, com giro anti-horário (angulação distal da coroa).

\subsubsection{Ativação $8 \mathrm{~mm}$ apical}

Ativação com a cabeça do microparafuso posicionada a $8 \mathrm{~mm}$ medial à cervical do molar e com a inserção do elástico na menor distância entre a cabeça do parafuso e a BTP. A Figura 69 e a Figura 70 mostram, em uma vista lingual, o deslocamento direcional A-P (no eixo Y). A cor vermelha indica que a coroa e a furca tendem a se deslocar para distal, enquanto que os terços apicais radiculares, imediatamente após a ativação, tendem a se deslocar para mesial (rotação semelhante à da ativação $2 \mathrm{~mm}$ cervical, mas em maior intensidade). A Figura $71 \mathrm{e}$ a Figura 72 mostram, em perspectiva, o deslocamento direcional vertical (no eixo Z). 
A cor vermelha indica que quase a metade lateral (vestibular) do dente tende a extruir e uma parte da medial (palatina) tende a intruir (rotação). A Figura 73 evidencia, em vista oclusal, a distribuição das tensões de tração (Tensão Máxima Principal) e a indicação de que o ponto em que há maior intensidade do esforço de tração está localizado na região mésio-vestibular da raiz disto-vestibular (Max). A Figura 74 evidencia, em vista oclusal, a distribuição das tensões de compressão (Tensão Mínima Principal) e a indicação de que o ponto em que há maior esforço de compressão está localizado no ápice da raiz palatina (Min). A Figura 75 evidencia, com a ferramenta Isosurface, as camadas (superfícies) de pontos com a mesma intensidade de deslocamento, o eixo em que se encontra o centro de resistência, representado pelo eixo que passa pelo centro dos círculos azuis (semelhante ao da ativação $8 \mathrm{~mm}$ média). A Figura 76 evidencia a ação das forças tensoras sobre 0 osso alveolar, distribuídas nos 3 eixos espaciais, presentes em maior intensidade no fundo do alvéolo da raiz palatina.

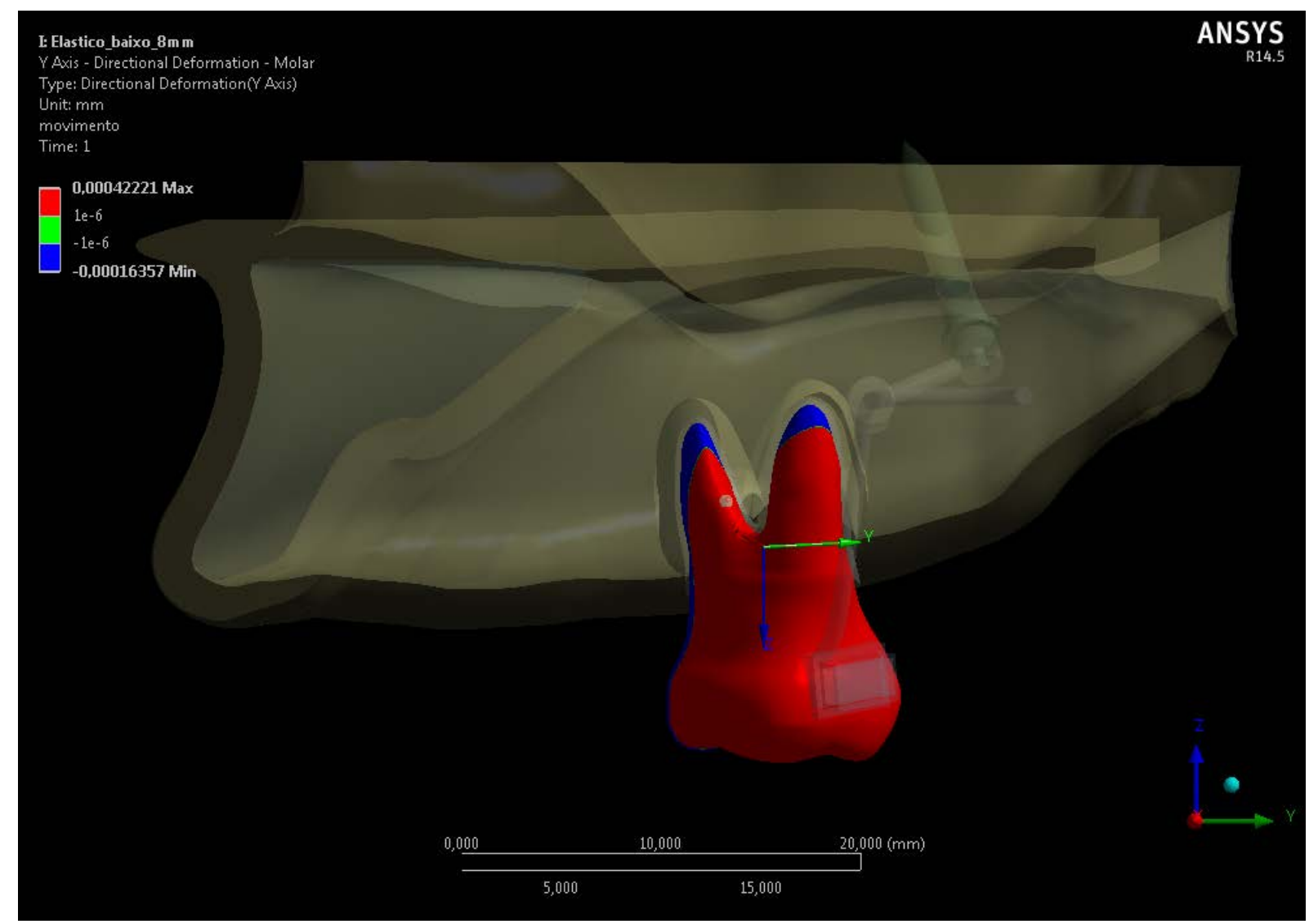

Figura 69 - Deslocamento direcional (eixo Y) com ativação 8 mm apical, 2 cores - vista lingual. 


\section{Elastico_baixo_ $8 \mathrm{~mm}$}

ANSYS

Y Axis - Directional Deformation - Molar

Thes - Direction Deformation $-M$

Unit: $\mathrm{mm}$

movimento

Time: 1
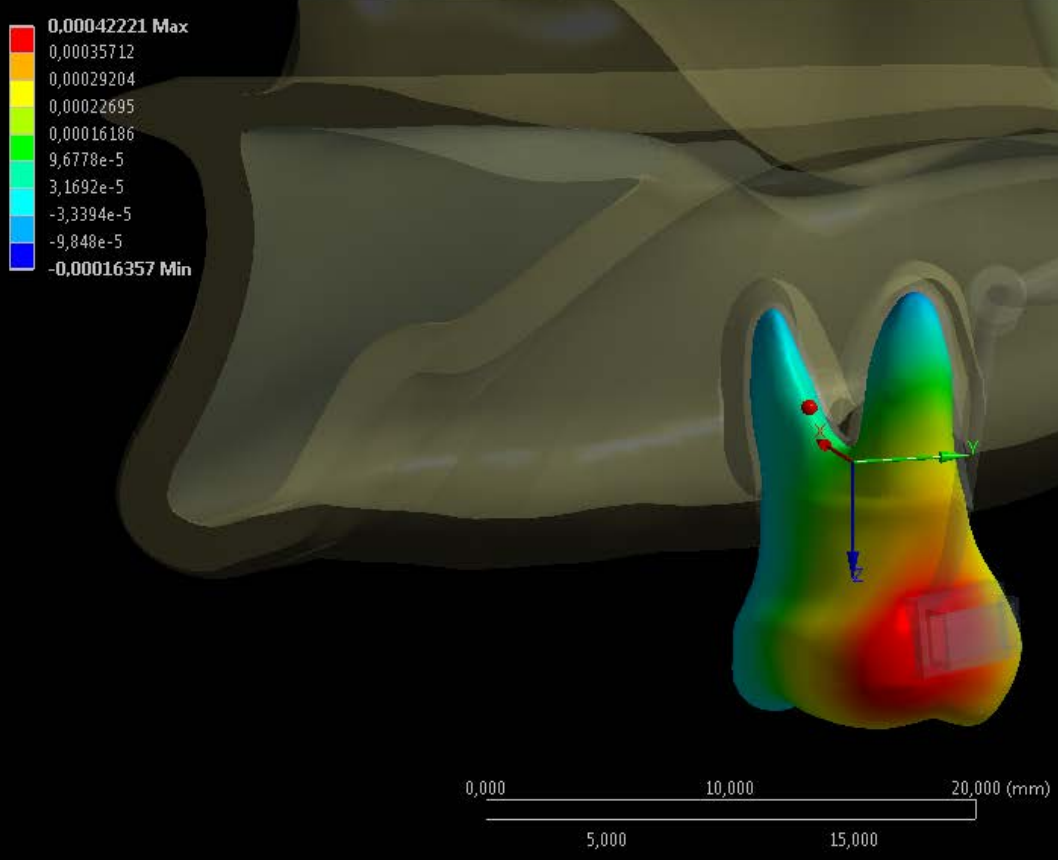

Figura 70 - Deslocamento direcional (eixo Y) com ativação 8 mm apical - vista lingual.

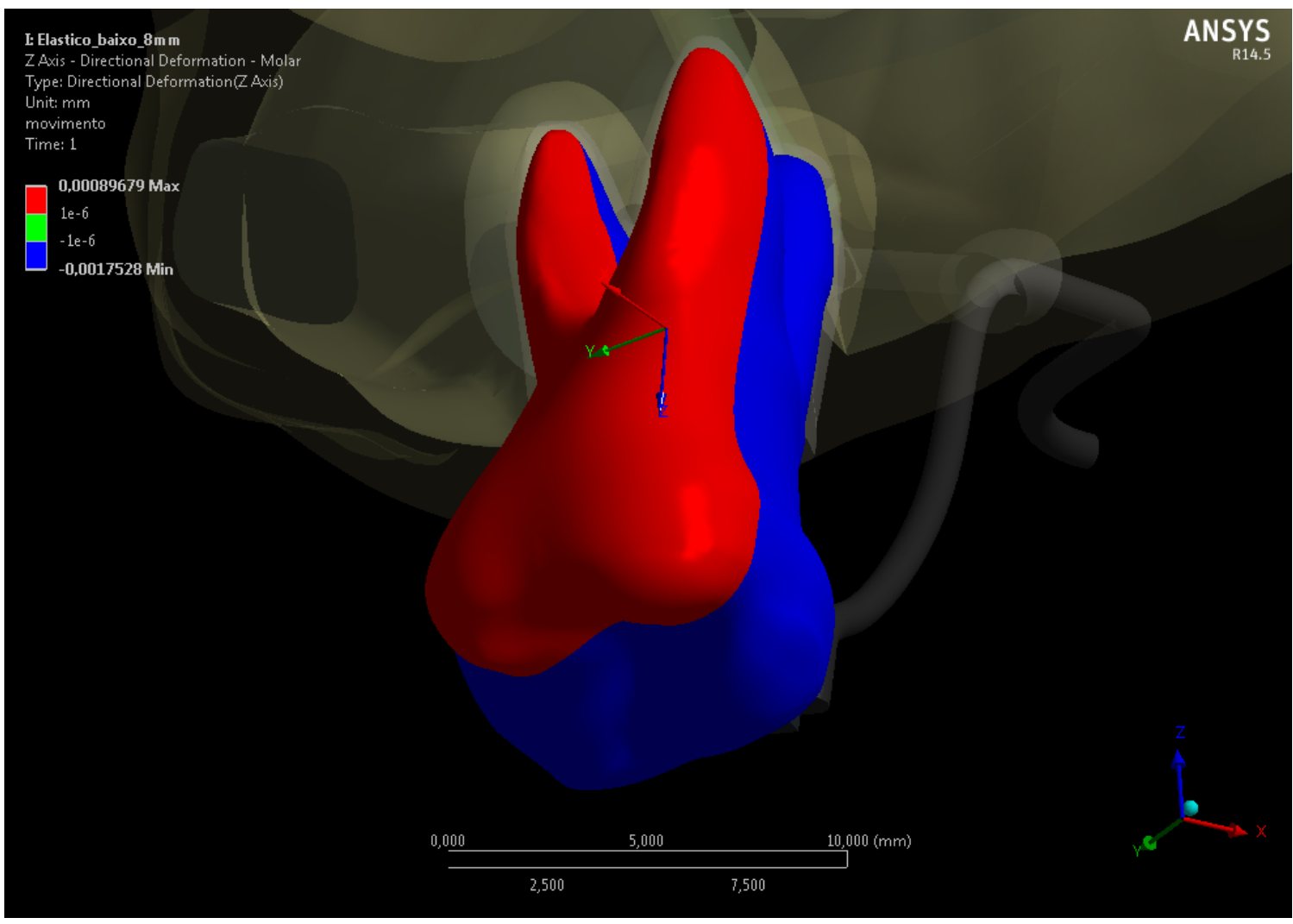

Figura 71 - Deslocamento direcional (eixo Z) com ativação 8 mm apical, 2 cores - perspectiva. 


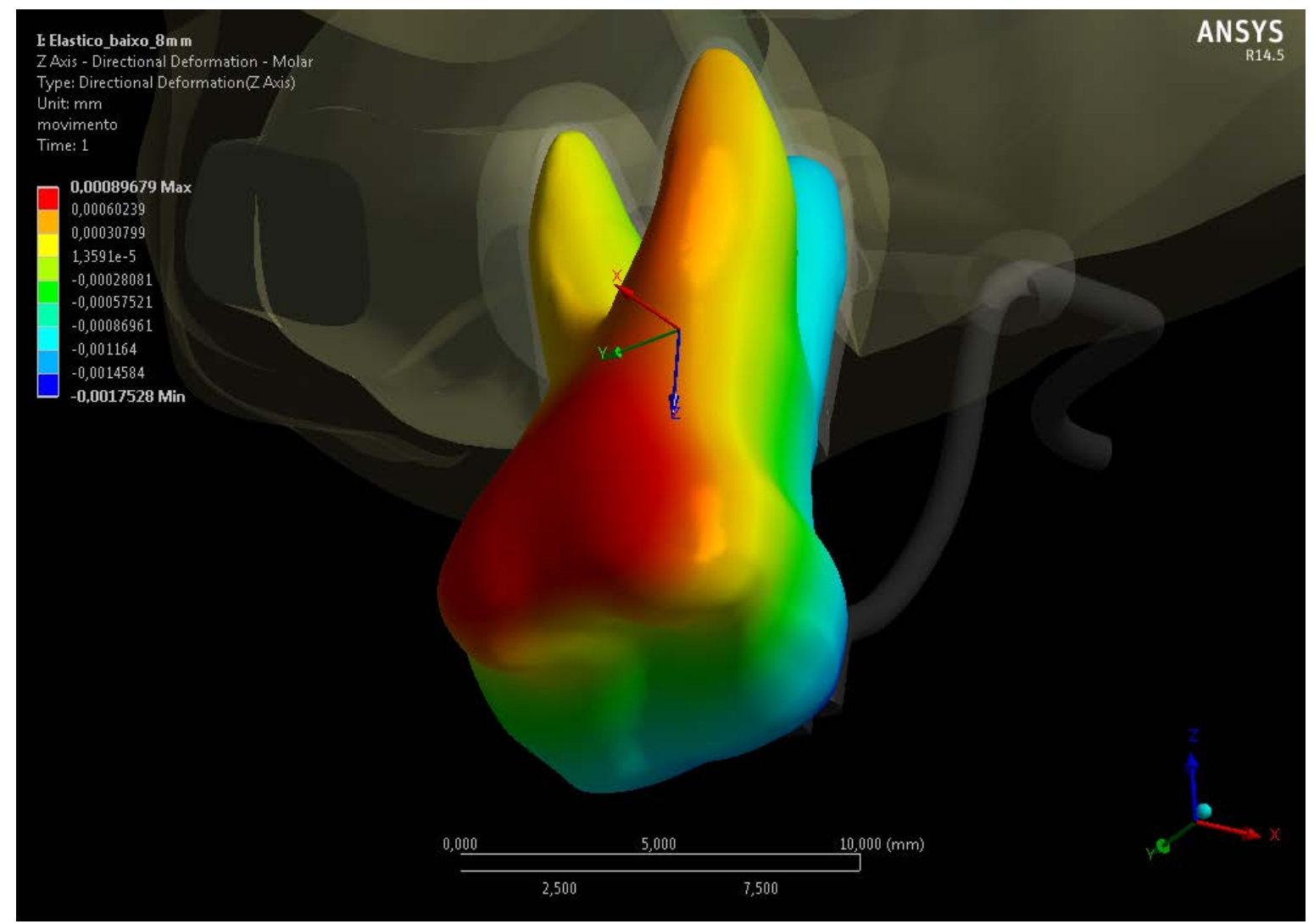

Figura 72 - Deslocamento direcional (eixo Z) com ativação 8 mm apical perspectiva.

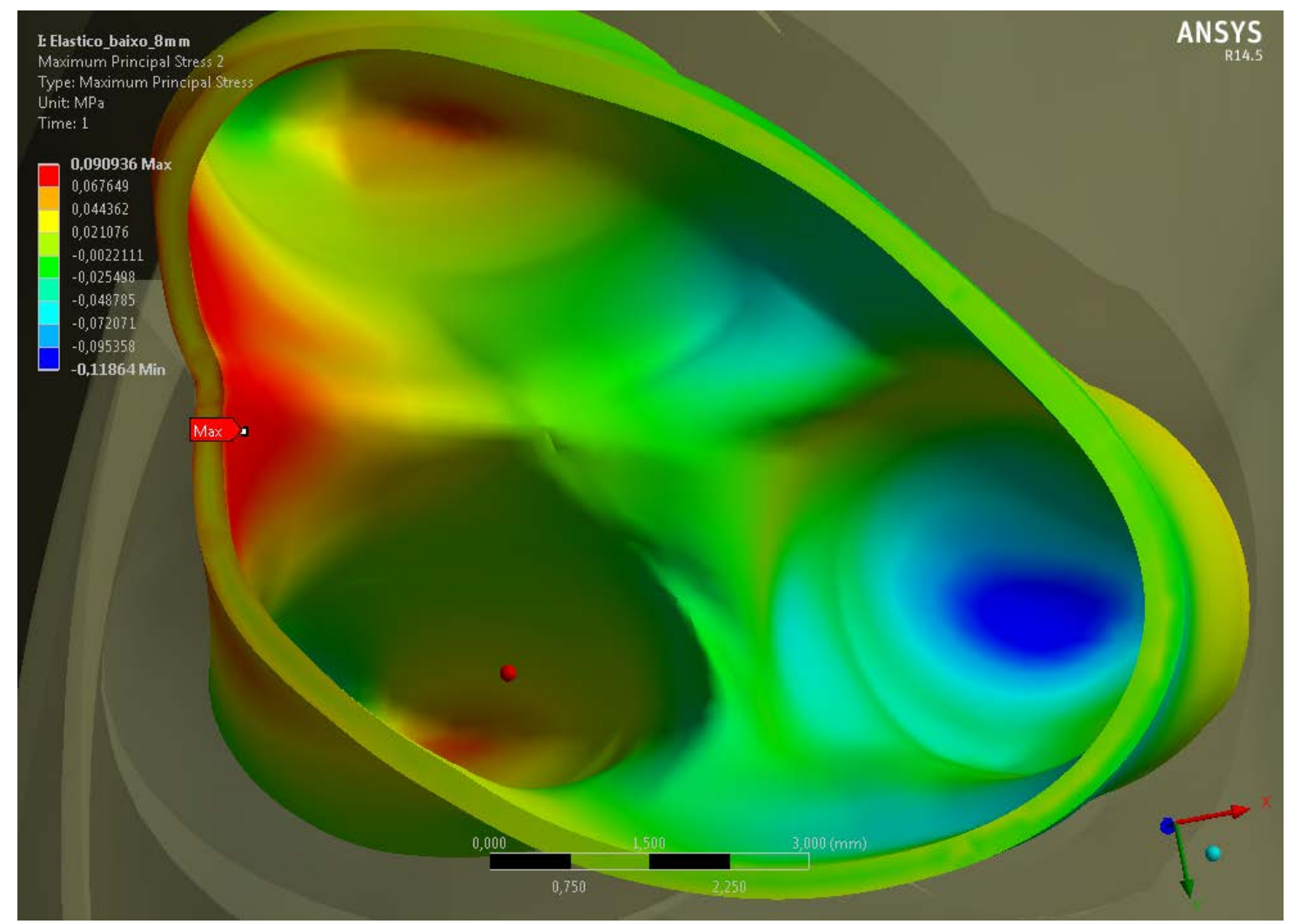

Figura 73 - Tensão Máxima Principal no ligamento periodontal com ativação 8 $\mathrm{mm}$ apical, vista oclusal. 


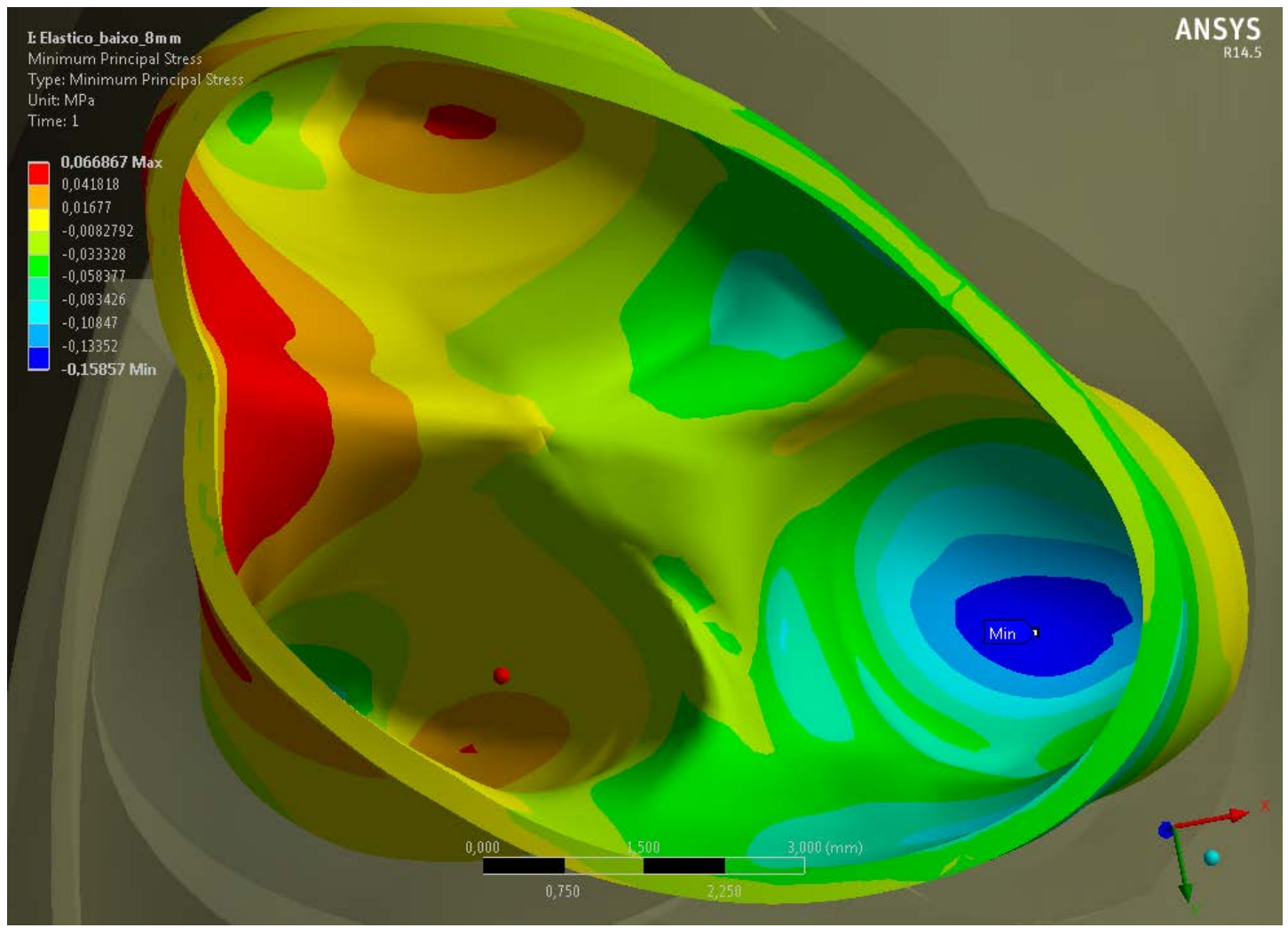

Figura 74 - Tensão Mínima Principal no ligamento periodontal com ativação 8 $\mathrm{mm}$ apical, vista oclusal.

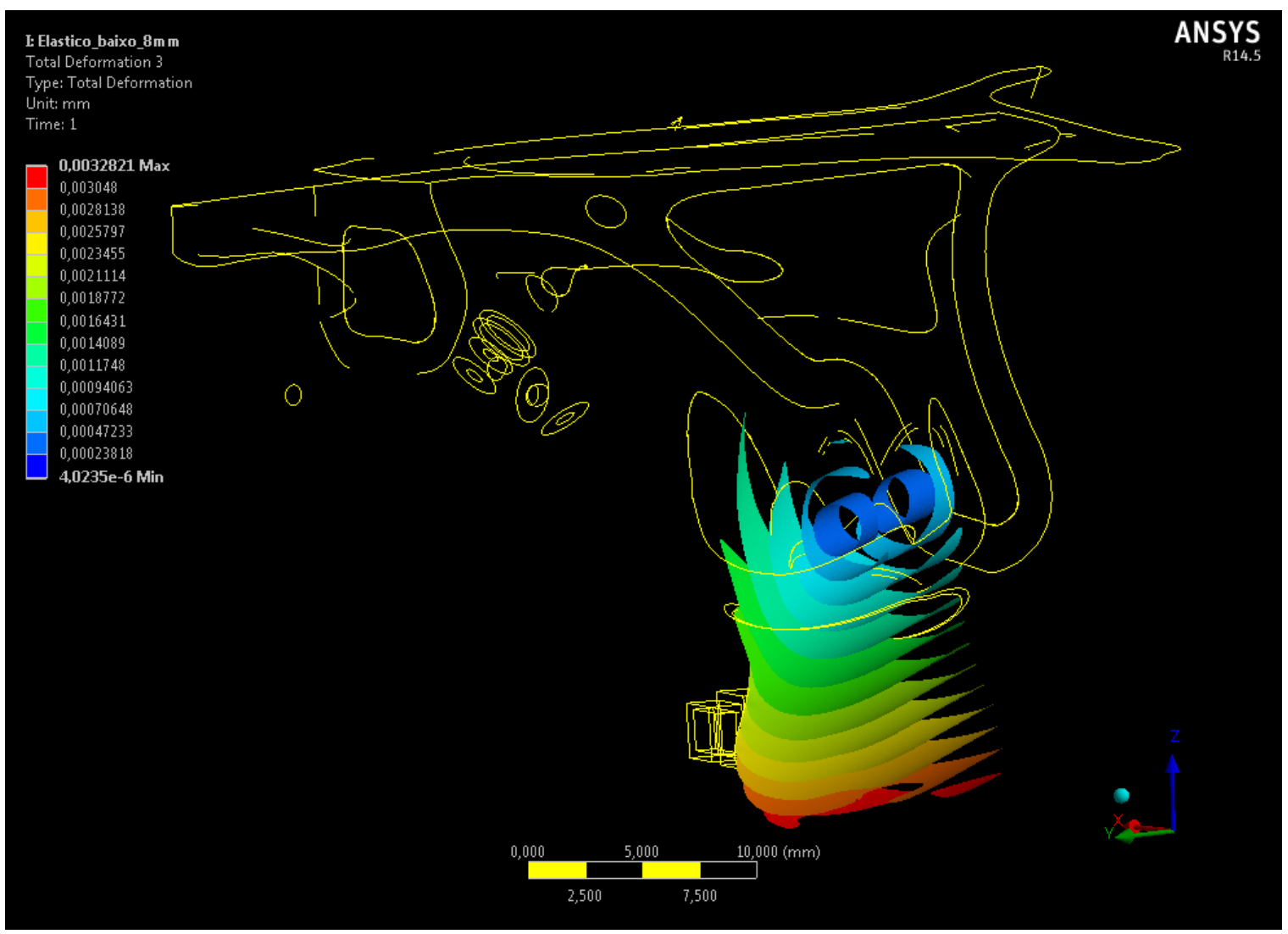

Figura 75 - Deslocamento Total com ativação 8 mm apical - Isosurface. 


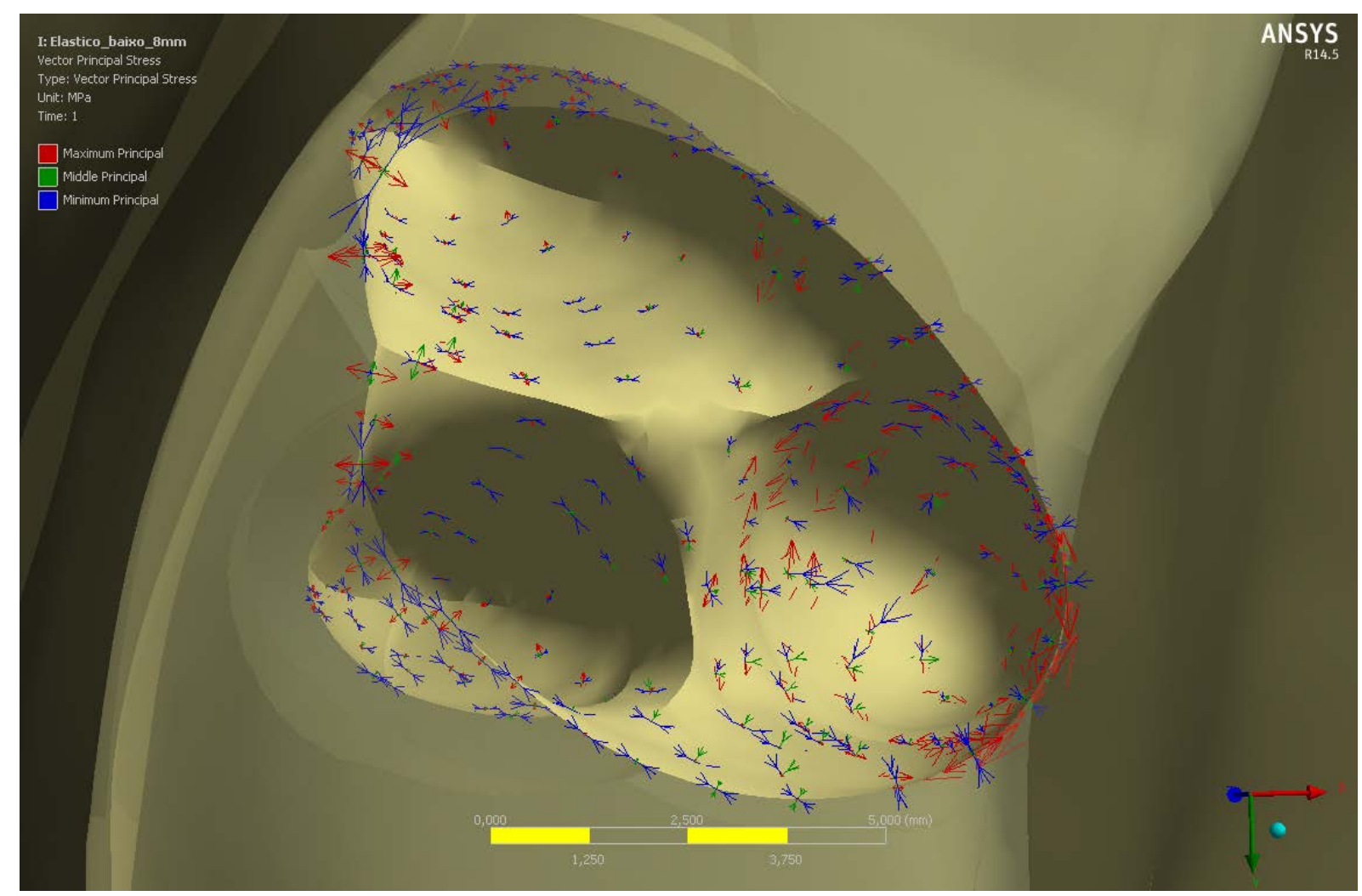

Figura 76 - Vetor de Tensão Principal no alvéolo com ativação 8 mm apical, vista oclusal.

Resultante = Efeito de muita intrusão e muito pouca distalização (menos da metade da obtida com a ativação $8 \mathrm{~mm}$ média) com muito giro anti-horário (angulação distal da coroa) - indicado para situações onde se deseja intruir o molar com muito pouca distalização. 


\section{DISCUSSÃO}

Sun Tzu (69), um antigo general, estrategista e filósofo chinês há muito disse que se conheceres a ti mesmo e a teu inimigo, serás vitorioso em todos os teus combates. Na ortodontia, vitória e derrota podem não ter consequências tão dramáticas como em uma batalha entre exércitos, mas subestimar a importância de se conhecer em profundidade nosso paciente e de se perceber a nossa incapacidade em resolver satisfatoriamente seus problemas, pode ser a diferença entre o sucesso e o fracasso. Nesse âmbito, a cooperação entre pesquisadores das Ciências Exatas e das Ciências da Saúde vem produzindo instrumentos reais e virtuais de diagnóstico e tratamento, desenvolvidos para obter informações de melhor qualidade do paciente, assim como sua resposta às terapias, tendo em vista diminuir o impacto dos aspectos negativos, ainda inerentes aos tratamentos ortodônticos, na vida dos pacientes.

\section{1 - O PROBLEMA E AS SOLUÇÕES}

A má oclusão de Classe II maxilar ou com leve protrusão dentária pode ser tratada de várias formas, que incluem extrações (4), cirurgia ortognática e a forma mais comum, em pacientes com pouco ou nenhum crescimento, com aparelhos que provoquem distalização dos molares (5). A distalização também pode ser indicada para tratamentos sem extração, como casos de Classe I com biprotrusão (distalização superior e inferior), correção de apinhamento e nos preparos ortocirúrgicos em pacientes Classe III (distalização superior) $(4,6)$.

O sacrifício da ancoragem e a dependência da cooperação do paciente são problemas que foram minimizados ou eliminados com as técnicas de ancoragem esquelética, dentre as quais os MPOs se destacam por apresentar como vantagens: a facilidade de aplicação em várias situações clínicas, o pequeno tamanho, simplicidade na técnica de instalação e remoção, possibilidade de se aplicar carga imediatamente após a instalação, custo razoável e principalmente, pela grande aceitação por parte dos pacientes $(10,13,16,21,36)$. Depois de Kanomi (12), vários autores demonstraram a versatilidade dos MPOs usando-os para vários tipos de ancoragem (61), como em tratamento de biprotrusão alveolar, preservação de ancoragem e torque de incisivos durante a retração anterior, descruzamento de 
mordida, verticalização, intrusão e especialmente distalização de molares, associados ou não a aparelhos intrabucais, sem efeitos colaterais nos dentes anteriores $(5,6,8,15,16,19,21,40)$.

No método tradicional de retração anterior ou distalização com MPOs, o local preferido para sua instalação é pela vestibular, entre as raízes dos molares e prémolares superiores $(2,6,16,36,40,61,62)$. Este procedimento é indicado quando não se deseja perda de ancoragem do segmento posterior ou quando a distalização necessária for de menor intensidade. Na distalização, é mais lento do que outros métodos com ancoragem intraoral recíproca, mas com tempo total de tratamento igual ou menor, porque os dentes anteriores são retraídos simultaneamente à distalização dos molares, embora com angulação distal de coroa, mais pronunciada nos segundos molares (16). Outra vantagem do uso do MPO é que de maneira geral, aparelhos distalizadores tendem a abrir a mordida e aumentar o ângulo mandibular ao distalizar os molares, o contrário do que acontece na distalização com MPOs, na qual o componente intrusivo tende a diminuir o ângulo mandibular, o que pode ser especialmente útil em pacientes com padrão facial vertical e/ou mordida aberta anterior (16). Porém, quando instalado pela vestibular, o próprio MPO pode ser um limitador do movimento distal, pois as raízes não podem transpassá-lo (8), por isso sua indicação é limitada a problemas de Classe II até meia cúspide (2). A solução encontrada para distalizar irrestritamente todos os dentes maxilares foi relocar os microparafusos quando houver grande proximidade com as raízes, uma abordagem simples mas de eficiência questionável, por primeiro distalizar o segmento posterior para depois retrair o segmento anterior, uma distalização em dois tempos que invariavelmente demanda mais tempo de tratamento $(2,7,8)$.

Do ponto de vista biomecânico, o osso interradicular, no processo alveolar, é um local vantajoso para instalação do MPO por sua proximidade ao Cres do dente (43). Por outro lado, existe o risco de contato ou dano radicular por haver pouco espaço interradicular e pela variação anatômica entre pacientes (43). Uma forma de evitar o reposicionamento do microparafuso foi encontrar um sítio de instalação que não interferisse no caminho a ser percorrido pelas raízes, que não oferecesse alto risco de afetar estruturas anatômicas nobres e que tivesse estrutura óssea suficiente para suportar cargas ortodônticas.

A região palatina $(8,13)$ distal aos molares é um local viável para instalação de MPOs $(19,21)$ e as vantagens do palato em relação aos outros sítios são: por ser 
um local favorável do ponto de vista biomecânico (BAUMGAERTEL 2009), as áreas medianas e paramedianas oferecem osso cortical com densidade e espessura suficientes $(8,13)$, podem ser instalados na região paramediana de pacientes em crescimento sem risco às suturas (13), a distância interradicular reduz o risco de contato com a raiz (43), a mucosa com espessura aproximada de $3 \mathrm{~mm}$ garante estabilidade biomecânica, a histomorfologia permite fácil instalação (11), a taxa de sucesso de MPOs instalados na região molar palatina é igual (50) ou maior do que nos instalados na região molar vestibular $(13,40)$ e os sistemas de força palatinos apresentam menos angulação radicular do que os sistemas de força por vestibular (9), possivelmente pelo braço de momento ser menor e passar mais próximo ao Cres do molar. Dobranszki (21) ressalta que, dependendo da posição, MPOs instalados no palato não interferem no caminho a ser percorrido pelas raízes dos molares durante a distalização, uma vantagem em relação aos MPOs instalados pela vestibular, que dependendo da quantidade de movimento necessária, podem requerer reposicionamento para retração $(6,8)$. Além disso, podem oferecer controle vertical simultâneo ao movimento ântero-posterior, mas foram encontrados poucos estudos que associem a distalização com MPOs vestibulares ao controle vertical concomitante $(2,4,6)$ e somente um que descreva um sistema de força usando a BTP e MPOs palatinos paramedianos (19), coincidentemente por meio de Análise de Elementos Finitos.

O complicado sistema tridimensional de forças ortodônticas é difícil de ser avaliado com precisão em condições clínicas e estudos demonstraram que a análise de elementos finitos (AEF) é um método confiável para este propósito $(19,24,61$, $62,63,66)$. A interação multidisciplinar permite a simulação de situações clínicas (10) em modelos computacionais, que apresentam resultados tão confiáveis quanto a fidelidade de sua formulação e eliminam grande parte das desvantagens de experimentos envolvendo seres vivos $(22,64,65)$.

\section{2 - ANÁlise DE ELEMENTOS FINITOS E DISCUSSÃO SOBRE A ELABORAÇÃO DO MODELO}

A idéia de Courant (52), de usar pequenos elementos geométricos para analisar tensões, foi desenvolvida por Greenstadt (53) que sugeriu dividir um problema contínuo em um número finito de problemas menores, base matemática da análise que é usada até hoje. Clough (51) foi o primeiro a usar o termo "Finite 
Element Method" (Análise de Elementos Finitos - AEF ou Método de Elementos Finitos - MEF) ao analisar tensões em aviões. Por envolver grande quantidade de cálculos matemáticos, tornou-se necessário um programa de computador que tornasse mais amigável a interface de inserção dos dados do problema a ser analisado, o que ocorreu em 1968, quando a Agência Espacial Norte-Americana (NASA) desenvolveu o programa NASTRAN (Nasa Structural Analysis). Na área odontológica, os primeiros a utilizarem o método foram Huang e Ledley (55) que elaboraram um modelo linear de um dente, avaliaram seu deslocamento de acordo com a magnitude e direção de uma força aplicada na coroa e também discutiram os erros e limitações do método.

Atualmente a AEF é bastante utilizada na Odontologia para análise de tensões (22) em dentes hígidos (59), com lesões cervicais e restaurações (58), elementos protéticos, como pinos intrarradiculares (56), movimentação ortodôntica $(19,23,24,57,61,66)$ e microparafusos ortodônticos $(60,62,63$, 65), em modelos criados a partir de livros de anatomia, artigos, modelos comerciais, médias de sua própria amostra ou de apenas um caso em particular. Como neste trabalho, vários autores usaram Tomografias volumétricas (Cone Beam) como base para elaborar os modelos e, na tentativa de criar um modelo representativo, buscaram formas geométricas que correspondessem a uma porção significativa da população, também baseados em valores médios $(19,30,57,58,62,66)$.

Para este estudo, tornou-se importante criar um modelo virtual de um indivíduo adulto médio, dentro do universo dos pacientes com características de uma má oclusão de Classe II esquelética (com o ângulo ANB inicial $>4^{\circ}$ ), para que os resultados pudessem ser extrapolados para uma porção considerável de pacientes em situação clínica de tratamento (64). Como reportado por Shelly et al. (32), o tratamento cirúrgico tem resultados pobres em pacientes com ANB inicial < $6^{\circ}$ e enfatizam o uso do ângulo ANB como parâmetro na decisão de quando tratar um paciente com abordagem cirúrgica, indicada para melhorar significativamente a estética do perfil nos casos de ângulo ANB inicial de pelo menos $6^{\circ}$. Neste estudo este parâmetro foi utilizado como critério de exclusão para escolha das tomografias dos indivíduos passíveis a tratamento sem abordagem cirúrgica, apenas com distalização molar. Nestas tomografias volumétricas selecionadas, dimensões palatinas foram mensuradas em comprimento, largura e profundidade, de forma semelhante à executada em modelos de estudo de gesso de 135 pacientes entre 12 
e 21 anos (amostra mais jovem) por Esteves \& Bommarito (31). Estes autores encontraram que a profundidade do palato é maior nos indivíduos do sexo masculino e em dolicofaciais, independente da má oclusão, com média de 19,58 mm $\pm 3,25$ $\mathrm{mm}$, valor semelhante ao utilizado neste estudo $(22,06 \mathrm{~mm} \pm 2,65 \mathrm{~mm})$. A distância intermolar também foi significantemente maior nos indivíduos do sexo masculino, com média de 50,00 $\pm 3,78 \mathrm{~mm}$ ), independente do padrão facial e da má oclusão, semelhante à encontrada neste estudo $(49,56 \mathrm{~mm} \pm 3,64 \mathrm{~mm})$. Em relação ao comprimento ântero-posterior, constataram diferença estatisticamente significante apenas para indivíduos com má oclusão de Classe II, que apresentaram arcos dentários superiores com maior comprimento ântero-posterior, com média de 30,86 $\pm 2,92 \mathrm{~mm}$. A diferença para os valores encontrados neste estudo $(26,46 \mathrm{~mm} \pm 2,60$ $\mathrm{mm}$ ) pode ter ocorrido pela diferença na forma de medir pois, neste estudo, a distância foi medida até o ponto de contato entre os incisivos superiores, enquanto que no trabalho de Esteves e Bommarito (31), a referência foi a vestibular dos incisivos superiores (64).

Dentre os softwares disponíveis no mercado, vários autores também utilizaram os programas Rhinoceros ${ }^{\circledR}$ para modelagem $(57,58)$ e ANSYS ${ }^{\circledR}$ para a AEF $(24,56,57,61,62,66)$, os mesmos utilizados neste estudo. O ligamento periodontal foi desenhado com espessura constante de 0,3 $\mathrm{mm}$ (58), que foi o valor mais frequentemente empregado em trabalhos tridimensionais. A espessura da lâmina dura foi baseada no trabalho de Hubar (26) com média de $1 \mathrm{~mm}$. A espessura do osso cortical na região molar foi baseada nos trabalhos de Deguchi et al. (30) e Baumgaertel (2009) com média de 2 mm, região adequada para instalação de MPOs segundo Deguchi et al. (30) e Gracco et al. (11). A espessura da mucosa palatina, que determinou a distância do stop da cabeça do MPO à superfície cortical, foi baseada no trabalho de Barriviera (34), com espessura média de $3 \mathrm{~mm}$. O uso de MPOs com grande perfil transmucoso é inevitável em sítios palatinos, pois a mucosa palatina normalmente tem maior espessura. Nestes casos Duaibis et al. (63) recomendam escolher microparafusos com maior diâmetro para se obter melhor estabilidade, como foi utilizado neste estudo e no caso clínico de Dobranszki (21).

Alguns trabalhos $(11,33)$ consideram que há osso cortical suficiente no palato para instalação de MPOs, seja na região anterior ou posterior. Dentre as considerações do uso destes sítios estão o aumento da espessura de tecido mole, composto principalmente por tecido adiposo e glândulas salivares menores, e a 
passagem de artérias, veias e nervos palatinos. O risco de perfuração da cavidade nasal aumenta com um MPO longo, ângulo de instalação perpendicular e inserção total do MPO $(11,40)$. Gracco et al. (11) recomendam a instalação de MPOs com parte funcional de 4 a $5 \mathrm{~mm}$ nas regiões de 16 a $24 \mathrm{~mm}$ distais ao forame incisivo. Embora estudos com elementos finitos mostrem que a cortical óssea absorve a maior parte das tensões e que isto pode ser um fator determinante na estabilidade dos MPOs $(35,60,62,63)$, não foram encontradas informações na literatura sobre quanto osso é necessário em volta do MPO para garantir estabilidade e sucesso, mas Motoyoshi et al. (60) encontraram que pacientes com espessura da cortical óssea $\geq 1 \mathrm{~mm}$ têm chances maiores de sucesso, por isso Baumgaertel (2009) recomenda, para inserção em regiões posteriores, não inserir completamente o microparafuso ou fazê-lo com angulação, o que também aumentaria o embricamento ósseo, o contrário do sugerido por Jasmine et al. (62), que recomendam inserir o MPO da maneira mais perpendicular possível, para melhor distribuição das tensões. Embora a perfuração nasal seja um fator de risco na instalação de MPOs, ela não é detrimental. Sob circunstâncias normais, pequenas perfurações oronasais cicatrizam rapidamente e sem complicações. Na prática, a inserção com angulação dificulta o posicionamento e adaptação do stop da cabeça do parafuso e pode tornar difícil ou impossível a ativação do MPO quando ocorre hiperplasia da mucosa palatina adjacente.

Com base em todas as orientações clínicas, neste estudo foi simulado o posicionamento do MPO distal ao primeiro molar superior, distante do forame palatino maior, com 1,8 $\mathrm{mm}$ de diâmetro, $8 \mathrm{~mm}$ de comprimento e $3 \mathrm{~mm}$ de perfil transmucoso (compatível com a espessura da mucosa palatina), de 2 a $8 \mathrm{~mm}$ da crista alveolar, instalado perpendicular à superfície cortical palatina, para melhor distribuição das tensões e a força foi aplicada com intensidade de $50 \mathrm{cN}$, seguindo o protocolo usado por Dobranszki (21).

O componente vertical da resultante da força pode ser determinado pela posição da cabeça do microparafuso, onde o material elástico fica conectado (16) e sua relação com o Cres dos elementos envolvidos (61). A localização do Cres dos dentes é essencial para o planejamento dos movimentos ortodônticos e permite que um sistema de forças seja aplicado na coroa do dente para se obter um determinado movimento $(59,61)$. Pesquisas experimentais, numéricas ou empíricas buscaram os Cres de dentes individuais e de segmentos de dentes, mas em alguns casos, a 
aplicação clínica destes conceitos encontrou efeitos colaterais, levantando questionamentos sobre a verdadeira posição do Cres em algumas situações (59). Entre pacientes, o Cres pode variar de acordo com o tamanho radicular, suporte de osso alveolar e número de dentes, mas mesmo em estudos com desenhos precisos e com vetores de aplicação de força passando pelo Cres dos 6 dentes anteriores superiores, o movimento de translação não ocorreu (61). Acreditava-se que seria possível determinar o Cres teórico do molar superior por investigação clínica, mas na prática muitos parâmetros interferem, como assimetria da raiz do dente e do ligamento periodontal, comportamento não-linear do ligamento periodontal, inconsistência na carga e na duração, a quantidade e direção da força $(47,66)$, se os dentes estão unidos ou não por um fio e sua rigidez, o que também pode reduzir o movimento dentário individual $(23,59)$ ou em massa $(23)$. O Cres da dentição maxilar também ainda não foi reportado, mas pode ser estimado a partir do Cres de cada dente que, segundo Choi (8), parece estar próximo ao Cres de todos os dentes, no sentido vertical e entre o primeiro e segundo pré-molares, no sentido sagital. Mas o principal problema é que para se determinar um ponto como sendo o Cres de um dente, todas as estruturas anatômicas deveriam ser simétricas, o que algumas vezes é criado com propósito de simplificação do modelo, mas que não condiz com a realidade (66).

Para se conseguir movimento dentário de translação pura, uma força única deve passar pelo Cres ou estar associada a um momento, quando aplicada no braquete (47). Alguns pesquisadores afirmaram que o Centro de Resistência teórico do primeiro molar superior localiza-se na trifurcação das raízes (20), outros afirmaram que ele se encontra um pouco mais oclusal (47) e alguns afirmam que ele não existe como um ponto no plano tridimensional, mas pode ser estimado por centros de resistência projetados em 2-D em um eixo de resistência 3-D. Como este ponto varia de acordo com o sentido do vetor de força, Viecilli et al. (66) sugeriram definir o Cres do primeiro molar superior como uma área, embora pequena o suficiente para ser clinicamente insignificante no planejamento do movimento dentário. Neste estudo, nenhuma das ativações produziu movimento de translação pura no molar, mas os eixos de resistência foram identificados em todas as ativações e discutidos a seguir. 


\subsection{DISCUSSÃO DOS RESULTADOS}

O movimento controlado dos dentes depende de diversas variáveis, dentre as quais o centro de resistência (Cres) é um fator crítico no planejamento e na previsão do tratamento $(2,5,19)$. Embora a força não possa ser aplicada diretamente no Cres do dente, é possível alterar as condições em sua volta para que a movimentação ocorra de forma previsível (24). Idealmente, as forças devem ser aplicadas o mais próximo possível do Cres (24), mas em condições clínicas, nem sempre é desejável o movimento puro de translação de um dente.

A análise de tensões von Mises se aplica melhor em materiais dúcteis, como metais. Por isso foi aplicada na análise dos componentes metálicos (MPO e BTP), nos testes preliminares. Para materiais como osso, considerados frágeis, o critério de Tensão Máxima Principal (Maximum Principal Stress) é mais comumente usado. Neste critério, a falha ocorre quando a Tensão Máxima Principal alcança a Força de Tração Máxima ou a Força de Compressão Máxima (63).

Os resultados indicaram que a mudança da posição de instalação do MPO e do ponto de ativação na BTP produziram diferentes efeitos na movimentação do molar, no sentido A-P, vertical e na rotação (angulação). O controle vertical pode ser obtido planejando-se a intensidade e direção da força, de acordo com a posição e quantidade de MPOs. Este controle é especialmente útil no tratamento de pacientes com padrão vertical, nos quais é desejável o controle vertical seletivo (em um dente) ou no arco, com efeito de rotação do plano oclusal $(2,6,16,19)$.

Para avaliar o deslocamento inicial do molar, imediatamente após a aplicação da carga, a ferramenta Deslocamento Direcional "Directional Deformation" foi usada para mostrar o deslocamento do molar em um eixo pré-determinado ( $X, Y$ ou $Z$ ). Para distalização e angulação, foi avaliado o Deslocamento Direcional no eixo $Y$ (A$P)$, para movimentos verticais, no eixo $Z$ e a soma dos vetores das Deformações Direcionais, o Deslocamento Total (24) "Total Deformation" (Figura 77) (70). Como a representação gráfica não foi feita perpendicular ao eixo de aplicação de força, o Cres não pode ser representado como um ponto, mas como um eixo, no qual a solução é apresentada no centro das camadas coloridas, correspondentes à soma de todos os vetores direcionais. 


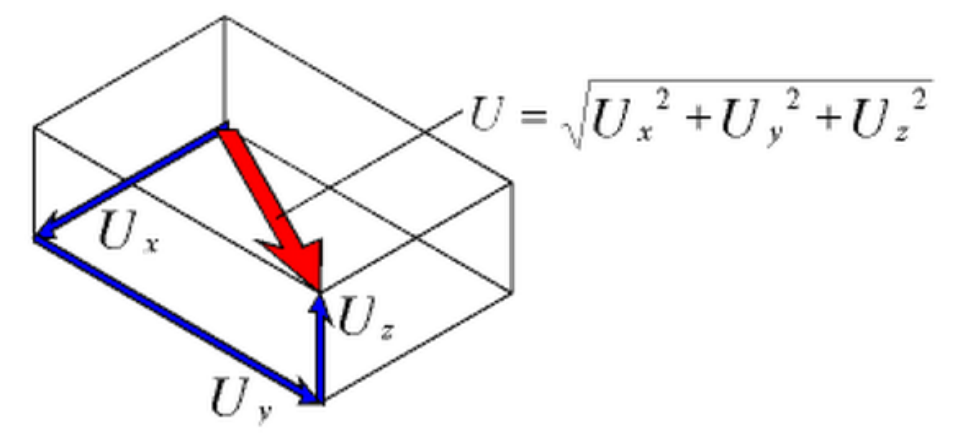

- Component deformations (Directional Deformation)

- Deformed shape (Total Deformation vector)

Figura 77 - Desenho esquemático da diferença entre Deslocamento Direcional e Deslocamento Total (70).

No modelo de teste preliminar, foram identificados os pontos de maior e menor Tensão Máxima Principal (ponto de maior tração e compressão) na região do perfil transmucoso do MPO, próximo ao local que seria a interface do término das espiras, região comum de fratura durante a instalação e remoção, semelhante ao encontrado por Dobranszki (65). No osso adjacente, os pontos coincidiram com a região encontrada no MPO. No ligamento periodontal, o ponto encontrado indicando maior valor de Tensão Máxima Principal é compatível com o esperado, na região distal, porém, seu posicionamento próximo à cervical pode indicar inclinação da coroa para distal. Além de estar cervical, também está lingualizado, um sinal de provável rotação no eixo $Z$, com maior deslocamento da face palatina para distal do que a vestibular. Essa rotação se confirma pelo ponto de menor Tensão Máxima Principal, encontrado na cervical da raiz mesiovestibular. Acredita-se que, por ser uma análise do movimento inicial, esta rotação ocorre por um pequeno deslocamento elástica da BTP após a ativação e tende a cessar quando a força da presilha da BTP, dentro do tubo lingual, resistir ao movimento rotacional, o que ocorreu clinicamente (21). Observou-se também a coloração azul na região apical da raiz palatina, indicativa de alto valor compressivo e sugestiva de movimento intrusivo, que desta vez não depende da deformação elástica da BTP, mas do vetor de força criado pela posição da cabeça do MPO. Este componente intrusivo também é encontrado em outros trabalhos de distalização com MPOs $(2,7,8,16)$.

A tensão von Mises foi aplicada para analisar as tensões na BTP e no osso 
cortical adjacente ao MPO, neste último somente para dar uma ideia de onde seria a concentração das tensões, sem orientação determinada. Os resultados mostraram grande concentração de tensões na dobra da BTP mesial à entrada do tubo lingual, região relativamente comum de fratura. No osso adjacente ao MPO, a imagem foi semelhante à de Tensão Máxima Principal, com grande concentração de tensões na borda externa da cortical mesial e muito semelhante aos achados de Duaibis et al. (63), que também utilizaram a tensão von Mises com este propósito. deslocamento do molar avaliado nos eixos $X$ (horizontal transversal), $Y$ (horizontal anteroposterior) e Z (vertical) mostrou-se compatível com os achados no ligamento periodontal, o que nos motivou a seguir com a base deste modelo para os testes definitivos.

No modelo definitivo, a ativação "2 mm baixo (apical)", próxima ao ômega central da BTP, foi a única que resultou em efeito extrusivo, em maior intensidade na raiz palatina. Imediatamente após a aplicação da força, as raízes e a furca tenderam a se deslocar para distal, enquanto que a coroa para mesial (rotação horária). A ferramenta isosurface usada na análise de Deslocamento Total evidenciou as camadas (superfícies) de pontos com a mesma intensidade de deslocamento, representado pelo eixo de resistência que passa pelo centro dos círculos azuis e um ponto neste eixo em que há o menor deslocamento, aparentemente com orientação A-P, mais apical na mesial. A ativação "A" de Ueno et al. (19) (Figura 4) também produziu movimento mesial da coroa, em maior intensidade até do que o movimento distal da raiz. Em uma comparação, a ativação "2 mm baixo (apical)" produziu menor efeito colateral de inclinação mesial de coroa, provavelmente com muito menos rotação, pois o MPO instalado próximo à sutura palatina mediana por Ueno et al. (19) tem um vetor de força horizontal maior, sem componente vertical. Após analisar os resultados, sugere-se que esta forma de ativação pode ser aplicada quando se deseja distalização com aumento da dimensão vertical, por extrusão do molar.

A ativação "2 mm alto (cervical)", próxima ao tubo lingual do molar, resultou em um efeito leve de intrusão, distalização e acentuado giro distal da coroa (antihorário), pois a coroa e a furca tenderam a se deslocar para distal, enquanto que os terços apicais radiculares, imediatamente após a ativação, tenderam a se deslocar para mesial. Outro indicativo de angulação distal de coroa foi a área de grande concentração de tensões compressivas (cor azul) na região distocervical entre as raízes distovestibular e palatina. Houve tendência à intrusão das raízes 
distovestibular e palatina, resultado quase inverso ao da ativação "2 $\mathrm{mm}$ baixo (apical)", no eixo vertical. A imagem de Deslocamento Total e isosurface mostram um eixo de rotação bem diferente da ativação "2 mm baixo (apical)", quase perpendicular ao eixo e aparentemente com orientação acentuadamente mais vertical. Após analisar os resultados, sugere-se que esta forma de ativação pode ser aplicada quando o molar encontra-se mésioangulado, como por exemplo, em uma situação onde ocorreu perda do segundo pré-molar e o primeiro molar permanente mesializou com angulação, ou quando o eixo de erupção do molar está para mesial e o segundo pré-molar está impactado.

$\mathrm{Na}$ ativação "5 mm média", na metade do comprimento do braço da BTP, o vetor de força passou paralelo à trifurcação do molar, no sentido vertical, mas a tendência ao deslocamento não foi de translação pura. Ocorreu tendência a giro anti-horário (coroa para distal) e leve movimento intrusivo, como no caso clínico com este método, apresentado por Dobranszki (21), semelhante ao que ocorre na ativação pela vestibular quando o MPO é instalado entre as raízes do primeiro molar e segundo pré-molar superiores $(6,16)$. Este efeito também foi encontrado no caso clínico com miniplacas apresentado por Nur et al. (15) e na amostra de Kaya et al. (14). A interpretação dos resultados indica que neste modelo, o eixo de resistência do molar encontrava-se ligeiramente mais apical do que a trifurcação, o que pode ser visualizado na imagem Deslocamento Total e isosurface. Após analisar os resultados, sugere-se que esta forma de ativação pode ser aplicada quando o molar encontra-se com leve mesioangulação e ligeiramente extruído, ou quando se deseja fechar levemente a mordida anterior, pois de todas as ativações, esta foi a que mais se aproximou de produzir movimento de translação. A extrapolação clínica desta interpretação é que, para se conseguir distalização pura do molar com este arranjo biomecânico, ou seja, sem efeito vertical ou de angulação da coroa, o MPO e o ponto de ativação na BTP devem ser ligeiramente mais apicais do que a trifurcação do molar.

As ativações de "8 mm" produziram os maiores vetores intrusivos. A ativação "8 mm médio" produziu pouco efeito de distalização e pouca angulação distal (giro anti-horário) da coroa (quase metade da distalização e menos de 1/3 da angulação encontrada na ativação "2 $\mathrm{mm}$ alto - cervical"). Este resultado foi semelhante ao encontrado por Ueno et al. (19) no modelo "B", na qual o vetor de força também passou próximo ao Cres, mas com componente intrusivo maior, pelo MPO ter sido 
instalado no centro do palato. O componente intrusivo também foi um pouco maior do que na ativação "5 mm médio". Após analisar os resultados, sugere-se que esta forma de ativação pode ser aplicada quando se deseja pouca distalização com intrusão quase pura do molar, com giro anti-horário (angulação distal da coroa).

Por fim, a ativação "8 mm apical" produziu muito pouca distalização (menos da metade da obtida com a ativação $8 \mathrm{~mm}$ média) com muito giro anti-horário (angulação distal da coroa), semelhante à da ativação $2 \mathrm{~mm}$ alta (cervical), mas em maior intensidade. A intrusão foi a força predominante nesta ativação, com deslocamento 1,5 vezes o obtido com a ativação "8 mm médio" e maior do que a ativação "C" de Ueno et al. (19). A imagem dos Vetores de Tensão Principal ilustra a ação das forças tensoras sobre o osso alveolar, presentes em maior intensidade no fundo do alvéolo da raiz palatina, sujeita à maior carga compressiva (efeito intrusivo). O Deslocamento Total, com isosurface, mostrou-se semelhante ao "8 mm médio". Após analisar os resultados, sugere-se que esta forma de ativação pode ser aplicada quando se deseja intruir o molar.

O trabalho de Ueno et al. (19) sugere que aplicação de força unilateral na BTP, com um MPO descentralizado em relação à sutura palatina mediana, produz maior quantidade de movimento no molar do lado em que se instalou o MPO. Encontraram também que se um dos molares está mais mesializado do que o outro e se o MPO for instalado deslocado para este lado do palato, o movimento lateral indesejado poderá corresponder a um quarto do movimento de mesialização. Sugerem ainda que o MPO pode ser instalado do lado de molares extruídos ou em pacientes com inclinação lateral do plano oclusal, por deformidade vertical do arco maxilar. Esta linha de pesquisa seria interessante para futuras investigações, analisando os efeitos verticais e A-P (distalização e mesialização) de ativações assimétricas, variando a posição de instalação dos MPOs e dos pontos de aplicação de força na BTP.

As desvantagens da técnica de distalização aqui estudada são semelhantes às de outras técnicas de ancoragem absoluta, sendo as principais a chance de insucesso do MPO $(6,8,16)$ (em torno de 13\%), necessidade de procedimento cirúrgico para instalação e remoção, com risco de fratura do MPO (6), adaptação do paciente aos dispositivos $(6,7)$, risco de danificar estruturas anatômicas tais como raízes, nervos e vasos sanguíneos (6) e remodelamento do periodonto (8). Apesar de estudos demonstrarem que a AEF é uma forma confiável de simular movimentos 
ortodônticos, existem limitações como em todo modelo teórico de um sistema biológico $(19,22,23,24,61,62)$. O modelo maxilar utilizado neste estudo representa a anatomia de um indivíduo Classe II médio (64) sem os outros dentes, portanto, a extrapolação dos resultados para uma situação clínica específica deve ser feita com reserva. Além disso, neste modelo a tendência de movimento do molar é avaliada no momento imediatamente após a ativação, podendo não representar um movimento contínuo $(19,22,23,61)$, pois clinicamente ocorre diminuição da força de ativação e os vetores podem mudar com a movimentação do dente e da BTP. 


\section{CONCLUSÃO}

$\mathrm{Na}$ análise feita no modelo virtual criado para simular uma maxila humana de um indivíduo característico com relação maxilomandibular de Classe II esquelética, os resultados das ativações testadas nos modelos preliminares deste estudo indicaram que:

- na barra transpalatina, a maior concentração de tensões foi encontrada na dobra da barra transpalatina próxima à entrada do tubo lingual, indicando o ponto de maior propensão à falha.

- no microparafuso, a maior concentração de tensões foi encontrada na região do pescoço próximo à transição do perfil transmucoso para as espiras, região em contato com a borda externa do osso cortical palatino, indicando o ponto de maior propensão à falha.

- no osso cortical palatino, a maior concentração de tensões foi encontrada na borda externa do osso cortical, mesial ao microparafuso, indicando o ponto em que provavelmente ocorreria maior demanda biológica inflamatória.

Os resultados das ativações testadas nos modelos definitivos sugeriram ser possível o controle vertical e rotacional durante a distalização molar, de acordo com a posição de instalação dos MPOs e o ponto de ativação na BTP, da seguinte forma:

- a ativação "2 mm apical", próxima ao ômega central da BTP, foi a única que resultou em efeito extrusivo, em maior intensidade na raiz palatina, além de rotação horária do dente - deslocamento mesial de coroa e distal das raízes e furca. Sugerese a aplicação desta forma de ativação quando se deseja distalização com aumento da dimensão vertical, por extrusão do molar.

- a ativação "2 mm cervical", próxima ao tubo lingual do molar, resultou em um efeito leve de intrusão, distalização e acentuado giro distal da coroa (anti-horário). Sugere-se que esta forma de ativação pode ser aplicada quando o molar encontrase mésioangulado.

- a ativação "5 mm média", na metade do comprimento do braço da BTP, o vetor de força passou paralelo à trifurcação do molar, no sentido vertical, mas a tendência ao deslocamento não foi de translação pura. Ocorreu tendência a giro anti-horário (coroa para distal) e leve movimento intrusivo. Sugere-se que esta forma de ativação pode ser aplicada quando o molar encontra-se com leve mesioangulação e ligeiramente extruído, ou quando se deseja distalizar fechando 
levemente a mordida anterior.

- a ativação "8 mm médio" produziu pouco efeito de distalização e pouca angulação distal (giro anti-horário) da coroa. Sugere-se que esta forma de ativação pode ser aplicada quando se deseja pouca distalização com intrusão quase pura do molar, com giro anti-horário (angulação distal da coroa).

- a ativação "8 mm apical" produziu muito pouca distalização com muito giro anti-horário (angulação distal da coroa). Sugere-se que esta forma de ativação pode ser aplicada quando se deseja intruir o molar. 


\section{REFERÊNCIAS}

1. Freitas MR, Freitas DS, Pinheiro FHSL, Freitas KMS. Prevalência das más oclusões em pacientes inscritos para tratamento ortodôntico na Faculdade de Odontologia de Bauru - USP. Rev Fac Odontol Bauru 2002;10(3):164-9.

2. Bechtold TE, Kim JW, Choi TH, Park YC, Lee KJ. Distalization pattern of the maxillary arch depending on the number of orthodontic miniscrews. Angle Orthod. 2013;83(2):266-73.

3. Björk A. The nature of facial prognathism and its relation to normal occlusion of the teeth. Am J Orthod. 1951 Feb;37(2):106-24.

4. Sugawara J, Kanzaki R, Takahashi I, Nagasaka H, Nanda R. Distal movement of maxillary molars into nongrowing patients with the skeletal anchorage system. Am J Orthod Dentofac Orthop. 2006;129(6):723-33.

5. Fudalej $\mathrm{P}$, Antoszewska J. Are orthodontic distalizers reinforced with the temporary skeletal anchorage devices effective? Am J Orthod Dentofac Orthop. 2011;139(6):722-9.

6. Yamada K, Kuroda S, Deguchi T, Takano-Yamamoto T, Yamashiro T. Distal movement of maxillary molars using microscrew anchorage in the buccal interradicular region. Angle Orthod. 2009;79(1):78-84.

7. Chung KR, Choo, HR, Kim SH, Ngan P. Timely relocation of mini-implants for uninterrupted full-arch distalization. Am J Orthod Dentofacial Orthop. 2010;138:839-49.

8. Choi YJ, Lee JS, Cha JY, Park YC. Total distalization of the maxillary arch in a patient with skeletal Class II malocclusion. Angle Orthod. 2011;139(6):823-33.

9. Antonarakis GS, Kiliaridis S. Maxillary Molar Distalization with Noncompliance Intramaxillary Appliances in Class II Malocclusion. Angle Orthod. 2008;78(6):1113-40.

10. Dobranszki A, Levy Neto F, Dobranszki NC, Vuolo JH, Laboissière Jr. MA. Distribuição de tensões em mini-implantes ortodônticos. Matéria. 2010;15(3):403-12.

11. Gracco A, Lombardo L, Cozzani M, Siciliani G. Quantitative cone-beam computed tomography evaluation of palatal bone thickness for orthodontic miniscrew placement. Am J Orthod Dentofacial Orthop. 2008;134(3):361-9.

12. Kanomi R. Mini-implant for orthodontic anchorage. J Clin Orthod 1997:31:763-7. 
13. Karagkiolidou A, Ludwig B, Panzera P, Gkanditis N, Pandis N, Katsaros C. Survival of palatal miniscrews used for orthodontic appliance anchorage: A retrospective cohort study. Am J Orthod Dentofac Orthop. 2013;143(6):767-72.

14. Kaya B, Sar Ç, Arman-Özçirpici A, Polat-Özsoy Ö. Palatal implant versus zygoma plate anchorage for distalization of maxillary posterior teeth. Eur $\mathrm{J}$ Orthod. 2013;35:507-14.

15. Nur M, Bayram M, Celikoglu M, Kilkis D, Pampus AA. Effects of maxillary molar distalization with Zygoma-Gear Appliance. Angle Orthod. 2012;82(4):596-602.

16. Park HS, Lee SK, Kwon OW. Group distal movement of teeth using microscrew implant anchorage. Angle Orthod. 2005;75(4):602-09.

17. Sherwood KH, Burch JG, Thompson WJ. Closing anterior open bites by intruding molars with titanium miniplate anchorage. Am J Orthod Dentofac Orthop. 2002;122(6):593-600.

18. Umemori M, Sugawara J, Mitani H, Nagasaka H, Kawamura H. Skeletal anchorage system for open-bite correction. Am J Orthod Dentofac Orthop. 1999;115(2):166-74.

19. Ueno S, Motoyoshi M, Mayahara K, Saito Y, Akiyama Y, Son S, Shimizu N. Analysis of a force system for upper molar distalization using a trans-palatal arch and mini-implant: a finite element analysis study. Eur J Orthod. 2013;35(5):628-33.

20. Worms FW, Isaacson RJ, Speidel TM. A concept and classification of centers of rotation and extraoral force systems. Angle Orthod. 1973;43(4):384-401.

21. Dobranszki A. Distalização de molares com barra transpalatina ancorada em mini-implantes ortodônticos: caso clínico. Rev Clín Ortod Dental Press. 2011 junjul;10(3):60-5.

22. Lotti RS, Machado AW, Mazzieiro ET, Landre Jr. J. Aplicabilidade científica do método dos elementos finitos. Rev Dental Press Ortodon Ortop Facial 2006 mar/abr;11(2):35-43.

23. Kojima Y, Fukui H. Numeric simulations of en-masse space closure with sliding mechanics. Am J Orthod Dentofac Orthop 2010 Dec:138:702.e1-702.e6.

24. Xue J, Ye N, Yang X, Wang S, Wang J, Wang Y Li J, Mi C, Lai W. Finite element analysis of rapid canine retraction through reducing resistance and distraction. J Appl Oral Sci. 2014;22(1):52-60.

25. McNamara, JA. Components of Class II malloclusion in children 8-10 years of age. Angle Orthod. 1981;51(3):177-202. 
26. Hubar JS. Quantification of the lamina dura. J Can Dent Assoc. 1993;59:997-1000.

27. Rosenblum RE. Class II malloclusion: mandibular retrusion or maxillary protrusion? Angle Orthod. 1995;65(1):49-62.

28. Riedel RA. The relation of maxillary structures to cranium in malocclusion and in normal occlusion. Angle Orthod. 1952 Jul;22(3):142-5.

29. Tukasan PC. Estudos dos valores cefalométricos da Análise Craniofacial da Fundação Tweed em Classe II, $1^{\mathrm{a}}$. divisão de Angle. Piracicaba. Tese [Doutorado em Odontologia] - Faculdade de Odontologia de Piracicaba da Universidade Estadual de Campinas; 2002.

30. Deguchi T, Nasu M, Murakami K, Yabuuchi T, Kamioka H, TakanoYamamoto T. Quantitative evaluation of cortical bone thickness with computed tomographic scanning for orthodontic implants. Am J Orthod Dentofacial Orthop. 2006;129(6):721.e7-12.

31. Esteves A, Bommarito S. Avaliação da profundidade do palato e das dimensões do arco dentário superior em indivíduos com má oclusão e diferentes tipos faciais. Rev Dental Press Ortodon Ortop Facial. 2007;12(4):84-98.

32. Shelly AD, Southard TE, Southard KA, Casko JS, Jakobsen Jr, Fridrich KL et al. Evaluation of profile esthetic change with mandibular advancement surgery. Am J Orthod Dentofacial Orthop. 2000;117(6):630-7.

33. Baumgaertel S. Quantitative investigation of palatal bone depth and cortical bone thickness for mini-implant placement in adults. Am J Orthod Dentofacial Orthop. 2009;136(1):104-8.

34. Barriviera M, Duarte WR, Januário AL, Faber J, Bezerra ACB. A new method to assess and measure palatal masticatory mucosa by cone-beam computerized tomography. J Clin Periodontol. 2009 Jul;36(7):564-8; doi: 10.1111/j.1600-051X.2009.01422.x.

35. Gracco A, Tracey S, Bacilero U. Miniscrew insertion and the maxillary sinus: an endoscopic evaluation. J Clin Orthod. 2010 Jul;44(7):439-43.

36. Poggio PM, Incorvati C, Velo S, Carano A. "Safe Zones": A Guide for Miniscrew Positioning in the Maxillary and Mandibular Arch. Angle Orthod. 2006;76(2):191-7.

37. Teixeira CS. Topografia do forame palatino maior em crânios macerados. Brasília. Tese [Mestrado em Ciências da Saúde] - Universidade de Brasília, 2007. 
38. Ikuta CRS, Lopes CC, Ferreira-Júnior O, et al. Forame palatino maior: Posicionamento em tomografia computadorizada de feixe cônico. XVIII Jornada da Associação Brasileira de Radiologia Odontológica; 2012 Oct 24-27; Foz do Iguaçu, Brasil.

39. Marassi, C. Carlo Marassi responde (parte II): Quais as principais aplicações clínicas e quais as chaves para o sucesso no uso dos mini-implantes em Ortodontia? Rev Clin Ortodon Dental Press 2006 Out/Nov;5(5):14-26.

40. Kuroda S, Sugawara Y, Deguchi T, Kyung HM. Clinical use of miniscrew implants as orthodontic anchorage: Success rates and postoperative discomfort. Am J Orthod Dentofacial Orthop. 2007 Jan;131(1):9-15.

41. Wilmes B, Su Y-Y, Sadigh L, Drescher D. Pre-drilling force and Insertion torques during orthodontic mini-implant insertion in relation to root contact. J Orofac Orthop. 2008;69(1):51-58.

42. Baumgaertel S. Predrilling of the implant site: Is it necessary for orthodontic mini-implants? Am J Orthod Dentofacial Orthop. 2010;137(6):825-9.

43. Cho UH, Yu W, Kyung HM. Root Contact during Drilling for Microimplant Placement. Angle Orthod. 2010;81(1):130-136.

44. Miyawaki S, Koyama I, Inoue M, Mishima K, Sugahara T, TakanoYamamoto T. Factors associated with the stability of titanium screws placed in the posterior region for orthodontic anchorage. Am J Orthod Dentofacial Orthop. 2003 Oct;124(4):373-8.

45. Creekmore TD, Eklund MK. The possibility of skeletal anchorage. J Clin Orthod. 1983;17(4):266-9.

46. Roberts WE, Marshall KJ, Mozsary PG. Rigid endosseous implant utilized as anchorage to protract molars and close an atrophic extraction site. Angle Orthod. 1990;60:135-52.

47. Dermaut LR, Kleutghen JPJ, De Clerk HJJ. Experimental determination of the center of resistance of the upper first molar in a macerated, dry human skull submitted to horizontal headgear traction. Am J Orthod Dentofacial Orthop. 1986;90(7):29-36.

48. Bondemark L, Karlsson I. Extraoral vs Intraoral Appliance for Distal Movement of Maxillary First Molars: A Randomized Controlled Trial. Angle Orthod. 2005;75(5):699-706.

49. Bernhart T, Vollgruber A, Gahleitner A, Dörtbudak O, Haas R. Alternative 
to the median region of the palate for placement of an orthodontic implant. Clin Oral Impl Res 2000;11:595-601.

50. Dobranszki A, Faber J, Scatolino IVMC, Dobranszki NPDC, Toledo AO. Analysis of factors associated with microscrew failure. Braz Dent J. 2014;25(4):34651.

51. Clough RW. The Finite Element Method in Plane Stress Analysis. Proceedings of 2nd American Society of Civil Engeneers - Conference on Electronic Computation. Pittsburgh (PA); 1960, Sep. 35p.

52. Courant R. Variational Methods for the Solutions of Problems of Equilibrium and Vibrations. Bulletin of American Mathematical Society;1943, 49:1-7.

53. Greenstadt J. On the Reduction of Continuous Problems to Discrete Form. IBM J Res Dev. 1959;3:355-63.

54. Meet the Finite Element Method [Internet]; [acesso em 2013 Jun 17]; p. 316. Disponível em:

http://media.wiley.com/product data/excerpt/89/04713707/0471370789.pdf

55. Huang HK, Ledley RS. Numerical Experiments with a Linear ForceDisplacement Tooth Model. JDR 1969 Jan;48(1):32-37.

56. Ribeiro JPF. Análise pelo método de elementos finitos, da distribuição de tensões em um dente com e sem remanescente coronário, utilizando diferentes pinos intra-radiculares. Ponta grossa. Tese [Mestrado em Odontologia] Universidade Estadual de Ponta Grossa, 2004.

57. Clement R, Schneider J, Brambs HJ, Wunderlich A, Geiger M, Sander FG. Quasi-automatic 3D finite element model generation for individual singlerooted teeth and periodontal ligament. Comput Methods Programs Biomed. 2004;73(2):135-44.

58. Ichim I, Schmidlin PR, Kieser JA, Swain MV. Mechanical evaluation of cervical glass-ionomer restorations: 3D finite element study. J Dent. 2007;35(1):2835.

59. Reimann S, Keilig L, Bourauel J, Bourauel C. Biomechanical finite-element investigation of the position of the centre of resistance of the upper incisors. Eur $\mathrm{J}$ Orthod. 2007;29:219-24.

60. Motoyoshi M, Inaba M, Ono A, Ueno S, Shimizu N. The effect of cortical bone thickness on the stability of orthodontic mini-implants and on the stress distribution in surrounding bone. Int J Oral Maxillofac Surg. 2009;38:13-18.

61. Sung SJ, Jang GW, Chun YS, Moon YS. Effective en-masse retraction 
design with orthodontic mini-implant anchorage: A finite element analysis. Am J Orthod Dentofac Orthop. 2010;137(5):648-57.

62. Jasmine IF, Yezdani A, Tajir F, Venud RM. Analysis of stress in bone and microimplants during en-masse retraction of maxillary and mandibular anterior teeth with different insertion angulations: A 3-dimensional finite element analysis study. Am J Orthod Dentofac Orthop. 2012 Jan:141(1);71-80.

63. Duaibis R, Kusnoto B, Natarajan R, Zhao L, Evans C. Factors affecting stresses in cortical bone around miniscrew implants. A three dimensional finite element study. Angle Orthod. 2012;82(5):875-80.

64. Dobranszki A, Noritomi PY, Faber J, Barriviera M, Dobranszki NPDC, Toledo AO. Obtenção de medidas de uma maxila típica de um paciente com máoclusão de Classe II esquelética por meio de mensurações em tomografias computadorizadas. R Odontol Planal Cent. 2013;3(1):2-10.

65. Dobranszki A. Análise de elementos finitos em microparafusos ortodônticos de diferentes formas e diâmetros. R Odontol Plan Cent. 2013 AgoDez;3(2):2-6.

66. Viecilli RF, Budiman A, Burstone CJ. Axes of resistance for tooth movement: Does the center of resistance exist in 3-dimensional space? Am J Orthod Dentofac Orthop 2013;134(2):163-72.

67. Houston WJB. The analysis of errors in orthodontics measurements. Am J Orhod 1983 May;83(5):382-390.

68. Anusavice K. Propriedades mecânicas dos materiais dentários. In Anusavice K. Materiais dentários. 10a. ed. Rio de Janeiro: Guanabara-Koogan; 1998. P.28-43.

69. Tzu S. A arte da guerra. São Paulo: Martin Claret; 2003.

70. Shared Hierarchical Academic Research Computing Network [homepage na internet]. [acesso em 13 out 2014]. Release 14.0, 2011 SAS IP, Inc. Disponível em: https://www.sharcnet.ca/Software/Fluent14/help/wb_sim/ds_Deformation.html 


\title{
APÊNDICES
}

\author{
APÊNDICE A - TERMO DE CONSENTIMENTO LIVRE E ESCLARECIDO
} (TCLE)

Você está sendo convidado(a) a participar, como voluntário(a) da pesquisa "ANÁLISE DE ELEMENTOS FINITOS DA DISTALIZAÇÃO DE MOLARES COM BARRA TRANSPALATINA ANCORADA EM MINI-IMPLANTES PALATINOS", pelos pesquisador responsável Dr. ADRIANO DOBRANSZKI da Universidade de Brasília UnB.

1 - Justificativa e objetivos: Alguns aparelhos grandes, desconfortáveis ou que exigem muitos procedimentos são necessários para movimentar o dente de uma certa maneira (distalização). Este trabalho busca respostas que facilitem o trabalho do dentista e diminuam o sacrifício do paciente no tratamento ortodôntico. Para tanto serão necessárias imagens tomográficas de sua boca (que já estão no banco de dados da clínica FENELON), para que possam ser digitalizadas e processadas em um programa de computador, que trará estas respostas.

2 - Procedimentos: Não será necessário nenhum procedimento invasivo, somente o uso das imagens de seus exames já realizados, arquivados no banco de dados da clínica radiológica.

3 - Desconfortos e riscos: Como os exames já foram realizados com outro propósito e nenhum outro procedimento será necessário, o uso das imagens não causará nenhum desconforto ou risco.

4- Benefícios: Não há benefício direto a você. Pode haver benefício eventual, se você for submetido a tratamento ortodôntico que necessite deste tipo de movimentação dentária (distalização).

5. Acompanhamento assistencial: O pesquisador responsável, Dr. ADRIANO DOBRANSZKI se compromete, no período da pesquisa, a responder qualquer pergunta relacionada à pesquisa.

6. Ressarcimento: Não há pagamento de qualquer valor em dinheiro pela autorização do uso da imagem, mas o pesquisador responsável garante que todas as despesas necessárias para a realização da pesquisa não serão da sua responsabilidade. Caso haja gastos adicionais estes serão absorvidos pelo orçamento da pesquisa.

7. Liberdade de recusar ou retirar o consentimento: É um direito seu deixar de participar da pesquisa a qualquer tempo, sem penalização alguma e sem prejuízo ao seu cuidado e tratamento.

8. Confidencialidade e privacidade: Todas as informações obtidas serão sigilosas, em caráter confidencial das informações. Em nenhum momento haverá sua identificação e estes dados não poderão ser usados para outros fins que não os 
previstos no protocolo e/ou no consentimento.

9. Uso de imagem: Na folha "Autorização para Uso de Imagem" consta a forma e a utilização previstas para as imagens.

10. Participantes analfabetos: Quando o voluntário e/ou o seu representante legal, forem analfabetos, o Termo de Consentimento deverá ser lido na frente de uma testemunha imparcial, sem envolvimento direto com o projeto de pesquisa. Esta pessoa deverá assinar o documento certificando que todas as informações foram dadas ao voluntário, ou ao seu representante legal, e que as perguntas suscitadas pelos mesmos foram amplamente esclarecidas pelo pesquisador.

11. Adolescentes: As pesquisas envolvendo adolescentes terão o Termo de Consentimento assinado por seus representantes. A recusa em participar, por parte do adolescente, será sempre acatada.

Após ser esclarecido(a) sobre a pesquisa e a sua participação como voluntário, e havendo uma confirmação livre e espontânea em aceitar a participar como voluntário(a), você deverá assinar ao final deste documento, em duas vias. Uma das vias ficará com você e a outra via permanecerá com o pesquisador responsável. Em caso de dúvida em relação a esse documento, você poderá procurar o Comitê de Ética em Pesquisa da UnB pelos telefones (61) 3307-2276-2520/ 3273-4069 e, ainda, você poderá procurar os pesquisadores responsáveis pela pesquisa pelos telefones(61) 3034-3344 ou (61) 3321-7010.

Termo de consentimento livre, após esclarecimento $\mathrm{Eu}$, li e/ou ouvi a leitura dos esclarecimentos acima e compreendi para que serve o estudo e qual procedimento a que serei submetido. A explicação que recebi esclarece os riscos e benefícios do estudo. Eu entendi que sou livre para interromper minha participação a qualquer momento, sem justificar minha decisão e que isso não afetará meu tratamento. Sei que meu nome não será divulgado, que não terei despesas e não receberei dinheiro por participar do estudo.

Concordo em participar do estudo.

Brasília, DF, de de 2011.

RG:

Assinatura do Voluntário(a) ou responsável legal

CPF:

Pesquisador Responsável: Adriano Dobranszki, Faculdade de Ciências da SaúdeUnB - Telefones Comerciais do pesquisador: 3034-3344 / 3321-7010 


\section{APÊNDICE B - DETALHAMENTO DOS TÍTULOS DAS COLUNAS DA TABELA A}

= Valor em milímetros da $1^{\mathrm{a}}$ e $2^{\mathrm{a}}$ Medições coronais da distância entre a linha que passa pelas pontas das cúspides mésio-vestibulares dos primeiros molares superiores (6-6) e a sutura palatina mediana

= Valor em milímetros da $1^{\mathrm{a}}$ e $2^{\mathrm{a}}$ Medições axiais da distância entre as pontas das cúspides mésio-vestibulares dos primeiros molares superiores (6-6)
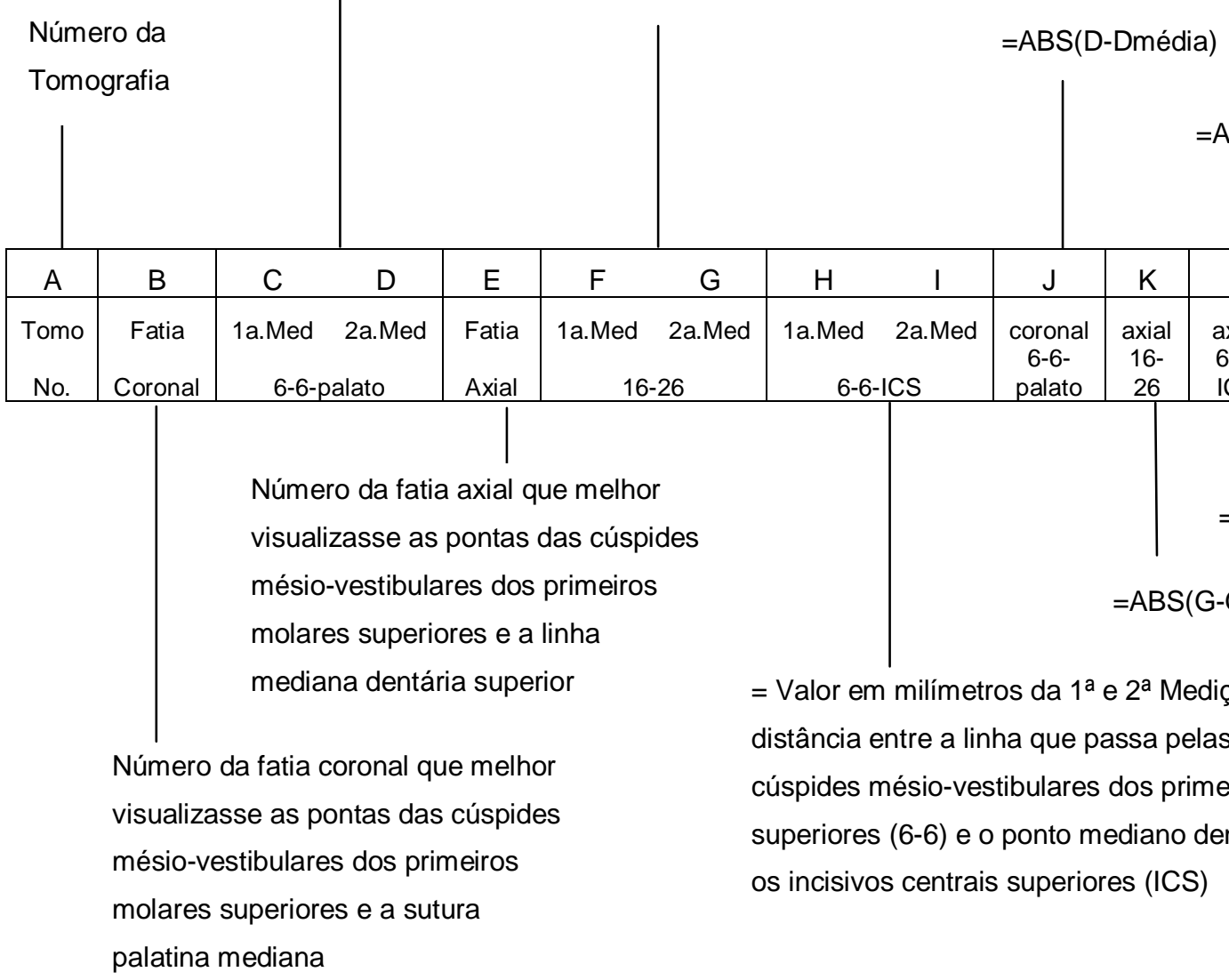

Tomografia 
APÊNDICE C - RESULTADOS DO SPSS - TESTE-T DE (A) 6-6-palato (vertical), (B) 16-26 (AXIAL transversal), E (C) 6-6-ICS (AXIAL A-P), ENTRE 1A. E 2A. MEDIÇÕES.

(A) T-TEST 6-6-PALATO

/TESTVAL $=\odot$

$/ M I S S I N G=A N A L Y S I S$

/VARIABLES=@1a.66CorPalato@2a.66CorPalato

/CRITERIA $=$ CI $(.95)$.

\begin{tabular}{|l|r|r|r|r|}
\hline \multicolumn{6}{|c|}{ One-Sample Statistics } \\
\hline & $\mathrm{N}$ & Mean & Std. Deviation & Std. Error Mean \\
\hline 1a.Med & 20 & 22,0690 & 2,63551 &, 58932 \\
2a.Med & 20 & 22,1050 & 2,66096 &, 59501 \\
\hline
\end{tabular}

One-Sample Test

\begin{tabular}{|c|c|c|c|c|c|c|}
\hline & \multicolumn{6}{|c|}{ Test Value $=0$} \\
\hline & \multirow[b]{2}{*}{$\mathrm{t}$} & \multirow[b]{2}{*}{$\mathrm{df}$} & \multirow[b]{2}{*}{ Sig. (2-tailed) } & \multirow{2}{*}{$\begin{array}{c}\text { Mean } \\
\text { Difference }\end{array}$} & \multicolumn{2}{|c|}{$\begin{array}{l}\text { 95\% Confidence Interval of the } \\
\text { Difference } \\
\end{array}$} \\
\hline & & & & & Lower & Upper \\
\hline 1a.Med & 37,448 & 19 &, 000 & 22,06900 & 20,8355 & 23,3025 \\
\hline 2a.Med & 37,151 & 19 & ,000 & 22,10500 & 20,8596 & 23,3504 \\
\hline
\end{tabular}

(B) T-TEST 16-26

/TESTVAL $=0$

/MISSING=ANALYSIS

/VARIABLES=@1a.66Axial@2a.66Axial

/CRITERIA=CI (.95).

\begin{tabular}{|l|r|r|r|r|}
\hline & $\mathrm{N}$ & Mean & Std. Deviation & Std. Error Mean \\
\hline 1a.Med & 20 & 48,8140 & 3,67388 &, 82150 \\
2a.Med & 20 & 48,9070 & 3,61174 &, 80761 \\
\hline
\end{tabular}

One-Sample Test

\begin{tabular}{|c|c|c|c|c|c|c|}
\hline & \multicolumn{6}{|c|}{ Test Value $=0$} \\
\hline & \multirow[b]{2}{*}{$\mathrm{t}$} & \multirow[b]{2}{*}{$\mathrm{df}$} & \multirow[b]{2}{*}{ Sig. (2-tailed) } & \multirow{2}{*}{$\begin{array}{c}\text { Mean } \\
\text { Difference }\end{array}$} & \multicolumn{2}{|c|}{$\begin{array}{c}\text { 95\% Confidence Interval of the } \\
\text { Difference }\end{array}$} \\
\hline & & & & & Lower & Upper \\
\hline 1a.Med & 59,420 & 19 & ,000 & 48,81400 & 47,0946 & 50,5334 \\
\hline 2a.Med & 60,558 & 19 & ,000 & 48,90700 & 47,2167 & 50,5973 \\
\hline
\end{tabular}


(C) T-TEST 6-6-ICS

/TESTVAL $=0$

$/ M I S S I N G=A N A L Y S I S$

/VARIABLES=@1a.66IncisAxial @2a.66IncisAxial

/CRITERIA=CI ( . 95) .

One-Sample Statistics

\begin{tabular}{|l|r|r|r|r|}
\hline & $\mathrm{N}$ & Mean & Std. Deviation & Std. Error Mean \\
\hline 1a.Med & 20 & 27,0110 & 2,65422 &, 59350 \\
2a.Med & 20 & 26,8885 & 2,56194 &, 57287 \\
\hline
\end{tabular}

One-Sample Test

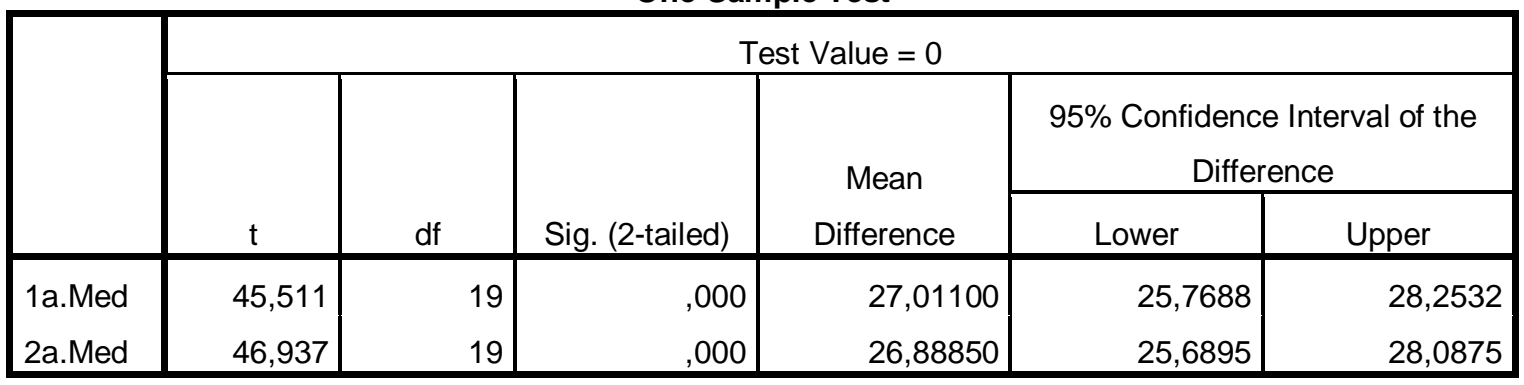




\section{Teste se a distribuição das variáveis é normal}

Para saber se uma variável é simétrica dividimos o coeficiente Skewness pelo erro padrão e se o resultado estiver entre 2 e -2 a distribuição é simétrica.

$$
\text { GET }
$$

FILE='D: \Doutorado \Tomografia \Medidas Tomo Amostra de 20.sav'.

DATASET NAME DataSet1 WINDOW=FRONT.

EXAMINE VARIABLES=@1a.66CorPalato

/PLOT BOXPLOT STEMLEAF

/COMPARE GROUPS

/STATISTICS DESCRIPTIVES

/CINTERVAL 95

/MISSING LISTWISE

/NOTOTAL.

\begin{tabular}{|c|c|c|c|c|}
\hline \multicolumn{5}{|c|}{ Descriptives } \\
\hline & & & Statistic & Std. Error \\
\hline \multirow[t]{13}{*}{ 1a.Med } & Mean & & 22,0690 &, 58932 \\
\hline & 95\% Confidence Interval for & Lower Bound & 20,8355 & \\
\hline & Mean & Upper Bound & 23,3025 & \\
\hline & 5\% Trimmed Mean & & 22,1450 & \\
\hline & Median & & 22,3750 & \\
\hline & Variance & & 6,946 & \\
\hline & Std. Deviation & & 2,63551 & \\
\hline & Minimum & & 16,94 & \\
\hline & Maximum & & 25,83 & \\
\hline & Range & & 8,89 & \\
\hline & Interquartile Range & & 4,98 & \\
\hline & Skewness & &,- 197 &, 512 \\
\hline & Kurtosis & & $-1,016$ & ,992 \\
\hline
\end{tabular}

então $-0,197 / 0,512=-0,384765625=$ distribuição simétrica

Para saber se uma variável é mesocurtica dividimos o coeficiente Kurtosis pelo erro padrão e se o resultado estiver entre 2 e -2 a distribuição é mesocúrtica.

então $-1,016 / 0,992=-1,024193548387097=$ mesocúrtica

Tests of Normality

\begin{tabular}{|r|r|r|r|r|r|r|}
\hline \multirow{2}{*}{} & \multicolumn{4}{|c|}{ Kolmogorov-Smirnov ${ }^{\mathrm{a}}$} & \multicolumn{3}{c|}{ Shapiro-Wilk } \\
\cline { 2 - 7 } & Statistic & \multicolumn{1}{c|}{$\mathrm{df}$} & Sig. & Statistic & \multicolumn{1}{c|}{ df } & \multicolumn{1}{c|}{ Sig. } \\
\hline 1a.Med &, 112 & 20 &, $200^{*}$ &, 950 & 20 &, 365 \\
\hline
\end{tabular}


Paired Samples Statistics

\begin{tabular}{|rr|r|r|r|r|}
\hline & & Mean & N & Std. Deviation & Std. Error Mean \\
\hline \multirow{2}{*}{ Pair 1 } & 1a.Med & 22,0690 & 20 & 2,63551 &, 58932 \\
& 2a.Med & 22,1050 & 20 & 2,66096 &, 59501 \\
\hline
\end{tabular}

Paired Samples Correlations

\begin{tabular}{|l|r|r|r|}
\hline & N & Correlation & \multicolumn{1}{c|}{ Sig. } \\
\hline Pair 1 $\quad$ 1a.Med \& 2a.Med & 20 &, 994 &, 000 \\
\hline
\end{tabular}

Paired Samples Test

\begin{tabular}{|c|c|c|c|c|c|c|c|c|}
\hline & \multicolumn{5}{|c|}{ Paired Differences } & \multirow[b]{3}{*}{$\mathrm{t}$} & \multirow[b]{3}{*}{ df } & \multirow{3}{*}{$\begin{array}{l}\text { Sig. (2- } \\
\text { tailed) }\end{array}$} \\
\hline & \multirow[b]{2}{*}{ Mean } & \multirow{2}{*}{$\begin{array}{c}\text { Std. } \\
\text { Deviation }\end{array}$} & \multirow{2}{*}{$\begin{array}{l}\text { Std. } \\
\text { Error } \\
\text { Mean }\end{array}$} & \multicolumn{2}{|c|}{$\begin{array}{c}95 \% \text { Confidence Interval } \\
\text { of the Difference }\end{array}$} & & & \\
\hline & & & & Lower & Upper & & & \\
\hline Pair 1 1a.Med - 2a.Med &,- 03600 & ,29246 &, 06540 &,- 17287 & ,10087 &,- 550 & 19 &, 588 \\
\hline
\end{tabular}


ANEXO

ANEXO A - Digitalização do Documento de Aprovação pelo Comitê de Ética em Pesquisa em Seres Humanos - Faculdade de Medicina - UnB.

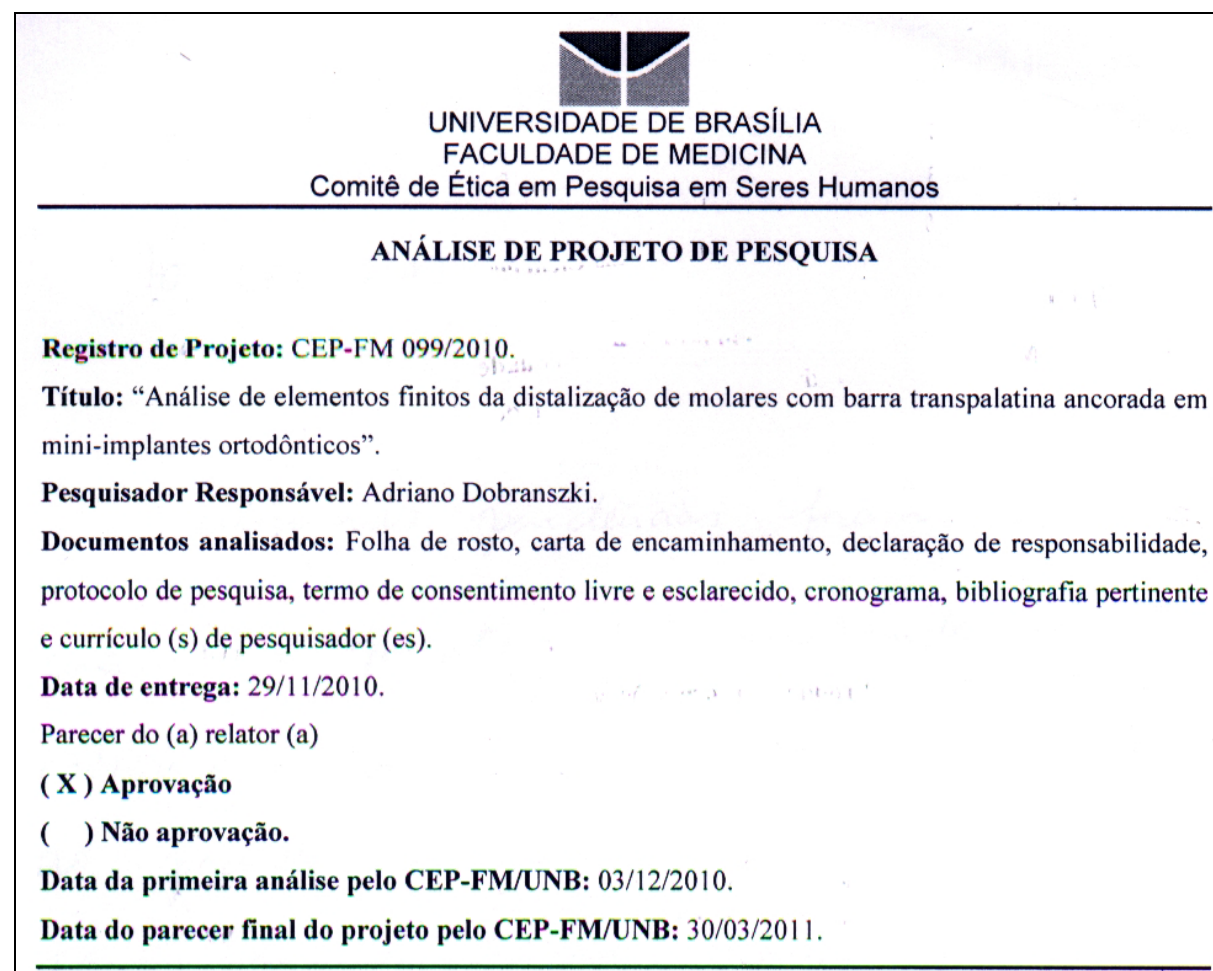

\section{PARECER}

Com base na Resolução CNS/MS n 196/96 e resoluções posteriores, que regulamentam a matéria, o Comitê de Ética em Pesquisa da Faculdade de Medicina da Universidade de Brasilia decidiu APROVAR, na reunião ordinária de 30/03/2011, conforme parecer do (a) relator (a) o projeto de pesquisa acima especificado, quanto aos seus aspectos éticos.

1. Modificações no protocolo devem ser submetidas ao CEP, assim como a notificação imediata de eventos adversos graves;

2. $\mathrm{O}(\mathrm{s})$ pesquisador (es) deve (m) apresentar relatórios periódicos do andamento da pesquisa ao CEP-FM, sendo o $1^{\circ}$ previsto para 01 de outubro de 2011.

Brasília, 31 de Março de 2011.

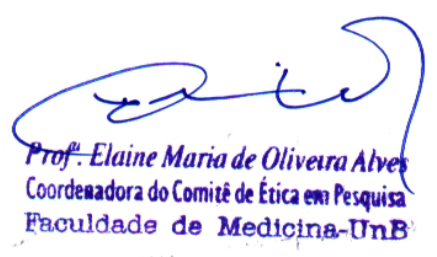


148

to CEP. Fm

Algumas pendeinaias fram Obseraidas, quando o projetó for analisado en 03/12/2010. A puinupal delas ufena-se ao pedido de isures de aplecaciol do TCLE, por se tratar, segundo os aitres, de une esturdo que var analisar retrospectivamente radiografias

I projeto for re-escito, com o objetivo de responder aos questionamentos anteriores e 0 TCLE for uncluido nesta nova versos.

Pun furcos disso, o voto da relation l' pela aprovafos do projeto intitulado "Anallise de elementos firutos da destalizaCow de molines corn bana trasplatina ancorada en mim.inglantes otodónticos".

De acordo.

Prof: Elaine Mariade Oliverra Alve

Coordenadora do Comité de Ética em Pesquisa

Faculdade de Medicina-tInR 